\author{
UNIVERSIDADE DE SÃO PAULO \\ INSTITUTO DE ASTRONOMIA, GEOFÍSICA E CIÊNCIAS \\ ATMOSFÉRICAS \\ Departamento de Ciências Atmosféricas
}

ANA PAULA MENDES EMYGDIO

Caracterização do aerossol biogênico primário na atmosfera da Região Metropolitana de São Paulo

São Paulo 


\section{Caracterização do aerossol biogênico primário na atmosfera da Região Metropolitana de São Paulo}

Versão Corrigida. O original encontra-se disponível na Unidade.

Tese apresentada ao Departamento de Ciências atmosféricas do Instituto de Instituto de Astronomia, Geofísica e Ciências Atmosféricas da Universidade de São Paulo como requisito parcial para obtenção do título de Doutor em Ciências

Área de concentração: Meteorologia Orientadora: Prof. Dra. Maria de Fátima Andrade

Coorientador: Prof. Dr. Fabio Luiz

Teixeira Goncalves

\section{São Paulo}


Emygdio, A. P. M. Caracterização do aerossol biogênico primário na atmosfera da Região Metropolitana de São Paulo. 2021. Tese (Doutorado em Meteorologia) - Departamento de

Ciências atmosféricas, Instituto de Astronomia, Geofísica e Ciências Atmosféricas, Universidade de São Paulo, São Paulo, 2021.

Aprovado em: 23 de março de 2021

Banca examinadora

Prof. Dr. Maria de Fatima Andrade

Instituição: Universidade de São Paulo (Instituto de Astronomia, Geofísica e Ciências Atmosféricas)

Julgamento: Aprovado

Prof. Dr. Paulo Hilario Nascimento Saldiva

Instituição: Universidade de São Paulo (Faculdade de Medicina)

Julgamento: Aprovado

Prof. Dr. Leila Droprinchinski Martins

Instituição: Universidade Tecnológica Federal do Paraná (UTFPR)

Julgamento: Aprovado

Prof. Dr. Célia dos Anjos Alves

Instituição: Universidade de Aveiro (UA)

Julgamento: Aprovado

Prof. Dr. Ricardo Henrique Moreton Godoi

Instituição: Universidade Federal do Paraná (UFPR)

Julgamento: Aprovado 


\section{AGRADECIMENTOS}

O presente trabalho foi realizado com apoio da Coordenação de Aperfeiçoamento de Pessoal de Nível Superior - Brasil (CAPES) - Código de Financiamento nº 1626084 e pela Fundação de Amparo à Pesquisa do Estado de São Paulo (FAPESP) - processos nº 2016/105943 e no $2018 / 03524-4$.

Agradeço a minha orientadora, Maria de Fátima Andrade, ao meu co-orientador Fábio Gonçalves, aos meus Pais Roberto e Heloísa Emygdio, ao meu noivo Rafael Zanetti, a minha irmã Alessandra, aos meus familiares, amigos e professores por todo o apoio, conselhos, força e incentivo.

Agradeço a todos os técnicos e pesquisadores que me auxiliaram de alguma forma, desde etapas de coleta até análise de dados, bem como por compartilharem seus conhecimentos e experiências. Reforço esses agradecimentos a Rosana Astolfo do LAPAt (USP), a Judith Chow, John Watson, Steven Kohl, Patrick Hurbain, Antony Chen e Mi Zhang da Environmental Analysis Facility, Desert Research Institute (Reno, EUA) e do laboratório Urban Air Quality Lab, School of Public Health da University of Nevada (Las Vegas, EUA). Também agradeço ao prof. Prashant Kumar pelos valiosos ensinamentos e a toda a sua família pelo acolhimento.

Agradeço a FAPESP e a CAPES pelo auxílio financeiro, o qual permitiu a realização desse trabalho tanto no Brasil como no exterior. Também agradeço a oportunidade e ao apoio do Instituto de Astronomia, Geofísica e Ciências Atmosféricas da Universidade de São Paulo. 
Because science carries us toward an understanding of how the world is, rather than how we would wish it to be, its findings may not in all cases be immediately comprehensible or satisfying (Sagan, 1997, p.31) 


\section{RESUMO}

EMYGDIO, A. P. M. Caracterização do aerossol biogênico primário na atmosfera da Região Metropolitana de São Paulo. 2021. p. 204. Tese (Doutorado em Ciências) - Instituto de Astronomia, Geofísica e Ciências Atmosféricas, Universidade de São Paulo, São Paulo, 2021. Versão corrigida.

A Região Metropolitana de São Paulo, (RMSP), Brasil, frequentemente apresenta concentrações de material particulado (MP) que excedem os padrões nacionais de qualidade do ar. Entender suas fontes é um passo fundamental para a descrição dos processos físico-químicos na atmosfera e para a criação de políticas destinadas à redução da concentração de poluentes no ar. Os bioaerossóis, que constituem o MP, são importantes atores na deflagração de doenças respiratórias além de interferirem em processos climáticos. Esse trabalho objetivou estimar a concentração, importância e as fontes das partículas biogênicas primárias e outros compostos orgânicos presentes na atmosfera da RMSP. A amostragem utilizou dois equipamentos de coleta de MP10 (MP Inalável, da <10 micra) em filtro, "MiniVol" e o "HiVol" e um amostrador de bioaerossóis: "Bukard". As amostras foram coletadas na Cidade Universitária da Universidade de São Paulo (USP) em São Paulo durante o ano de 2017 e 2018 e diversos compostos foram analisados: elementos traço do $\mathrm{MP}_{10}$; carbono orgânico e elementar; compostos orgânicos (carboidratos e ácidos orgânicos); íons; proteínas solúveis em água (WSP); e esporos de fungos. O arabitol e o manitol correlacionaram-se com diversos tipos fúngicos, indicando uma origem em comum. Um fator de conversão de $3,0 \mathrm{pg}$ de arabitol/esporo e 4,5 pg de manitol/esporo foi proposto para São Paulo no período de coleta para converter a concentração de açúcares em número de esporos fúngicos. Através de fatores de conversão da literatura, atribuiu-se aos esporos fúngicos, em média, 1,5\% e 3,7\% da massa de $\mathrm{MP}_{10}$ e carbono orgânico, respectivamente. A correlação entre WSP com alguns elementos e com levoglucosano e $\mathrm{K}^{+}$permite indicar que a ressuspensão do solo e a queima de biomassa são importantes fontes de bioaerossóis. A concentração de levoglucosano em São Paulo foi menor em 2017 em comparação com anos anteriores, sendo associado a meteorologia e/ou políticas públicas de redução da queima de biomassa (cana de açúcar) na agricultura do Estado. Assim, também se discutiu a importância da agricultura e da produção sucroalcooleira, bem como outras possíveis fontes de levoglucosano (ressuspensão do solo, desgaste de pneu, fogueiras etc.). Das seis fontes obtidas com a aplicação do PMF (Positive Matrix Factorization) para o $\mathrm{MP}_{10}$, os Bioaerossóis, a Ressuspensão do solo/pavimento e o Aerossol Inorgânico Secundário explicaram 12,7\%, 25,9\% e 20,9\% da massa do $\mathrm{MP}_{10}$, respectivamente. As demais 
fontes foram a Emissão Veicular, Aerossol Marinho e Queima de Biomassa. Apesar da fonte biogênica e de queima de biomassa não contribuírem para uma grande fração da massa do $\mathrm{MP}_{10}$, ambas têm um importante papel nos processos climáticos e na saúde. Diversas espécies de fungos foram testadas para determinar seu potencial como núcleos de gelo usando um banho termostático e contudo, apenas a Macrolepiota e a Abortiporus sp. apresentaram uma temperatura inicial de congelamento abaixo de $-10^{\circ} \mathrm{C}$. Os resultados desta pesquisa indicam a importância de analisar compostos que são marcadores específicos de fontes e que não são geralmente incluídos em modelos receptores. Além disso, foi elucidada a importância dos bioaerossóis e esporos fúngicos para as partículas da atmosfera de São Paulo.

Palavras-chave: Bioaerossóis. Distribuição de fontes de aerossol. Material particulado. Núcleo de gelo. Esporos fúngicos. 


\begin{abstract}
EMYGDIO, A. P. M. Primary biogenic aerosol characterization in the Metropolitan area of São Paulo. 2021. p. 204. Tese (Doutorado em Ciências) -Instituto de Astronomia, Geofísica e Ciências Atmosféricas, Universidade de São Paulo, São Paulo, 2021. Corrected version.
\end{abstract}

The metropolitan area of São Paulo (MASP), Brazil, frequently shows particulate matter concentrations (PM) that exceed national air quality standards. Understanding its sources is a fundamental step in describing the physical-chemical processes in the atmosphere and in creating polices aimed at reducing the concentration of pollutants in the air. Bioaerosols, which make up the PM, are important players in the outbreak of respiratory diseases in addition to interfering in climatic processes, such as the ice nuclei formation. This work aimed to estimate the concentration, importance and sources of primary biogenic particles and others organic compounds present in the MASP atmosphere. The sampling used two equipment for collecting $\mathrm{PM}_{10}$ (inhalable PM, da <10 $\mu \mathrm{m}$ ): "MiniVol" and "HiVol" and one bioaerosol sampler: "Burkard". The samples were collected at University city, of the University of São Paulo in São Paulo during 2017 and 2018 and several compounds were analyzed: trace elements of the $\mathrm{PM}_{10}$; organic and elemental carbon; organic compounds (carbohydrates and organic acids); ions; water soluble protein (WSP); and fungal spores. Arabitol and Mannitol correlated with several fungal types, indicating a common origin. A conversion factor of $3.0 \mathrm{pg}$ of arabitol/spore and $4.5 \mathrm{pg}$ of mannitol/spore was proposed for São Paulo during the sampling period to convert the sugar concentration into fungal spore number. Through conversion factors present in the literature, fungal spores were attributed, on average, to $1.5 \%$ and $3.7 \%$ of the $\mathrm{PM}_{10}$ and organic carbon mass, respectively. A correlation between WSP with some elements and with levoglucosan and $\mathrm{K}^{+}$allows to indicate that the soil resuspension and biomass burning are important sources of bioaerosols. Levoglucosan concentration in São Paulo was lower in 2017 compared with previous years, being associated with meteorology and/or public policies to reduce biomass burning (sugar cane) in agriculture (do Estado). Thus, the importance of agriculture and sugar and alcohol production was also discussed, as well as other possible sources of levoglucosan (soil resuspension, tire wear, bonfires, etc.). Of the six sources obtained with the PMF application (Positive Matrix Factorization) for $\mathrm{PM}_{10}$, the Bioaerosols, Soil/pavement resuspension and Secondary Inorganic Aerosol explained 12.7\%, 25.9\% and $20.9 \%$ of the $\mathrm{PM}_{10}$ mass, respectively. The other sources were vehicle emission, marine aerosol, biomass burning. Although the biogenic source and the biomass burning do not contribute to a large fraction of the $\mathrm{PM}_{10}$ mass, both have an important role on the climatic process and health. 
Several fungal species were tested to determine their potential as ice nuclei, using a thermostatic bath, however, only Macrolepiota and the Abortiporus sp. had an initial freezing temperature below $10^{\circ} \mathrm{C}$. The results of this research indicate the importance of analyzing compounds which are specific markers of sources and that usually are not included in receptor models. In addition, the importance of bioaerosols and fungal spores for particles in the atmosphere of São Paulo has been elucidated.

Key words: Bioaerosols. Aerosol source apportionment. Particulate matter. Ice nuclei. Fungal spores. 


\section{LISTA DE ILUSTRAÇÃO}

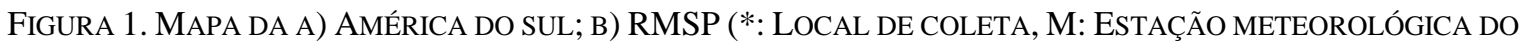
IAG, C: CIDADE DE CUBATÃo, S: CidADE DE SANTOS); C) LOCAL DE COLETA (R: RESERVA FloRESTAL “ARMANDo SALLES DE OliveIrA").

FigURA 2. CALENDÁRIO dE 2017 E 2018 MOSTRANDO A CONCENTRAÇão DiÁRIA DE MP 10 NOS 69 DIAS

AMOSTRADOS.

FiguRA 3. IMAGEM DE ALGUNS ESPOROS FÚNGICOS ANALISAdOS. A: SPEGAZZINIA SP.; B: DRECHSLERA-LIKE; C:

GLIOMATIX-LIKE; D: PARAPHAEOSPHAERIA SP.; E: PERICONIA SP.; F: BASIDIÓSPORO HIALINO.

FIGURA 4. ENSAIO DE CONGELAMENTO DE GOTÍ́CULAS MOSTRANDO A BANDEJA DE METAL COM PARAFINA E AS GOTíCULAS LÍQUIDAS (TRANSPARENTES) E CONGELADAS (BRANCAS OPACAS) DE $10 \mu$ L DA SOLUÇÃO DE ESPOROS UTILIZADA NOS TESTES DE ICE NUCLEI.

FIGURA 5. SÉRIE TEMPORAL DAS VARIÁVEIS METEOROLÓGICAS.

FIGURA 6. ROSA DOS VENTOS PARA O TODO O PERÍODO AMOSTRADO

FigURA 7. BALANÇO ENTRE A) $\mathrm{NH}_{4} \mathrm{HSO}_{4},\left(\mathrm{NH}_{4}\right)_{2} \mathrm{SO}_{4} \mathrm{E} \mathrm{NH}_{4}{ }^{+}$, ONDE FOI PLOTADA AS CONCENTRAÇÕES OBTIDAS NA EQUAÇÃO 5 VERSUS A CONCENTRAÇÃO DE $\mathrm{NH}_{4}^{+}$; B) ÍONS (CÁTIONS E ÂNIONS), ONDE FOI PLOTADA A RELAÇÃO CÁTIONS (EIXO X) E ANÍONS (EIXO Y) - VERDE; ANÍONS (EIXO X) E CÁTIONS (EIXO Y) - AZUL.

FIGURA 8. RAZÃO ENTRE A CONCENTRAÇÃO EM MASSA DOS ÂNIONS (A) E OS CÁTIONS (C) CONSIDERANDO TODO O PERÍODO AMOSTRADO.

FigURA 9. SERIE TEMPORAL DA RECONSTRUÇão DA MASSA (MR), SOMA DAS ESPÉCIES (SS) E MASSA DO MP 10 CALCULADA PELA GRAVIMETRIA.

FIGURA 10. CONTRIBUIÇÃO PROPORCIONAL DOS COMPONENTES DA RECONSTRUÇÃO DA MASSA PARA O MP ${ }_{10} \ldots . . . .65$

FigURA 11. VARIAÇão MENSAL, SAZONAL E ANUAL DA RECONSTRUÇão DA MASSA (MR), SOMA DAS ESPÉCIES (SS) E DA MASSA DO MP ${ }_{10}$ OBTIDA POR GRAVIMETRIA

FigURA 12. VARIAÇÃO SAZONAL, MENSAL E ANUAL DOS COMPONENTES DA RECONSTRUÇÃO DE MASSA

FIGURA 13. CONTRIBUIÇÃO PERCENTUAL SAZONAL DOS COMPONENTES DA RECONSTRUÇÃO DA MASSA PARA O $\mathrm{MP}_{10}$. 68

FIGURA 14. SÉRIE TEMPORAL DA CONCENTRAÇÃO DOS COMPOSTOS ORGÂNICOS E CARBONO ELEMENTAR. .73

FigURA 15. PORCENTAGEM DA CONTRIBUIÇÃO DA SOMA DOS COMPOSTOS ORGÂNICOS (ACETATO, FORMIATO, SUCCINATO, MALEATO, MSA, OXALATO, ARABITOL, MANITOL, GLICOSE/XILOSE, LEVOGLUCOSANO, MANOSANO) PARA O OC DURANTE O PERÍODO AMOSTRADO.

FIGURA 16. CORRELAÇÃO DE SPEARMAN ENTRE OS COMPOSTOS ORGÂNICOS E O EC...... .74

FigURA 17. NÚMERO DE DIAS COM FOCOS DE INCÊNDIOS ATIVOS PARA OS ESTADOS DE SÃo PAULO, GOIÁS E AMAZÔNIA CONSIDERANDO TODOS OS DIAS DO MÊS (30 OU 31 DIAS)

Figura 18. CONCENTRAÇÃo DE LEVOGLUCOSANO (LEV), MANOSANO (MANNO), ÍON POTÁSSIO ( $\mathrm{K}^{+}$), CARBONO ELEMENTAR (EC) E A QUANTIDADE DE FOCOS DE QUEIMADAS PARA O ESTADO DE SÃo PAULO CONSIDERANDO O PERÍODO COLETADO.

Figura 19. CONCENTRAÇÃO MÉDIA DE LEVOGLUCOSANO (LEV) DURANTE OS DIAS DE SEMANA E FINAIS DE SEMANA CONSIDERANDO TODO O PERÍODO COLETADO.

FigURA 20. RAZÃo FormiATO E ACETATO (F/A) DURANTE O PERÍODO AMOSTRADO. A LINHA HORIZONTAL 
FIGURA 21. CONCENTRAÇÃO SAZONAL DOS DIÁCIDOS DIVIDIDO PELO CARBONO TOTAL (TC) E MP 10 . 93

Figura 22. CORRELAÇÃO DE SPEARMAN ENTRE OS DiÁCIDOS E ALGUNS POLUENTES (CO, $\left.\mathrm{O}_{3}, \mathrm{SO}_{4}{ }^{2-}, \mathrm{NO}_{3}{ }^{-}, \mathrm{NH}_{4}{ }^{+}\right)$.

FIGURA 23. CONCENTRAÇÃO DIÁRIA DE MITÓSPOROS (MS), ASCÓSPOROS (AS), BASIDIÓSPOROS (BS), DESCONHECIDO (UD), ESPOROS TOTAIS (TS) EM ESPOROS/M³ E ARABITOL, MANITOL E PROTEÍNAS SOLÚVEIS EM ÁGUA (WSP) EM MG/M³ E PRECIPITAÇÃO ACUMULADA EM MM (PREC.). 105

FIGURA 24. CORRELAÇÃo DE SPEARMAN $(\mathrm{P}<0,05)$ ENTRE AÇUCARES (ARABITOL E MANITOL), WSP E TS (ESPOROS TOTAIS). 108

FIGURA 25. SÉRIE TEMPORAL DA CONCENTRAÇÃO DE CLADOSPORIUM SP. E ALTERNARIA SP. . 110

FIGURA 26. CONCENTRAÇÃO MÉDIA DOS PRINCIPAIS GRUPOS DE ESPOROS (MS, AS, BS E UD) E OS ESPOROS TOTAIS (TS) CONSIDERANDO OS PERÍODOS DO DIA (MANHÃ, TARDE, NOITE E MADRUGADA) DE TODO O PERÍODO AMOSTRADO.

FIGURA 27. FONTES IDENTIFICADAS COM A FATORAÇÃO DE MATRIZ POSITIVA (PMF) E PORCENTAGEM DA CONTRIBUIÇÃO DOS SEIS FATORES PARA A MASSA DO MP $\mathrm{MP}_{10}$

FIGURA 28. GRÁFICOS POLARES DA FUNÇÃO DE PROBABILIDADE BIVARIADA CONDICIONAL (CBPF) PARA OS FATORES OBTIDOS COM A FATORAÇÃO DE MATRIZ POSITIVA (PMF).

FIGURA 29. GRÁFICOS POLARES DA FUNÇÃO DE PROBABILIDADE BIVARIADA CONDICIONAL (CBPF) PARA A MASSA DO MP 10 (WS - VELOCIDADE DO VENTO).

FIGURA 30. NÚMERO CUMULATIVO DE NÚCLEOS DE GELOS POR TIPO DE FUNGO POR TEMPERATURA DE ACORDO COM O CÁLCULO PROPOSTO POR VALI (1971). 128

FIGURA A I. CONCENTRAÇÃO DA MASSA $\left(\mu \mathrm{G} / \mathrm{M}^{3}\right)$ OBTIDA COM OS TRÊS EQUIPAMENTOS MINIVOL (MVPCA, MVPCB, MVPCC) E O PARTISOL 2025I (PS), CONSIDERANDO O PERÍODO COLETADO.

Figura A II. Correlação de PEARSON ENTRE os três MiniVol (MVPCA, MVPCB, MVPCC) E O PARTiSOL 2025I (PS).

FIGURA A III. REGRESSÃO LINEAR ENTRE A CONCENTRAÇÃO DA MÉDIA DOS TRÊS MINIVOL E DO PARTISOL 2520I.

FIGURA A IV. CONCENTRAÇÃO DA MASSA ( $\left.\mu \mathrm{G} / \mathrm{M}^{3}\right)$ OBTIDA COM O MiNIVOL COM FILTRO DE POLICARBONATO (MVPC - MP $10-2,5)$, MiniVOL COM FILTRO DE QUARTZO (MVQ - MP 10 ) E O PARTISOL 2025I (PS - MP ${ }_{10}$ ), CONSIDERANDO O PERÍODO COLETADO.

FIGURA A V. CORRELAÇÃO ENTRE MVPC (FILTRO DE POLICARBONATO COM MINIVOL - MP ${ }_{10-2,5}$ ), MVQ (FILTRO DE QUARTZO COM MINIVOL - MP 10 ) E PS (FILTRO DE TEFLON COM PARTISOL 2025I - MP 10 ).

FIGURA A VI. CONCENTRAÇÃO DA MASSA ( $\left.\mu \mathrm{G} / \mathrm{M}^{3}\right)$ DE MP 2,5 OBTIDA COM O MINIVOL COM FILTRO DE POLICARBONATO (MVPC), COM O MINIVOL COM FILTRO DE QUARTZO (MVQ) E COM O PARTISOL 2025I COM FILTRO DE TEFLON (PS), CONSIDERANDO O PERÍODO COLETADO.

Figura A VII. CORRELAÇÃO ENTRE MVPC (FILTRO DE POLICARBONATO COM MINIVOL), MVQ (FILTRO DE QUARTZO COM MINIVOL) E PS (FILTRO DE TEFLON COM PARTISOL 2025I) PARA O MP $2,5$.

FIGURA A VIII. CONCENTRAÇÃO EM MASSA ( $\left.\mu \mathrm{G} / \mathrm{M}^{3}\right)$ PARA MP ${ }_{10}$ OBTIDA COM O MINIVOL COM FILTRO DE POLICARBONATO (MVPC), MiNIVOL COM FILTRO DE QUARTZO (MVQ) HIVOL COM FILTRO DE QUARTZO (HVQ) E DADOS DA CETESB, CONSIDERANDO O PERÍODO COLETADO. 
FigURA A IX. CORRELAÇÃO ENTRE O MVPC (MiniVOL COM FILTRO DE POLICARBONATO), MVQ (MiNIVOL COM FILTRO DE QUARTZO), HVQ (HIVOL COM FILTRO DE QUARTZO) E OS DADOS DA CETESB, CONSIDERANDO O PERÍODO COLETADO PARA MP 10 156

FigURA A X. CONCENTRAÇÃO DOS ELEMENTOS $\left(\mu \mathrm{G} / \mathrm{M}^{3}\right)$ ANALISADOS COM O EDX E COM O ICP. 157 FiguRA A XI. MATRIZ DE CORRELAÇÃo (PEARSON) SIGNIFICATIVA (P < 0,05) ENTRE OS ELEMENTOS DO EDX E ICP.

Figura A XII. CONCENTRAÇão DiÁRIA E TOTAL (MÉDIA) DOS ÍONS ( $\mu \mathrm{G} / \mathrm{M}^{3}$ ) ANALISADOS NO LAPAT E NO DRI EM 2017.

FiguRA A XIII. MATRIZ DE CORRELAÇão (PEARSON) SIGNIFICATIVA ( $<<0,05)$ ENTRE OS ÍONS ANALISADOS NO DRI E LAPAT. LEGENDA: ESPAÇOS EM BRANCO INDICAM UMA CORRELAÇÃO NÃO SIGNIFICATIVA $(P>0,05) \ldots . . . .161$ FIGURA A XIV. ERRO PERCENTUAL RELATIVO DA MÉDIA (\%) CONSIDERANDO OS ÍONS ANALISADOS NO DRI E LAPAT. 162

Figura A XV. MATRIZ DE CORRELAÇÃo (PEARSON) SIGNIFICATIVA (P<0,05) ENTRE ALGUNS ÍONS E ELEMENTOS ANALISADOS NO DRI E LAPAT INCLUINDO TODOS OS DADOS DE 2017. 163

FIGURA C I. ROSA DOS VENTOS SAZONAL PARA O PERÍODO AMOSTRADO (FREQUÊNCIA DE CONTAGENS POR DIREÇÃO DO VENTO (\%)). 168

Figura C II. BALANÇO DOS ÍONS ANALISADOS NO LAPAT ENTRE A) $\mathrm{NH}_{4} \mathrm{HSO}_{4},\left(\mathrm{NH}_{4}\right)_{2} \mathrm{SO}_{4} \mathrm{E} \mathrm{NH}_{4}^{+}$; B) ÍONS (CÁTIONS E ÂNIONS)

FIGURA C III. RAZÃO ENTRE A CONCENTRAÇÃO EM MASSA DOS ÂNIONS (A) E OS CÁTIONS (C) DOS ÍONS ANALISADOS NO LAPAT, CONSIDERANDO TODO O PERÍODO AMOSTRADO. 169

FigURA C IV. CORRELAÇÃo DE PEARSON ENTRE OS COMPOSTOS ORGÂNICOS COM A FREQUÊNCIAS POR DIA DAS DIFERENTES DIREÇÕES DO VENTO CONSIDERANDO TODO O PERÍODO AMOSTRADO. 169 FIGURA C V. CORRELAÇÃO ENTRE AS CONCENTRAÇÕES DE OC E EC EM DIFERENTES RAMPAS DE TEMPERATURA E ALGUNS COMPONENTES ORGÂNICOS. 170

FIGURA C VI. TRAGETÓRIA BACKWARD DO HYSPLIT DOS DIAS COLETADOS EM JUNHO, UTILIZANDO O VERTICAL MOTION MODEL VERTICAL VELOCITY, 24 HORAS DE RODADA, 3 ALTURAS DA CAMADA $(100,500,1000)$ E METEOROLOGIA GDAS (1 DEGREE, GLOBAL, 2006-PRESENT). O DIA ANALISADO CORRESPONDE AO DIA ANTERIOR AO DIA DO FINAL DA TRAJETÓRIA 176

FIGURA C VII. Focos DE QUEIMADAS PARA OS DIAS COLETADOS EM JUNHO (INPE, 2019). 179 Figura C VIII. CORRELAÇão de SPEARMAN ENTRE os ÁCIDOS ORGÂNICOS, CARbOIDRATOS E WSP PARA O OUTONO DE 2017. Legenda: ACETATO (ACE), Formiato (For), OXalato (OXA), Succinato (SuC), Maleato (Mal), Metanosulfonato (MSA), Levoglucosano (Lev), Manosano (Manno), Arabitol (Ara), Manitol (MANni), Glicose (Glu), ProteínAs SOLÚVEIS EM ÁGUA (WSP) E K $\mathrm{K}^{+}$* INDICA P<0,05, ** INDICA $\mathrm{P}<0,01 \mathrm{E} * * *$ INDICA $\mathrm{P}<0,001$

FigURA C IX. GRÁFICOS POLARES BIVARIADOS CONDICIONAL (CBPF) DAS CONCENTRAÇÕES DE LEVOGLUCOSANO, MANOSANO, ARABITOL, GLICOSE, MANITOL, WSP, ACETATO, FORMIATO, OXALATO, SUCCINATO, MALEATO, MSA, EC E OC NO OUTONO DE 2017. 181 Figura C X. CORRELAÇão de SPEARMAN ENTRE OS ÁCIDOS ORGÂNICOS, CARBOIDRATOS E WSP PARA O

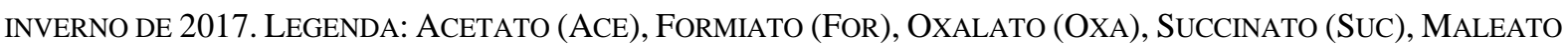
(Mal), Metanosulfonato (MSA), Levoglucosano (Lev), Manosano (Manno), Arabitol (Ara), 
Manitol (MANNi), Glicose (GLU), ProteínAs SOlúVEIS EM ÁGUA (WSP) E K * * INDICA P<0,05, ** INDiCA $\mathrm{P}<0,01 \mathrm{E} * * *$ INDICA $\mathrm{P}<0,001$.

FIGURA C XI. GRÁFICOS POLARES BIVARIADOS CONDICIONAL (CBPF) DAS CONCENTRAÇÕES DE LEVOGLUCOSANO, MANOSANO, ARABITOL, GLICOSE, MANITOL, WSP, ACETATO, FORMIATO, OXALATO, SUCCINATO, MALEATO, MSA, EC E OC NO INVERNO DE 2017.

Figura C XII. CORRELAÇÃo de SPEARMAN ENTRE os ÁCIDOS ORGÂNICOS, CARbOIDRATOS E WSP PARA A PRIMAVERA DE 2017. LEgENDA: ACETATO (ACE), Formiato (For), OXAlato (OXA), SucCinAto (Suc), Maleato (Mal), Metanosulfonato (MSA), LeVoglucosano (LeV), MANOSANo (MANNo), ARABitol (ARA), Manitol (MAnNi), Glicose (Glu), ProteínAs SOlúVEIS EM ÁGUA (WSP) E K ${ }^{+}$* INDiCA P<0,05, ** INDICA $\mathrm{P}<0,01 \mathrm{E} * * *$ INDICA $\mathrm{P}<0,001$.

FIGURA C XIII. GRÁFICOS POLARES BIVARIADOS CONDICIONAL (CBPF) DAS CONCENTRAÇÕES DE LEVOGLUCOSANO, MANOSANO, ARABITOL, GLICOSE, MANITOL, WSP, ACETATO, FORMIATO, OXALATO, SUCCINATO, MALEATO, MSA, EC E OC NA PRIMAVERA DE 2017

FIGURA C XIV. CORRELAÇÃO DE SPEARMAN ENTRE OS ÁCIDOS ORGÂNICOS, CARBOIDRATOS E WSP PARA O Outono De 2018. Legenda: AceTAto (ACE), Formiato (For), OXAlato (OXA), Succinato (Suc), Maleato (MAl), Metanosulfonato (MSA), Levoglucosano (LeV), MANosano (MANNo), Arabitol (ARA),

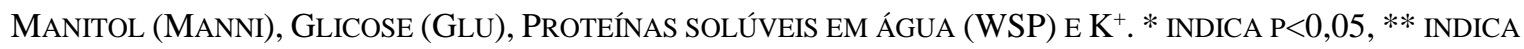
$\mathrm{P}<0,01 \mathrm{E} * * *$ INDICA $\mathrm{P}<0,001$.

FIGURA C XV. GRÁFICOS POLARES BIVARIADOS CONDICIONAL (CBPF) DAS CONCENTRAÇÕES DE LEVOGLUCOSANO, MANOSANO, ARABITOL, GLICOSE, MANITOL, WSP, ACETATO, FORMIATO, OXALATO, SUCCINATO, MALEATO, MSA, EC E OC NO OUTONO DE 2018.

FIGURA C XVI. CONCENTRAÇÃO MÉDIA SAZONAL DOS PRINCIPAIS TIPOS FÚNGICOS. 188

FIGURA C XVII. CORRELAÇÃO DE SPEARMAN ENTRE ARABITOL, MANITOL E WSP COM VARIÁVEIS METEOROLÓGICAS.

FIGURA C XVIII. CORRELAÇÃo DE SPEARMAN ENTRE TS, AS, MS, BS E UD COM VARIÁVEIS METEOROLÓGICAS.

Figura C XIX. CORRELAÇÃo DE SPEARMAN ENTRE TS (ESPOROS TOTAIS), MS (MitÓSPOROS), AS (ASCÓSPOROS), BS (BASIDIÓSPOROS), UD (DESCONHECIDO), ARABITOL, MANITOL E WSP NO PERÍODO ÚMIDO (DIAS COM CHUVA).

Figura C XX. CorrelaÇÃo de SPEARMAN ENTRE TS (ESPOROS TOTAIS), MS (MitósPoros), AS (ASCÓSPOROS), BS (BASIDIÓSPOROS), UD (DESCONHECIDO), ARABITOL, MANITOL E WSP NO PERÍODO SECO (DIAS SEM CHUVA).

Figura C XXI. CORRELAÇÃo DE SPEARMAN ENTRE TS (ESPOROS TOTAIS), MS (Mitósporos), AS (ASCÓSPOROS), BS (BASIDIÓSPOROS), UD (DESCONHECIDO), ARABITOL, MANITOL E WSP CONSIDERANDO TODO O PERÍODO AMOSTRADO.

FIGURA C XXII. CORRELAÇÃO DE SPEARMAN ENTRE ARABITOL E MANITOL COM ALGUNS TIPOS FÚNGICOS PERTENCENTES AO GRUPO MS.

FIGURA C XXIII. CORRELAÇÃO DE SPEARMAN ENTRE ARABITOL E MANITOL COM ALGUNS TIPOS FÚNGICOS PERTENCENTES AO GRUPO BS E DESCONHECIDO. 
FIGURA C XXIV. CORRELAÇÃO DE SPEARMAN ENTRE ARABITOL E MANITOL COM ALGUNS TIPOS FÚNGICOS PERTENCENTES AO GRUPO AS

FIGURA C XXV. SÉRIE TEMPORAL DA CONTRIBUIÇÃO DOS FATORES OBTIDOS COM A FATORAÇÃO DE MATRIZ POSITIVA (PMF) DURANTE O PERÍODO AMOSTRADO. 197 FIGURA C XXVI. VARIAÇÃO SAZONAL DOS FATORES OBTIDOS COM A FATORAÇÃO DE MATRIZ POSITIVA (PMF). 198

FIGURA C XXVII. PORCENTAGEM DA CONTRIBUIÇÃO DOS SEIS FATORES PARA A MASSA DO LEVOGLUCOSANO NA ANÁLISE DE FATORAÇÃo DE MATRIZ POSITIVA (PMF). 


\section{LISTA DE TABELAS}

TABEla 1. Estudos PUbliCAdos SOBRE A DETERMINAÇÃo DE FONTES DO MP NA CIDADE DE SÃo PAULO E REGIÃO METROPOLITANA.

TABELA 2. RESUMO DA METODOLOGIA DE COLETA E ANALÍTICA

TABELA 3. MÉDIA DO ERRO, INCERTEZA TOTAL, LQL (PARA O ERRO E PARA A CONCENTRAÇÃO) PARA OS ELEMENTOS OBTIDOS COM O EDX. 39

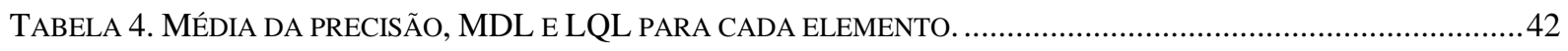

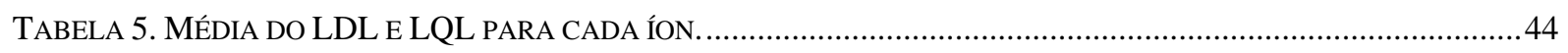

TABELA 6. MÉDIA DA PRECISÃO, ACURÁCIA, LQL E MDL PARA CADA ÍON. .......................................................46

TABELA 7. MÉDIA DA PRECISÃO, MDL (SETE ANÁLISES RÉPLICAS DOS PADRÕES 0,05-0,2 MG/ML) E ACURÁCIA PARA CADA CARBOIDRATO.

TABELA 8. MÉDIA DO LQL E MDL (NOVE ANÁLISES RÉPLICAS DO PADRÃO DE 0,05 $\mu$ G/ML) PARA CADA CARBOIDRATO.

TABELA 9. MÉDIA DA PRECISÃO, MDL E LQL PARA O TC, OC E EC.

TABELA 10. MÉDIA DAS VARIÁVEIS METEOROLÓGICAS PARA TODO O PERÍODO AMOSTRADO E AS ESTAÇÕES DO ANO, CONSIDERANDO O PERÍODO AMOSTRADO.

TABELA 11. CONCENTRAÇÃO MÉDIA, DESVIO PADRÃO, CONCENTRAÇÃO MÁXIMA E MÍNIMA E PORCENTAGEM DA CONTRIBUIÇÃO DAS VARIÁVEIS PARA O MP ${ }_{10}$, ORDENADO PELAS VARIÁVEIS COM MAIORES CONCENTRAÇÕES.....62 TABELA 12. FORMULAÇÃO PARA A RECONSTRUÇÃO DA MASSA E TODOS OS COMPOSTOS QUÍMICOS E ESPÉCIES CONSIDERADAS.

TABELA 13. RAZÕES ENTRE CARBONO ORGÂNICO (OC), CARBONO ELEMENTAR (EC), CARBONO TOTAL (TC) E K ALÉM DA CONCENTRAÇÃO DE POC E SOC EM MG/M³ CONSIDERANDO AS ESTAÇÕES DO ANO E A MÉDIA TOTAL DO PERÍODO.

TABElA 14. CONCENTRAÇÃo DE LEVOGLUCOSANO E A RAZÃo LEVOGLUCOSANO/MANOSANO PARA SÃO PAULO PARA MP $\mathrm{MP}_{2,5} \mathrm{E} \mathrm{MP}_{10}$ SEGUNDO A LITERATURA.

TABELA 15. COMPARAÇÃO ENTRE CONCENTRAÇÕES MEDIDAS DOS ÁCIDOS ORGÂNICOS COM OUTROS TRABALHOS PRESENTES NA LITERATURA, INDICANDO O MÉTODO USADO (IC OU GC), O PERÍODO COLETADO, LOCAL DE COLETA, SE NA FASE GASOSA OU FRAÇÃO DO MP, O TEMPO DE COLETA E AS CONCENTRAÇÕES. 87

TABELA 16. POST-HOC DO TESTE DE KRUSKAL-WALLIS CONSIDERANDO AS CONCENTRAÇÕES SAZONAIS DOS COMPOSTOS ORGÂNICOS ANALISADOS, BEM COMO ALGUNS COMPONENTES CHAVE DO MP ${ }_{10}$ E GASES PRESENTES NA ATMOSFERA. ESSA TABELA INDICA AS VARIÁVEIS QUE APRESENTAM UMA DIFERENÇA SIGNIFICATIVA CONSIDERANDO AS ESTAÇÕES DO ANO $(\mathrm{P}<0,05)$

TABEla 17. CORRELAÇÃo de SPEARMAN ENTRE OS ÁCIDOS ORGÂNICOS, ANIDROAÇUCARES E WSP COM CO, $\mathrm{O}_{3}$, $\mathrm{SO}_{4}{ }^{2-}, \mathrm{NH}_{4}{ }^{+}, \mathrm{NO}_{3}{ }^{-}, \mathrm{OC}, \mathrm{EC}, \mathrm{AL}, \mathrm{FE}, \mathrm{Cl}, \mathrm{CU}$ E PB PARA O OUTONO DE 2017. OS VALORES MOSTRADOS INDICAM UMA CORRELAÇÃO SIGNIFICATIVA.

TABELA 18. CORRELAÇÃo de SPEARMAN ENTRE OS ÁCIDOS ORGÂNICOS, ANIDROAÇÚCARES E WSP COM CO, O $\mathrm{SO}_{4}{ }^{2-}, \mathrm{NH}_{4}{ }^{+}, \mathrm{NO}_{3}{ }^{-}, \mathrm{OC}, \mathrm{EC}, \mathrm{AL}, \mathrm{FE}, \mathrm{CL}, \mathrm{CU}$ E PB PARA O INVERNO DE 2017.

TABEla 19. CORRELAÇÃo de SPEARMAN ENTRE OS ÁCIDOS ORGÂNICOS, ANIDROAÇUCARES E WSP COM CO, O $\mathrm{SO}_{4}{ }^{2-}, \mathrm{NH}_{4}{ }^{+}, \mathrm{NO}_{3}{ }^{-}, \mathrm{OC}, \mathrm{EC}, \mathrm{AL}, \mathrm{FE}, \mathrm{CL}, \mathrm{CU}$ E PB PARA A PRIMAVERA DE 2017. 
TABEla 20. CORRElaÇÃo de SPEARMAN ENTRE os ÁCIDOS ORGÂNICOS, ANIDRO AÇÚCAR E WSP COM CO, O $\mathrm{SO}_{4}{ }^{2-}, \mathrm{NH}_{4}{ }^{+}, \mathrm{NO}_{3}{ }^{-}, \mathrm{OC}, \mathrm{EC}, \mathrm{AL}, \mathrm{FE}, \mathrm{CL}, \mathrm{CU}$ E PB PARA O OUTONO DE 2018. 100

TABELA 21. CONCENTRAÇÃO MÉDIA ( \pm DESVIO PADRÃO) EM NG/M³ PARA ARABITOL, GLICOSE/XILOSE, MANITOL, PROTEÍNAS SOLÚVEIS EM ÁGUA (WSP) E ESPOROS TOTAIS (TS) CONSIDERANDO A MÉDIA DE TODO O PERÍODO AMOSTRADO (N=66 PARA TS E N=69 PARA OS AÇUCARES E WSP) E AS ESTAÇÕES DO ANO.

TABELA 22. CONCENTRAÇÃO MÉDIA \pm DESVIO PADRÃO (QUANDO DISPONÍVEL) EM NG/M³ PARA ARABITOL, GLICOSE/XILOSE, MANITOL, PROTEÍNAS SOLÚVEIS EM ÁGUA (WSP) CONSIDERANDO A LITERATURA.

TABELA 23. CONCENTRAÇÃO DE ARABITOL, MANITOL E ESPOROS FÚNGICOS, E O FATOR DE CONVERSÃO OBTIDOS NESSE TRABALHO, POR EMYGDIO ET AL (2016; 2018A) E POR BAUER ET AL. (2008A).

TABELA 24. CONTRIBUIÇÃO DOS ESPOROS FÚNGICOS PARA A CONCENTRAÇÃO EM MASSA DE MP ${ }_{10}$ E OC EM PORCENTAGEM USANDO OS DADOS DESSE TRABALHO E OS FATORES DE CONVERSÃO (ARABITOL E MANITOL PARA ESPOROS) PROPOSTOS NESSE TRABALHO, NO TRABALHO DE EMYGDIO ET AL. (2016; 2018A) E DE BAUER ET AL. $\left(2008 A^{3}\right)$ CONSIDERANDO AS ESTAÇÕES DO ANO E TODO O PERÍODO AMOSTRADO.

TABELA 25. CONTRIBUIÇÃO EM PORCENTAGEM DOS ESPOROS FÚNGICOS PARA O OC E MP 10 CONSIDERANDO A LITERATURA*.

TABELA 26. CONFIGURAÇÕES UTILIZADAS NA APLICAÇÃO DA FATORAÇÃO DE MATRIZ POSITIVA (PMF).

TABEla 27. Resumo do diagnÓSTICO DA FATORAÇÃo DE MATRIZ POSITIVA (PMF) COM RODADAS COM DIFERENTES NÚMEROS DE FATORES

TABELA A I. CONCENTRAÇÃO DA MASSA $\left(\mu \mathrm{G} / \mathrm{M}^{3}\right)$ DO MP 10 OBTIDO COM O PARTISOL 2025I, MP $10-2,5$ OBTIDO

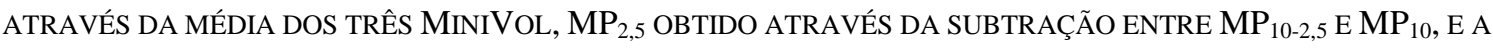
CONCENTRAÇÃO DE MP10 OBTIDA COM A EQUAÇÃO DA RETA.

TABELA A II. CONCENTRAÇÃO MÉDIA ( \pm DESVIO PADRÃO) DOS ELEMENTOS E ERRO PERCENTUAL RELATIVO DA MÉDIA (\%) DOS ELEMENTOS ANALISADOS NO ICP E NO EDX. A COLUNA DO ERRO PERCENTUAL RELATIVO (ICP, \%) INDICA O ERRO QUANDO OS DADOS DO ICP SÃO CONSIDERADOS C 2 (A CONCENTRAÇÃO MÉDIA VERDADEIRA), ENQUANTO ERRO PERCENTUAL RELATIVO (EDX, \%) INDICA O ERRO QUANDO OS DADOS DO EDX SÃO CONSIDERADOS $\mathrm{C}_{2}$.

TABELA B I. RESUMO DA METODOLOGIA DE COLETA E ANALÍTICA PARA A COMPARAÇÃO ENTRE EQUIPAMENTOS, FILTROS E SUPORTES. 164

TABELA B II. INCLINAÇÃO (A2), INTERCEPTAÇÃO (B2) FATOR DE CORRELAÇÃO (R2) E VAZÃO DE OPERAÇÃO PARA CADA VERIFICAÇÃO DA CALIBRAÇÃO REALIZADA NO HIVOL. 164

TABELA B III.CONCENTRAÇÃO MÉDIA \pm DESVIO PADRÃO $\left(\mathrm{MG} / \mathrm{M}^{3}\right)$ DO OC E EC EM CADA RAMPA DE TEMPERATURA. 164

TABELA B IV. RESUMO DAS POSSÍVEIS FONTES DOS COMPOSTOS ORGÂNICOS 164

TABELA B V. POST-HOC DO TESTE DE KRUSKAL-WALLIS, CONSIDERANDO AS CONCENTRAÇÕES SAZONAIS DOS PRINCIPAIS GRUPOS FÚNGICOS (AS - ASCÓSPOROS, BS - BASIDIÓSPOROS E UD - DESCONHECIDO) E TS (ESPOROS TOTAIS). ESSA TABELA INDICA AS VARIÁVEIS QUE MOSTRARAM DIFERENÇA SIGNIFICATIVA CONSIDERANDO A ESTAÇÃO RESPECTIVA $(\mathrm{P}<0,05)$

TABEla B VI. VARiÁVEIS UTILIZAdAS NA FATORAÇÃo DE MATRIZ PositiVA (PMF) E METOdOLOGIA ANALÍTICA USADA 


\section{LISTA DE SIGLAS}

ABNT Associação Brasileira de Normas Técnicas

AS Ascósporos

BC Black Carbon (Carbono negro)

BS Basidiósporos

CBPF Função de Probabilidade Bivariada Condicional

CETESB Companhia Ambiental do Estado de São Paulo

CMB Balanço Químico de Massa

CONAB Companhia Nacional de Abastecimento

CONAMA Conselho Nacional do Meio Ambiente

CV Coeficiente de Variação

DRI Desert Research Institute

EC Carbono Elementar

EDX Espectrometria de Fluorescência de Raio X por Energia Dispersiva

FB Field Blank (Branco de campo)

GC Cromatógrafo Gasoso

HiVol Amostrador de Alto Volume

Hysplit Hybrid Single-Particle Lagrangian Integrated Trajectory

IAG Instituto de Astronomia, Geofísica e Ciências Atmosférica

IBGE Instituto Brasileiro de Geografia e Estatistica

IC Cromatografia de Ílons

ICP-MS Espectrometria de Massa com Plasma Indutivamente Acoplado

IF Instituto de Física

IQ Instituto de Química

LAPAt Laboratório de Análises e Processos Atmosféricos

LQL Limite Quantificável Inferior

MDL Limite Detectável Mínimo

MiniVol Amostrador de Baixo Volume

MP Material Particulado

$\mathrm{MP}_{10} \quad$ Material Particulado com diâmetro aerodinâmico menor do que $10 \mu \mathrm{m}$

$\mathrm{MP}_{2,5} \quad$ Material Particulado com diâmetro aerodinâmico menor do que $2.5 \mu \mathrm{m}$

MPO Material particulado Orgânico

MR Reconstrução de Massa

MS Mitósporos 


$\begin{array}{ll}\text { MSA } & \text { Metanesulfonato } \\ \text { OC } & \text { Carbono orgânico } \\ \text { OM } & \text { Matéria orgânica } \\ \text { PBAP } & \text { Partículas de Aerossol Biogênico Primário } \\ \text { PCA } & \text { Análise de Componentes Principais } \\ \text { PMF } & \text { Fatoração de Matriz Positiva } \\ \text { POC } & \text { Carbono Orgânico Primário } \\ \text { PTS } & \text { Partículas Totais em Suspensão } \\ \text { RMSP } & \text { Região Metropolitana de São Paulo } \\ \text { SOC } & \text { Carbono Orgânico Secundário } \\ \text { SS } & \text { Soma das Espécies } \\ \text { TC } & \text { Carbono Total } \\ \text { TCA } & \text { Aerossol Carbonáceo Total } \\ \text { TS } & \text { Esporos Totais } \\ \text { UD } & \text { Desconhecido } \\ \text { UNLV } & \text { Universidade de Nevada Las Vegas } \\ \text { USP } & \text { Universidade de São Paulo } \\ \text { WHO } & \text { Organização Mundical da Saúde } \\ \text { WSP } & \text { Proteínas Solúveis em Água }\end{array}$




\section{SUMÁRIO}

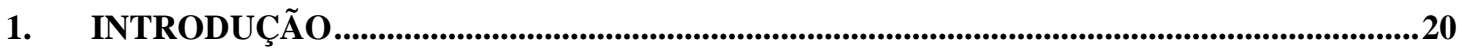

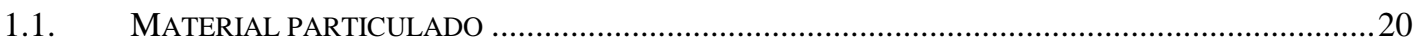

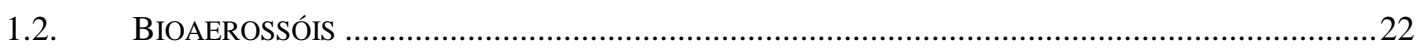

1.3. IDENTIFICAÇÃO DAS FONTES DO MATERIAL PARTICULADO ……………….........................26

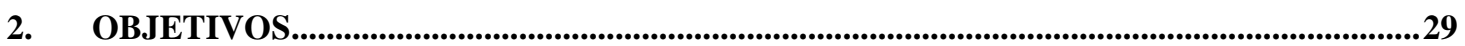

3. METODOLOGIA ..................................................................................................................................29

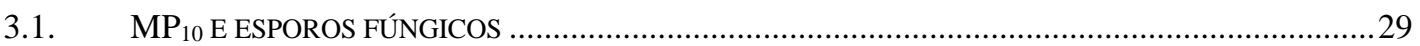

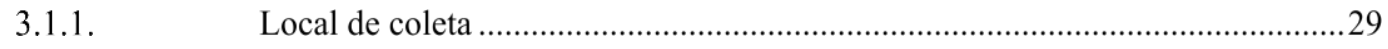

3.1.2. Período de amostragem ...........................................................................

3.1.3. Metodologia analítica de coleta e análise............................................................

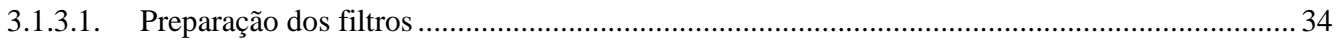

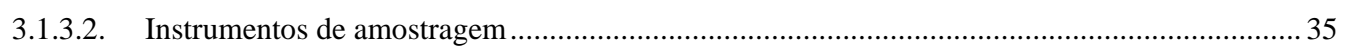

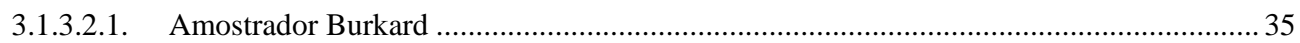

3.1.3.2.2. Amostrador de baixo volume (MiniVol) .................................................................... 36

3.1.3.2.3. Amostrador de alto volume $(\mathrm{HiVol})$............................................................................. 36

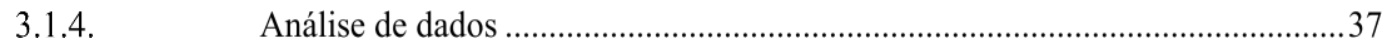

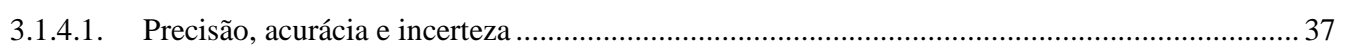

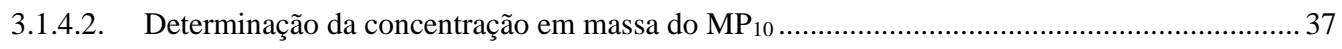

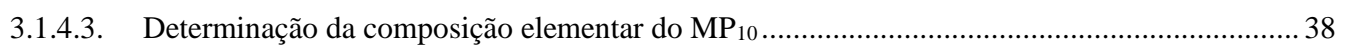

3.1.4.3.1. Análise elementar por espectrometria de fluorescência de raio X por energia dispersiva 38

3.1.4.3.2. Análise elementar por espectrometria de massa com plasma indutivamente acoplado .... 39

3.1.4.4. Determinação da concentração do carbono negro ................................................................ 42

3.1.4.5. Determinação dos íons, carboidratos e ácidos orgânicos........................................................ 43

3.1.4.5.1. Análise de íons com o cromatógrafo de íons (Metrohm) …........................................... 43

3.1.4.5.2. Análises de íons, carboidratos e ácidos orgânicos com o cromatógrafo de íons (Dionex) 44

3.1.4.6. Determinação do carbono elementar e orgânico....................................................................... 47

3.1.4.7. Quantificação de proteína solúveis em água......................................................................... 48

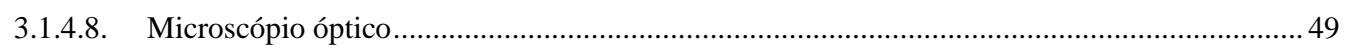

3.2. ESTUDO DA HABILIDADE DOS BIOAEROSSÓIS COMO NÚCLEOS DE GELO ..............................50

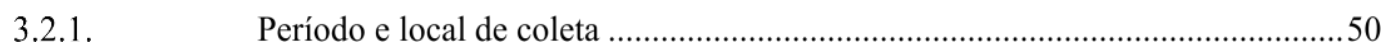

3.2.2. Impressão de esporos (Basidiomycota) ........................................................50

3.2.3. Coleta dos esporos (fungos anamorfos) ............................................................51

3.2.4. Atividade dos esporos como núcleo de gelo .................................................51

3.3. ANÁLISES ESTATÍSTICAS E ANÁLISE DE TRAJETÓRIAS ...................................................52

3.3.1. Análises estatísticas não paramétricas...........................................................53

3.3.2. Fatoração de Matriz Positiva (PMF) ….......................................................54

3.3.3. Função de Probabilidade Bivariada Condicional (CBPF) ..................................55

3.3.4. Hysplit (Hybrid Single-particle Lagrangian Integrated Trajectory)...................55

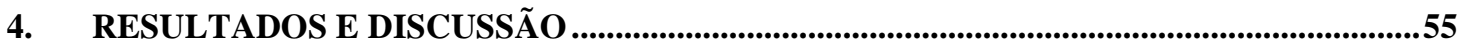




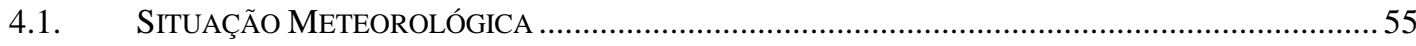

4.2. COMPARAÇÃO ENTRE DADOS DE DIFERENTES EQUIPAMENTOS ...........................................58

4.3. ANÁLISE DA COMPOSIÇÃO DO MP ${ }_{10}$, RECONSTRUÇÃO DA MASSA E CARACTERIZAÇÃO DE

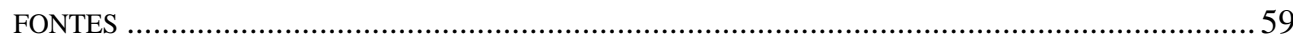

4.3.1. Avaliação da normalidade da distribuição das variáveis .................................. 59

4.3.2. Balanço de massa dos íons......................................................................... 59

4.3.3. Composição do $\mathrm{MP}_{10}$ e reconstrução da massa .............................................. 62

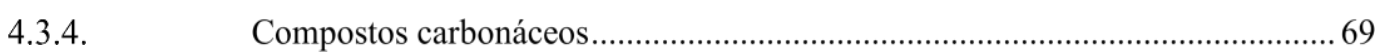

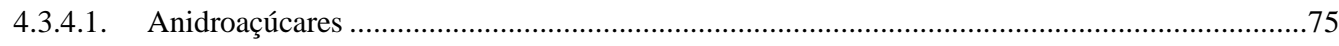

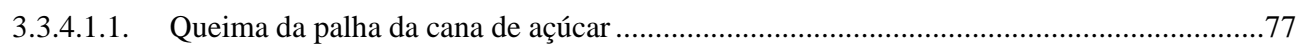

3.3.4.1.2. Razão Levoglucosano/Manosasno e $\mathrm{K}^{+} /$Levoglucosano ................................................80

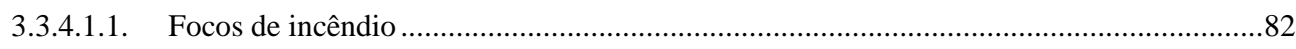

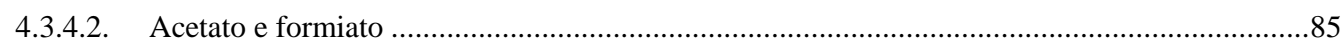

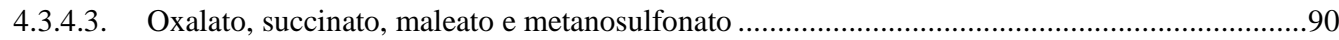

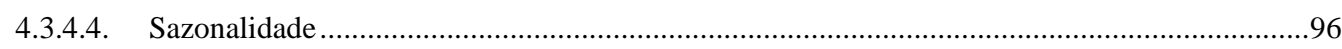

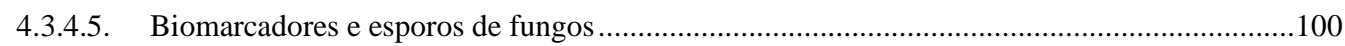

4.3.4.5.1. Concentração e variação temporal dos bioaerossóis .........................................................100

4.3.4.5.2. Influência das variáveis meteorológicas nos bioaerossóis ................................................103

4.3.4.5.3. Correlação entre gases, componentes do $\mathrm{MP}_{10} \mathrm{e}$ biomarcadores ....................................106

4.3.4.5.4. Limiar para o surgimento de sintomas alérgicos para alguns fungos ...............................109

4.3.4.5.5. Relação entre os carboidratos e os esporos de fungos .......................................................111

4.3.4.5.6. Variação sazonal....................................................................................................115

4.3.4.5.7. Variação diária dos esporos fúngicos .....................................................................116

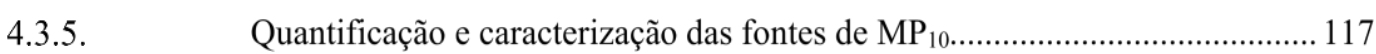

4.3.5.1. Fontes identificadas com o PMF................................................................................... 117

4.4. POTENCIAL DE ALGUNS FUNGOS COMO NÚCLEADORES DE GELO ....................................... 127

5. CONCLUSÃO

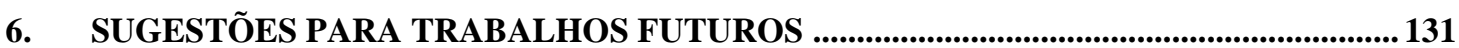

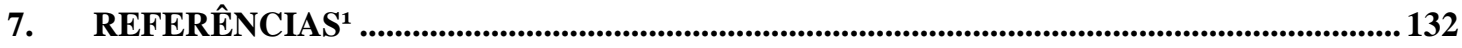

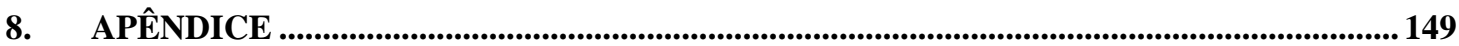

APÊNDICE A -COMPARAÇÃO ENTRE DADOS DE DIFERENTES EQUIPAMENTOS .............................. 149

APÊNDICE Aa -Comparação entre os equipamentos para a determinação da concentração de massa obtida com diferentes arranjos experimentais ........................................................... 149

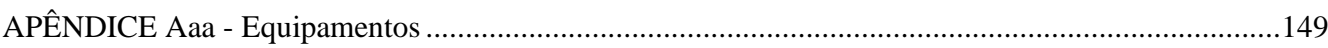

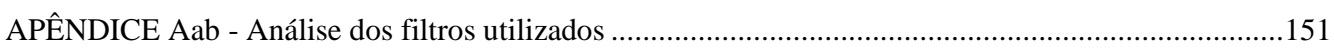

APÊNDICE Aac - Análise da concentração de $\mathrm{MP}_{2,5}$ obtidas por diferentes equipamentos .....................153

APÊNDICE Aad - Análise da concentração de MP10 obtidas por diferentes equipamentos .....................155

APÊNDICE Ab -Comparação entre as concentrações elementar obtidas com (ICP e EDX) com diferentes equipamentos e filtros

APÊNDICE Ac -Comparação da concentração de íons e elementos obtidas por diferentes equipamentos e filtros. 
9. TABELAS..................................................................................................................................164

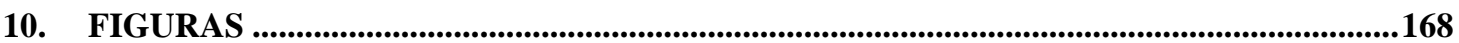





\section{Introdução}

\subsection{Material particulado}

A presença de poluentes na atmosfera tem causado vários impactos negativos, incluindo desfechos em saúde para os humanos, animais e danos aos ecossistemas e comunidades (EPA, 2020; Marco et al., 2019; Apte et al., 2018; Burnett et al., 2018; Deng et al., 2019; Andreão et al., 2020; Di Domenico, 2020; Pal et al., 2015; Barker et al., 1961). A poluição do ar em ambientes externos causou 4,2 milhões de mortes em 2016 (WHO, 2018a; 2018b). Os poluentes do ar em ambiente externo que causam a maior parte das complicações de saúde são o dióxido de enxofre $\left(\mathrm{SO}_{2}\right)$, material particulado $(\mathrm{MP})$, dióxido de nitrogênio $\left(\mathrm{NO}_{2}\right)$ e ozônio $\left(\mathrm{O}_{3}\right)(\mathrm{WHO}$, 2020c).

O MP é um dos poluentes que pode causar problemas severos para humanos, particularmente para a saúde, uma vez que está relacionado com a ocorrência de doenças como câncer do pulmão, infecções respiratórias, doenças do coração, e doenças pulmonares obstrutivas crônicas (WHO, 2018b). As partículas também têm um papel essencial na atmosfera, contribuindo para a formação de nuvens e para o balanço radiativo da Terra (Seinfeld e Pandis, 2006). O MP consiste em partículas solidas e líquidas e a mistura das fases que podem se diferenciar em composição, tamanho, morfologia, densidade, massa, propriedades físicas e químicas e permanecer suspensas na atmosfera (Seinfeld e Pandis, 2006). Este também pode ser classificado em diferentes categorias com o propósito de se estudar seus efeitos na saúde. Partículas com o diâmetro aerodinâmico entre 2,5 e 10 m são chamadas de partículas grossas, que somadas com as partículas finas (material particulado com tamanho aerodinâmico menor que 2,5 $\mu \mathrm{m}$ ) são chamadas de partículas inaláveis $\left(\mathrm{MP}_{10}\right)$ (WHO, 2005). Partículas maiores (maiores do que $100 \mu \mathrm{m}$ ) são definidas como material particulado depositável (Godish, 2004) e partículas menores (menores do que $0,1 \mu \mathrm{m}$ ) são chamadas de partículas ultrafinas (WHO, 2005). O material particulado fino $\left(\mathrm{MP}_{2,5}\right)$ pode causar mais problemas de saúde do que o $\mathrm{MP}_{10}$ pois penetra mais profundamente no pulmão e sistema sanguíneo (WHO, 2018b). A organização mundial da saúde (WHO) estima que 91\% da população mundial em 2016 foi exposta às concentrações de $\mathrm{MP}_{2,5}$ maiores do que a média anual proposta em suas diretrizes de valores guias (WHO, 2018a; 2018b). Na região metropolitana de São Paulo (RMPS - Brasil), o $\mathrm{MP}_{2,5}$ e $\mathrm{MP}_{10}$ estão entre os poluentes que causam maior impacto na qualidade do ar (Perez et al., 2014).

O MP é composto por uma ampla variedade de compostos, incluindo os inorgânicos e orgânicos. Esses compostos podem ser emitidos diretamente na atmosfera como partículas 
(partículas primárias) ou podem ser emitidas como gases na atmosfera e então transformados em partículas (partículas secundárias), por processos de conversão gás-partícula.

Atualmente, na Região Metropolitana de São Paulo (RMSP) acumulou-se uma grande quantidade de informações sobre as fontes de compostos inorgânicos do $\mathrm{MP}_{10}$ e $\mathrm{MP}_{2,5} \mathrm{em}$ consequência de estudos feitos desde a década de 80 (Ynoue et al., 2004; Miranda et al., 2002; Andrade et al., 2012; Castanho e Artaxo 2001; Oyama et al., 2015; Brito et al., 2013), e revisados por Andrade et al. (2017). Contudo, poucos estudos têm analisado a contribuição de fontes orgânicas para o MP na RMSP, com exceção de alguns trabalhos sobre a contribuição veicular (Oyama et al., 2015; Brito et al., 2013), queima de biomassa (Caumo et al., 2016) e modelos receptores (Pereira et al., 2017). Contudo, a fração orgânica do material particulado (MPO) consiste em uma parte significativa do $\mathrm{MP}_{10}$ e a maior parte da massa do $\mathrm{MP}_{2,5}$ (Oyama et al., 2015; Pereira et al., 2017; Emygdio et al., 2018a) e pode apresentar várias fontes incluindo as biogênicas e antropogênicas (Godish, 2004).

O material carbonáceo presente no material particulado é geralmente classificado como carbono orgânico (OC) e carbono elementar (EC) e ambos são importantes no balanço radioativo da atmosfera. A radiação solar é principalmente espalhada pelo OC, mas também pode ser absorvida, resultando em uma força radiativa negativa (IPCC, 2007; IPCC, 2014). Em contrapartida, o EC absorve a radiação solar, contribuindo significativamente para o efeito estufa e, consequente aquecimento da superfície da terra (Novakov et al., 2005; Rengarajan et al., 2011; IPCC, 2007; IPCC, 2014). O OC é uma mistura complexa de compostos de hidrocarbonetos e oxigênio ( $\mathrm{Na}$ et al., 2004), e pode ser classificado como carbono orgânico primário (POC) ou carbono orgânico secundário (SOC) (Rengarajan et al., 2011; Castro et al., 1999). Como um exemplo, os compostos orgânicos secundários, resultantes da oxidação de compostos orgânicos voláteis, representam de $20 \%$ a $80 \%$ de todo o material particulado orgânico (MPO) em áreas rurais e urbanas (Turpin et al., 1995; Schauer et al., 1996; Castro et al., 1999). Entre os compostos primários estão os bioaerossóis e produtos de queima dos combustíveis fósseis e não fósseis.

Alguns estudos feitos em São Paulo estimaram a fração de OC no MP. Oyama et al. (2015) analisaram dois diferentes túneis em São Paulo e propuseram que a emissão de compostos de carbono por veículos leves contribui para $36 \%$ da massa do $\mathrm{MP}_{2,5}$, enquanto veículos pesados contribuem com 43\%. Brito et al. (2013), sugeriram que aproximadamente $40 \%$ do $\mathrm{MP}_{2,5}$ é OC considerando análise em túneis. Castanho e Artaxo (2001) encontraram que o OC representa $40 \%( \pm 16 \%)$ e $35 \%( \pm 14 \%)$ da massa de MP fino no inverno e verão respectivamente em 1998. Souza et al. (2014) encontraram que o MPO contribui para $26 \%$ do 
$\mathrm{MP}_{2,5}$. Considerando esses estudos e outros (Miranda e Andrade, 2005; Albuquerque et al., 2012) é possível entender que a massa de compostos orgânicos é uma importante fração da concentração em massa do material particulado.

\subsection{Bioaerossóis}

Uma fração importante do carbono orgânico primário são os bioaerossóis, que tem como principais componentes as plantas, fungos, bactérias, que podem ser viáveis ou não viáveis além de seus subprodutos (Després et al., 2012; Fröhlich-Nowoisky et al., 2016). Esses componentes liberam várias partículas na atmosfera, que podem apresentar diferentes concentrações dependendo do tamanho, condição meteorológica, taxa de urbanização, diferentes usos do solo e outras influências antropogênicas, como poluição do ar (Matthias-Maser e Jaenicke, 2000a; Després et al., 2012; Fröhlich-Nowoisky et al., 2016; Gong et al., 2020). A importância dessas partículas são muitas e incluem efeitos na saúde humana e processos atmosféricos (Douwes et al., 2003; Möhler et al., 2007; Morris et al., 2008; 2011; 2012).

Globalmente, tem havido um aumento na prevalência de doenças alérgicas (como alguns tipos de asma, rinites, conjuntivites, angioedema, urticária e muitas outras) como um resultado de uma mistura de fatores, os quais incluem, mas não são limitados a aumento da poluição do ar (em ambientes internos e externos), urbanização e diminuição da biodiversidade (Pawankar, 2014). Essas doenças afetam pessoas de todas as rendas (baixa, média e alta) e resultam em um custo econômico para o indivíduo e para o país (Pawankar et al., 2014). De acordo com Johansson et al. (2004), alergia é uma reação de hipersensibilidade iniciada por um mecanismo imunológico. Essa hipersensibilidade resulta em sintomas iniciados após a exposição a algum estímulo que pode ser um antígeno como um alérgeno, o qual normalmente não causaria uma reação. Rinites alérgicas afetam de 10 a 30\% dos adultos (Pawankar et al., 2013), enquanto a asma, que é uma doença crônica, afetou mais de 339 milhões de pessoas em 2016 (Vos, 2017). Ambas as doenças podem ser exacerbadas por bioaerossóis, como pólen e mofos (fungos) (Żukiewicz-Sobczak, 2013). De acordo com o "White book on allergy" da Organização mundial da alergia e referências apresentadas nele, o pólen de gramínea, árvores e ervas daninhas são os alérgenos mais comuns em ambientes externos, enquanto a alergia ao mofo apesar de também ser importante, não apresenta uma sazonalidade bem definida como a dos pólens (Platts-Mills et al., 2013).

Além do impacto na saúde humana, os bioaerossóis podem interferir em processos climatológicos e meteorológicos. Os bioaerossóis tem o potencial de serem núcleos de condensação de nuvem, que desencadeiam a formação de gotas de nuvem e chuva, e núcleos de gelo, que desencadeiam a formação de cristais de gelo, influenciando no balanço radioativo 
da Terra (Möhler et al., 2007; Morris et al., 2008; 2011; 2012; Hassett et al., 2015). Entre os aerossóis que podem atuar como núcleo de gelo, os bioaerossóis são as principais partículas que podem atuar em temperaturas superiores a $-10^{\circ} \mathrm{C}$ (Morris et al., 2012). Como apontado por Morris et al. (2012), padrões de vegetação e agricultura influenciam a formação de nuvens e precipitação, o que poderia ser explicado pela presença desses bioaerossóis nesses ambientes. A distribuição temporal e espacial dos bioaerossóis varia de acordo com as condições do ambiente e como resultado também o seu potencial para influenciar a atmosfera (Morris et al., 2008; 2011; 2012). Na literatura, há vários estudos descrevendo a habilidade de bactérias (Kaneda, 1986; Kim et al., 1987; Lindow et al., 1978), pólens (Diehl et al., 2001) e fungos (Pouleur et al., 1992; Kieft e Ruscetti, 1990) de atuarem como núcleos de gelo.

Apesar de todos esses impactos a real contribuição dos bioaerossóis globalmente e em particular para a atmosfera da Região Metropolitana de São Paulo (RMSP) é incerta. Há muitas incertezas na composição, contribuição e impacto dos bioaerossóis como constituinte do aerossol atmosférico. Alguns estudos apontam que os bioaerossóis contribuem muito pouco para a fração inalável do MP (Lin e Li, 2000; Glikson et al., 1995), enquanto outros indicam que os bioaerossóis contribuem com uma grande fração (Matthias-maser et al., 2000b; Elbert et al., 2007). É importante contudo, considerar o local, os fatores meteorológicos e climáticos, uso do solo, tipo de vegetação, biodiversidade e ainda muitos outros fatores relevantes para se estabelecer se a contribuição dos bioaerossóis para o MP é relevante ou não.

Um dos bioaerossóis mais comuns na atmosfera são os fungos (Glikson et al., 1995; Ataygul et al., 2007; Després et al., 2012) e eles podem ser encontrados em quase todos os ecossistemas do mundo. As principais espécies encontradas na atmosfera pertencem aos filos Ascomycota e Basidiomycota (Fröhlich-Nowoisky et al., 2012; Elbert et al., 2007; Zoppas et al., 2006; Butinar et al., 2007; Emygdio, 2016). A contribuição dos fungos para a atmosfera é principalmente devido aos esporos e conídios, os quais têm uma concentração em número de $7,3 \times 10^{2}$ esporos $/ \mathrm{m}^{3}$ (Bauer et al., 2002a) ou entre $10^{3} \mathrm{a} 10^{4}$ esporos $/ \mathrm{m}^{3}$ no ar e uma concentração em massa entre 0,1 e $1 \mu \mathrm{g} / \mathrm{m}^{3}$ (Elbert et al., 2007). O tamanho, entre os esporos mais comuns, varia entre 2 e $10 \mu \mathrm{m}$ (Bauer et al., 2002b; Elbert et al., 2007), contudo, esporos com $1 \mu \mathrm{m}$ a $50 \mu \mathrm{m}$ também são observados (Després et al., 2012).

Os esporos de fungos são um importante alérgeno e contribuem para uma importante fração dos bioaerossóis (Grinn-Gofroń and Rapiejko, 2009; Żukiewicz-Sobczak, 2013). Cladosporium e Alternaria são gêneros de fungos que são amplamente reportados devido ao seu importante potencial alergênico, sendo considerados como os principais gêneros encontrados na Europa (Gravesen, 1979; Grinn-Gofroń and Rapiejko, 2009). Alguns autores 
têm estimado e usado um limite clínico em que esses fungos podem resultar em sintomas alérgicos, uma vez que a concentração de esporos na atmosfera irá determinar a intensidade das reações alergênicas (Sadys et al., 2016; Sindt et al., 2016; Kasprzyk et al., 2015; Kustrzeba et al., 2014; Grinn-Gofroń and Rapiejko, 2009; Rapiejko et al., 2007; Gravesen, 1979). Gravesen (1979) relatou um limite de 3000 esporos $/ \mathrm{m}^{3}$ para o Cladosporium spp. e 100 esporos $/ \mathrm{m}^{3}$ para a Alternaria spp., enquanto Sadys et al. (2016) no Reino Unido (UK), usou um limite diferente para a Alternaria sp. de 50 esporos $/ \mathrm{m}^{3}$. Rapiejko et al. (2007) observou que o aparecimento de sintomas alérgicos em pessoas com hipersensibilidade a certos alérgenos na Polônia ocorreu para o Cladosporium spp. em uma concentração de 2800 esporos $/ \mathrm{m}^{3}$ e para a Alternaria spp. em uma concentração de 80 esporos $/ \mathrm{m}^{3}$.

As bactérias também estão em grande quantidade na atmosfera. Apesar de serem menores $(\leq 1 \mu \mathrm{m})$ do que os fungos, as bactérias estão geralmente aglomeradas e aderidas a outras partículas (como as originadas no solo ou folhas) e, por isso também podem estar presentes na faixa de tamanho das partículas grossas (Bauer et al., 2002a; Burrows et al., 2009; Després et al., 2012). Després et al. (2012) analisando outros estudos, propôs que a concentração das bactérias em ambientes urbanos é maior do que no ambiente rural, apesar de possuir menor diversidade. Ademais, tem-se proposto que a concentração em número das bactérias é ao redor de $1,2 \times 10^{4}$ células $/ \mathrm{m}^{3}$ no continente (Bauer et al., 2002a).

Os grãos de pólen são o gametófito reprodutivo masculino das plantas (Burge e Rogers, 2000). Dentre os bioaerossóis mais comuns, eles estão entre os maiores, variando em tamanho de 10 a $100 \mu \mathrm{m}$. Eles apresentam uma parede externa rígida que protege a célula espermática durante o processo de transporte, o qual pode ser através do vento, água ou animais (Burge e Rogers, 2000; Després et al., 2012). As plantas que liberam os pólens que são principalmente transportados pelo vento (anemofilia), os produzem em grande quantidade para compensar o transporte menos efetivo, comparado com um transporte por insetos (entomofilia) por exemplo, e como mencionado anteriormente, são a principal causa de alergias em muitos países (Burge e Rogers, 2000; Platts-Mills et al., 2013).

Diferentes metodologias podem ser aplicadas para determinar as fontes biológicas e sua participação na concentração de MP na atmosfera. Contudo, cada método tem suas limitações e vantagens e não há um único método eficiente para todas as situações, requerendo uma combinação de métodos específicos para cada situação (Levetin, 2004; Degobbi, 2010). Usando métodos tradicionais a concentração em número de fungos e pólens pode ser obtida por equipamentos do tipo Hirst e posterior análise ao microscópio óptico, enquanto a concentração em unidade formadora de colônias (UFC) de fungos e bactérias pode ser obtida por meio de 
cultura (Després et al., 2012). Um modo indireto para estimar a concentração de bioaerossóis na atmosfera é através da análise de biomarcadores (Després et al., 2012). Através desse método é possível conhecer a ocorrência, biomassa total e contribuição para $\mathrm{o} \mathrm{MP}_{10}$ das fontes biogênicas, além de ser mais rápidas e com um procedimento analítico mais simples quando comparado com metodologias tradicionais (Bauer et al., 2008a, Bauer et al., 2008b; Bauer et al., 2002b; Zhang et al., 2015; Zhang et al., 2010). Arabitol, manitol, ergosterol, ácido graxo 3hidroxi, glicose, frutose e sacarose podem ser usados como traçadores para a presença de bioaerossóis na atmosfera (Bauer et al., 2008a; Burshtein et al., 2011; Lau et al., 2006; Lee et al., 2004; Zhang et al., 2010; Fu et al., 2012; Rathnayake et al., 2016). Arabitol, manitol e ergosterol são conhecidos biomarcadores de esporos de fungos na atmosfera (Bauer et al., 2008a; Burshtein et al., 2011; Lau et al., 2006; Nirmalkar et al., 2015; Zhang et al., 2010). Contudo, o arabitol e manitol além de serem substâncias de armazenamento (reserva de energia) de fungos, também são encontrados em plantas (e.g., pólens), algas e bactérias (Loescher et al., 1992; Burshtein et al., 2011; Webster et al.,1995; Fu et al., 2012; Rathnayake et al., 2017). O ácido graxo 3-hidroxi é um traçador de bactéria (Lee et al., 2004), enquanto a glicose, frutose, e sacarose estão relacionados com a emissão pela vegetação (Sullivan et al., 2011; Fu et al., 2012; Rathnayake et al., 2016) e também podem ser traçadores de pólen (Fu et al., 2012; Rathnayake et al., 2017). De acordo com os mesmos autores, a glicose pode ser usada sozinha como um traçador de pólen na atmosfera (Rathnayake et al., 2017). Proteínas solúveis em água (do inglês Water Soluble Protein, WSP) representam todos os tipos de bioaerossóis no MP 10 , já que as proteínas estão presentes em todos os organismos vivos. Contudo, os bioaerossóis apresentam muitos outros compostos que contribuem para a sua massa. As WSP possuem várias fontes, incluindo o solo, queima de biomassa, fungos, bactérias e pólen (Menetrez et al., 2007a; Rathnayake et al., 2016; Kang et al., 2012).

No geral, alguns desses compostos (arabitol, manitol, glicose e WSP) estão presentes na fração grossa do MP na atmosfera (Zhang et al., 2010; Zhang et al., 2015, Nirmalkar et al., 2015; Rathnayake et al., 2017; Menetrez et al., 2007a; Menetrez et al., 2007b). Apesar disso, Rathnayake et al. (2017) mostraram que durante períodos de chuva, a contribuição do manitol e glicose para a fração fina do MP pode aumentar, enquanto depois dos períodos de chuva os traçadores de fungos tiveram maior concentração no MP grosso. Os autores explicaram essa situação devido a três fatores, remoção pela chuva das partículas grande dos fungos, mecanismos passivos de liberação de esporos durante os períodos de chuva (respingos de chuva e movimento mecânico da gota de chuva na vegetação) e mecanismos ativos de liberação de esporos após dias chuvosos. Nirmalkar et al. (2015) discutiram que a maior parte da 
concentração de arabitol e manitol na fração grossa do MP pode ser explicada pela ressuspensão do solo e a aglomeração de esporos de fungos. Já a presença da glicose na fração grossa do MP pode ser explicada pela sua presença nos pólens, os quais variam de tamanho de 10 a $100 \mu \mathrm{m}$ (Rathnayake et al., 2017). Em contrapartida, a ruptura da parede do pólen devido à pressão osmótica causada pela absorção de água da chuva é possivelmente a principal razão da presença da glicose na fração fina do MP durante eventos de chuva (Rathnayake et al., 2017). Como indicado acima, a maioria dos componentes biológicos na atmosfera estão presentes na fração grossa do MP, o que explica a presença do WSP, um traçador de todos os tipos de bioaerossóis, na fração grossa.

Mundialmente, muitas estimativas da concentração e contribuição dos bioaerossóis para o MP têm sido feitas utilizando esses biomarcadores e usando fatores de conversão, como em Vienna para esporos de fungos (Bauer et al., 2008b e 2002b), no Canadá para fungos e pólens (Womiloju et al., 2003), em Hong Kong para esporos de fungos (Lau et al., 2006), na ilha de Hainan (China) para esporos de fungos (Zhang et al., 2010), em Iowa (USA) para pólen e fungos (Rathnayake et al., 2016), em São Paulo (Brasil) para esporos de fungos (Emygdio et al., 2018a).

A contribuição dos bioaerossóis para o MP varia bastante, com uma média de 1\% (primavera) e 4\% (verão) do $\mathrm{MP}_{10}$ em um local urbano em Vienna (Bauer et al., 2008b), 4 a $11 \%$ do $\mathrm{MP}_{2,5}$ no Canadá (Womiloju et al., 2003), média de 7,9\% do $\mathrm{MP}_{10}$ nas montanhas do Jianfengling na ilha de Hainan (China) (Zhang et al., 2010), 2 a 5\% das partículas totais (TSP) durante o período seco e 17 a 23\% durante o período chuvoso em Iowa (Rathnayake et al., 2016) e uma média de 2\% do MP 10 (outono-inverno) em São Paulo (Emygdio et al., 2018a). Essa variação ocorreu provavelmente devido a fatores já mencionados como local, fatores meteorológicos e climáticos, uso do solo, biodiversidade e tipo de vegetação. Contudo, todos estes estudos mostraram que a contribuição dos bioaerossóis para o aerossol na atmosfera é relevante e merece maior atenção.

\subsection{Identificação das fontes do Material Particulado}

Existem vários modelos receptores usados na identificação e quantificação das fontes do Material Particulado, como a Análise de Componentes Principais (PCA), Análise de Fatores, Fatoração de Matriz Positiva (PMF) e balanço químico de massa (CMB) (Hopke et al., 2020). De acordo com os mesmos autores, entre 2014 e 2019 o método mais usado foi o PMF, enquanto o PCA e o CMB devem ser usados com cautela, uma vez que pode ocorrer uma estimativa incorreta da contribuição das fontes (Hopke et al., 2020). Belis et al. (2013) e Banerjee et al. 
(2015), observaram um aumento na quantidade de análises utilizando o PMF em detrimento da Análise de Fatores para a Europa e Índia, respectivamente.

Com a ampliação das medidas de $\mathrm{MP}_{2,5}$ houve um aumento dos estudos sobre a distribuição de fontes dessa fração comparado com o $\mathrm{MP}_{10}$ ao redor do mundo considerando o período de 2014 a 2019 (Hopke et al., 2020). Várias revisões de fontes identificadas com a aplicação de modelos receptores têm sido feitas ao redor do mundo e, no geral, as fontes encontradas são similares, sendo as cinco principais: (i) crosta/minerais, poeira/solo, poeira/estrada, poeira/ressuspensão do solo; (ii) aerossol inorgânico secundário; (iii) emissão veicular/tráfego; (iv) queima de biomassa e (v) aerossol marinho, sal marinho ou spray marinho (Belis et al., 2013; Banerjee et al., 2015; Zhang et al., 2017).

Belis et al. (2013), em um trabalho de revisão analisaram 108 publicações, considerando a distribuição de fontes Européias. Eles separaram em seis categorias principais: com menor participação o sal marinho/ sal de estradas; em seguida poeira da crosta/mineral que foi a segunda principal fonte do $\mathrm{MP}_{10}$; o aerossol inorgânico secundário, que contribuiu mais para o $\mathrm{MP}_{2,5}$ do que para o MP 10 , contudo em ambos foi a principal fonte; a fonte de tráfego, que inclui exaustão e ressuspensão da poeira de rua (freio e desgaste de pneu), foi a segunda principal fonte para o $\mathrm{MP}_{2,5}$ e a terceira principal para o $\mathrm{MP}_{10}$; fonte local, que inclui principalmente combustão de óleo, emissão industrial, áreas portuárias e representa a quarta e terceira fonte principal para o $\mathrm{MP}_{10}$ e $\mathrm{MP}_{2,5}$, respectivamente; e a fonte de queima de biomassa (Belis et al., 2013).

A Índia e China estão entre os países com maiores concentrações de $\mathrm{MP}_{2,5}$ e $\mathrm{MP}_{10}$ como indicado pela Organização mundial da Saúde (WHO, 2018a, 2020a, 2020b). Uma revisão da distribuição de fontes feita na Índia, com estudos até 2010 indicou que as fontes encontradas incluem: poeira do solo/pavimento ou elementos da crosta/poeira, a qual é geralmente a principal fonte nos estudos convencionais; emissão veicular que pode incluir tanto emissões derivadas da exaustão como da não exaustão (as vezes somada a elementos da crosta e indústria); emissões industriais (i.e. farmacêutica, petroquímica, cerâmica, metalúrgica, entre outras); queima de combustíveis (carvão e petróleo); aerossol marinho; e queima de biomassa/rejeitos (i.e. madeira, esterco de animais, resíduos agrícolas, queima de resíduos e incêndios florestais) (Banerjee et al., 2015). Zhang et al. (2017) revisaram a distribuição de fontes de 21 cidades da China entre 2004 e 2014 e observaram que a fonte aerossóis secundários é a principal fonte para ambos norte e sul da China, representando $22 \%$ e $32 \%$, respectivamente. A exaustão veicular é a segunda principal fonte seguida da combustão de carvão, poeira, queima de biomassa e emissão industrial para o norte, enquanto para o sul, a emissão industrial é a 
terceira principal fonte seguida da queima de biomassa, poeira e combustão de carvão (Zhang et al., 2017).

Adicionalmente, algumas classificações determinaram fontes diferentes, através de uma identificação mais detalhada, como encontrado em vários locais no estado de Nova York entre 2005 e 2016 usando o PMF (Squizzato et al., 2018). Esses autores encontraram sete fontes principais para $\mathrm{o} \mathrm{MP}_{2,5}$, entre as quais a principal foi o sulfato secundário, com maiores concentrações encontradas nas áreas rurais, seguida no geral pelo nitrato secundário, emissão de veículos a gasolina (com um motor com ignição; emitem mais carbono orgânico - OC) e emissão de veículo a diesel (emitem mais carbono elementar - EC), com maiores concentrações em áreas urbanas. Outras fontes encontradas foram: poeira de rua, queima de biomassa, fonte rica em matéria orgânica pirolisada (aerossol secundário envelhecido) e em alguns locais também o sal marinho envelhecido, sal marinho fresco, sal de estrada, óleo residual e industrial (Squizzato et al., 2018).

Na tabela 1 são apresentados estudos de distribuição de fontes do MP na cidade de São Paulo e região metropolitana. Muitos estudos na RMSP, inclusive os apresentados na tabela 1 , têm apontado que o tráfego de veículos é a principal fonte de MP e que o carbono orgânico é o componente que mais contribui para a massa do MP apesar de ser pouco frequente a sua especiação (Albuquerque et al., 2012; Pereira et al., 2017; Andrade et al., 2012; Castanho e Artaxo, 2001; CETESB, 2019b).

Tabela 1. Estudos publicados sobre a determinação de fontes do MP na cidade de São Paulo e região metropolitana.

\begin{tabular}{|c|c|c|c|c|}
\hline Fontes/Estudos & $\begin{array}{l}\text { Castanho e Artaxo } \\
\text { (2001) }\end{array}$ & $\begin{array}{l}\text { Andrade et al. } \\
(2012)\end{array}$ & $\begin{array}{l}\text { Pereira et } \\
\text { al. }(2017)\end{array}$ & $\begin{array}{l}\text { CETESB } \\
(2019 b)\end{array}$ \\
\hline Período amostrado & Inverno de 1997 & 2007 até 2008 & 2014 & 2018 \\
\hline Fração do MP & $\mathrm{MP}_{2,5}$ & $\mathrm{MP}_{2,5}$ & $\mathrm{MP}_{10}$ & $\mathrm{MP}_{10}$ \\
\hline Veículos no geral & 28 & 40 & 39,2 & 40,1 \\
\hline Veículos leve & - & 12 & - & 6,7 \\
\hline Veículos pesados & - & 28 & - & 31,7 \\
\hline Motocicletas & - & - & - & 1,7 \\
\hline Industria & 5 & (SIA & 9,5 & 10 \\
\hline Aerossol inorgânico secundário (SIA) & 23 & indústria) & 17,9 & 25 \\
\hline Ressuspensão do solo & 25 & 13 & 25,7 & 25 \\
\hline Queima de biomassa & - & - & 7,6 & - \\
\hline Óleo industrial & 18 & - & - & - \\
\hline Bioaerossol & - & - & - & - \\
\hline Marinha & - & - & - & - \\
\hline
\end{tabular}

As fontes da fração inorgânica do MP no RMSP são relativamente bem descritas, mas ainda há uma grande incerteza em relação a matéria orgânica $(\mathrm{OM})$, e poucas informações sobre a natureza biogênica das partículas. A determinação das principais fontes de aerossol biogênico 
primário para a massa do carbono orgânico total e para o material particulado é essencial para compreender a composição do MP e seus efeitos nos processos da atmosfera e na saúde humana. Em 2015, um estudo usando biomarcadores de esporos fungos (arabitol e manitol) foi realizado na RMSP e foi encontrado que, em média, $2 \%$ do $\mathrm{MP}_{10}$ tem uma origem fúngica (Emygdio et al., 2018a). Contudo, mostrou-se também que havia necessidade de mais estudos com a caracterização de diferentes biomarcadores para estimar com maior precisão a contribuição das fontes biológicas para o MP.

\section{Objetivos}

O objetivo geral deste trabalho é determinar a contribuição das partículas de aerossol biogênico primário (PBAP) para o material particulado presente na atmosfera da RMSP e estimar a contribuição de compostos orgânicos para o aerossol atmosférico. Como objetivos específicos pode-se elencar:

- Determinaras as principais fontes do $\mathrm{MP}_{10}$ na RMSP, incluindo as fontes biológicas, através do uso de modelos receptores como o PMF.

- Verificar a contribuição, relação e variabilidade de compostos orgânicos, como alguns carboidratos e ácidos orgânicos, para o $\mathrm{MP}_{10}$.

- $\quad$ Estimar a concentração em massa dos esporos fúngicos nas diferentes estações do ano (primavera, outono e inverno) usando fatores de conversão e estimar a sua contribuição para o carbono orgânico $(\mathrm{OC})$ e $\mathrm{MP}_{10}$;

- Determinar um fator de conversão para a concentração em massa dos biomarcadores, manitol e arabitol, em concentração em número de esporos fúngicos, considerando sazonalidade, fatores ambientais e diversidade fúngica;

- Estimar o potencial, como núcleos de gelo, de algumas espécies de fungos observados na cidade de São Paulo.

Neste trabalho discutimos a hipótese que os compostos biogênicos contribuem significativamente para a concentração em massa do material particulado, apesar de serem, no geral, negligenciados.

\section{Metodologia}

\subsection{MP10 e esporos fúngicos}

\subsubsection{Local de coleta}


Fundada em 1554, a cidade de São Paulo é hoje uma das maiores metrópoles do mundo, com uma população de aproximadamente 12 milhões de habitantes (IBGE, 2017a) e área metropolitana composta por 39 cidades com 20,9 milhões de habitantes ( $10 \%$ da população do Brasil) (CETESB, 2019a). A densidade geográfica do município de São Paulo é de aproximadamente 7,4 mil habitantes por $\mathrm{km}^{2}$ de acordo com o último censo populacional realizado em 2010 (IBGE, 2011), e apresenta uma grande frota veicular de aproximadamente 7,3 milhões de veículos (CETESB, 2019a). A cidade de São Paulo está localizada em um plateau a 760 metros acima do nível do mar e a $56 \mathrm{~km}$ do porto de Santos e $45 \mathrm{~km}$ da cidade de Cubatão (em linha reta), uma área industrial (com um complexo petroquímico), ambos localizados a sudeste da cidade de São Paulo.

O clima de São Paulo pode ser descrito como subtropical úmido, com invernos secos e verões chuvosos. De acordo com o boletim anual climatológico da estação climatológica do IAG (IAG, 2017) o ano de 2017 teve uma precipitação acumulada de 1648,8 mm, sendo acima da média climatológica $(1402,3 \mathrm{~mm})$.

A plataforma de coleta está localizada no telhado do prédio principal de 4 andares $(\sim 15$ metros) do Instituto de Astronomia, Geofísica e Ciências Atmosférica (IAG), da Universidade de São Paulo, no campus universitário nas coordenadas $23^{\circ} 33^{\prime} 33.77^{\prime \prime S}$ latitude e $46^{\circ} 44^{\prime} 0.21^{\prime \prime O}$ longitude na região oeste da cidade de São Paulo (Figura 1). O local é um ponto estratégico, pois é rodeado por grandes avenidas com uma elevada densidade de frota veicular, que é uma das principais fontes de poluição em São Paulo, com picos de emissão na manhã (6-8 horas) e tarde (17-20 horas). Ao mesmo tempo, é uma das poucas áreas florestadas da cidade de São Paulo, estando a 450 metros do fragmento florestal da "Reserva florestal Armando Salles de Oliveira" e próximo de outros fragmentos vegetais. Esse local de coleta foi escolhido primeiro devido ao fácil acesso, sua localização única e também a disponibilidade de dados de outros poluentes medidos na região, como material particulado e compostos gasosos. A Companhia Ambiental do Estado de São Paulo (CETESB) tem dois locais de medição da qualidade do ar próximo ao local de coleta (Estações de Qualidade do ar Cid. Universitária (IPEN) e Pinheiros), o que irá complementar os dados desse trabalho. 


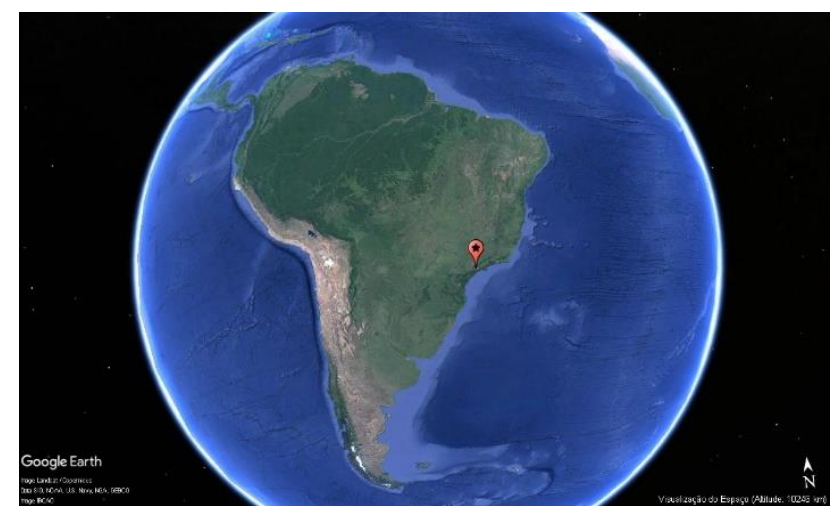

b)
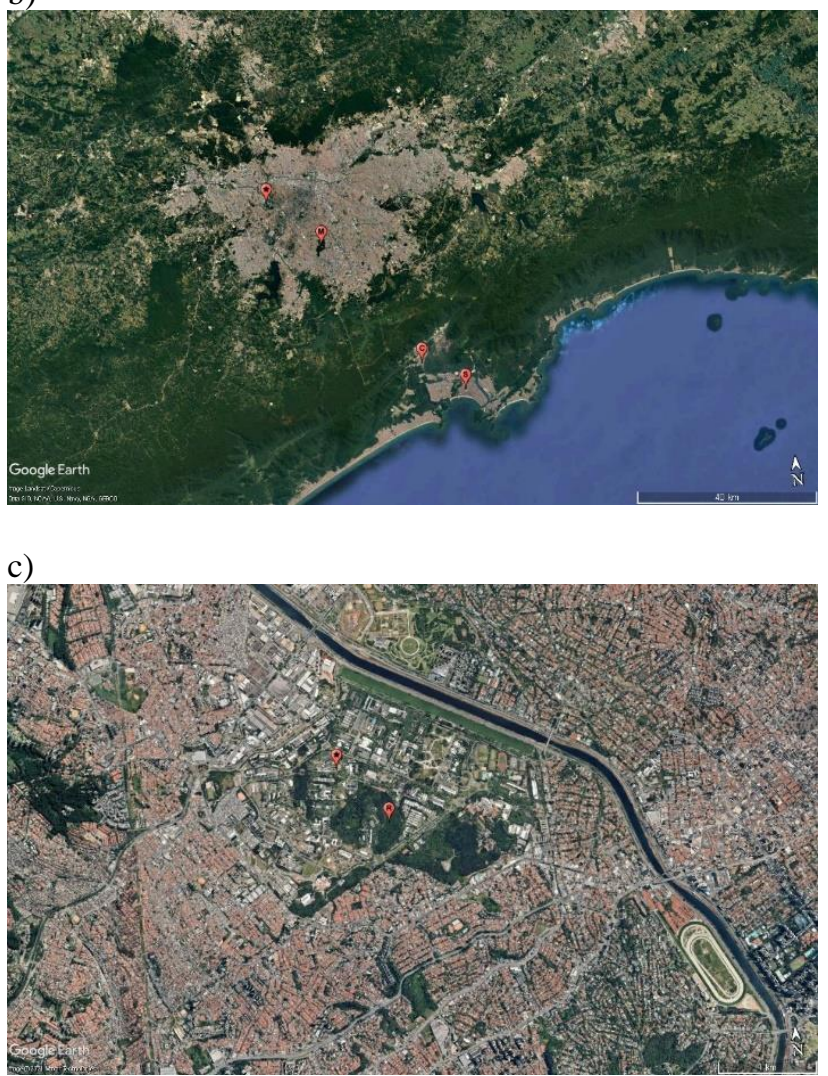

Figura 1. Mapa da a) América do sul; b) RMSP (*: Local de coleta, M: Estação meteorológica do IAG, C: Cidade de Cubatão, S: Cidade de Santos); c) Local de coleta (R: Reserva florestal "Armando Salles de Oliveira").

Fonte: A imagem foi obtida através do Google Earth.

\subsubsection{Período de amostragem}

As amostras foram coletadas em 3 períodos de campanha nos anos de 2017 e 2018 sendo (i) de 29 de maio a 14 de junho de 2017 (outono; 12 dias), (ii) de 08 de agosto a 10 de novembro de 2017 (inverno; 21 dias e primavera;18 dias) e (iii) de 13 de março a 24 de abril de 2018 (transição do verão para o outono; 14 dias). Os dias amostrados estão ilustrados na Figura 2, juntamente com as concentrações de $\mathrm{MP}_{10}$ diárias obtidas nesse trabalho. As amostras foram coletadas principalmente em dias de semana ( $90 \%$ dos dias coletados), com apenas 4 sábados e 3 domingos. 
As amostras foram amostradas durante 24 horas por dia (meio-dia ao meio-dia), totalizando 95 dias amostrados. Contudo, as análises das amostras foram feitas com apenas 69 amostras (dias). Os dias 13 a 16 de março de 2018 foram considerados na análise total, mas não a estação do ano (verão de 2018) devido ao baixo número amostral.

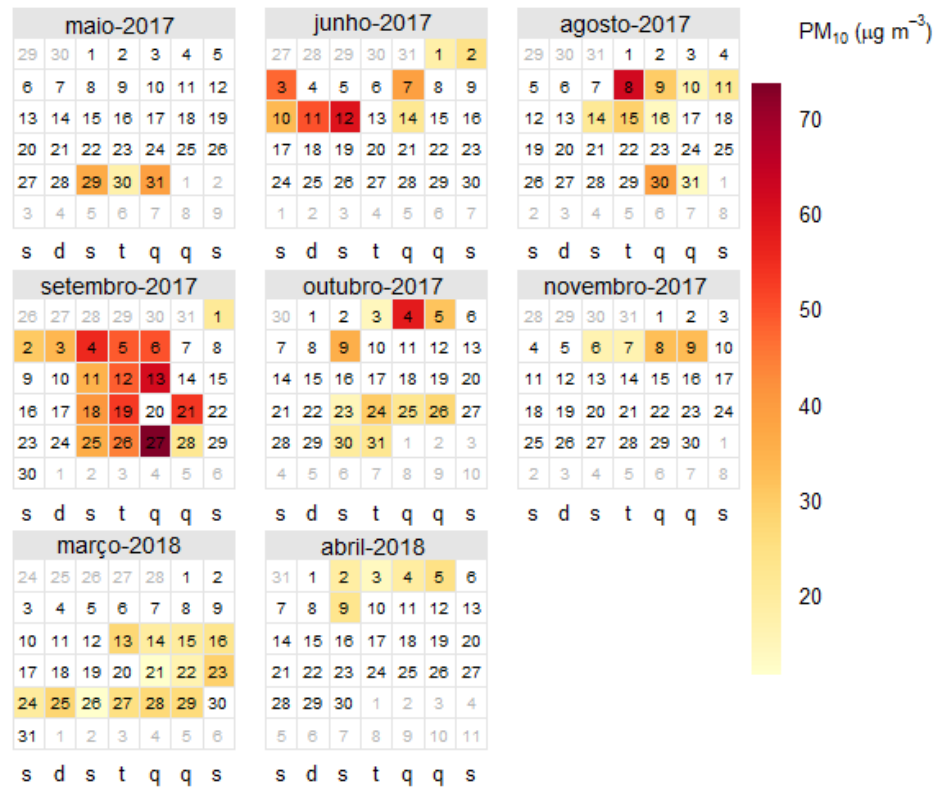

Figura 2. Calendário de 2017 e 2018 mostrando a concentração diária de $\mathrm{MP}_{10}$ nos 69 dias amostrados.

As concentrações de $\mathrm{MP}_{10}$ observadas durante o período amostrado (69 dias) não ultrapassaram os padrões de qualidade do ar nacional (Resolução No 491, de 19 de novembro de 2018) nem estadual de São Paulo (Decreto Estadual n 59113 de 23/04/2013) de 120 g/m³ para média de 24 horas. Contudo, houve 8 dias em que a concentração de $\mathrm{MP}_{10}$ ultrapassou os valores recomendados pela Organização mundial da saúde de $50 \mu \mathrm{g} / \mathrm{m}^{3}$ (média de 24 horas) (WHO, 2005).

\subsubsection{Metodologia analítica de coleta e análise}

As amostras para a análise principal foram obtidas a partir de coletas de MP com diferentes amostradores coletando ao mesmo tempo, que serão descritos em detalhes: o amostrador de alto volume (HiVol - High Volume Sampler: Energética ind. e com. LTDA., Rio de Janeiro, Brazil; $\mathrm{MP}_{10}$ inlet: Thermo Andersen, USA) com um suporte de $\mathrm{MP}_{10}$ da Thermo Andersen (EUA) utilizado com filtros de quartzo (203 x $254 \mathrm{~mm}$ ) (Chow et al., 1995), amostrador de baixo volume (MiniVol; AIRmetrics, Springfield, OR, EUA) com filtro de 47 mm de diâmetro de policarbonato (Chow et al., 1995), e um amostrador volumétrico para captura de esporos (Burkard Manufacturing Co., Ltd., Rickmansworth, Inglaterra) (Levetin, 2004). Também foi feita uma comparação entre equipamentos, filtros e suportes utilizando os 
equipamentos MiniVol, HiVol e Partisol 2025i (Thermo Fisher Scientific, Franklin, MA, EUA), sendo este último utilizando filtro de $47 \mathrm{~mm}$ de diâmetro de teflon (Chow et al., 1995), (Thermo Fisher Scientific, Franklin, MA, EUA).

O material amostrado foi submetido a várias análises para determinação dos compostos constituintes do $\mathrm{MP}_{10}$, incluindo a concentração em massa, OC (Carbono Orgânico), EC (Carbono Elementar) e TC (Carbono Total), íons, elementos, carboidratos, ácidos orgânicos e proteínas solúveis em água, tipos e concentração de esporos de fungos. Na tabela 2 é apresentado um resumo da metodologia, incluindo o equipamento utilizado para amostragem, tipo de substrato, instrumentos de análise, parâmetros medidos e laboratório onde a análise foi realizada. Para a comparação entre equipamentos, filtros e suportes o resumo da metodologia está apresentado na tabela B I.

Tabela 2. Resumo da metodologia de coleta e analítica

\begin{tabular}{|c|c|c|c|c|c|}
\hline Equipamento & Substrato & Instrumento(s) & $\begin{array}{l}\text { Parâmetro } \\
\text { medido(s) }\end{array}$ & $\begin{array}{l}\text { Local de } \\
\text { análise }\end{array}$ & $\begin{array}{c}\text { Dias } \\
\text { amostrados }\end{array}$ \\
\hline Burkard & Fita Melinex & $\begin{array}{l}\text { Microscópio } \\
\text { óptico }\end{array}$ & $\begin{array}{l}\text { Tipos fúngicos e } \\
\text { número de } \\
\text { esporos } / \mathrm{m}^{3}\end{array}$ & $\begin{array}{l}\mathrm{IAG}^{1} \\
\text { (USP) }\end{array}$ & 85 \\
\hline \multirow[t]{4}{*}{ MiniVol } & $\begin{array}{c}\text { Filtro de } \\
\text { policarbonato }\end{array}$ & $\begin{array}{c}\text { Balança } \\
\text { microanalítica }\end{array}$ & $\mathrm{MP}_{10}$ em $\mu \mathrm{g} / \mathrm{m}^{3}$ & $\mathrm{IAG}^{\mathbf{1}}$ (USP) & 95 \\
\hline & & $\begin{array}{l}\text { Espectrômetro de } \\
\text { fluorescência de } \\
\text { raios-x (Shimadzu } \\
\text { EDX-700) }\end{array}$ & $\begin{array}{l}\text { Elementos de } \\
11(\mathrm{Na}) \sim 92(\mathrm{U})\end{array}$ & $\mathrm{IAG}^{1}$ (USP) & 95 \\
\hline & & IC (Metrohm) & $\begin{array}{l}\text { Ílons (Cátions e } \\
\text { ânions) }\end{array}$ & $\mathrm{IAG}^{\mathbf{1}}$ (USP) & 72 \\
\hline & & Refletância & $\begin{array}{l}\text { Carbono negro } \\
\text { (Black carbon) }\end{array}$ & $\mathrm{IAG}^{\mathbf{1}}$ (USP) & 95 \\
\hline \multirow[t]{4}{*}{ HiVol } & Filtros de quartzo & $\begin{array}{l}\text { Cromatografia de } \\
\text { íons (IC - Dionex) }\end{array}$ & $\begin{array}{l}\text { Carboidratos, íons } \\
\text { (Cátions e ânions) } \\
\text { e ácidos orgânicos }\end{array}$ & $\mathrm{DRI}^{3}$ & 69 \\
\hline & & $\begin{array}{c}\text { Analisador de } \\
\text { carbono óptico } \\
\text { /térmico de vários } \\
\text { comprimentos de } \\
\text { onda (DRI Model } \\
\text { 2015) }\end{array}$ & OC e EC & $\mathrm{DRI}^{3}$ & 69 \\
\hline & & $\begin{array}{l}\text { Espectrômetro de } \\
\text { massa com } \\
\text { plasma } \\
\text { indutivamente } \\
\text { acoplado (ICP- } \\
\text { MS) }\end{array}$ & Elementos & $\mathrm{DRI}^{3}$ & 69 \\
\hline & & $\begin{array}{c}\text { Leitor de } \\
\text { microplaca de } \\
\text { fluorescência } \\
\left(\mathrm{FL}_{\mathrm{x}} 800-\text { Bio- }\right. \\
\text { tek) }\end{array}$ & $\begin{array}{c}\text { Proteínas solúveis } \\
\text { em água }\end{array}$ & $\begin{array}{c}\mathrm{UNLV}^{4} \\
\mathrm{DRI}^{3}\end{array}$ & 69 \\
\hline
\end{tabular}

1IAG (USP) - Instituto de Astronomia, Geofísica e Ciências Atmosférica (IAG), Universidade de São Paulo (USP). Laboratório de análises e processos atmosféricos (LAPAt), São Paulo, Brasil. 
${ }^{2} \mathrm{IQ}$ (USP) - Instituto de Química (IQ), University of São Paulo (USP), São Paulo, Brazil.

${ }^{3}$ DRI - Desert Research Institute (DRI), Reno, Nevada, USA

${ }^{4}$ UNLV - University of Nevada Las Vegas, Las Vegas, Nevada, USA

Dados meteorológicos como temperatura, umidade relativa, velocidade e direção do vento foram obtidas da estação meteorológica do IAG localizado no parque CIENTEC (Água Funda), na área sul de São Paulo ( 15,2 km do local de coleta), e da Companhia ambiental do estado de São Paulo (CETESB) na estação Pinheiros, localizada na área oeste da cidade de São Paulo ( 3,2 km do local de coleta). Esses dados foram tratados para obtenção da média ou acumulação (no caso da precipitação) para um período de 24 horas, considerando a hora de início das amostragens as 12 horas (meio-dia) do dia analisado e a hora final as 12 horas (meio dia) do dia seguinte. Isso foi feito para que os dados meteorológicos correspondessem ao mesmo período de coleta dos filtros (12h-12h). Desta forma, as médias diárias (12h-12h) foram obtidas através da média dos dados horários, enquanto para o vento foi considerada a direção predominante, isto é, a direção do vento mais frequente durante o dia.

Concentração dos poluentes gasosos como $\mathrm{O}_{3}, \mathrm{NO}_{2}, \mathrm{NO}, \mathrm{NO}_{\mathrm{x}}$ e a concentração em massa do $\mathrm{MP}_{2,5}$ foram obtidas da estação de qualidade do ar da CETESB na estação da Cidade Universitária-USP-IPEN ( 800 metros do local de coleta) e da estação Pinheiros. Outros poluentes como $\mathrm{CO}$ e MP10 também foram obtidos da estação Pinheiros da CETESB.

\subsubsection{Preparação dos filtros}

Os filtros de quartzo de $47 \mathrm{~mm}$ e os de $203 \times 254 \mathrm{~mm}$ foram colocados em um forno mufla (no Instituto de Química e no Instituto de Física da USP) a temperatura de $\sim 550^{\circ} \mathrm{C}$ por 7 horas e $\sim 500^{\circ} \mathrm{C}$ por 6 horas, respectivamente (Lee et al., 2004). Os filtros aquecidos foram empacotados em papel alumínio pré-aquecido a uma temperatura de $400^{\circ} \mathrm{C}$ por 4 horas e colocados em sacos individuais herméticos. Os filtros de quartzo foram armazenados em um refrigerador $\left(-18^{\circ} \mathrm{C}\right)$ antes e depois da amostragem (Oyama et al., 2016). Todo o manuseio do filtro foi feito com luvas e pinças. Os filtros de policarbonato foram removidos da sua embalagem original e colocados em placas de petri. Em seguida os filtros foram armazenados em uma sala no laboratório LAPAt com temperatura e umidade controlados antes e depois da amostragem para o processo de pesagem. Para considerar potenciais contaminantes ou artefatos resultantes do manuseio das amostras, filtros brancos (Field blank, FB) foram submetidos a todo o processo de amostragem, mas sem que houvesse a coleta em si (sem ligar o equipamento de coleta). Os dados resultantes foram usados para corrigir as medidas através da subtração do 
valor do filtro branco do valor amostrado. Esse procedimento é padrão em amostragem e estimativa de massa de particulado (Oyama, 2015).

Após a amostragem com o Hivol, os filtros de quartzo foram transportados (por avião) para serem analisados no laboratório (DRI - Reno e UNLV - Las Vegas, Nevada, EUA) em uma bolsa térmica com vários "gel packs" para manter a temperatura baixa. Assim que os filtros chegaram foram armazenados dentro do refrigerador $\left(\sim 4{ }^{\circ} \mathrm{C}\right)$ dentro de uma bolsa térmica. Os filtros foram então cortados em 3 círculos de aproximadamente $47 \mathrm{~mm}$ e colocados em placas de petri individuais e em sacos herméticos e então armazenados em um refrigerador $\left(\sim 4{ }^{\circ} \mathrm{C}\right)$ até a análise. No total 117 círculos foram medidos para estimar a área e uma média do resultado foi usado como área a ser analisada. Também foram medidas as áreas de 8 filtros de quartzo amostrados com o Hivol para estimar a área total de exposição do filtro (incluindo os lados e área central dos filtros) e foram considerados com valores uma média dos resultados. De acordo com a ABNT (NBR 9547/1997) a área nominal exposta do Hivol - PTS (partículas totais) é $406,5 \mathrm{~cm}^{2}$.

Os volumes amostrados pelo Hivol e Minivol foram calculados através do ajuste para as condições padrões ao nível do mar de temperatura $\left(25^{\circ} \mathrm{C}\right)$ e pressão atmosférica $(760$ $\mathrm{mmHg}$ ), como indicado no manual do Hivol. Assim, as concentrações dos compostos de ambos os equipamentos puderam ser comparadas.

\subsubsection{Instrumentos de amostragem}

\subsection{Amostrador Burkard}

O equipamento Burkard (de coleta por 7 dias) foi usado para se obter a concentração em número por metro cúbico de esporos de fungo. Esse equipamento é um impactador do tipo Hirst com um fluxo de 10 litros por minuto, que tem uma fenda estreita para a entrada de ar, onde as partículas são aspiradas e impregnadas em uma fita transparente "Melinex" (Levetin, 2004). Após sete dias de amostragem, as fitas foram divididas em períodos de $24 \mathrm{~h}$, cortadas e fixadas em uma lâmina. As lâminas foram analisadas em um microscópio ótico com uma magnitude de 1000x (100x para a objetiva e 10x para a ocular) usando a metodologia de um traço longitudinal. A amostragem das partículas, montagem das lâminas e contagem de esporos foi feita de acordo com Rogers \& Muilenberg (2001). A identificação dos esporos foi feita de acordo com Haines et al. (2000).

$\mathrm{O}$ amostrador Burkard tem um erro associado com a taxa de fluxo, que de acordo com Oteros et al. (2017) pode variar entre 5 e 72\%. Além disso, de acordo com Gottardini et al. (2009) tem um viés na contagem de partículas, incluindo diferentes concentrações de partículas 
no centro e nos cantos da lâmina, o que implica em diferentes concentrações em diferentes varreduras analisadas. Assim, há um erro na contagem de pólen que pode variar entre 7-55\% do valor médio (Gottardini et al., 2009).

\subsection{Amostrador de baixo volume (MiniVol)}

O amostrador portátil de baixo volume (MiniVol, Airmetrics) com um fluxo contínuo de 5 litros por minuto foi usado para coletar amostras de $\mathrm{MP}_{10}, \mathrm{MP}_{2,5}$ e $\mathrm{MP}_{2,5-10}$. As amostras foram coletadas com filtro de $47 \mathrm{~mm}$ de policarbonato e de quartzo. As amostras de $\mathrm{MP}_{2,5} \mathrm{e}$ $\mathrm{MP}_{2,5-10}$ e as feitas com filtro de quartzo foram usadas apenas para comparar diferentes equipamentos, suportes e filtros (Tabela B1). Além disso, filtros com $\mathrm{MP}_{10}$ foram analisados para elementos, íons, carbono negro (black carbon), e concentração em massa. Quando mais de um amostrador foi utilizado (i.e., para comparação de equipamentos) eles foram montados próximos um do outro. Os filtros foram montados no suporte em um fluxo laminar e pinças foram usadas para manipular os filtros. O horímetro, vazão e o horário foram registrados antes e após cada amostragem e quando necessário o fluxo foi ajustado. Após a amostragem os suportes com os filtros amostrados foram transportados de volta ao laboratório, os filtros foram removidos do suporte e armazenados da mesma forma que eles estavam antes da coleta. Os filtros de policarbonato foram armazenados na sala da balança com a temperatura e umidade controladas e o filtro de quartzo foi colocado no congelador $\left(\sim-18^{\circ} \mathrm{C}\right)$.

\subsection{Amostrador de alto volume (HiVol)}

O amostrador de alto volume (Hivol; Energética ind. e com. LTDA., Rio de Janeiro, Brazil; suporte $\mathrm{MP}_{10}$ : Thermo Andersen, USA) com um fluxo contínuo de $\sim 1,13 \mathrm{~m}^{3} / \mathrm{min}$ foi usado para coletar amostras de $\mathrm{MP}_{10}$. $\mathrm{O} \mathrm{MP}_{10}$ foi amostrado com filtro de quartzo (203 x 254 mm) para análise de íons, elementos, compostos orgânicos (carboidratos, ácidos orgânicos e proteínas solúveis em água), carbono orgânico (OC) e carbono elementar (EC). Algumas amostras também foram usadas para se obter a massa do $\mathrm{MP}_{10}$ para comparar com outros equipamentos e filtros. Os filtros foram transportados para o local de coleta em suas embalagens (papel alumínio), que só foram removidos para serem colocados no amostrador. Os filtros foram manipulados com luvas e pinças. O horímetro, pressão do manômetro, horário, temperatura, umidade e pressão atmosférica foram registrados antes e após cada coleta. Após a amostragem os filtros foram removidos do amostrador e embalados da mesma forma que antes da coleta (papel alumínio, previamente aquecido e saco hermético) e, então, armazenados em um refrigerador $\left(\sim-18^{\circ} \mathrm{C}\right)$. 
A verificação da calibração foi feita onze vezes durante o período de amostragem seguindo as instruções do fabricante. Os dias de calibração foram: 10-05-2017, 11-05-2017, 1605-2017, 26-05-2017, 08-08-2017, 20-09-2017, 13-03-2017, 21-03-2017, 16-04-2017 e duas vezes no dia 17-04-2017. O declive (a2), intercepto (b2), fator de correlação (r2) e taxa de fluxo de operação para cada verificação de calibração estão presentes nas informações suplementares (Tabela B II).

\subsubsection{Análise de dados}

\subsubsection{Precisão, acurácia e incerteza}

A precisão e incerteza foram obtidas através da repetição da análise feita com a primeira amostra de um grupo de dez para todas as análises feitas no DRI, e adaptando a metodologia proposta por Chow e Watson (2017) (Equação 1). Os Field blank (FB) foram usados para obter o limite quantificável inferior (LQL), calculado como 2 vezes o desvio padrão seguindo a metodologia proposta por Chow et al. (1996). A incerteza do volume medido foi considerada como 5\% do volume real. A incerteza total, que inclui a incerteza analítica e incerteza do volume foi calculada de acordo com a equação 2. Os padrões usados a cada conjunto de 10 amostras foram usados para indicar se o instrumento estava operando apropriadamente. A acurácia foi obtida comparando as concentrações padrões com aquelas obtidas na análise (da análise padrão) seguindo a metodologia proposta por Watson et al. (2001) (Equação 3).

$$
\begin{gathered}
C V=\left|\frac{c_{i}-c_{i, r}}{\left(c_{i}+c_{i, r}\right) / 2} \times 100\right| \text {, se } c_{i}>10 \times \mathrm{LQL}\left(\text { ou MDL) and } c_{i, r}>10 \times \mathrm{LQL}(\text { ou MDL })\right. \\
C V=10 \text {, se } c_{i}<10 \times L Q L(\text { ou } M D L) e c_{i, r}<10 \times \mathrm{LQL}(\text { ou } M D L) \\
\text { Incerteza analítica }=\sqrt{\left(\overline{C V} \times c_{i}\right)^{2}+\left(\frac{L Q L(o u M D L)}{3}\right)^{2}}
\end{gathered}
$$

onde $c_{i}$ é a concentração da amostra, $c_{i, r}$ é a concentração da réplica, $i$ é cada amostra para cada componente, $M D L$ é o limite detectável mínimo, $L Q L$ é o limite quantificável inferior e $C V$ é o coeficiente de variação (Chow et al., 2017).

$$
u T=\sqrt{\frac{u c^{2}}{V^{2}}+\frac{c_{i}^{2} u V^{2}}{V^{4}}}
$$

onde $u T$ é a incerteza total em $\mu \mathrm{g} / \mathrm{m}^{3}, u C$ é a incerteza analítica da amostra ( $\mu \mathrm{g} /$ filtro), $u V$ é a incerteza do volume para cada amostra (5\%), $c_{i}$ é a concentração da amostra $\left(\mu \mathrm{g} /\right.$ filtro) e $V$ é o volume $\left(\mathrm{m}^{3}\right)$.

$$
\text { Acurácia }=\sum_{\mathrm{i}=1}^{\mathrm{N}} \frac{c_{i}-c_{f}}{c_{f}} / \mathrm{N}
$$

onde $c_{i}$ é a concentração da espécie i obtida com o padrão (Material de referência padrão), $c_{f}$ é a concentração real da espécie no padrão e $N$ é o número de repetições feitas para cada espécie.

Todas as concentrações iguais ou menores do que zero foram substituídas pelo LQL dividido por 2 e quando não foi possível pelo MDL dividido por 2 (as exceções foram apontadas nos tópicos específicos para cada composto).

\subsubsection{Determinação da concentração em massa do $M P_{10}$}


A massa do $\mathrm{MP}_{10}$ foi obtida através da gravimetria do filtro de policarbonato, usando uma balança microanalítica com uma precisão nominal de $1 \mu \mathrm{g}$ (Mettler-Toledo, modelo MX5) localizada no LAPAt - IAG/USP (Laboratório dos Processos Atmosféricos do Instituto de Astronomia, Geofísica e Ciências Atmosféricas da Universidade de São Paulo).

Os filtros foram condicionados por pelo menos 24 horas na sala da balança com umidade e temperatura controladas antes da pesagem dos filtros (brancos e amostrados). Antes de colocar o filtro na balança, o filtro passou por um eletrodo ionizador em forma de U (Mettler Toledo, Kit Antiestático), usado para eliminar carga estática. O filtro foi pesado duas vezes antes e após a amostragem. A diferença da massa entre as duas pesagens foi menor do que $10 \mu \mathrm{g}$ para todas as amostras. Após a pesagem, os filtros foram armazenados em um local com temperatura e umidade controladas até as análises posteriores.

A incerteza analítica para a massa do $\mathrm{MP}_{10}$ foi calculada de acordo com a equação indicada no "Fundamentos e guia do usuário do PMF 5.0", com o MDL sendo $1 \mu \mathrm{g}$ e a incerteza relativa considerada como $10 \%$ da concentração de $\mathrm{MP}_{10}$ e a incerteza total foi calculada de acordo com a equação 2 .

\subsubsection{Determinação da composição elementar do MP10}

3.1.4.3.1. Análise elementar por espectrometria de fluorescência de raio $\mathrm{X}$ por energia dispersiva

O filtro de policarbonato coletado com o MiniVol foi submetido à análise de concentração elementar com o equipamento Shimadzu EDX-700 (Espectrômetro de fluorescência de raio X por energia dispersiva (EDX) localizado no "Laboratório de Análise dos Processos Atmosférico" (LAPAt - IAG - USP), usando um detector semicondutor de Si (Li) para medir os elementos em uma faixa de 11(Na) a 92(U). Mais informações sobre calibração podem ser obtidas em Veríssimo (2016). O EDX permite a identificação e determinação dos elementos encontrados na amostra. O sistema consiste em um tubo que emite raios $\mathrm{X}$ que excita os elementos de uma amostra, induzindo um salto quântico que resulta em uma perda de energia emitida como fóton de raio X. A liberação de energia irá formar linhas espectrais conhecidas que são diferentes para cada elemento, permitindo a sua identificação (Veríssimo, 2016). A intensidade da energia (número de raios x detectado por unidade de tempo) é relacionada com a concentração do elemento na amostra (Nascimento Filho e Simabuco, 1996).

A análise pelo EDX leva aproximadamente 16 minutes por filtro. O EDX gera um espectro que para o propósito da análise foi dividido em dois, um com elementos de alta energia ( $Z$ de 21 a 82) e outro para elementos de baixa energia ( $Z$ de 11 a 20). O espectro foi então 
ajustado utilizando o WinQxas (Quantitative X-Ray Analysis System for Windows) patrocinado pela Agência Internacional de Energia Atômica (Capote et al., 2000).

A incerteza analítica para os elementos do EDX não foi calculada da mesma forma que para as outras análises, uma vez que não havia repetições da análise no mesmo filtro. Assim, no lugar da incerteza analítica foi utilizado o erro fornecido pelo modelo do EDX, que foi obtido com uma propagação de erro da incerteza no fator de resposta, incerteza na massa e a incerteza da calibração por mínimos quadrados matricial (Veríssimo, 2016). A incerteza total foi calculada da mesma forma que descrito na equação 2 , considerando o erro como incerteza analítica. Os dados faltantes da concentração e erro foram substituídos pelo LQL/2. O valor médio do erro, incerteza total, LQL (para o erro e para a concentração) estão apresentados na tabela 3 .

Tabela 3. Média do erro, incerteza total, LQL (para o erro e para a concentração) para os elementos obtidos com o EDX.

\begin{tabular}{|c|c|c|c|c|}
\hline Nomes & $\begin{array}{l}\text { Erro } \\
\mu \mathrm{g} / \mathrm{m}^{3} \\
\end{array}$ & $\begin{array}{l}\text { Incerteza } \\
\text { total } \\
\mu \mathrm{g} / \mathrm{m}^{3}\end{array}$ & $\begin{array}{l}\text { LQLE }^{1} \\
\mu \mathrm{g} / \text { filtro }\end{array}$ & $\begin{array}{l}\text { LQLC }^{2} \\
\mu \mathrm{g} / \text { filtro }\end{array}$ \\
\hline $\mathrm{Na}$ & 0,045 & 0,059 & 0,148 & 3,325 \\
\hline $\mathrm{Mg}$ & 0,029 & 0,030 & 0,014 & 0,459 \\
\hline $\mathrm{Al}$ & 0,055 & 0,060 & 0,011 & 0,393 \\
\hline $\mathrm{Si}$ & 0,070 & 0,090 & 0,006 & 0,383 \\
\hline $\mathrm{P}$ & 0,023 & 0,024 & 0,004 & 0,102 \\
\hline S & 0,210 & 0,255 & 0,011 & 0,215 \\
\hline $\mathrm{Cl}$ & 0,088 & 0,091 & 0,004 & 0,147 \\
\hline $\mathrm{K}$ & 0,048 & 0,056 & 0,001 & 0,059 \\
\hline $\mathrm{Ca}$ & 0,061 & 0,067 & 0,005 & 0,294 \\
\hline $\mathrm{Ti}$ & 0,038 & 0,038 & 0,008 & 0,500 \\
\hline $\mathrm{V}$ & 0,002 & 0,002 & 0,001 & 0,011 \\
\hline $\mathrm{Cr}$ & 0,008 & 0,009 & 0,006 & 0,504 \\
\hline $\mathrm{Mn}$ & 0,004 & 0,004 & 0,001 & 0,026 \\
\hline $\mathrm{Fe}$ & 0,138 & 0,146 & 0,021 & 1,346 \\
\hline $\mathrm{Ni}$ & 0,002 & 0,002 & 0,002 & 0,032 \\
\hline $\mathrm{Cu}$ & 0,012 & 0,012 & 0,004 & 0,131 \\
\hline $\mathrm{Zn}$ & 0,008 & 0,010 & 0,003 & 0,022 \\
\hline $\mathrm{Se}$ & 0,004 & 0,004 & 0,003 & 0,018 \\
\hline $\mathrm{Br}$ & 0,006 & 0,006 & 0,003 & 0,029 \\
\hline $\mathrm{Pb}$ & 0,008 & 0,008 & 0,004 & 0,037 \\
\hline
\end{tabular}

\subsection{Análise elementar por espectrometria de massa com plasma indutivamente acoplado}

A composição elementar do MP 10 amostrada no filtro de quartzo foi determinada com um Espectrômetro de massa com plasma indutivamente acoplado (Perkin-Elmer NexIon 300D 
ICP-MS) e as espécies obtidas foram Li, Be, Na, Mg, Al, Si-DRC, P-KED, K, Ca-44drc, Ti, V, Cr, Mn, Fe-57, Co, Ni, Cu, Zn, As-75, Se, Rb, Sr, Nb, Mo, Pd, Ag, Cd, Sn, Sb, Cs, Ba, La, Ce, Pr, Nd, Sm, Ta, W, Pt , Tl , Pb, Bi, Th e U. Observe que KED significa discriminação de energia cinética e DRC significa célula de reação dinâmica como explicado abaixo.

O ICP-MS é uma técnica usada para determinar os elementos químicos presentes na amostra, sendo que este método consegue detectar e quantificar baixas concentrações (ppb). Resumidamente o equipamento funciona com a introdução de uma amostra líquida no sistema. A amostra passa através de um nebulizador que transforma a amostra líquida em um pequeno aerossol. O aerossol é então separado em diferentes tamanhos na câmara do nebulizador. Em seguida, o aerossol é transportado pelo gás argônio e submetida a uma tocha de plasma, onde é vaporizada (gás), atomizada (átomo) e ionizada (íons) (Thomas, 2004).

Os átomos e íons resultantes são transferidos para o MS (quadruplo duplo) onde são separados de acordo com a sua relação massa-carga $(\mathrm{m} / \mathrm{z})$ e depois detectados por um detector dinodo (fotomultiplicador de elétrons) (Aguiar, 2017). O resultado é um espectro de massa com duas dimensões, um sinal de intensidade (abundância das espécies iônicas) e uma razão m/z.

Além do módulo padrão do ICP que usa o gás argônio, também foi usado o módulo de célula de colisão (KED) e o módulo de célula de reação (DRC) para reduzir a interferência que pode ocorrer na análise de ICP-MS. Além disso, várias correções foram aplicadas para ajustar a concentração de alguns elementos que tem peso semelhante e poderiam ser identificados erroneamente. No KED, o gás He é usado para fazer o ArAr+e as interferências poliatômicas perderem energia cinética e não serem capaz de entrarem no analisador quadrupolo (Nelms, 2016). Em resumo, o gás He é inserido na célula de colisão e também o analito e as interferências poliatômicas. Quando o íon poliatômico corre na célula de colisão eles colidem com o gás He mais frequentemente do que os íons monatômicos, já que tem uma maior área de seção transversal de colisão. Isso faz os íons poliatômicos terem uma energia cinética menor. Usando um filtro como uma barreira de tensão, é possível separar os íons poliatômicos dos íons monoatômicos de mesma massa e com isso impedir que os íons poliatômicos entrem no analisador quadruplo.

Essa técnica melhora a acurácia dos resultados, já que os íons poliatômicos que têm a mesma massa dos íons monoatômicos não irão interferir na análise final. Mais informações sobre esse modulo podem ser encontradas em Nelms (2016) (http://analyteguru.com/crashbang-wallop-how-does-an-icp-ms-collision-cell-work-part-1/). No DRC, a amônia é usada para reagir com algumas interferências e da mesma forma que o KED, reduzir a interferência de íons com a mesma massa dos íons de interesse. 
Os filtros de quartzo coletados com o HiVol foram cortados em uma área circular com diâmetro de aproximadamente $47 \mathrm{~mm}$. Um pedaço de cada filtro foi usado para fazer a análise no ICP. Para isso, cada pedaço foi dobrado duas vezes e colocados no fundo de um tubo digestivo. Uma solução de 3,2 $\mathrm{ml} \mathrm{H}_{2} \mathrm{O}_{2}, 1,6 \mathrm{ml} \mathrm{HNO}_{3}$ e $0,5 \mathrm{ml} \mathrm{HCl}$ foram adicionados em cada tubo para digerir o filtro e liberar os elementos aderidos no filtro. $\mathrm{O}$ filtro foi então colocado em um bloco quente (hotblock) em uma temperatura de aproximadamente $105^{\circ} \mathrm{C}$ por duas horas. Na sequência, os filtros foram deixados por 60 minutos para esfriar e então água destilada e deionizada foi adicionada até atingir o volume final de $40 \mathrm{ml}$. Os filtros foram analisados de 4 a 6 dias após a digestão. Antes de começar a rodar as amostras, a tocha do ICP foi deixada aquecendo por aproximadamente 50 minutos e a solução padrão do instrumento foi adicionada para verificar as condições do instrumento. Os padrões de calibração usados para a curva de calibração foram adicionados em diferentes concentrações 0,1 ppb, 1 ppb, 10 ppb, 50 ppb, 100 ppb, 250 ppb, 1000 ppb. Também foi utilizada uma solução matriz $\left(2 \% \mathrm{HNO}_{3}, 8 \% \mathrm{H}_{2} \mathrm{O}_{2}-\right.$ branco da Matriz) para verificar a performance do instrumento durante a corrida da amostra e cinco brancos do método, que passaram pelos mesmos procedimentos que as amostras (menos o filtro), para representar o branco do reagente. Um padrão externo também foi usado para verificar a concentração e para comparar os padrões de marcas diferentes.

A configuração do software para a injeção das amostras no ICP foi configurada para: curva dos padrões de calibração (0,1 ppb, 1 ppb, 10 ppb, 50 ppb, 100 ppb, 250 ppb, 1000 ppb), solução matriz, um padrão (Padrão de verificação - dois frascos), dez amostras, repetição da primeira amostra do ciclo, uma solução matriz, um padrão de verificação da calibração (dois frascos), dez amostras, repetição da primeira amostra do ciclo, uma solução matriz e um padrão (dois frascos) e o ciclo continua até todas as amostras terem sido analisadas. Já que o ICP só pode rodar um número limitado de filtros por vez, foi necessário correr o ICP três vezes para analisar todas as amostras. O elemento que rodou com o KED foi o fósforo (P) para algumas amostras, enquanto para o DRC os elementos foram sílicio $(\mathrm{S})$, cálcio $(\mathrm{Ca})$ e ferro $(\mathrm{Fe})$ para todas as amostras e Alumínio ( $\mathrm{Al})$ para algumas amostras.

A média da precisão, acurácia, LQL e MDL para cada elemento é apresentada na tabela 4. A acurácia foi obtida através da média dos padrões que foram injetados na primeira corrida (0,1 ppb, 1 ppb, 10 ppb, 50 ppb, 100 ppb, 250 ppb e 1000 ppb). O MDL fornecido pelo DRI foi calculado para o filtro de teflon; como o filtro usado na amostragem foi de quartzo, o valor do MDL em ng/filtro foi dividido pela área de depósito do filtro de teflon para se obter o MDL in $\mathrm{ng} / \mathrm{cm}^{2}$. 
Tabela 4. Média da precisão, MDL e LQL para cada elemento.

\begin{tabular}{llll}
\hline $\mathrm{Elemento}$ & $\begin{array}{l}\text { Precisão } \\
(\%)\end{array}$ & $\begin{array}{l}\mathrm{MDL} \\
\left(\mathrm{ng} / \mathrm{cm}^{2}\right)\end{array}$ & $\begin{array}{l}\mathrm{LQL} \\
(\mathrm{ng} / \mathrm{ml})\end{array}$ \\
\hline $\mathrm{Ag}$ & 7,587 & 0,00001 & 0,006 \\
$\mathrm{Al}$ & 5,808 & 0,00570 & 21,278 \\
$\mathrm{As}$ & 10,000 & 0,00001 & 0,307 \\
$\mathrm{Ba}$ & 8,069 & 0,00011 & 16,302 \\
$\mathrm{Be}$ & 10,000 & 0,00003 & 0,008 \\
$\mathrm{Bi}$ & 9,502 & 0,00001 & 0,019 \\
$\mathrm{Ca}$ & 10,000 & 0,02657 & 398,061 \\
$\mathrm{Cd}$ & 10,000 & 0,00002 & 0,448 \\
$\mathrm{Ce}$ & 1,421 & 0,00003 & 0,009 \\
$\mathrm{Co}$ & 9,439 & 0,00001 & 0,032 \\
$\mathrm{Cr}$ & 8,795 & 0,00009 & 1,522 \\
$\mathrm{Cs}$ & 6,673 & 0,00001 & 0,004 \\
$\mathrm{Cu}$ & 3,097 & 0,00006 & 3,677 \\
$\mathrm{Fe}$ & 6,307 & 0,00323 & 11,910 \\
$\mathrm{~K}$ & 3,769 & 0,00082 & 8,741 \\
$\mathrm{La}$ & 2,155 & 0,00001 & 0,008 \\
$\mathrm{Li}$ & 10,726 & 0,00003 & 0,064 \\
$\mathrm{Mg}$ & 2,436 & 0,00057 & 2,429 \\
$\mathrm{Mn}$ & 2,053 & 0,00006 & 0,390 \\
$\mathrm{Mo}$ & 10,000 & 0,00005 & 768,126 \\
$\mathrm{Na}$ & 5,738 & 0,00158 & 46,783 \\
$\mathrm{Nb}$ & 5,137 & 0,00001 & 0,008 \\
$\mathrm{Nd}$ & 5,986 & 0,00001 & 0,005 \\
$\mathrm{Ni}$ & 10,000 & 0,00003 & 16,067 \\
$\mathrm{P}$ & 10,000 & 0,00709 & 7,442 \\
$\mathrm{~Pb}$ & 5,015 & 0,00004 & 0,152 \\
$\mathrm{Pd}$ & 10,000 & 0,00010 & 0,083 \\
$\mathrm{Pr}$ & 4,617 & 0,00000 & 0,002 \\
$\mathrm{Pt}$ & 10,000 & 0,00001 & 0,179 \\
$\mathrm{Rb}$ & 1,516 & 0,00001 & 0,010 \\
$\mathrm{Sb}$ & 2,762 & 0,00003 & 0,036 \\
$\mathrm{Se}$ & 9,315 & 0,00027 & 0,268 \\
$\mathrm{Si}$ & 10,000 & 0,02078 & 1141,278 \\
$\mathrm{Sm}$ & 6,727 & 0,00001 & 0,007 \\
$\mathrm{Sn}$ & 4,741 & 0,00002 & 0,095 \\
$\mathrm{Sr}$ & 2,660 & 0,00003 & 0,080 \\
$\mathrm{Ta}$ & 10,000 & 0,00001 & 0,016 \\
$\mathrm{Th}$ & 14,083 & 0,00000 & 0,018 \\
$\mathrm{Ti}$ & 2,164 & 0,00006 & 0,216 \\
$\mathrm{Tl}$ & 14,795 & 0,00001 & 0,002 \\
$\mathrm{U}$ & 18,766 & 0,00001 & 0,001 \\
$\mathrm{~V}$ & 12,258 & 0,00004 & 0,849 \\
$\mathrm{H}$ & & 0,00001 & 0,015 \\
& 0,00030 & 5,530 \\
\hline
\end{tabular}

\subsubsection{Determinação da concentração do carbono negro}

Para estimar a concentração de carbono negro (BC, do inglês black carbon), os filtros de policarbonato foram submetidos a um reflectómetro "Diffusion Sistem Ltda" modelo “Smoke Stain Reflectometer - Modelo 43". O filtro de policarbonato amostrado foi exposto a uma lâmpada de tungstênio e a luz refletida foi detectada por um fotossensor. Para converter a 
luz refletida para a concentração de carbono negro (partículas que absorvem luz) a seguinte equação de calibração foi usada (Loreiro et al., 1994 apud Hetem, 2014):

$\left.\left.B C=82,794-(73,206 \times \log (R))+\left(15,901 \times\left(\log (R)^{2}\right)\right)\right) \times(13,2)\right) /(V)$

Onde BC é o carbono negro, $\mathrm{R}$ é a refletância em \% e V é o volume amostrado em m³.

Inicialmente, a lâmpada de tungstênio foi submetida a um filtro branco (field blank) para representar um filtro sem absorbância (100\% reflectância) e calibrar o sensor. Com essa calibração, a chance do filtro de policarbonato em si, sem nenhuma partícula, interferir na reflectância detectada pelo fotossensor é menor. A cada cinco filtros analisados, um filtro branco (Field blank) foi exposto à lâmpada de tungstênio para zerar a calibração e garantir que o sensor estava sempre calibrado.

\subsubsection{Determinação dos íons, carboidratos e ácidos orgânicos}

A cromatografia de íons (IC) consiste na separação do analito (íons) da mistura, que pode ser realizada através de uma resina de troca iônica, que depende do tamanho e carga do íon. Os diferentes tempos de retenção como resultado da separação permite a identificação dos íons. O detector de condutividade cria uma corrente elétrica no eluente que resulta em um pico de condutividade permitindo a detecção do íon. A área do pico indica a quantidade de íons quando comparado com uma solução padrão que tem uma concentração conhecida (Chow e Watson, 2017).

Para verificar a consistência dos dados obtidos com a cromatografia de íons e verificar as formas presentes na atmosfera, um balanço entre as concentrações de $\mathrm{NH}_{4}{ }^{+}, \mathrm{SO}_{4}{ }^{2-} \mathrm{e} \mathrm{NO}_{3}{ }^{-}$foi elaborado considerando a equação 5. Em seguida, os dados foram plotados contra o valor de $\mathrm{NH}_{4}{ }^{+}$. Um balanço entre cátions e ânions também foi elaborado considerando a equação 6.

$$
\begin{aligned}
& \text { a) } \mathrm{NH}_{4} \mathrm{HSO}_{4}=\left(0,29 \times \mathrm{NO}_{3}^{-}\right)+\left(0,19 \times \mathrm{SO}_{4}^{-2}\right) \\
& \text { b) }\left(\mathrm{NH}_{4}\right)_{2} \mathrm{SO}_{4}=\left(0,29 \times \mathrm{NO}_{3}^{-}\right)+\left(0,38 \times \mathrm{SO}_{4}^{-2}\right)
\end{aligned}
$$

Onde o $\mathrm{NH}_{4} \mathrm{HSO}_{4}$ é o bissulfato de amônio, $\left(\mathrm{NH}_{4}\right)_{2} \mathrm{SO}_{4}$ é o sulfato de amônio.

$$
\begin{gathered}
\text { Cátions }=\frac{\mathrm{NH}_{4}^{+}}{18}+\frac{\mathrm{Na}^{+}}{23}+\frac{\mathrm{K}^{+}}{39}+\frac{\mathrm{Ca}^{+2}}{20}+\frac{\mathrm{Mg}^{+2}}{12} \\
\text { Ânions }=\frac{\mathrm{Cl}^{-}}{35,45}+\frac{\mathrm{NO}_{3}^{-}}{62}+\frac{S O_{4}^{-2}}{48}+\frac{\mathrm{Br}^{-}}{80}+\frac{\mathrm{NO}_{2}^{-}}{46}
\end{gathered}
$$

\subsection{Análise de íons com o cromatógrafo de íons (Metrohm)}

A análise de íons realizada com os filtros de policarbonato coletados com o Minivol foi realizada com o cromatógrafo de íons Metrohm no LAPAT. 
Os filtros de policarbonato foram diluídos em água para remover as espécies solúveis, sendo então colocados em tubos e $10 \mathrm{ml}$ de água ultrapura foi adicionada. Os tubos foram agitados por uma hora e meia para otimizar a extração dos íons do filtro. Em seguida a solução foi filtrada com uma seringa e um filtro Millex (Milipore) de 0,22 $\mu \mathrm{m}$, que havia sido previamente condicionado. A solução foi então adicionada no cromatógrafo de íons. Para os cátions a corrida dura aproximadamente 20 minutos por amostra, enquanto para os ânions a corrida dura 27 minutos por amostra.

O cromatógrafo de íons (Metrohm) utiliza um detector de condutividade e as espécies obtidas foram: $\mathrm{Na}^{+}, \mathrm{NH}_{4}{ }^{+}, \mathrm{K}^{+}, \mathrm{Ca}^{+}, \mathrm{Mg}^{2+}$ (cátions) e $\mathrm{Cl}^{-}, \mathrm{NO}_{3}{ }^{-}, \mathrm{SO}_{4}{ }^{2-}$ (ânions). Os cátions foram separados em uma coluna analítica Metrosep C 4 (150,0 mm X 4,0 mm), uma solução eluente de ácido oxálico (27 mmol/L) e uma taxa de fluxo de $0,9 \mathrm{ml} / \mathrm{min}$. Os ânions foram separados em uma coluna analítica Metrosep A Supp 5 (250 mm X 4,0 mm), uma solução eluente de $\mathrm{Na}_{2} \mathrm{CO}_{3}(4 \mathrm{mmol} / \mathrm{L})$ e $\mathrm{NaHCO}_{3}(1 \mathrm{mmol} / \mathrm{L})$ e uma taxa de fluxo de $0,7 \mathrm{ml} / \mathrm{min}$.

Para essa análise, não foram feitas repetições, e assim a precisão e incerteza não foram calculadas. Contudo, o balanço de íons e o balanço de $\mathrm{NH}_{4}{ }^{+}, \mathrm{SO}_{4}{ }^{2-}$ e $\mathrm{NO}_{3}{ }^{-}$foi realizado, considerando as equações 4 e 5 . A média do LQL está apresentada na tabela 5.

Tabela 5. Média do LDL e LQL para cada íon.

\begin{tabular}{ll}
\hline Nomes & $\begin{array}{l}\mathrm{LQL} \\
\mu \mathrm{mol} / \mathrm{L}\end{array}$ \\
\hline $\mathrm{Na}^{+}$ & 2,253 \\
$\mathrm{NH}_{4}{ }^{+}$ & 0,870 \\
$\mathrm{~K}^{+}$ & 1,801 \\
$\mathrm{Mg}^{+2}$ & 2,162 \\
$\mathrm{Ca}^{+}$ & 5,257 \\
$\mathrm{Cl}^{-}$ & 0,668 \\
$\mathrm{NO}_{3}{ }^{-}$ & 1,975 \\
$\mathrm{SO}_{4}{ }^{-2}$ & 1,976 \\
$\mathrm{C}_{2} \mathrm{O}_{4}{ }^{-2}$ & 0,502 \\
\hline
\end{tabular}

3.1.4.5.2. Análises de íons, carboidratos e ácidos orgânicos com o cromatógrafo de íons (Dionex)

As análises de íons, carboidratos e ácidos orgânicos, realizadas com os filtros de quartzo coletados com o Hivol foi feita com o cromatógrafo de íons Dionex no DRI, Reno, Nevada, EUA. Os dados foram processados no software "Chromeleon".

A extração do filtro seguiu a metodologia descrita em Chow e Watson (2017).

Os filtros foram colocados em tubos com $15 \mathrm{ml}$ de água destilada deionizada (DDW). A solução foi então colocada em um banho ultrassónico (sonicador) por 60 minutos em uma temperatura abaixo de $20^{\circ} \mathrm{C}$ para evitar perdas evaporativas (Chow e Watson, 2017). As amostras foram então agitadas por 120 minutos em uma frequência de 60 ciclos por minuto. A 
solução foi armazenada em uma temperatura abaixo de $4^{\circ} \mathrm{C}$ durante a noite ( 12 horas) para a completa dissolução dos componentes e para que o material sólido se depositasse no fundo do frasco (Stevens et al., 1978 apud Chow e Watson, 2017). O branco do reagente (Brancos do método) foram preparados e foram submetidos a todo o procedimento amostral.

Após a preparação da amostra, $1 \mathrm{ml}$ dela foi adicionada em tubos para análise em diferentes cromatógrafos para a determinação de íons e carboidratos. Para os íons, a maioria das amostras foram diluídas, já que a concentração foi muito alta (mais alta do que o padrão mais elevado) e não se encaixaria na curva de calibração.

A fim de se verificar se a linha de base e a área padrão estão estáveis, a análise de água destilada deionizada (DDW) foi realizada, seguida por algumas corridas do padrão com maior concentração (3ppm).

O software para a injeção da amostra em ambos os cromatógrafos (íons e carboidratos) foi configurado para correr na seguinte sequência: duas águas (DDW), padrões $(0,02$ ppm, 0,05 ppm, 0,1 ppm, 0,2 ppm, 0,5 ppm, 1 ppm, 2 ppm e $3 \mathrm{ppm}$ ) para a curva de calibração, dois padrões (padrão Dionex e padrão de checagem), dois brancos do método, dez amostras, repetição da primeira amostra do ciclo, uma DDW, um padrão, dez amostras, repetição da primeira amostra do ciclo, uma DDW e um padrão e assim por diante até todas as amostras terem sido analisadas. A quantidade de cada espécime foi obtida usando a área do pico, que garante uma melhor acurácia e precisão comparados com a altura de pico (Chow e Watson, 2017).

Os ácidos orgânicos foram analisados no DRI pelos funcionários do instituto utilizando a mesma solução extraída do filtro que foi utilizada para as análises de íons e de carboidratos.

As espécies aniônicas foram analisadas em um cromatógrafo de íons (IC- Dionex ICS$5000+$ ) e as espécies obtidas foram $\mathrm{NH}_{4}{ }^{+}, \mathrm{Ca}^{+}, \mathrm{Mg}^{2+}, \mathrm{K}^{+}, \mathrm{Na}^{+}$(cátions) e $\mathrm{Cl}^{-}, \mathrm{Br}^{-}, \mathrm{NO}_{3}{ }^{-}, \mathrm{NO}_{2}^{-}$, $\mathrm{PO}_{4}{ }^{3-}, \mathrm{SO}_{4}{ }^{2-}$ (ânions). Os cátions foram separados em uma coluna analítica Ion Pac CS16 (5x250 mm), uma coluna guarda Ion Pac CG16 (5x50 mm), uma solução eluente de Ácido metanossulfônico (MSA) resultante de um gerador de eluente em uma taxa de fluxo de 1 ml/min. Os ânions foram separados em uma coluna analítica Ion Pac AS20 (4x250 mm), uma coluna guarda Ion Pac AG20 (4×50 mm), uma solução eluente de hidróxido de potássio $(\mathrm{KOH})$ resultante de um gerador de eluente em uma taxa de fluxo de $1 \mathrm{ml} / \mathrm{min}$. A bomba usada é uma “ICS-5000 dual pump" (DP).

Os carboidratos e ácidos orgânicos foram analisados com um cromatógrafo Thermo Scientific /Dionex ICS 5000-PAD, que é baseado no mecanismo de troca iônica com detecção por pulso amperométrico. Esse detector combina uma troca iônica com uma detecção 
eletroquímica (Chow and Watson, 2017). Os carboidratos obtidos foram: Arabinose, Arabitol, Frutose, Galactose/Maltitol, Glicose/Xilose, Galactosan, Levoglucosano, Manitol e Manosano. Os carboidratos foram separados em uma coluna analítica CarboPac MA1 (4x250 mm), uma coluna guarda CarboPac MA1 (4x50 mm), uma solução eluente de hidróxido de sódio $(\mathrm{NaOH})$ em um fluxo de 0,4 ml/min. Os ácidos orgânicos obtidos foram: Acetato, Succinato, Maleato, Formiato, Metanosulfonato e Oxalato.

Os limites de detecção mínimos (MDL) para os íons, carboidratos e ácidos orgânicos foram fornecidos pelo laboratório do DRI. O MDL dos íons foi obtido através de várias análises de filtros brancos (Lab blanks, LB) no instrumento, enquanto para os carboidratos o MDL foi obtido através de sete réplicas de análises do padrão de 0,05-0,2 $\mu \mathrm{g} / \mathrm{ml}$ e para os ácidos orgânicos o MDL foi obtido através de nove análises réplicas do padrão de $0,05 \mu \mathrm{g} / \mathrm{ml}$. A média da precisão, acurácia, e LQL para cada íon é apresentada na tabela 6, enquanto a precisão, MDL e acurácia para cada carboidrato é apresentada na tabela 7 e o MDL e LQL para o ácido graxo é apresentada na tabela 8. A acurácia foi obtida através da média de cada padrão, 0,2 ppm, 0,5 ppm, 1 ppm, 2 ppm e 3 ppm para os íons (com exceção do $\mathrm{NH}_{4}{ }^{+}, \mathrm{SO}_{4}{ }^{2-}$ e $\mathrm{NO}_{3}{ }^{-}$que não foi considerado o 0,2 ppm), enquanto para os carboidratos foram usados 0,05 ppm, 0,1 ppm, 0,2 ppm, 0,5 ppm, 1 ppm, 2 ppm, 5 ppm e 10 ppm. Para os carboidratos, os FB tiveram uma concentração igual a zero, o que significa que a quantidade presente nos FB é menor do que o limite de detecção da metodologia. Considerando isso, o LQL é igual a zero.

Tabela 6. Média da precisão, acurácia, LQL e MDL para cada íon.

\begin{tabular}{lllll}
\hline & Precisão $(\%)$ & $\begin{array}{l}\text { LQL } \\
(\mu \mathrm{g} / \text { filtro })\end{array}$ & $\begin{array}{l}\text { MDL } \\
(\mathrm{ppm})\end{array}$ & $\begin{array}{l}\text { Acurácia } \\
(\%)\end{array}$ \\
\hline $\mathrm{Na}^{+}$ & 1,085 & 0,474 & 0,065 & $7,875( \pm 7,24)$ \\
$\mathrm{NH}_{4}{ }^{+}$ & 1,469 & 0,005 & 0,002 & $\begin{array}{l}4,167 \\
( \pm 3,545)\end{array}$ \\
& & & & $\begin{array}{l}5,375 \\
\mathrm{~K}^{+}\end{array}$ \\
& 1,681 & 0,038 & 0,011 & $( \pm 6,255)$ \\
$\mathrm{Cl}^{-}$ & 2,85 & 0,045 & 0,024 & $4,75( \pm 2,659)$ \\
$\mathrm{NO}_{3}{ }^{-}$ & 2,744 & 0,171 & 0,005 & $6,333( \pm 2,16)$ \\
$\mathrm{SO}_{4}{ }^{2-}$ & 2,202 & 1,417 & 0,008 & 4,833 \\
& & & & $( \pm 2,787)$ \\
$\mathrm{Ca}^{+}$ & 5,289 & 1,997 & 0,006 & 3,875 \\
& & & & $( \pm 3,271)$ \\
$\mathrm{Mg}^{2+}$ & 3,356 & 0,029 & 0,002 & $5,5( \pm 3,964)$ \\
$\mathrm{Br}^{-}$ & 10 & 0,336 & 0,004 & 4,125 \\
& & & & $( \pm 1,553)$ \\
\hline
\end{tabular}

Tabela 7. Média da precisão, MDL (sete análises réplicas dos padrões 0,05-0,2 $\mu \mathrm{g} / \mathrm{ml}$ ) e acurácia para cada carboidrato.

\begin{tabular}{llll}
\hline & Precisão $(\%)$ & MDL $(\mathrm{ppm})$ & Acurácia $(\%)$ \\
\hline Arabinose & 10 & 0,058 & $9,086( \pm 2,606)$ \\
Arabitol & 8,927 & 0,033 & $2,616( \pm 1,173)$ \\
Frutose & 10 & 0,258 & $6,489( \pm 10,655)$ \\
\hline
\end{tabular}




\begin{tabular}{llll}
\hline Galactosan & 8,914 & 0,001 & $12,38( \pm 6,5)$ \\
Galactose.Maltitol & 10 & 0,056 & $4,481( \pm 2,287)$ \\
Glicose/Xilose & 10 & 0,113 & $10,783( \pm 7,478)$ \\
Levoglucosano & 7,422 & 0,02 & $3,261( \pm 3,998)$ \\
Manitol & 10 & 0,109 & $3,915( \pm 3,504)$ \\
Manosano & 10 & 0,04 & $5,949( \pm 6,633)$ \\
\hline
\end{tabular}

Tabela 8. Média do LQL e MDL (nove análises réplicas do padrão de $0,05 \mu \mathrm{g} / \mathrm{ml}$ ) para cada carboidrato.

\begin{tabular}{lll}
\hline & $\begin{array}{l}\mathrm{LQL} \\
(\mu \mathrm{g} / \text { filtro })\end{array}$ & $\begin{array}{l}\text { MDL } \\
(\mathrm{ppm})\end{array}$ \\
\hline Acetato & 4,717 & 0,006 \\
Formiato & 0,256 & 0,005 \\
Maleato & 0 & 0,02 \\
Metanosulfonato & 0,023 & 0,011 \\
Oxalato & 0,084 & 0,01 \\
Succinato & 0 & 0,035 \\
\hline
\end{tabular}

Para os carboidratos os valores abaixo ou iguais a zero foram substituídos pelo MDL. As análises dos ácidos orgânicos tiveram sua incerteza fornecida pelo laboratório do DRI, nesse caso, para subtrair o branco da incerteza foi necessário utilizar a equação 7. A incerteza total foi calculada da mesma forma que as outras variáveis (seção 2.1.4.1).

$$
\text { Incerteza analítica }=\sqrt{u C^{2}+\mathrm{B}^{2}}
$$

onde $u C$ é a incerteza analítica da amostra previamente calculada e $B$ é o branco da amostra (field blank).

Foram usados de 9 a 11 pontos para fazer a curva de calibração dos carboidratos, enquanto os íons tiveram 8 pontos para os ânions e 6 para os cátions.

\subsubsection{Determinação do carbono elementar e orgânico}

O Analisador de carbono óptico/térmico de comprimento de onda múltiplo (Modelo DRI 2015), com o protocolo de evolução termal IMPROVE_A (The Interagency Monitoring of Protected Visual Environments) (Chow et al., 1993; Chow et al., 2007; Chow, et al., 2015; Chen et al., 2015) foi usado para obter as concentrações de carbono orgânico (OC), carbono elementar (EC) e carbono total (TC). Esse protocolo permite medir o OC e EC considerando que o OC é quase todo decomposto ou evaporado em uma atmosfera inerte de He $(>99,99 \%)$ e com uma temperatura de $580^{\circ} \mathrm{C}$, enquanto o EC é decomposto em uma atmosfera de $98 \% \mathrm{He}$ e $2 \% \mathrm{O}_{2}$ com uma temperatura de $840^{\circ} \mathrm{C}$. Também foi considerado que a pirólise do $\mathrm{OC}$ pode ocorrer e por isso há um ajuste para a refletância.

Para a análise das amostras, os filtros foram cortados em pequenos círculos de aproximadamente $0,55 \mathrm{~cm}^{2}$ e inseridos no instrumento. Os filtros permanecem dentro do equipamento por 90 segundos para que o vapor de água seque antes que a análise se inicie para não interferir nas medidas. Após esse procedimento, os filtros foram submetidos a diferentes 
rampas de temperatura em diferentes atmosferas e o gás resultante foi analisado em um detector não dispersivo de infravermelho (NDIR). Para o OC, a atmosfera é inerte e constituída de $\mathrm{He}$ (>99,99\%) e as rampas de temperatura são $190^{\circ} \mathrm{C}(\mathrm{OC} 1), 280^{\circ} \mathrm{C}(\mathrm{OC} 2), 480^{\circ} \mathrm{C}(\mathrm{OC} 3)$ e $580^{\circ} \mathrm{C}$ (OC4) e para o EC a atmosfera é constituída de $98 \%$ He e $2 \% \mathrm{O}_{2}$ e as rampas de temperatura são $580^{\circ} \mathrm{C}(\mathrm{EC} 1), 740^{\circ} \mathrm{C}(\mathrm{EC} 2)$ e $840^{\circ} \mathrm{C}(\mathrm{EC} 3)$. O carbono é queimado e volatilizado transformando-se em um gás que é oxidado a $\mathrm{CO}_{2}$ através a forno de oxidação $\left(\mathrm{MnO}_{2}\right)$, e então analisados em um NDIR (Chow et al., 2015). No analisador também há sete lasers de diodo com comprimento de onda de 405, 445, 532, 635, 780, 808 e $980 \mathrm{~nm}$, que medem a transmitância e refletância (Chow et al., 2015). O laser com comprimento de onda de $635 \mathrm{~nm}$ foi usado para corrigir a pirólise do OC, o qual se não for corrigido pode resultar em um erro de subestimação da concentração de OC e superestimação da concentração de EC. A transmitância e refletância aumentam com o carbono absorvedor de luz (EC), enquanto que diminuem com a pirólise, permitindo assim determinar quando esta ocorreu. No final de cada análise de filtro um padrão interno de metano foi injetado (Chow et al., 2015).

Mais informações sobre o sistema de operação, design do instrumento e especificações podem ser encontradas em Chow et al. (1993), Chow et al. (2007), Chen et al. (2015) e Chow et al. (2015). Essa análise foi realizada no DRI, Reno, Nevada, USA.

A concentração de OC foi obtida através da soma de todas as concentrações de OC obtidas com as diferentes rampas de temperatura, além da pirólise obtida com o laser de refletância $635 \mathrm{~nm}$. Para o EC, a concentração foi obtida através da soma de todas as concentrações de EC obtidas com as diferentes rampas de temperatura, menos a pirólise obtida com o laser de refletância $635 \mathrm{~nm}$. A concentração de TC foi obtida através da soma de todos os OC e EC.

O limite de detecção mínima (MDL) para o TC, OC e EC foi fornecido pelo laboratório DRI (procedimento de operação padrão). A média da precisão, LQL para o TC, OC e EC estão apresentadas na tabela 9. Os dados foram verificados e alguns "outliers" foram removidos.

Tabela 9. Média da precisão, MDL e LQL para o TC, OC e EC

\begin{tabular}{llll}
\hline & $\begin{array}{l}\text { Precisão } \\
(\%)\end{array}$ & $\begin{array}{l}\text { MDL } \\
\mu \mathrm{g} / \mathrm{cm}^{2}\end{array}$ & $\begin{array}{l}\text { LQL } \\
\mu \mathrm{g} / \text { filtro }\end{array}$ \\
\hline TC & 2,898 & 0,42 & 18,422 \\
OC & 6,32 & 0,41 & 18,44 \\
EC & 10,023 & 0,11 & 1,372 \\
\hline
\end{tabular}

\subsubsection{Quantificação de proteína solúveis em água}

A análise de proteínas solúveis em água foi feita na University of Nevada Las Vegas pela pesquisadora Mi Zhang e Prof. Dr. Antony Chen, seguindo o protocolo adaptado e 
elaborado pelo laboratório Urban Air Quality Laboratory do Department of Environmental and Occupational Health da University of Nevada Las Vegas em parceria com o Environmental Analysis Facility da Division of Atmospheric Sciences do Desert Research Institute. A concentração de proteínas solúveis em água (WSP) foi obtida usando um ensaio à base de corante fluorescente (AccuOrange Protein Quantitation kit; Biotium). Resumidamente, a análise consiste em extrair as proteínas do filtro com água destilada e deionizada, incubar os extratos com o ensaio por 20 minutos e detectar o sinal de fluorescência usando um leitor de microplaca (FLx800; BioTek Instruments, Inc.). Uma curva de calibração WSP foi estabelecida com o padrão de proteína de albumina de soro bovino (BSA). Esse teste tem uma faixa de detecção de proteína de 0,1-15 $\mu \mathrm{g} / \mathrm{ml}$, sendo mais sensível que outros ensaios, tem melhor linearidade e o sinal de fluorescência é estável por mais tempo (16 horas) (Biotium, 2016).

\subsubsection{Microscópio óptico}

Os tipos fúngicos foram identificados através da morfologia dos esporos (cor, tamanho e forma) de acordo com Haines et al. (2000) e outras referências (Smith, 1990; Burge et al., 2006). Os esporos foram identificados inicialmente através da sua classificação em grandes grupos considerando sua filogenia, os Ascosporos, Basidiosporos, Mitosporos e desconhecidos. Quando possível, os esporos foram identificados em nível de gênero ou agrupados considerando similaridades morfológicas. Na figura 3 são mostradas algumas imagens dos esporos identificados.

Após a contagem e identificação dos esporos, a concentração de número por metro cúbico foi determinada para ambos seguindo a equação 8 .

$$
\frac{\text { Esporos/Pólen }}{m^{3}}=\frac{n}{\frac{d_{c v} \times n_{v}}{l_{t}} \times t_{a} \times f}
$$

onde $n$ é o número de esporos ou pólen; $d c v$ corresponde ao diâmetro do campo de visão; $n v$ corresponde ao número de varreduras; $l t$ é o comprimento do traço analisado, $t a$ é o tempo de amostragem e $f$ é a taxa de fluxo.

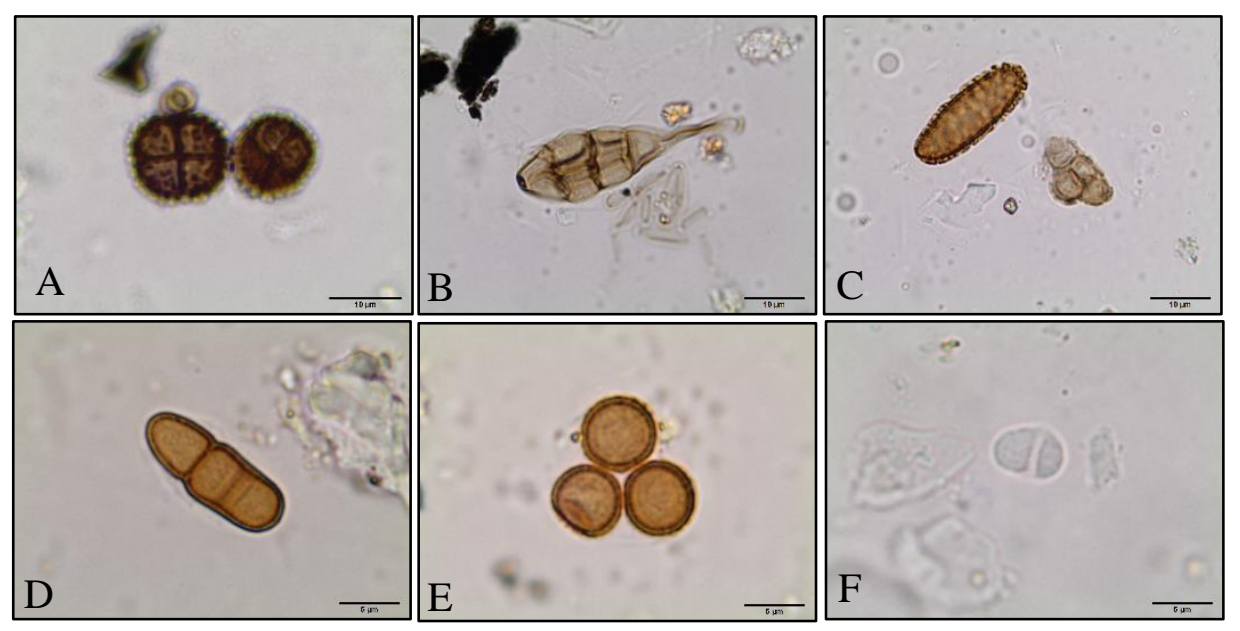


Figura 3. Imagem de alguns esporos fúngicos analisados. A: Spegazzinia sp.; B: Drechslera-like; C: Gliomatixlike; D: Paraphaeosphaeria sp.; E: Periconia sp.; F: Basidiósporo hialino.

Fonte: Emygdio et al., 2016

A incerteza total para os esporos de fungos foi calculada usando $10 \%$ da sua concentração.

\subsection{Estudo da habilidade dos bioaerossóis como núcleos de gelo}

\subsubsection{Período, local de coleta e equipamento de análise}

Para determinar o potencial dos esporos de fungos como potenciais núcleos de gelo, as amostras foram coletadas de duas formas diferentes na Região Metropolitana de São Paulo.

As espécies pertencentes ao filo Basidiomycota, tiveram os corpos de frutificação coletados em 23 de novembro de 2017. As coletas foram realizadas no fragmento florestal "Parque Estadual das Fontes do Ipiranga" na região sul da cidade de São Paulo com a auxílio do Dr. Ricardo Matheus Pires, que na época era estudante de doutorado no programa "Biodiversidade Vegetal e Meio Ambiente" do "Instituto de Botânica". A região de coleta pertence ao Sistema Nacional de Unidades de Conservação (SNUC - ICMBio) e é definida como parque estadual, sendo uma área de proteção integral (Lei n ${ }^{\circ}$ 9.985, de 18 de julho de 2000).

Os esporos dos fungos anamorfo (com reprodução assexuada) foram colhidos de colônias previamente isoladas de amostras de ar coletadas em Ibiúna, São Paulo pela Dra. Dulcilena de Matos Castro e Silva pesquisadora do Núcleo de Micologia do Instituto Adolfo Lutz. Essa coleta ocorreu em 24 de outubro de 2017.

O equipamento usado para determinar o potencial dos esporos fúngicos como núcleos de gelo foi o Banho Ultratermostático Microprocessado com Circulador (Quimis). Esse equipamento foi preenchido com uma solução de etanol $96 \%$ e tem uma faixa de temperatura que varia de $-20^{\circ} \mathrm{C}$ a $120^{\circ} \mathrm{C}$. Para o congelamento das amostras de fungos, uma bandeja de metal revestida com parafina (solução de parafina a $2 \%$ em xileno, com o solvente removido por aquecimento em placa quente) foi colocada sob a superfície da solução. O equipamento está localizado no Instituto de Química da USP sob a responsabilidade do Professor Dr. Fábio Rodrigues. Para a realização dessa etapa foi utilizada a metodologia proposta por Araujo et al. (2019). É importante ressaltar que esse experimento foi apenas um piloto para direcionar futuras análises.

\subsubsection{Impressão de esporos (Basidiomycota)}

Os esporos pertencentes ao filo Basidiomycota foram coletados através da metodologia de impressão de esporos. Esse método consiste em duas lâminas autoclavadas e uma fonte de 
umidade (papel molhado) colocados em uma câmara plástica. O píleo do fungo é então colocado com as lamelas para baixo na superfície de uma das lâminas e a câmara é fechada por 24 horas (Gimenes et al., 2010). Essa câmara irá induzir o fungo a liberar seus esporos. Após 24 horas, a lâmina contendo os esporos foi coberta com a lâmina vazia e armazenadas no refrigerador (aproximadamente $-3^{\circ} \mathrm{C}$ ) até o seu uso.

\subsubsection{Coleta dos esporos (fungos anamorfos)}

Os esporos dos fungos anamorfos foram coletados através do método de colheita. Inicialmente foram coletados 250 litros de ar com o AR MAS 100-ECO (Merck, FR) em uma placa de petri contendo um meio de cultura de ágar de batata dextrose com cloranfenicol pela Dra. Dulcilena de Matos Castro e Silva. Após o crescimento dos fungos em uma estufa apropriada, as colônias foram isoladas e foram colocadas para crescer por 7 dias. Para a obtenção dos esporos dos fungos, a superfície do meio de cultura foi lavada com uma solução de etanol e a solução obtida foi armazenada até o seu uso. Com essa metodologia, não apenas os esporos são coletados, mas também suas hifas.

\subsubsection{Atividade dos esporos como núcleo de gelo}

Os esporos e hifas obtidas com ambas as metodologias (impressão de esporos e colheita de esporos) foram diluídos em $2 \mathrm{ml}$ de água deionizada (1:1). Em seguida, $1 \mathrm{ml}$ da solução homogeneizada foi adicionada a um tubo de ensaio de plástico com tampa e diluído em 1,9 ml de água deionizada. Esse procedimento foi feito 2 vezes para se obter soluções menos concentradas.

Para se determinar a concentração de esporos na solução, $20 \mu 1$ da solução foi analisada em uma câmera de Neubauer e um microscópio óptico e o número de esporos em cada quadrante foi contado. A concentração de esporos por volume de cada solução foi obtida através da equação 9.

$$
\frac{\text { Cells }}{\mu l}=\frac{N}{A \times Q \times P \times D}
$$

onde $N$ é o número total de celulas contadas, $A$ é a área contada ( $\mathrm{mm}^{2}$ por quadrante), $Q$ é o número de quadrantes contados, $P$ é a profundidade da câmara e $D$ é a diluição.

A atividade como núcleo de gelo para cada amostra foi quantificada pelo ensaio de congelamento de gotículas (Figura 4). As soluções foram arranjadas, em uma bandeja de metal revestida com parafina, em 32 gotas de $10 \mu$ cada para cada diluição e cada tipo fúngico coletado. Em seguida, a bandeja foi coberta com uma tampa de acrílico transparente selada nas bordas e colocada na superfície do banho termostático de $96 \%$ de etanol. O número de gotas congeladas foi verificado a cada diminuição em $1^{\circ} \mathrm{C}$ na temperatura até a temperatura atingir $20^{\circ} \mathrm{C}$ ou todas as gotas tenham congelado. A temperatura do banho foi medida com um 
termômetro de mercúrio submergido. O número de gotas congeladas foi contado cumulativamente e no final do teste todas ou quase todas as gotas haviam congelado. Para considerar potenciais contaminações ou problemas com o método, 32 gotas de água deionizada (Milli-Q) também foram adicionadas na bandeja para verificar o seu ponto de congelamento.

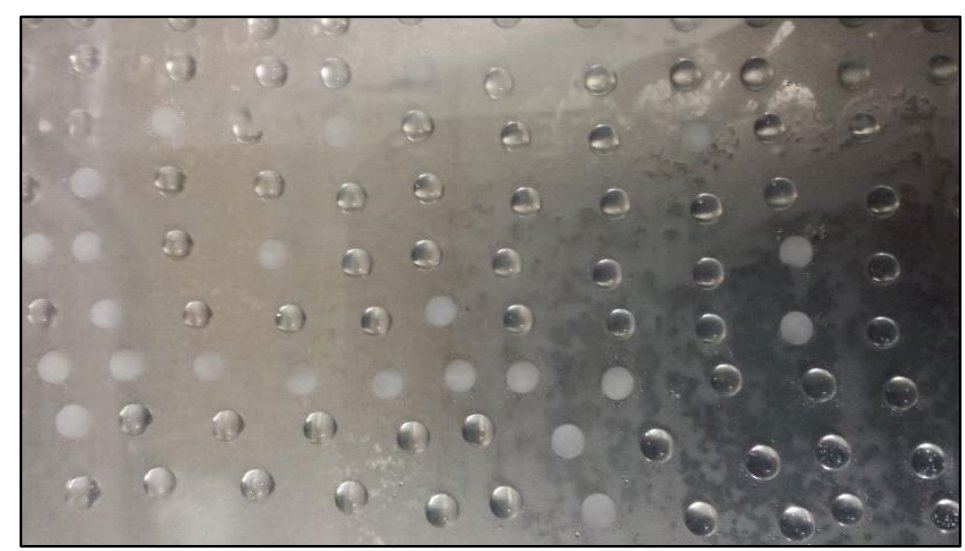

Figura 4. Ensaio de congelamento de gotículas mostrando a bandeja de metal com parafina e as gotículas líquidas (transparentes) e congeladas (brancas opacas) de $10 \mu 1$ da solução de esporos utilizada nos testes de ice nuclei.

Considerando a concentração de esporos por diluição e o número de gotas congeladas por espécie, foi possível estimar o número cumulativo de núcleos de gelo por esporos de acordo com os cálculos propostos por Vali (1971) (equação 10) e aplicado em vários estudos (Pouleur et al., 1992; Cochet e Widehem, 2000; Bowers et al., 2009; Conen et al., 2012; Morris et al., 2012).

$$
K t=\frac{\left(\ln \left(n_{t}\right)-\ln \left(n_{n c}\right)\right)}{d}
$$

onde $K t$ é o espectro de núcleos cumulativos (concentração cumulativa de núcleos de gelo ativos em cada temperatura medida), $n_{t}$ é o número total de gotas, $n_{n c}$ é o número de gotas não congeladas, e $d$ é o número de células em cada gota $(10 \mu 1)$.

\subsection{Análises estatísticas e análise de trajetórias}

As análises estatísticas foram realizadas usando os softwares Excel, Statistica 10, RStudio (R Core Team, 2020), com os pacotes: readxl (Wickham and Bryan, 2019), dplyr (Wickham et al., 2020), openair (Carslaw e Ropkins, 2012), psych (Revelle, 2020), pastecs (Grosjean and Ibanez, 2018), ggplot2 (Wickham, 2016), pgirmess (Giraudoux, 2018), Httr (Wickham, 2020), magrittr (Bache and Wickham, 2014), plyr (Wickham, 2011), corrplot (Wei and Simko, 2017), gridExtra (Auguie, 2017), janitor (Firke, 2020), entre outros.

Para determinar se os dados apresentaram uma distribuição normal, foi usado o teste Shapiro. Os testes rejeitam a hipótese de normalidade quando " $p<0,05$ ”, e nesse caso, os dados são considerados não paramétricos e análise estatística adequada devem ser usadas (Field et al., 2012). Assim, as análises estatísticas usadas foram: Análise descritiva, correlação de Pearson, 
correlação de Spearman, teste de Kruskal-Wallis, teste de soma de postos Wilcoxon (equivalente ao teste de Mann-Whitney), erro percentual relativo, Análise de Cluster, regressão múltipla, Análise de componentes principais (PCA), Fatoração de Matriz Positiva (PMF), Função de probabilidade bivariada condicional (CBPF).

\subsubsection{Análises estatísticas não paramétricas}

Estatísticas não paramétrica foram feitas de acordo com Field et al. (2012) e Vieira (2004). Correlação de Spearman é uma análise não paramétrica equivalente à correlação de Pearson, contudo, não requer a suposição que a variável é linear, que os dados são ordinários, ou que a variável tem uma distribuição normal. Essa correlação considera postos para representar os valores das variáveis e indica a posição no qual o número ocupa quando todos os dados são classificados em ordem crescente. Esse teste irá aceitar ou negar a hipótese nula e indicar se as variáveis são correlacionadas ou não (Vieira, 2004). A equação que calcula o coeficiente de correlação de Spearman está apresentada na equação 11.

$$
r_{s}=1-\left[\frac{6 \sum D^{2}}{n\left(n^{2}-1\right)}\right]
$$

onde $r s$ representa o coeficiente de correlação de Spearman, $D$ é a diferença entre os postos do mesmo indivíduo e $n$ é o número de pares dos indivíduos em uma amostra.

O teste de Kruskal-Wallis rejeita ou aceita a hipótese que diferentes populações têm a mesma distribuição (i.g., se há uma diferença significativa entre as concentrações de esporos em diferentes estações do ano). Esse teste requer que as variáveis sejam medidas em uma escala numérica ou ordinal e usa postos para representar os valores das variáveis (Vieira, 2004). A equação para calcular o teste de Kruskal-Wallis está apresentada na equação 12.

$$
H=\frac{12}{n(n+1)} \sum_{i=1}^{k} \frac{R_{j}^{2}}{n_{j}}-3(n+1)
$$

onde $n$ é o número de amostras; $n j$ é o número de elementos na amostra $j ; R j$ é a soma de elementos na amostra $j$ e $\Sigma$ nj é o número total de elementos em todas as amostras combinadas.

Teste de soma de postos de Wilcoxon, equivalente ao teste de Mann-Whitney, foi usado para comparar duas condições independentes (e.g., se há uma diferença significativa entre a concentração de esporos em diferentes anos coletados). Esse teste aceita ou rejeita a hipótese de que as duas populações têm a mesma distribuição e utiliza-se de postos para representar as variáveis. Geralmente, o menor valor de W é escolhido. A equação que calcula o teste de Wilcoxon está apresentada na equação 13.

$$
W_{j}=\sum r_{j}-\frac{N_{j}\left(N_{j}+1\right)}{N_{j}}
$$

onde $r$ são os postos em cada condição $j, N$ é a quantidade de amostras em cada condição $j$. 
O cálculo do valor $\mathrm{p}$ associado irá indicar se as duas condições diferem significativamente ou não $(\mathrm{p}<0,05)$.

\subsubsection{Fatoração de Matriz Positiva (PMF)}

A determinação e quantificação das fontes do $\mathrm{MP}_{10}$ foi feita com o modelo Fatoração de Matriz Positiva (PMF) usando o software da EPA PMF5.0 (Brown et al., 2015, Norris et al., 2014). O PMF é um modelo receptor multivariado, que fornece a contribuição e perfil de um fator através da decomposição de uma matriz de espécies presentes em uma amostra. O PMF considera que as concentrações dos compostos medidos é uma combinação de fontes diferentes. A incerteza das medidas tem um papel importante na estimativa da melhor solução para o perfil e contribuição do fator (Brown et al., 2015 e referências nele). O balanço químico de massa é resolvido através da estimativa do perfil das espécies em cada fator e a contribuição da sua massa, através da equação 14 (Brown et al., 2015, Norris et al., 2014). Essa análise considera que a amostra não pode ter uma contribuição negativa de fatores e de compostos, e a melhor solução é aquela com a menor função Q (robust) (Equação 15).

$$
x_{i j}=\sum_{k=1}^{p} g_{i k} f_{k j}+e_{i j}
$$

onde $x$ é a matriz de dados; $i$ é o número da amostra; $j$ é a variável; $p$ é o número do fator; $k$ é o fator; $g$ é a quantidade de massa; $f$ é o perfil da fonte e $e$ é o erro do modelo.

$$
Q=\sum_{i=1}^{n} \sum_{j=1}^{m}\left[\frac{x_{i j}=\sum_{k=1}^{p} g_{i k} f_{k j}}{u_{i j}}\right]^{2}
$$

onde $m$ é o número de espécies químicas; $i$ é o número da amostra; $j$ é a variável; $x$ é a matriz de dados; $p$ é o número do fator; $k$ é o fator; $g$ é a quantidade de massa; $f$ é o perfil da fonte; $e$ é o erro do modelo; e $u$ é a incerteza.

Para determinar o número de fatores a ser usado no PMF o mapeamento Bootstrap (BS), Deslocamento (Displacement - DISP), BS-DISP e a relação entre o Qtrue (Qt) com o Qexpected (Qe) foram analisados. O mapeamento dos fatores no BS menor do que $100 \%$ significa que o fator derivado da nova simulação do BS não se correlacionou com o mesmo fator obtido na simulação base. Isso significa que o fator não teve uma reprodutibilidade (Brown et al., 2015). Contudo, de acordo com o Guia do Usuário do PMF, um mapeamento dos fatores de $80 \%$ ou mais no BS é considerado aceitável e o número de fatores escolhidos pode ser aplicável (Norris et al., 2014). Na análise de BS-DISP, se ocorrerem trocas de fator para a menor diferença máxima possível entre a base e o $Q$ modificado $\left(\mathrm{dQ}^{\text {máx }}\right)$, que é igual a 0,5 , a solução não é bem restrita (constrained) e a ambiguidade rotacional é significativa (Brown et al., 2015), o que significa que a sua interpretação deve ser feita com cautela (Norris et al., 2014). Além disso, uma diminuição do Q com o DISP ou BS-DISP, significa que o Q na corrida base não é o mínimo global (Brown et al., 2015). Uma diminuição do Q maior do que $1 \%$ é significativa e acima de 0,5\% precisa ser reavaliado (Norris et al., 2014; Brown et al., 2015). A análise residual 
também é importante já que um resíduo maior do que 3 pode indicar que a espécie não foi bem ajustada pelo PMF ou que a fonte onde essa espécie está presente, não é frequente. A razão Q/Qexp devem também ser analisada, já que um Q/Qexp maior do que 2 pode indicar que a espécie não foi bem modelada pelo PMF.

\subsubsection{Função de Probabilidade Bivariada Condicional (CBPF)}

A função de probabilidade bivariada condicional (CBPF) (Uria-Tellaetxe and Carslaw, 2014; Jeričević et al., 2019) foi usada para analisar a origem das variáveis através da identificação da relação da direção predominante do vento ponderada pela velocidade do vento com a concentração das espécies. O CBPF usa a estatística CPF (função de probabilidade condicional) com a adição da velocidade do vento para estimar a probabilidade que a fonte de um poluente é originada em uma certa seção de direção do vento considerando um critério de intervalo de concentração. De acordo com Uria-Tellaetxe and Carslaw (2014) e Jeričević et al. (2019), o CBPF é calculado através da divisão de uma amostra que têm uma contribuição de concentração de fonte maior do que um critério de limite (em uma direção do vento e intervalo de velocidade do vento específicos), pelo número total de amostras presentes na mesma direção do vento e intervalo de velocidade do vento para o período amostrado.

O cálculo do CBPF foi realizado com um critério de limite da concentração de fonte de percentil $75^{\circ}$ e um parâmetro de suavização (k) de 40 . A velocidade e direção do vento foram obtidas da estação climatológica do IAG localizada no parque CIENTEC (-23³9'08.8"S; $\left.46^{\circ} 37^{\prime} 20.6^{\prime \prime} \mathrm{W}\right)$, a aproximadamente $15,2 \mathrm{~km}$ do local de coleta.

\subsubsection{Hysplit (Hybrid Single-particle Lagrangian Integrated Trajectory)}

O modelo NOAA Hysplit (Stein et al., 2015) foi usado para se obter as trajetórias individuais de alguns dos dias coletados e estimar a direção predominante da massa de ar considerando como ponto central o local de coleta (IAG/USP). Foram feitas trajetórias para trás (backward) com duração de 24 horas iniciando as $12 \mathrm{~h}$ e considerando os 9 dias coletados em junho de 2017. O método de cálculo do movimento vertical foi o modelo de velocidade vertical, e a meteorologia foi a GDAS (1 degree, global, 2006-present) apresentando 3 alturas da camada $(100,500,1000)$. As cores das linhas indicam diferentes altitudes da massa de ar, sendo que a linha vermelha represente uma altitude de chegada de $500 \mathrm{~m}$, a linha azul represente uma altitude de chegada de $1000 \mathrm{~m}$ e a linha verde representa uma altitude de chegada de $1500 \mathrm{~m}$. Cada ponto na trajetória representa um período de 6 horas.

\section{Resultados e discussão}

\subsection{Situação Meteorológica}


Segundo o boletim climatológico anual da Estação Climatológica do IAG/USP (IAG, 2017) no ano de 2017 a acumulação pluviométrica foi de 1648,8mm, estando acima da média climatológica $(1412,3 \mathrm{~mm})$. Durante o período amostrado as maiores precipitações ocorreram em março 2018 (222,2 mm), seguida de novembro 2017 (194,6 mm), maio 2017 (135,9 mm), outubro 2017 (124,6 mm), junho 2017 (102,0 mm), com os meses mais secos em setembro 2017 (45,5 mm), abril 2018 (50,9 mm) e agosto 2017 (75,8 mm). Os meses com temperaturas mais elevadas, foram outubro de 2017, março e abril de 2018 e os meses com maiores umidade relativa foram maio e junho de 2017, março e abril de 2018 (IAG, 2017; IAG, 2018a; IAG, 2018b).

Na tabela 10 são apresentadas as médias das variáveis meteorológicas considerando apenas os dias amostrados para todo o período de coleta e as estações do ano, enquanto na figura 5 são apresentadas as médias diárias das variáveis meteorológicas para os dias amostrados (69 dias).

Tabela 10. Média das variáveis meteorológicas para todo o período amostrado e as estações do ano, considerando o período amostrado.

\begin{tabular}{llllll}
\hline & $\begin{array}{l}\text { Temperatura média } \\
(\text { máxima; mínima) } \\
\left({ }^{\circ} \mathrm{C}\right)\end{array}$ & $\begin{array}{l}\text { Umidade } \\
\text { média } \\
\text { mínima })(\%)\end{array}$ & $\begin{array}{l}\text { relativa } \\
(\text { máxima; }\end{array}$ & $\begin{array}{l}\text { Precipitação } \\
\text { acumulada } \\
(\text { máxima; mínima) } \\
(\mathrm{mm})\end{array}$ & $\begin{array}{l}\text { Velocidade do vento } \\
\text { média } \\
\text { mínima })(\mathrm{km} / \mathrm{h})\end{array}$ \\
\hline Todo o período & $19,3(11,9 ; 26,1)$ & $78,6(50,5 ; 96,1)$ & $180,8(0 ; 39,1)$ & $5,3(2,2 ; 11,8)$ \\
Outono de 2017 & $16,7(11,9 ; 21,3)$ & $81,5(72,5 ; 94,2)$ & $14,2(0 ; 7,1)$ & $4,7(2,2 ; 11,8)$ \\
Inverno de 2017 & $18,3(14,6 ; 23,5)$ & $74,3(50,5 ; 96,1)$ & $25,1(0 ; 12,5)$ & $5,4(3,4 ; 9,3)$ \\
Primavera de 2017 & $19,0(15,0 ; 23,9)$ & $79,3(60,4 ; 90,2)$ & $58,9(0 ; 39,1)$ & $5,9(3,2 ; 8,8)$ \\
Outono de 2018 & $22,0(20,3 ; 24,7)$ & $82,3(72,1 ; 90,5)$ & $49,5(0 ; 14,8)$ & $4,7(2,8 ; 6,9)$ \\
\hline
\end{tabular}



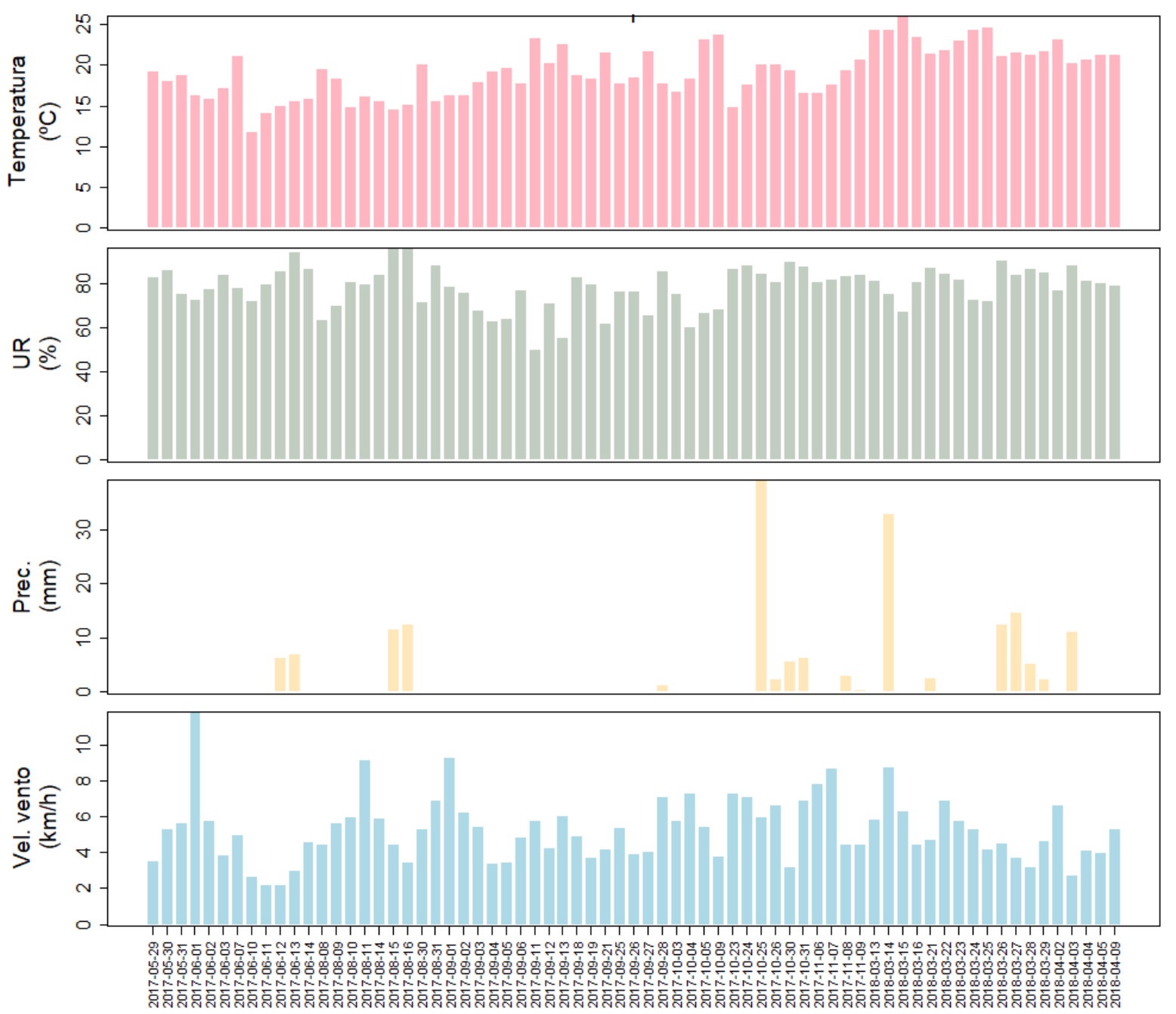

Figura 5. Série temporal das variáveis meteorológicas.

Legenda: Temperatura média diária (Temperatura), Umidade relativa média diária (UR), Precipitação acumulada no dia (Prec.), e Velocidade média diária do vento (Vel. vento).

Observaram-se as maiores temperaturas médias para 2017 em setembro e outubro com aproximadamente $19^{\circ} \mathrm{C}$, enquanto em 2018 a maior temperatura média foi em março $(23,1 \pm$ $1,6^{\circ} \mathrm{C}$ ) e a estação com maior temperatura também foi em 2018 (outono). A umidade relativa média foi maior em novembro $(82,6 \pm 1,5 \%)$ para 2017 e abril $(81,4 \pm 4,4 \%)$ para 2018 , enquanto a estação com maior umidade relativa média foi outono de 2018 (82,3 $\pm 5,5 \%)$. Para a velocidade média do vento, observa-se os maiores valores em novembro para $2017(6,4 \pm 2,3$ $\mathrm{km} / \mathrm{h})$ e março para $2018(5,3 \pm 1,5 \mathrm{~km} / \mathrm{h})$, sendo a primavera de $2017(5,9 \pm 1,6 \mathrm{~km} / \mathrm{h})$ a estação com maiores velocidades médias. A precipitação acumulada foi mais elevada em outubro de 2017 (53,9 mm) e março de $2018(71,4 \mathrm{~mm})$, sendo a primavera de $2017(58,9 \mathrm{~mm})$ a estação que apresentou a maior precipitação. Na primavera de 2017 a precipitação foi 2,3 vezes maior do que no inverno e 4,1 vezes maior do que no outono de 2017, e o outono de 2018 teve uma precipitação 2 vezes maior do que no inverno e 3,5 vezes maior do que no outono de 2017. 
A rosa dos ventos considerando todo o período amostrado é apresentada na figura 6 , enquanto a rosa dos ventos sazonal pode ser observada no Apêndice (Figura C I).

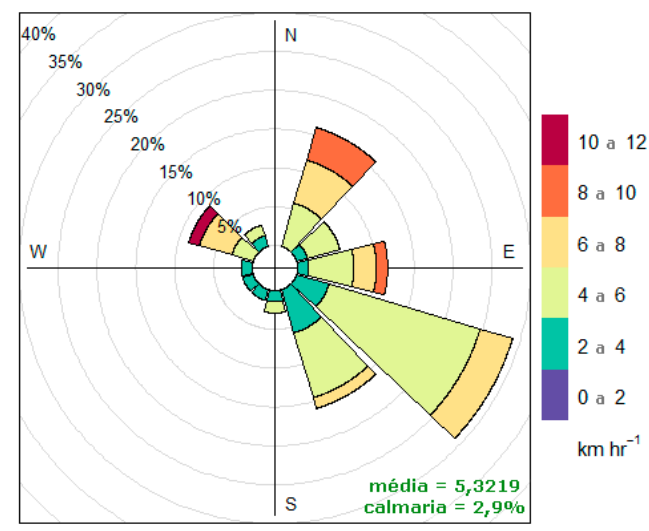

Figura 6. Rosa dos ventos para o todo o período amostrado Legenda: Frequência das contagens pela direção do vento (\%).

Observa-se que durante o período amostrado a maior frequência de ventos foi da região sudeste, enquanto a região noroeste apresentou a maior velocidade do vento (> $11 \mathrm{~km} / \mathrm{h}$ ) em junho de 2017. Na sequência, as maiores velocidades do vento foram observadas na região nordeste e leste. Considerando as estações do ano, o Outono de 2017 apresentou 1 dia com uma velocidade do vento elevada (> $11 \mathrm{~km} / \mathrm{h}$ ) de direção noroeste, contudo a maior frequência de ventos é de sudeste, da mesma forma que no inverno e primavera. As maiores velocidades do vento no inverno ocorreram de nordeste enquanto na primavera ocorreram de leste. No outono de 2018 há um comportamento diferente, com maior frequência e velocidade do vento de nordeste.

Assim, o período amostrado apresentou um outono em 2018 mais quente e úmido com mais ventos de nordeste e uma primavera em 2017 com mais chuvas e ventos mais velozes e com maior frequência de sudeste. O outono de 2017 foi mais frio que as outras estações e com menos chuvas, enquanto o inverno apresentou menores umidade relativa, ambos com mais ventos vindos de sudeste.

\subsection{Comparação entre dados de diferentes equipamentos}

Para realizar todas as análises propostas nesse trabalho e se obter uma caracterização química apropriada do MP foi necessário utilizar diversos equipamentos e substratos como sugerido por Chow et al. (1995). Diferentes substratos são necessários para análise de orgânicos, inorgânicos e concentração em massa. Dessa forma, obteve-se uma base de dados com a superposição de medida de alguns compostos. Para a verificação da equivalência entre os métodos, foi necessário saber o grau de correlação e se a massa coletada com os diferentes equipamentos e filtros são equivalentes. Para isso foram feitos testes com os equipamentos 
Minivol, Hivol e Partisol 2025i com diferentes filtros (quartzo, policarbonato e teflon) e suportes (Apêndice I). Diferentes equipamentos com diferentes suportes podem apresentar princípios de operação, fluxos e curva de eficácia de amostragem diferentes (Chow et al., 1995). Os equipamentos podem utilizar filtros variados, os quais apresentam diferentes eficiência de amostragem de partículas, estabilidade mecânica, estabilidade química, estabilidade térmica, concentração do branco, resistência do fluxo e capacidade de carregamento (Chow et al., 1995). Considerando isso, entende-se que há diversas variáveis que podem influenciar na concentração final obtida, e sendo assim se faz necessário compreender se os equipamentos são equivalentes tanto para a concentração em massa, quanto para a concentrações dos elementos e íons.

Essa comparação entre filtros, suportes, equipamentos de coleta e análise, considerando a massa, composição elementar e íons está apresentada no Apêndice A.

4.3. Análise da composição do MP10, reconstrução da massa e caracterização de fontes

\subsubsection{Avaliação da normalidade da distribuição das variáveis}

As variáveis foram testadas para verificar se a sua distribuição era normal com o teste "Shapiro test". Quando considerado todo o período estudado, todas as variáveis analisadas apresentaram uma distribuição não-normal, enquanto se considerarmos apenas a distribuição anual, mensal ou sazonal, algumas variáveis apresentaram uma distribuição normal. Para padronizar as análises da forma mais correta possível, as análises estatísticas realizadas foram não paramétricas.

\subsubsection{Balanço de massa dos íons}

A amônia é um gás alcalino que tem uma função neutralizadora na atmosfera, processo esse que ocorre através da conversão de gás para partícula. Em uma atmosfera com uma quantidade de amônia baixa, o ácido sulfúrico, na fase aerossol, estará na forma de $\mathrm{H}_{2} \mathrm{SO}_{4}$ (aquoso). Assim a fase aerossol será mais ácida. Com o aumento na concentração de $\mathrm{NH}_{3}$ pode haver uma neutralização e conversão de $\mathrm{H}_{2} \mathrm{SO}_{4}$ para $\mathrm{HSO}_{4}{ }^{-}$e $\mathrm{NH}_{4} \mathrm{HSO}_{4}$ (sólido). Em uma atmosfera rica em $\mathrm{NH}_{3}$, o $\mathrm{H}_{2} \mathrm{SO}_{4}$ poderá ser convertido a $\mathrm{SO}_{4}{ }^{2-}$ e $\left(\mathrm{NH}_{4}\right)_{2} \mathrm{SO}_{4}$. Com uma concentração intermediária de $\mathrm{NH}_{3}$ também poderá haver a formação de $\left(\mathrm{NH}_{4}\right)_{3} \mathrm{H}_{(}\left(\mathrm{SO}_{4}\right)_{2}$ (letovicite). Um excesso de amônia na atmosfera permanecerá na forma gasosa. A conversão do $\mathrm{H}_{2} \mathrm{SO}_{4}$ é dependente da umidade relativa. Em uma umidade elevada (i.e., maior que $75 \%$ ) o $\mathrm{H}_{2} \mathrm{SO}_{4}$ é primeiro convertido a $\mathrm{HSO}_{4}{ }^{-}$e com um aumento da concentração da amônia total em $\mathrm{SO}_{4}{ }^{2-}$ e só com um aumento ainda maior de $\mathrm{NH}_{3}$ será convertido para $\left(\mathrm{NH}_{4}\right)_{2} \mathrm{SO}_{4}$ (Seinfeld and Pandis, 2006). 
Em uma atmosfera com elevada concentração de amônia e baixa concentração de sulfato ou com esse neutralizado também pode haver a formação de $\mathrm{NH}_{4} \mathrm{NO}_{3}$ através da reação da amônia com o ácido nítrico. Essa reação e a forma como o nitrato de amônia estará na atmosfera dependerá da umidade e da temperatura. Assim de forma resumida, se a atmosfera for rica em amônia (mais de 2 vezes a quantidade molar de sulfato) então a fase aerossol será neutralizada, com a reação com o sulfato, enquanto a amônia que não reagir com o sulfato poderá reagir com o nitrato e produzirá $\mathrm{NH}_{4} \mathrm{NO}_{3}$. Em uma situação oposta em que a atmosfera é pobre em amônia, o aerossol se manterá ácido, e nem o sulfato nem nitrato serão neutralizados (Seinfeld and Pandis, 2006).

Para compreender esse balanço na atmosfera de São Paulo e verificar as formas presentes na atmosfera considerando o período amostrado foi elaborado um balanço entre $\mathrm{NH}_{4}{ }^{+}$, $\mathrm{SO}_{4}{ }^{2-} \mathrm{e} \mathrm{NO}_{3}{ }^{-}\left(\mathrm{NH}_{4} \mathrm{HSO}_{4} \mathrm{e}\left(\mathrm{NH}_{4}\right)_{2} \mathrm{SO}_{4}\right)$ utilizando a equação 5 , e os dados foram plotados contra os valores de $\mathrm{NH}_{4}{ }^{+}$(Figura 7a). Um balanço entre cátions e ânions também foi realizado considerando a equação 6 (Figura 7b).
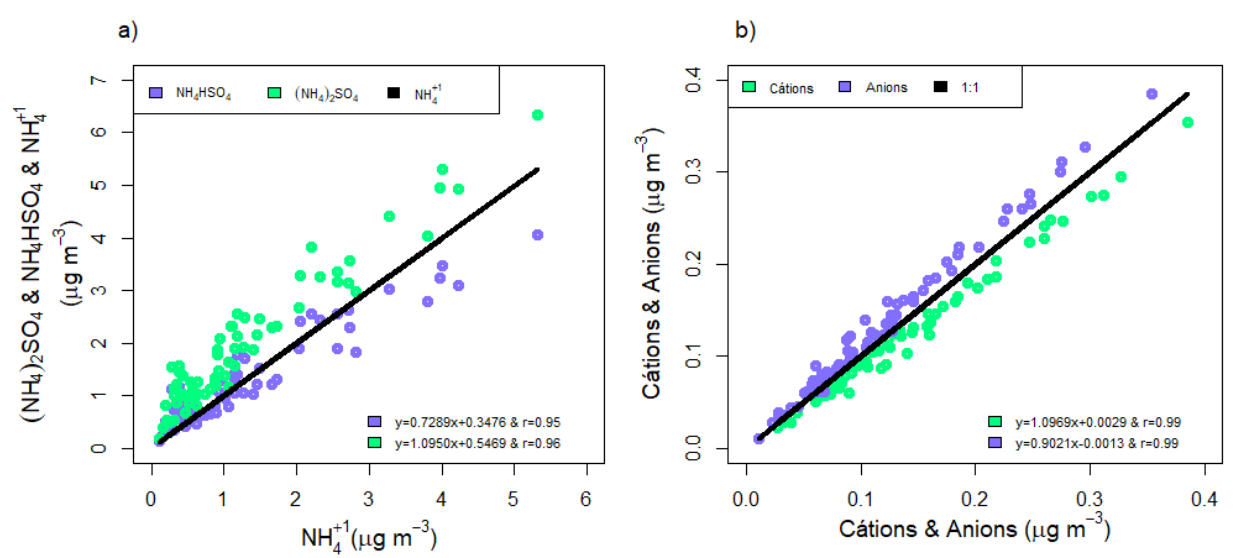

Figura 7. Balanço entre a) $\mathrm{NH}_{4} \mathrm{HSO}_{4},\left(\mathrm{NH}_{4}\right)_{2} \mathrm{SO}_{4}$ e $\mathrm{NH}_{4}{ }^{+}$, onde foi plotada as concentrações obtidas na equação 5 versus a concentração de $\mathrm{NH}_{4}^{+}$; b) Ílons (cátions e ânions), onde foi plotada a relação cátions (eixo x) e aníons (eixo y) - verde; aníons (eixo x) e cátions (eixo y) - azul.

Apesar dos dados não apresentarem uma distribuição normal, a correlação de Pearson entre os íons $\mathrm{NH}_{4}{ }^{+}$e $\mathrm{SO}_{4}{ }^{2-}$ com r=0,93 e $\mathrm{NO}_{3}{ }^{-} \mathrm{e} \mathrm{NH}_{4}{ }^{+}$com r $=0,80$ é um indicativo de que eles estão na atmosfera provavelmente na forma de $\mathrm{NH}_{4} \mathrm{NO}_{3}, \mathrm{NH}_{4} \mathrm{HSO}_{4}$ ou $\left(\mathrm{NH}_{4}\right)_{2} \mathrm{SO}_{4}$. Apesar da diferença ser muito pequena, na figura 7 a é mostrado que a correlação e a inclinação da reta para a equação do $\left(\mathrm{NH}_{4}\right)_{2} \mathrm{SO}_{4}$ estão mais próximo de 1 do que na equação do $\mathrm{NH}_{4} \mathrm{HSO}_{4}$, indicando que esses três íons possivelmente estavam na forma de $\left(\mathrm{NH}_{4}\right)_{2} \mathrm{SO}_{4}$ e $\mathrm{NH}_{4} \mathrm{NO}_{3}$ (Shen et al., 2008; Wang et al., 2013). Além disso, com essa informação compreende-se que a quantidade de amônia na atmosfera de São Paulo é elevada o suficiente para haver uma predominância de $\left(\mathrm{NH}_{4}\right)_{2} \mathrm{SO}_{4}$. Wang et al. (2013) fez os mesmos cálculos para a China e obteve 
que o íon $\mathrm{NH}_{4}{ }^{+}$se correlacionava bem com $\mathrm{SO}_{4}{ }^{2-}$ e $\mathrm{NO}_{3}{ }^{-}$(coeficiente de correlação > 0,9) e que devido à inclinação da reta para a equação do $\mathrm{NH}_{4} \mathrm{HSO}_{4}$ estar mais perto da unidade do que para a equação do $\left(\mathrm{NH}_{4}\right)_{2} \mathrm{SO}_{4}$, concluiu que os íons existiam na forma de $\mathrm{NH}_{4} \mathrm{HSO}_{4} \mathrm{e} \mathrm{NH}_{4} \mathrm{NO}_{3}$, o oposto que encontramos com os dados apresentados nesse trabalho. Shen et al. (2008) encontrou os mesmos resultados que Wang et al. (2013) para o TSP (partículas totais em suspensão), isto é, íons se encontravam na forma de $\mathrm{NH}_{4} \mathrm{HSO}_{4}$ e $\mathrm{NH}_{4} \mathrm{NO}_{3}$, enquanto para o $\mathrm{MP}_{2,5}$ encontrou que os íons predominantes eram $\left(\mathrm{NH}_{4}\right)_{2} \mathrm{SO}_{4}$ e $\mathrm{NH}_{4} \mathrm{NO}_{3}$. Ynoue et al. (2004) mostrou que em agosto de 1999 a atmosfera estava rica em amônia e todo o sulfato foi neutralizado pelo amônio.

O balanço de íons permite compreender melhor o equilíbrio ácido-base para o aerossol (Shen et al., 2008). Considerando o balanço de íons (equação 6), a alta correlação entre os íons confirma que as medidas estão consistentes $(\mathrm{r}=0,99)$ e que a atmosfera possivelmente está neutralizada já que a inclinação da reta para os ânions $(0,9021)$ e para os cátions $(1,0969)$ está próximo de 1 (Shen et al., 2008). Apesar disso, a razão entre ânions e cátions (A/C) durante o período amostrado indica que a maior parte dos dias apresenta uma razão A/C menor do que 1 (64 dias) e apenas 5 dias com a razão A/C maior do que 1. Esse comportamento implica que considerando o período amostrado os dias foram predominantemente mais alcalinos do que ácidos (Shen et al., 2008; Wang et al., 2013). Os dias que apresentaram razão A/C maior do que 1 ocorreram em março de 2018, enquanto agosto e setembro de 2017 foram os meses que apresentaram uma média da razão mais baixa (mais longe de 1), indicando uma atmosfera mais alcalina (Figura 8).

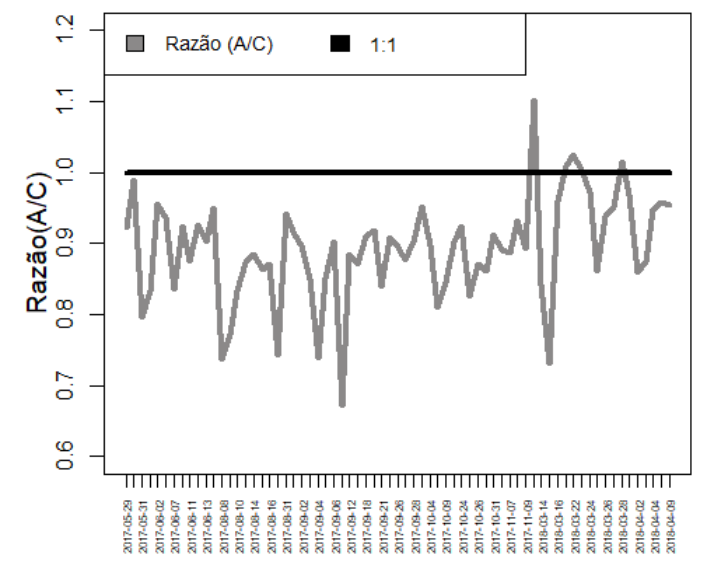

Figura 8. Razão entre a concentração em massa dos ânions (A) e os cátions (C) considerando todo o período amostrado.

Considerando os íons coletados com o MiniVol com filtro de policarbonato e analisados no LAPAt, os resultados são semelhantes (Figura C II e III), com algumas diferenças como a razão A/C que excede o valor de 1 apenas em dois dias de junho de 2017. 


\subsubsection{Composição do MP10 e reconstrução da massa}

A concentração média do $\mathrm{MP}_{10}$ durante o período amostrado foi de $30,67 \pm 14,51 \mu \mathrm{g} / \mathrm{m}^{3}$ (faixa $11,67-73,21 \mu \mathrm{g} / \mathrm{m}^{3}$ ). Na tabela 11 são apresentadas as concentrações médias, desvio padrão, concentração máxima, mínima e a porcentagem de contribuição para o $\mathrm{MP}_{10}$ dos principais compostos analisados.

Tabela 11. Concentração média, desvio padrão, concentração máxima e mínima e porcentagem da contribuição das variáveis para o $\mathrm{MP}_{10}$, ordenado pelas variáveis com maiores concentrações.

\begin{tabular}{|c|c|c|c|c|c|c|}
\hline Variáveis ${ }^{1}$ & $\begin{array}{l}\text { Média } \\
\left(\mu \mathrm{g} / \mathrm{m}^{3}\right)\end{array}$ & $\begin{array}{l}\text { Desvio padrão } \\
\left(\mu \mathrm{g} / \mathrm{m}^{3}\right)\end{array}$ & $\begin{array}{l}\text { Máximo } \\
\left(\mu \mathrm{g} / \mathrm{m}^{3}\right)\end{array}$ & $\begin{array}{l}\text { Mínimo } \\
\left(\mu \mathrm{g} / \mathrm{m}^{3}\right)\end{array}$ & $\begin{array}{l}\text { Porcentagem do } \mathrm{MP}_{10} \\
(\%)^{2}\end{array}$ & $\begin{array}{l}\text { Incerteza total } \\
\left(\mu \mathrm{g} / \mathrm{m}^{3}\right)\end{array}$ \\
\hline Massa do $\mathrm{MP}_{10}$ & 30,67 & 14,51 & 73,21 & 11,67 & 100 & 3,4304 \\
\hline $\mathrm{OC}$ & 5,71 & 3,59 & 18,11 & 1,08 & 18,62 & 0,4733 \\
\hline $\mathrm{BC}$ & 4,12 & 3 & 12,99 & 0,86 & 13,43 & $0,6187^{3}$ \\
\hline $\mathrm{SO}_{4}{ }^{2-}$ & 3,47 & 2,35 & 11,98 & 0,26 & 11,31 & 0,1899 \\
\hline $\mathrm{S}$ & 2,88 & 1,74 & 9,26 & 0,59 & 9,39 & 0,2553 \\
\hline $\mathrm{EC}$ & 2,6 & 1,55 & 6,66 & 0,41 & 8,48 & 0,2914 \\
\hline $\mathrm{NO}_{3}{ }^{-}$ & 2,08 & 1,77 & 7,27 & 0,28 & 6,78 & 0,1189 \\
\hline $\mathrm{NH}_{4}{ }^{+}$ & 1,26 & 1,13 & 5,31 & 0,11 & 4,11 & 0,0655 \\
\hline $\mathrm{Si}$ & 1,09 & 0,93 & 4,17 & 0,11 & 3,55 & 0,0901 \\
\hline $\mathrm{Fe}$ & 0,77 & 0,59 & 2,62 & 0,12 & 2,51 & 0,1456 \\
\hline $\mathrm{Na}$ & 0,71 & 0,41 & 1,79 & 0,05 & 2,31 & 0,0594 \\
\hline $\mathrm{Na}^{+}$ & 0,7 & 0,58 & 2,22 & 0,04 & 2,28 & 0,0362 \\
\hline $\mathrm{K}$ & 0,52 & 0,38 & 1,84 & 0,08 & 1,7 & 0,0557 \\
\hline $\mathrm{Ca}$ & 0,52 & 0,33 & 1,58 & 0,19 & 1,7 & 0,0672 \\
\hline $\mathrm{Al}$ & 0,42 & 0,46 & 2,09 & 0,01 & 1,37 & 0,0604 \\
\hline $\mathrm{Cl}^{-}$ & 0,37 & 0,53 & 2,4 & 0,01 & 1,21 & 0,0215 \\
\hline $\mathrm{Ca}^{+}$ & 0,35 & 0,2 & 0,99 & 0,05 & 1,14 & 0,0277 \\
\hline $\mathrm{K}^{+}$ & 0,26 & 0,18 & 0,79 & 0,01 & 0,85 & 0,0136 \\
\hline $\mathrm{Cl}$ & 0,23 & 0,63 & 4,56 & 0 & 0,75 & 0,0905 \\
\hline Oxalato & 0,2 & 0,2 & 0,76 & 0 & 0,65 & 0,0154 \\
\hline Levoglucosano & 0,18 & 0,22 & 0,94 & 0,01 & 0,59 & 0,0163 \\
\hline Acetato & 0,12 & 0,15 & 0,9 & 0 & 0,39 & 0,0273 \\
\hline $\mathrm{Zn}$ & 0,11 & 0,1 & 0,6 & 0,03 & 0,36 & 0,0098 \\
\hline $\mathrm{Mg}^{2+}$ & 0,08 & 0,05 & 0,23 & 0,01 & 0,26 & 0,0048 \\
\hline WSP & 0,07 & 0,03 & 0,15 & 0,02 & 0,23 & 0,0308 \\
\hline $\mathrm{Cr}$ & 0,07 & 0,12 & 0,86 & 0 & 0,23 & 0,0095 \\
\hline $\mathrm{P}$ & 0,06 & 0,05 & 0,25 & 0 & 0,2 & 0,0236 \\
\hline Glicose/Xilose & 0,05 & 0,04 & 0,19 & 0,01 & 0,16 & 0,0109 \\
\hline Manitol & 0,05 & 0,04 & 0,14 & 0,01 & 0,16 & 0,0105 \\
\hline $\mathrm{Ti}$ & 0,05 & 0,05 & 0,26 & 0 & 0,16 & 0,0382 \\
\hline $\mathrm{Mg}$ & 0,04 & 0,02 & 0,14 & 0 & 0,13 & 0,0295 \\
\hline Arabitol & 0,03 & 0,02 & 0,11 & 0,01 & 0,1 & 0,0043 \\
\hline Formiato & 0,03 & 0,04 & 0,22 & 0 & 0,1 & 0,0058 \\
\hline Metanosulfonato & 0,03 & 0,02 & 0,09 & 0 & 0,1 & 0,003 \\
\hline Manosano & 0,02 & 0,02 & 0,11 & 0 & 0,07 & 0,0042 \\
\hline Succinato & 0,02 & 0,02 & 0,13 & 0 & 0,07 & 0,0037 \\
\hline Maleato $^{4}$ & 0,02 & 0,02 & 0,08 & 0 & 0,07 & 0,0017 \\
\hline $\mathrm{Cu}$ & 0,02 & 0,02 & 0,11 & 0 & 0,07 & 0,0123 \\
\hline $\mathrm{Pb}(\mathrm{ICP})^{5}$ & 0,01 & 0,01 & 0,03 & 0 & 0,03 & 0,0006 \\
\hline $\mathrm{Br}^{-}$ & 0,01 & 0 & 0,02 & 0,01 & 0,03 & 0,002 \\
\hline $\mathrm{NO}_{2}^{-}$ & 0,01 & 0 & 0,02 & 0 & 0,03 & 0,0027 \\
\hline $\mathrm{Mn}$ & 0,01 & 0,01 & 0,05 & 0 & 0,03 & 0,0039 \\
\hline $\mathrm{Br}$ & 0,01 & 0 & 0,03 & 0 & 0,03 & 0,006 \\
\hline $\mathrm{Pb}$ & 0,01 & 0,01 & 0,03 & 0 & 0,03 & 0,0079 \\
\hline As $(\mathrm{ICP})^{5}$ & 0 & 0 & 0 & 0 & 0 & 0,0001 \\
\hline $\mathrm{Se}(\mathrm{ICP})^{5}$ & 0 & 0 & 0,01 & 0 & 0 & 0,0003 \\
\hline
\end{tabular}




\begin{tabular}{|c|c|c|c|c|c|c|}
\hline $\mathrm{Sb}(\mathrm{ICP})^{5}$ & $\overline{0}$ & $\overline{0}$ & 0,01 & $\overline{0}$ & $\overline{0}$ & 0,0002 \\
\hline Galactosan & 0 & 0,01 & 0,04 & 0 & 0 & 0,0005 \\
\hline V & 0 & 0 & 0,01 & 0 & 0 & 0,002 \\
\hline $\mathrm{Ni}$ & 0 & 0,01 & 0,06 & 0 & 0 & 0,0016 \\
\hline $\mathrm{Se}$ & 0 & 0 & 0,01 & 0 & 0 & 0,0042 \\
\hline
\end{tabular}

1 elementos obtidos com o EDX (LAPAt) quando não sinalizado

2 foi feita a média e depois a porcentagem

$315 \%$ da concentração

${ }^{4}$ um outlier foi removido

5 analisado no ICP (DRI)

Os componentes que mais contribuíram para o $\mathrm{MP}_{10}$ foram o $\mathrm{OC}$, sulfato e EC. A contribuição média dos elementos para o $\mathrm{MP}_{10}$ foi de $25,3 \%$ se considerarmos os elementos não oxidados.

Foi feita a soma de todas as espécies medidas (na forma não oxidada), com exceção da forma iônica ou elementar quando havia repetição. As espécies usadas nessa análise foram $\mathrm{Al}$, $\mathrm{Si}, \mathrm{P}, \mathrm{Cl}, \mathrm{K}, \mathrm{Ca}, \mathrm{Ti}, \mathrm{V}, \mathrm{Cr}, \mathrm{Mn}, \mathrm{Fe}, \mathrm{Ni}, \mathrm{Cu}, \mathrm{Zn}, \mathrm{Se}, \mathrm{Br}, \mathrm{Pb}, \mathrm{Na}^{+}, \mathrm{NH}_{4}{ }^{+}, \mathrm{NO}_{3}{ }^{-}, \mathrm{SO}_{4}{ }^{2-}, \mathrm{Mg}^{2+}$ e Carbono total (soma do OC e EC) e representou $65 \pm 11 \%$ da massa do $\mathrm{MP}_{10}$.

A reconstrução da massa do $\mathrm{MP}_{10}$ foi calculada considerando uma adaptação das equações propostas em Chow et al. (2015). Segundo Chow et al. (2015), a reconstrução de massa pode ser utilizada para três fins: identificar e corrigir potenciais erros, entender a variação temporal e espacial da composição química e entender a contribuição das fontes do MP e sua contribuição para a extinção da radiação.

Os elementos considerados para a reconstrução da massa (MR) foram os analisados com o EDX (filtro de policarbonato) e os íons obtidos da cromatografia de íons (Dionex) nos filtros de quartzo. $\mathrm{O}$ balanço final pode ser observado na tabela 12, o qual se assemelha à equação 5 apresentada em Chow et al. (2015), com algumas diferenças. A série temporal da concentração em massa do $\mathrm{MP}_{10}$ calculada pela gravimetria, a soma das espécies e equação final da reconstrução da massa é apresentada na figura 9.

Tabela 12. Formulação para a reconstrução da massa e todos os compostos químicos e espécies consideradas

\begin{tabular}{ll}
\hline Componentes químicos & Equação \\
Íons inorgânicos & $\mathrm{SO}_{4}{ }^{--}+\mathrm{NO}_{3}{ }^{-}+\mathrm{NH}_{4}{ }^{+}$ \\
Matéria orgânica & $1,5 \times \mathrm{OC}$ \\
Carbono elementar & $1 \times \mathrm{EC}$ \\
Minerais geológicos & $1,89 \mathrm{Al}+2,14 \mathrm{Si}+1,4 \mathrm{Ca}+1,43 \mathrm{Fe}$ \\
Sais & $\mathrm{Na}^{+}+\mathrm{Cl}^{-}$ \\
Elementos traço & $M g+P+K+\mathrm{Ti}+\mathrm{V}+\mathrm{Cr}+\mathrm{Mn}+\mathrm{Ni}+\mathrm{Cu}+\mathrm{Zn}+\mathrm{Se}+\mathrm{Br}+\mathrm{Pb}$ \\
\hline
\end{tabular}




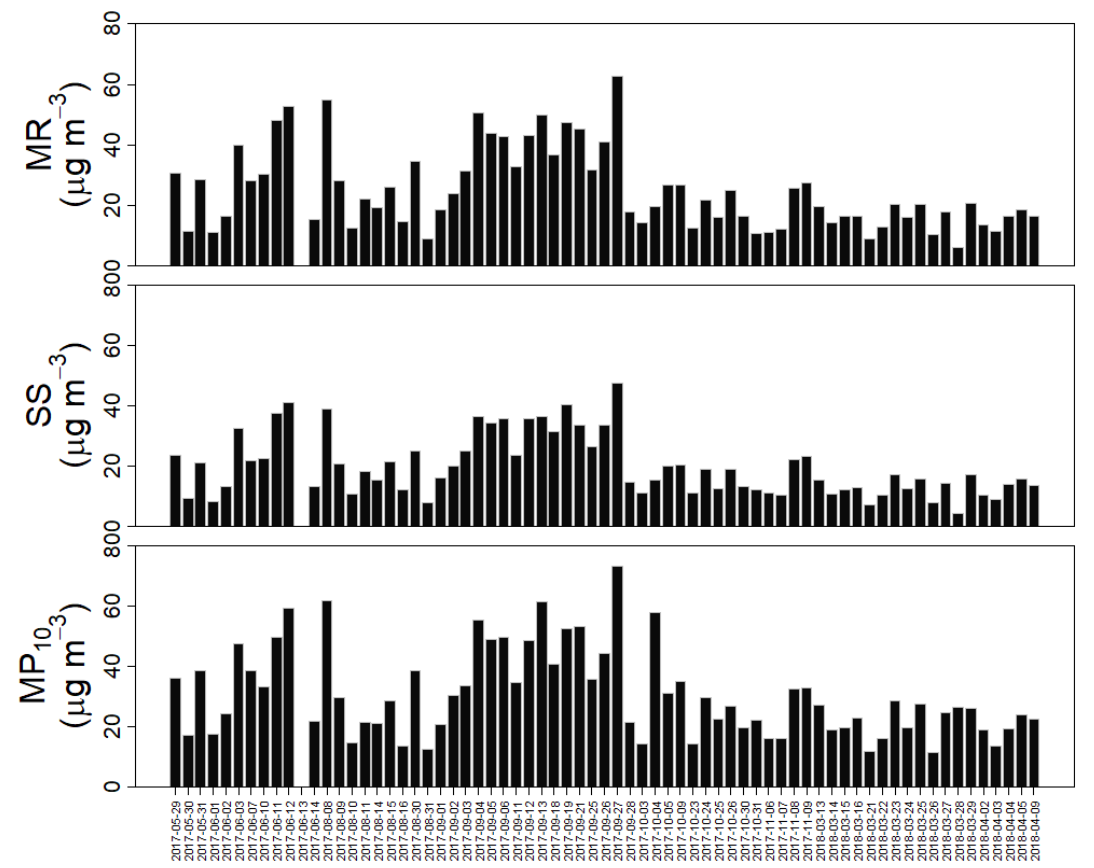

Figura 9. Serie temporal da reconstrução da massa (MR), soma das espécies (SS) e massa do MP 10 calculada pela gravimetria.

A MR representou $80 \pm 14 \%$ da massa do $\mathrm{MP}_{10}$, sendo que o restante da massa do $\mathrm{MP}_{10}$ que não foi contabilizada ( 20\%), pode estar associada com compostos não medidos ou ainda fatores e artefatos como umidade e perda ou adição de compostos voláteis (Chow et al., 2015). Deve-se ainda considerar que os compostos foram medidos em dois tipos de filtros diferentes, o que pode resultar em uma diferença na concentração dos componentes. Existe uma correlação positiva e significativa entre a massa do $\mathrm{MP}_{10}$, a reconstrução de massa e a soma das espécies $(\rho>0,9)$, o que significa que mesmo com as incertezas e diferenças na metodologia, são similares.

A contribuição em porcentagem de cada componente da MR para o $\mathrm{MP}_{10}$ está indicada na figura 10. A matéria orgânica $(\mathrm{OM})$ é o componente que mais contribui para a massa do $\mathrm{MP}_{10}$, seguido dos íons orgânicos, e minerais geológicos, sendo $\sim 20 \%$ da massa do $\mathrm{MP}_{10}$ desconhecida. 


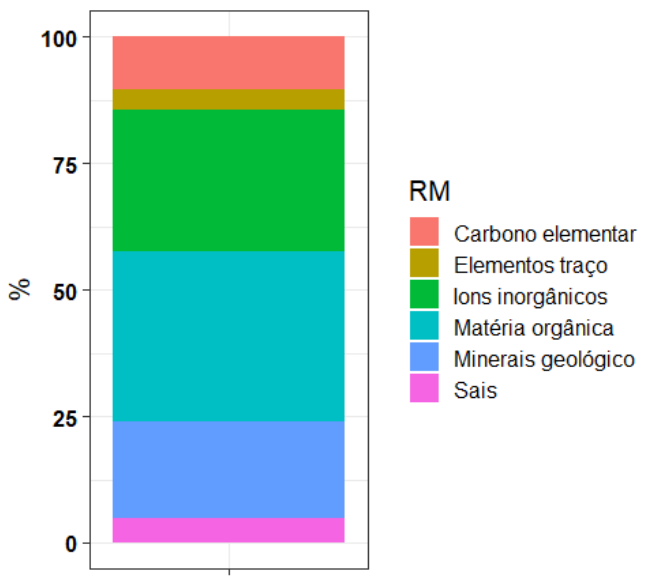

Figura 10. Contribuição proporcional dos componentes da reconstrução da massa para o $\mathrm{MP}_{10}$.

A reconstrução da massa, soma das espécies e massa do $\mathrm{MP}_{10}$ apresentaram maior concentração no inverno, no mês de setembro e em 2017 (Figura 11). Os seis componentes da reconstrução da massa apresentaram maiores concentrações em 2017, provavelmente porque em 2018 só foram considerados os meses de março e abril, representando o outono, no qual houve uma elevada umidade e a segunda estação (considerando o período amostrado) com maior precipitação acumulada. O carbono elementar, matéria orgânica e os sais apresentaram maiores concentrações no outono de 2017, seguido pelo inverno de 2017 (Figura 12). Os íons inorgânicos e minerais geológicos apresentaram maiores concentrações no inverno e em setembro de 2017 e menores no outono de 2018. Os elementos traços, de fontes variadas, tiveram maiores concentrações no inverno e outono de 2017 , sendo setembro e junho os meses com maiores concentrações. 

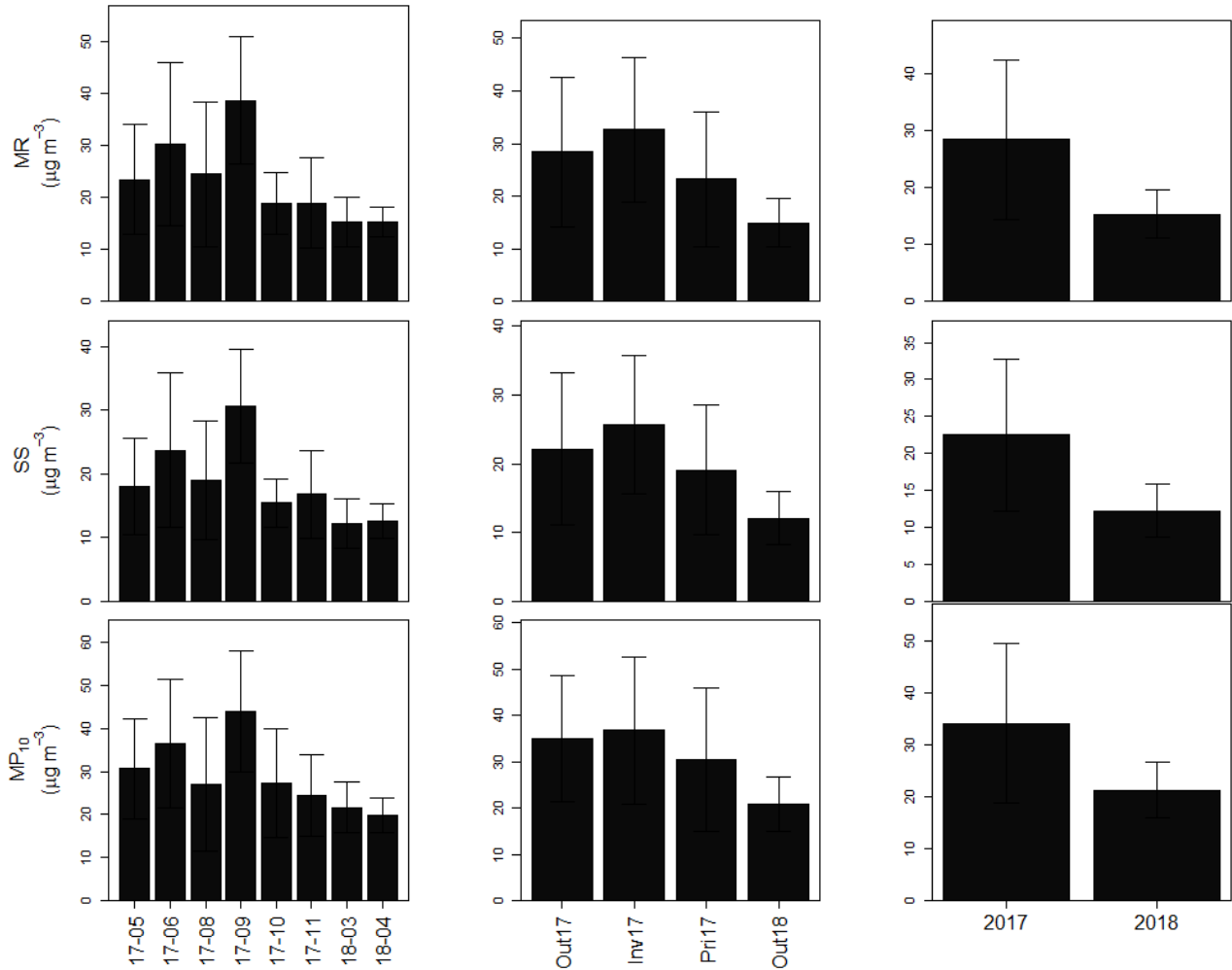

Figura 11. Variação mensal, sazonal e anual da reconstrução da massa (MR), soma das espécies (SS) e da massa do $\mathrm{MP}_{10}$ obtida por gravimetria. 

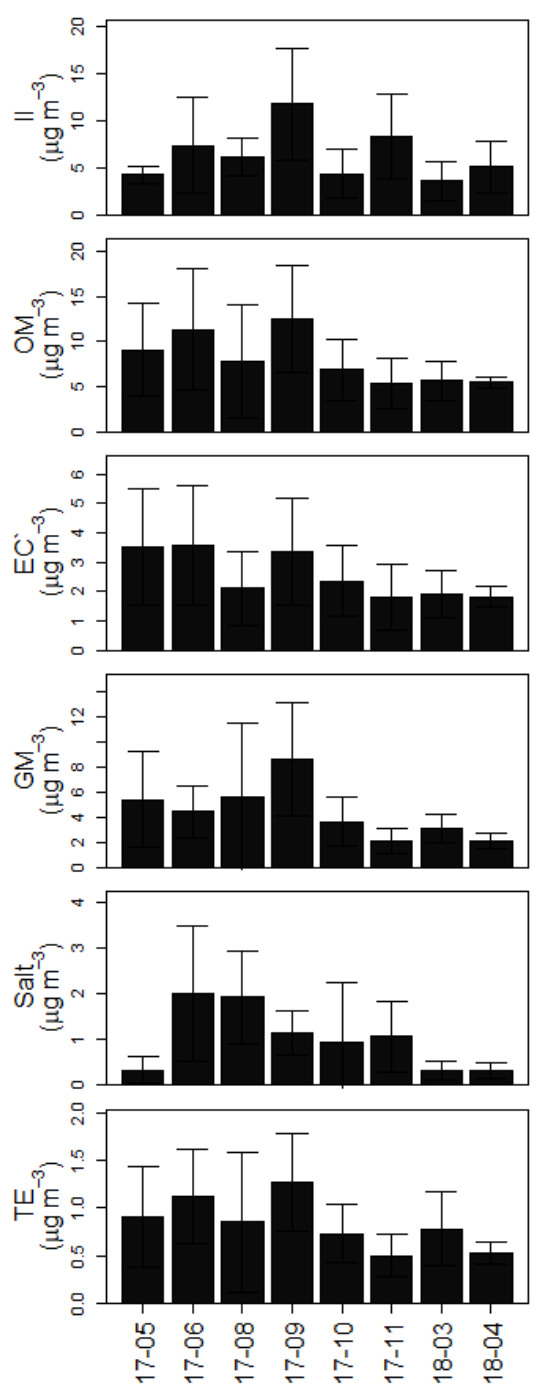
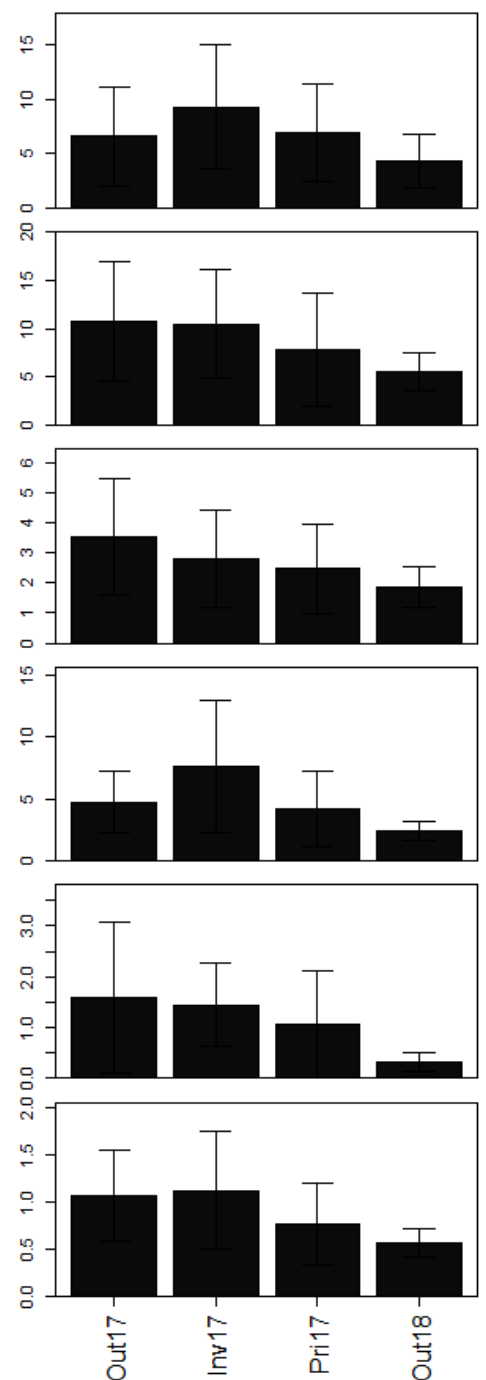
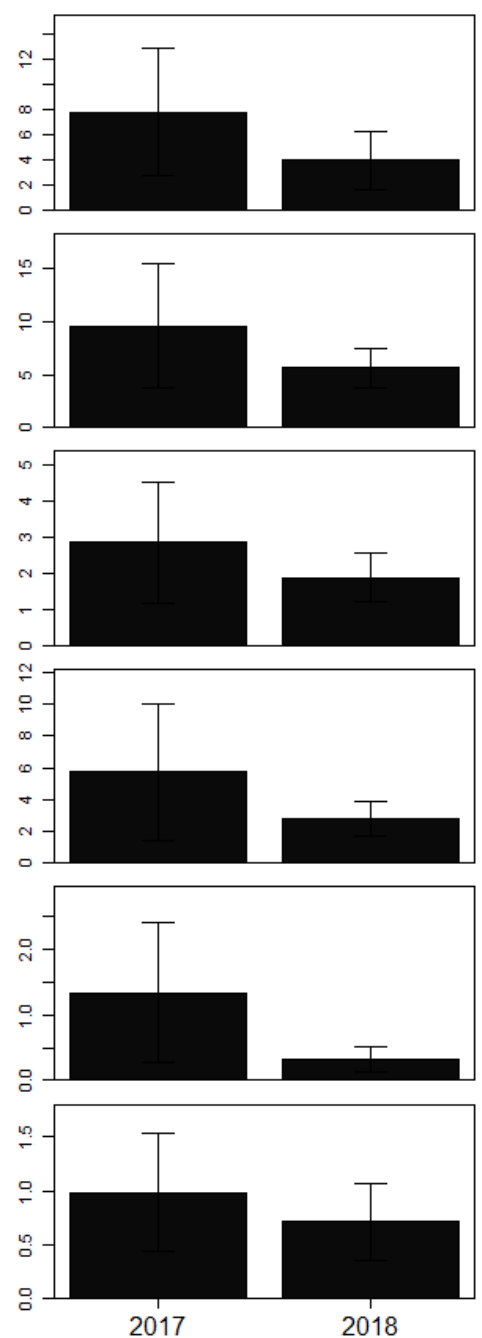

Figura 12. Variação sazonal, mensal e anual dos componentes da reconstrução de massa.

Legenda: Íons inorgânicos (II), Matéria orgânico (OM), Carbono elementar (EC), Minerais geológicos (GM), Sais (Salt), Elementos traços (TE).

A contribuição sazonal para o MP 10 dos componentes da $\mathrm{MR}$ foi no geral semelhante em todas as estações (Figura 13). Deve-se destacar a contribuição dos minerais geológicos para o $\mathrm{MP}_{10}$ que foi maior no inverno $(20,7 \%)$ comparada com a menor concentração no outono de 2018 com 11,4\%. Os componentes matéria orgânica, sais e carbono elementar, contribuíram mais para o $\mathrm{MP}_{10}$ no outono de 2017 , enquanto os minerais geológicos e íons inorgânicos contribuíram mais para o $\mathrm{MP}_{10}$ no inverno. Novamente os elementos traço tiveram uma contribuição para o MP 10 semelhante no outono e no inverno de 2017. O outono de 2018, apresentou a maior porcentagem do componente desconhecidos (indefinida), indicando maior contribuição dos artefatos ou maior presença de compostos não medidos. 
Outono 2017

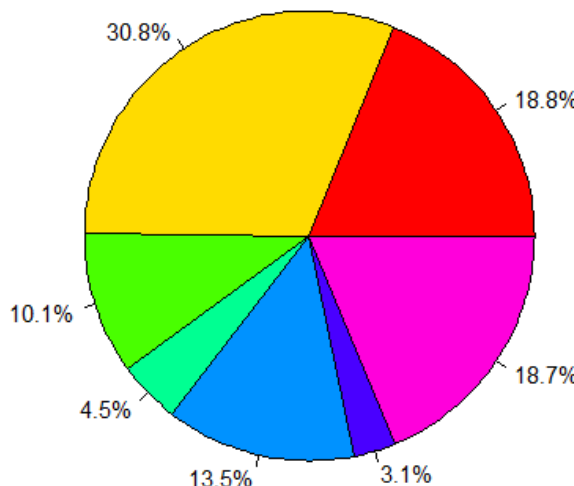

Primavera 2017

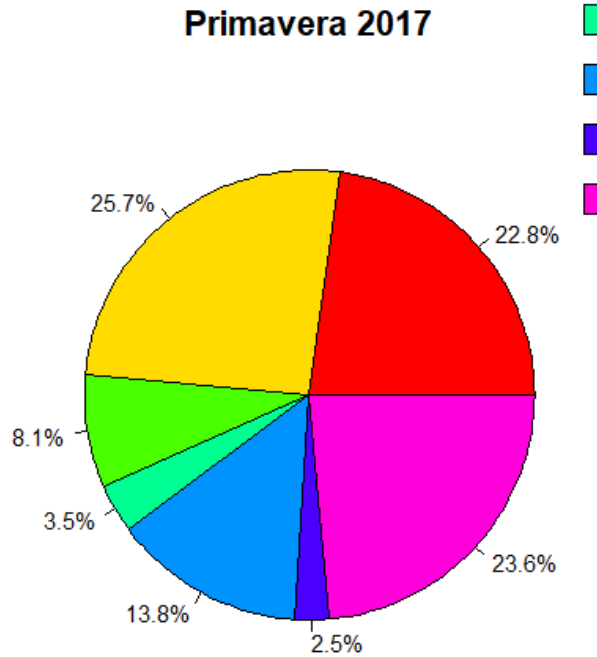

Inverno 2017

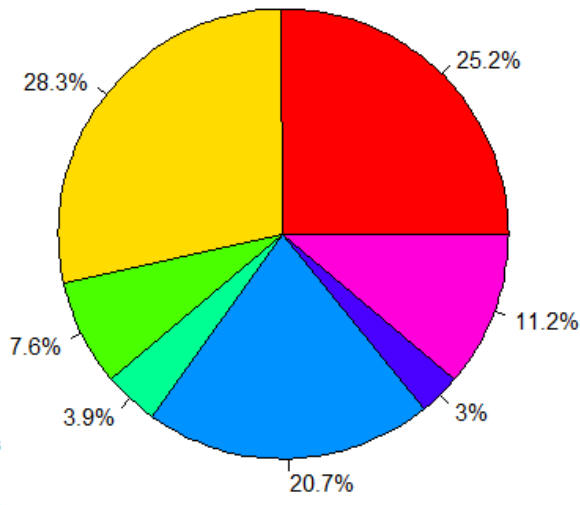

Outono 2018

Minerais geológicos

Elementos traço

Indefinida

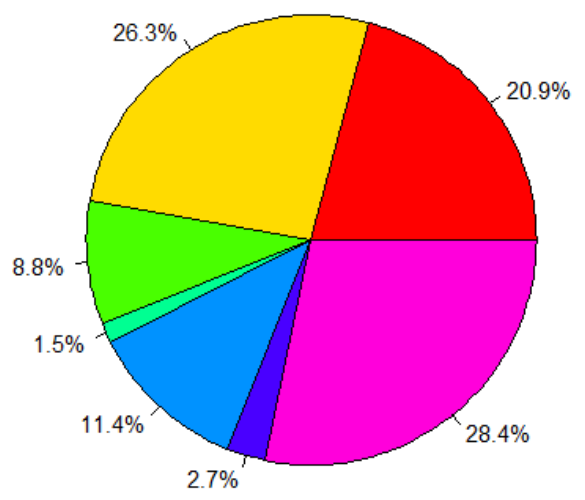

Figura 13. Contribuição percentual sazonal dos componentes da reconstrução da massa para o $\mathrm{MP}_{10}$.

Como esperado, a matéria orgânica, foi o componente da MR que mais contribuiu para a massa do $\mathrm{MP}_{10}$, seguida dos íons inorgânicos. A importância do OC para o MP na RMSP foi enfatizada por Miranda e Andrade (2005), que analisou o $\mathrm{MP}_{2,5}$ e encontrou que o OC foi o composto dominante, seguido do black carbon, dos componentes do solo e dos elementos associados com a emissão industrial. Castanho e Artaxo (2001) também observaram que o OC foi o que mais contribuiu para o PM, seguido pelo black carbon, sulfatos e componentes do solo. Outros estudos também mostraram a importância do OM para a concentração de MP no RMSP (Andrade et al., 2012; Albuquerque et al., 2012; Pereira et al., 2017). Contudo, apesar do $\mathrm{OM}$ representar a maior parte da massa, poucos estudos nessa região examinaram sua especiação, apesar de alguns terem quantificado o OC. 
Segundo o relatório da CETESB (2019b), as fontes de $\mathrm{MP}_{10}$ e suas respectivas contribuições em porcentagem para o $\mathrm{MP}_{10}$ na região metropolitana de São Paulo são: veículos pesados $(31,7 \%)$, seguido da ressuspensão do solo (25\%) e aerossol secundário (25\%), processos industriais (10\%), veículos leves $(6,7 \%)$ e motocicletas (1,7\%). Em uma análise da poeira de rua/pavimento feita no mesmo local de coleta desse trabalho (IAG/USP) utilizando uma câmara de ressuspensão, foi observado que esta apresenta principalmente $\mathrm{Al}_{2} \mathrm{O}_{3}, \mathrm{SiO}_{2}$, $\mathrm{Fe}_{2} \mathrm{O}_{3}, \mathrm{~K}_{2} \mathrm{O}, \mathrm{CaCO}_{3}$ e $\mathrm{MgO}$ (Hetem et al., 2016). O Cu é considerado um traçador da emissão de veículos leves enquanto o sulfato e BC são traçadores de veículos principalmente pesados (Sánchez-Ccoyllo et al., 2008; Hetem et al., 2016). O Zn é adicionado em aditivos e lubrificantes na gasolina e pode estar presente no etanol devido ao armazenamento, transporte ou produção deste (Silva et al., 2010). Silva et al. (2010) mostraram que as maiores taxas de emissão de elementos inorgânicos para a exaustão de veículos utilizando gasool (gasolina com 22 a $25 \%$ de etanol) são de $\mathrm{Fe}, \mathrm{S}, \mathrm{Al}, \mathrm{Si}, \mathrm{Br}, \mathrm{Zn}$ e P nessa ordem, enquanto para o etanol os elementos com a maior emissão são $\mathrm{Fe}, \mathrm{S}, \mathrm{Ca}, \mathrm{Br}$ e Si, nessa ordem. Notar que outros elementos também estavam presentes tanto na exaustão de veículos a gasool ou etanol, mas com uma taxa de emissão média menor. Silva et al. (2010) também mostraram que a gasolina emite mais partículas do que o etanol (3 vezes mais). Segundo Adachi e Tainosho (2004), o desgaste do pneu tem como principal metal traçador o $\mathrm{ZnO}$, enquanto o pó de freio (brake dust) é caracterizado pela presença de $\mathrm{Fe}, \mathrm{Cu}, \mathrm{Zr}, \mathrm{Sb}$ e $\mathrm{Ba}$. A tinta amarela presente na estrada para sinalização, apresenta $\mathrm{Cr}$ e $\mathrm{Pb}$ como principais metais pesados e a poeira do pneu (tire dust) o Al, Si, K, Ca e em menor escala Fe, S, Mg e Zn (Adachi e Tainosho, 2004). Alves et al. (2020), utilizando um simulador de rua, observaram que o $\mathrm{S}$ e o $\mathrm{Zn}$, são os elementos presentes predominantemente nos fragmentos de pneu seguidos de $\mathrm{Na}, \mathrm{Al}$ e $\mathrm{Ca}$, enquanto no $\mathrm{MP}_{10}$ coletado, os elementos predominantes foram $\mathrm{Al}, \mathrm{Ca}, \mathrm{Na}, \mathrm{Fe}$ e $\mathrm{K}$ e o $\mathrm{OC}$ representou $10 \%$ da massa total.

\subsubsection{Compostos carbonáceos}

O carbono negro (black carbon - BC) é um material carbonáceo que tem algumas características como ser insolúvel em água e em alguns solventes orgânicos, manter a sua estrutura básica mesmo em temperaturas elevadas, apresentar uma morfologia agregada e absorver luz visível (Bond, 2013). O EC (carbono elementar) é medido através de um processo térmico e oxidativo indicando a concentração de carbono como uma estrutura de grafite que é termicamente refratário (Salako et al., 2012). O BC é determinado através de sua capacidade de absorver radiação visível, incluindo o EC e parte do carbono orgânico absorvedor. 
A concentração de EC obtida com um analisador de carbono termo/óptico e o BC, obtido com o refletômetro teve uma alta correlação de Pearson de $r=0,93(p<0,05)(\rho=0,91$ para a correlação de Spearman), e uma equação da reta “ $y=-0,3467 x+1,6793$ ”. A razão BC/EC média apresentou um valor de 1,64, indicando que o BC na média apresenta concentrações maiores do que o EC. Essa concentração mais elevada do BC comparada ao EC também foi observada por Salako et al. (2012) na maioria dos países analisados (6 locais em 5 países comparando com um total de 9 locais em 8 países). Uma vez que a medida utilizada nesse trabalho para medir o BC apresenta muitas incertezas resultantes do trabalho manual envolvido e que o EC é mais comumente reportado nos trabalhos que envolve análise dos compostos orgânicos, os dados apresentados nesse trabalho utilizaram apenas os valores de EC.

O aerossol carbonáceo total (TCA) calculado através da soma da OM (1,5xOC) com o EC (Ram e Sarin, 2011), representou 35,6\% do $\mathrm{MP}_{10}$. A razão média para OC/EC foi de 2,2 (faixa 1,2- 4,8), TC/EC foi de 3,2 (faixa 2,2-5,8) e OC/TC foi de 0,7 (faixa 0,5-0,8), sem apresentar muita diferença entre as estações do ano (Tabela 13). Várias conclusões podem ser obtidas dessas razões. Valores elevados da razão OC/TC pode ser indicativo de queima de biomassa $(0,88)$, enquanto valores mais baixos $(0,52)$ indicam emissão veicular (Sandradewi et al., 2008). Como o valor observado nesse trabalho para o OC/TC foi 0,7 , não se pode chegar a nenhuma conclusão definitiva. Pio et al. (2011) em uma revisão de diversos artigos apontou que na Europa as emissões de queima de combustíveis em veículos apresentaram um valor de OC/EC que variou entre 0,3 e 0,4. Ao mesmo tempo, valores da razão OC/EC maiores do que 2, podem ser um indicativo da presença de aerossol orgânico secundário (Chow et al., 1996). Contudo, como apontado por Na et al. (2004) a suposição de que valores altos de OC/EC indicam aerossol orgânico secundário deve ser feita com cautela. Assim, entende-se que o valor de 2,2 para a razão OC/EC observada nesse trabalho indica a presença de aerossol orgânico secundário na amostra. Os valores encontrados nesse trabalho são semelhantes ao observado por Caumo et al. (2016) em São Paulo no inverno de 2012 e 2013.

Alguns autores sugerem para compreender melhor as fontes de emissão analisar as razões $\mathrm{K}^{+} / \mathrm{OC}$ e K/EC (Ram e Sarin, 2011; 2010). De acordo com esses autores o $\mathrm{K}^{+}$é emitido pela queima de biomassa (além de outras fontes como solo e sal marinho), mas sua emissão por combustíveis fosseis é insignificante. Em contrapartida, o OC e EC são emitidos pelos veículos e pela queima de biomassa. Contudo, Andreae (1983) afirma que o $\mathrm{K}_{\text {excess }}$ apresenta como única fonte a combustão da biomassa, enquanto o potássio no material particulado fino pode também apresentar uma origem na combustão de combustíveis fósseis. De acordo com Ram e Sarin (2011), um valor da razão $\mathrm{K}^{+} / \mathrm{OC}$ de 0,04 igual as apresentadas nesse trabalho (Tabela 13) 
indica a queima de biomassa. Ademais, uma razão $\mathrm{K}^{+} / \mathrm{EC}$ elevada indica queima de biomassa e baixa indica emissão de combustíveis fósseis (Ram e Sarin, 2011; Ram e Sarin, 2010). Observa-se que o valor médio apresentado nesse trabalho para o $\mathrm{K}^{+} / \mathrm{EC}$ é baixo $(0,10)$, sendo então possivelmente indicativo de emissão a partir de combustíveis fósseis. Apesar disso, o $\mathrm{K}^{+}$ também pode ser originário de fontes como solo e sal marinho. Considerando que a concentração de potássio proveniente do sal marinho pode ser calculada pela fórmula $(0,036 \mathrm{x}$ $\mathrm{Na}^{+}$, Nayebare et al., 2016), o valor das razões nssK ${ }^{+} / \mathrm{OC}$ e nssK ${ }^{+} / \mathrm{EC}$ são muito parecidas com os valores da razão $\mathrm{K}^{+} / \mathrm{OC}$ e $\mathrm{K}^{+} / \mathrm{EC}(0,04$ e 0,09 , respectivamente).

Para compreender melhor os dados, o carbono orgânico primário (POC) e carbono orgânico secundário (SOC) foram calculados. O POC foi calculado considerando o valor mínimo da razão OC/EC $(1,2)$ multiplicado pela concentração de EC, enquanto o SOC foi calculado subtraindo da concentração de OC o valor de POC (Na et al., 2004; Ram e Sarin, 2011; Castro et al., 1999). Os resultados médios obtidos foram: POC com 3,12 $\mu \mathrm{g} / \mathrm{m}^{3}$ e SOC com 2,59 $\mu \mathrm{g} / \mathrm{m}^{3}$ (Tabela 13), indicando uma contribuição mais acentuada de carbono orgânico primário do que secundário. Isso representa que o SOC contribui com 43\% do OC, valor semelhante ao obtido em Kanpur (sítio urbano) por Ram e Sarin (2011). Uma concentração mais elevada de SOC foi observada no inverno de 2017 e de POC no outono de 2017. Essa elevada concentração de SOC no inverno não coincide com o observado em outros trabalhos, onde as maiores concentrações de SOC ocorreram no verão ou durante o dia, onde há elevada atividade fotoquímica (Na et al., 2004; Ram e Sarin, 2011). Essa elevada concentração de SOC no inverno é possivelmente uma consequência das condições atmosféricas do inverno na região, com uma camada limite mais baixa, com piores condições para dispersão dos poluentes e baixa precipitação o que resulta no acúmulo de poluentes próximos à superfície incluindo compostos orgânicos precursores do SOC. Outros compostos que têm como principal fonte a formação secundária como o oxalato, acetato e formiato também apresentaram maiores concentrações no inverno. Em contrapartida, a elevada concentração do POC no outono de 2017 coincide com as elevadas concentrações observadas para alguns açúcares (Figura 14).

Tabela 13. Razões entre carbono orgânico (OC), carbono elementar (EC), carbono total (TC) e $\mathrm{K}^{+}$, além da concentração de POC e SOC em $\mu \mathrm{g} / \mathrm{m}^{3}$ considerando as estações do ano e a média total do período.

\begin{tabular}{llllllll}
\hline & OC/EC & TC/EC & OC/TC & $\mathrm{K}^{+} / \mathrm{OC}$ & $\mathrm{K}^{+} / \mathrm{EC}$ & $\begin{array}{l}\mathrm{POC} \\
\left(\mu \mathrm{g} / \mathrm{m}^{3}\right)\end{array}$ & $\begin{array}{l}\mathrm{SOC} \\
\left(\mu \mathrm{g} / \mathrm{m}^{3}\right)\end{array}$ \\
\hline Outono 2017 & 2,09 & 3,09 & 0,67 & $0,05( \pm 0,02)$ & 0,11 & 4,25 & 2,93 \\
& $( \pm 0,63)$ & $( \pm 0,63)$ & $( \pm 0,06)$ & & $( \pm 0,04)$ & $( \pm 2,33)$ & $( \pm 2,55)$ \\
Inverno & 2,56 & 3,56 & 0,71 & $0,06( \pm 0,02)$ & 0,15 & 3,36 & 3,60 \\
& $( \pm 0,71)$ & $( \pm 0,71)$ & $( \pm 0,05)$ & & $( \pm 0,06)$ & $( \pm 1,97)$ & $( \pm 2,13)$ \\
Primavera & 2,11 & 3,11 & 0,67 & $0,04( \pm 0,02)$ & 0,08 & 2,96 & 2,26 \\
& $( \pm 0,35)$ & $( \pm 0,35)$ & $( \pm 0,04)$ & & $( \pm 0,02)$ & $( \pm 1,81)$ & $( \pm 2,19)$ \\
\hline
\end{tabular}




\begin{tabular}{llllllll}
\hline Outono 2018 & 2,03 & 3,03 & 0,67 & $0,03( \pm 0,02)$ & 0,06 & 2,22 & 1,44 \\
& $( \pm 0,38)$ & $( \pm 0,38)$ & $( \pm 0,04)$ & & $( \pm 0,03)$ & $( \pm 0,81)$ & $( \pm 0,66)$ \\
Média (Todo o período) & 2,24 & 3,24 & 0,68 & 0,04 & 0,10 & 3,12 & 2,59 \\
& $(1,20-$ & $(2,20-$ & $(0,55-$ & $(0,01-0,1)$ & $(0,01-$ & $(0,49-$ & $(0,0-$ \\
& $4,82)$ & $5,82)$ & $0,83)$ & & $0,27)$ & $7,99)$ & $10,12)$ \\
\hline
\end{tabular}

Como observado na figura 14, a maioria dos componentes do OC (açucares e ácidos orgânicos), com exceção dos álcoois de açúcares, apresentaram uma diminuição na concentração no outono de 2018. Nessa estação, observa-se elevada precipitação, umidade relativa e temperatura, e a direção predominante do vento é de nordeste ao invés de sudeste como as outras estações. No geral, os ácidos orgânicos apresentaram maior concentração no inverno, seguido pela primavera de 2017 (o metano-sulfonado apresentou no outono de 2017 sua segunda maior concentração). Os carboidratos apresentaram um comportamento diferente, sendo o levoglucosano e manosano, assim como o OC, EC com maiores concentrações no outono de 2017 seguido pelo inverno, primavera e outono de 2018. Os outros carboidratos como arabitol, glicose e manitol bem como as proteínas solúveis em água apresentaram maiores concentrações no outono de 2018.

Os compostos com maiores concentrações médias são o oxalato, levoglucosano e acetato, respectivamente. A soma de todos esses compostos orgânicos (acetato, formiato, succinato, maleato, MSA, oxalato, arabitol, manitol, glicose/xilose, levoglucosano, manosano) representa apenas $\sim 13,4 \%$ do OC, contudo essa porcentagem varia em relação aos dias amostrados, podendo chegar a mais de 50\% da massa do OC (Figura 15). 
73
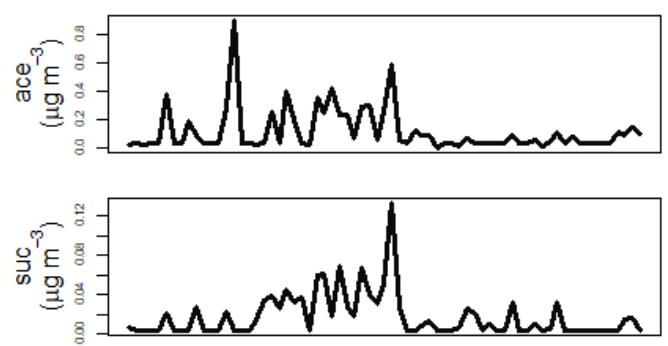

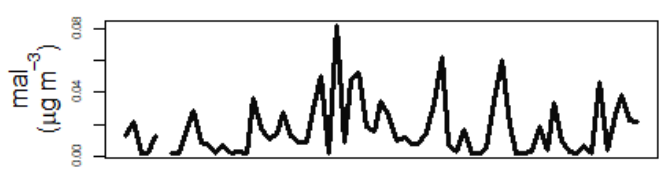

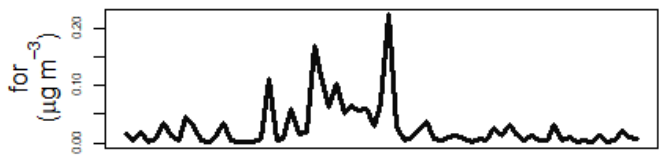

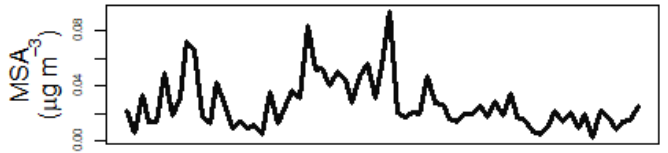
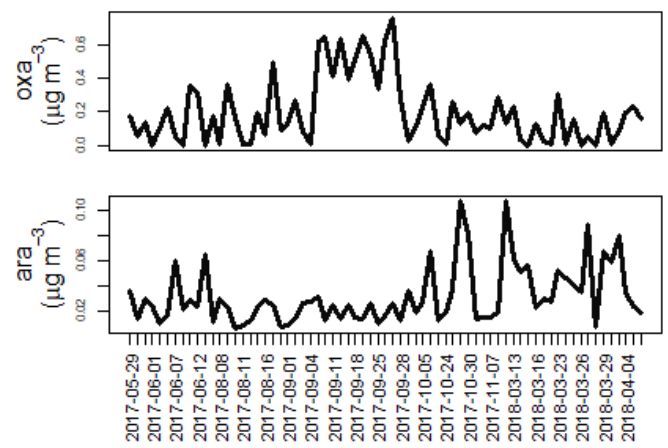
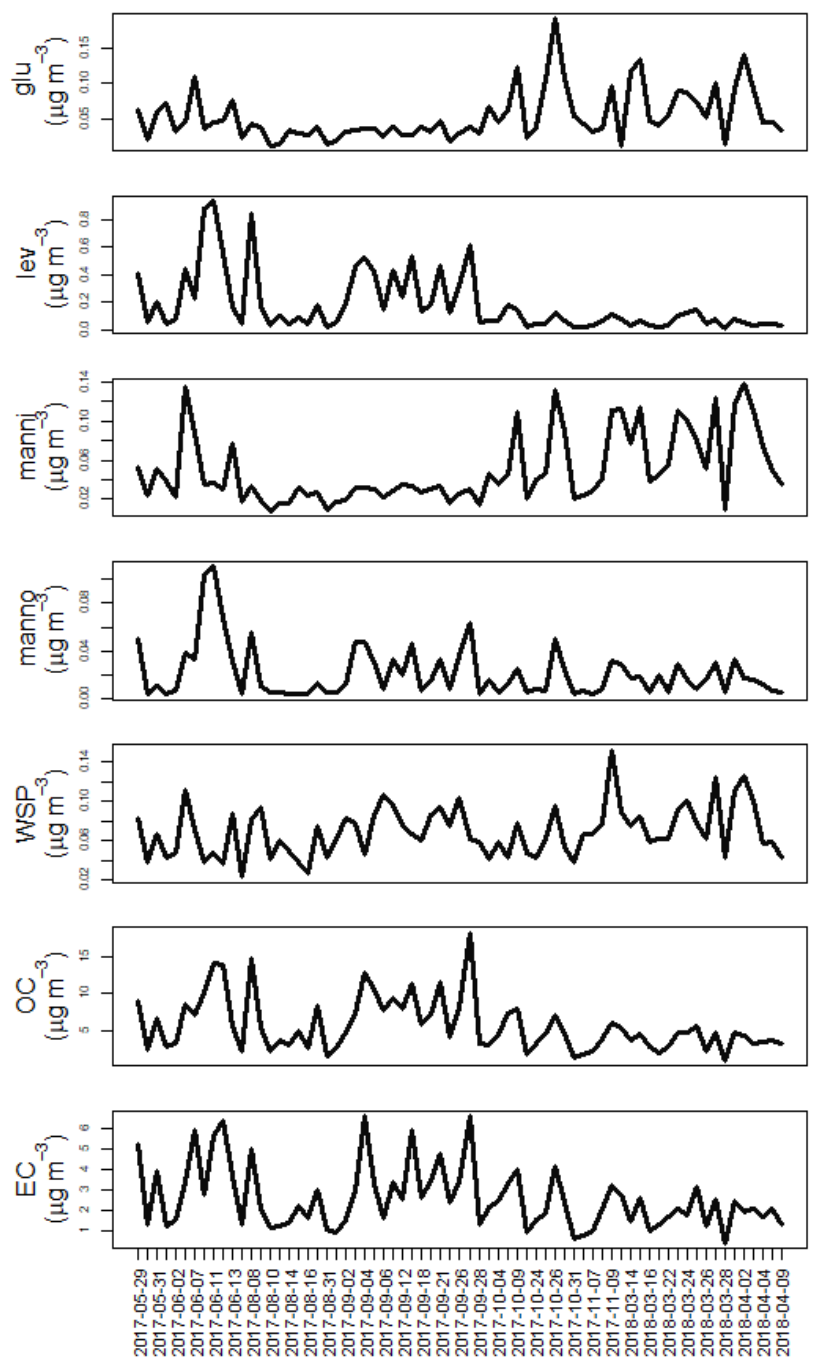

Figura 14. Série temporal da concentração dos compostos orgânicos e carbono elementar. Legenda: ace (acetato), suc (succinato), mal (maleato), for (formiato), MSA (metanesulfonato), oxa (Oxalato), ara (arabitol), glu (glicose/xilose), lev (levoglucosano), manni (manitol), manno (manosano), WSP (proteínas solúveis em água), OC (carbono orgânico), EC (carbono elementar).

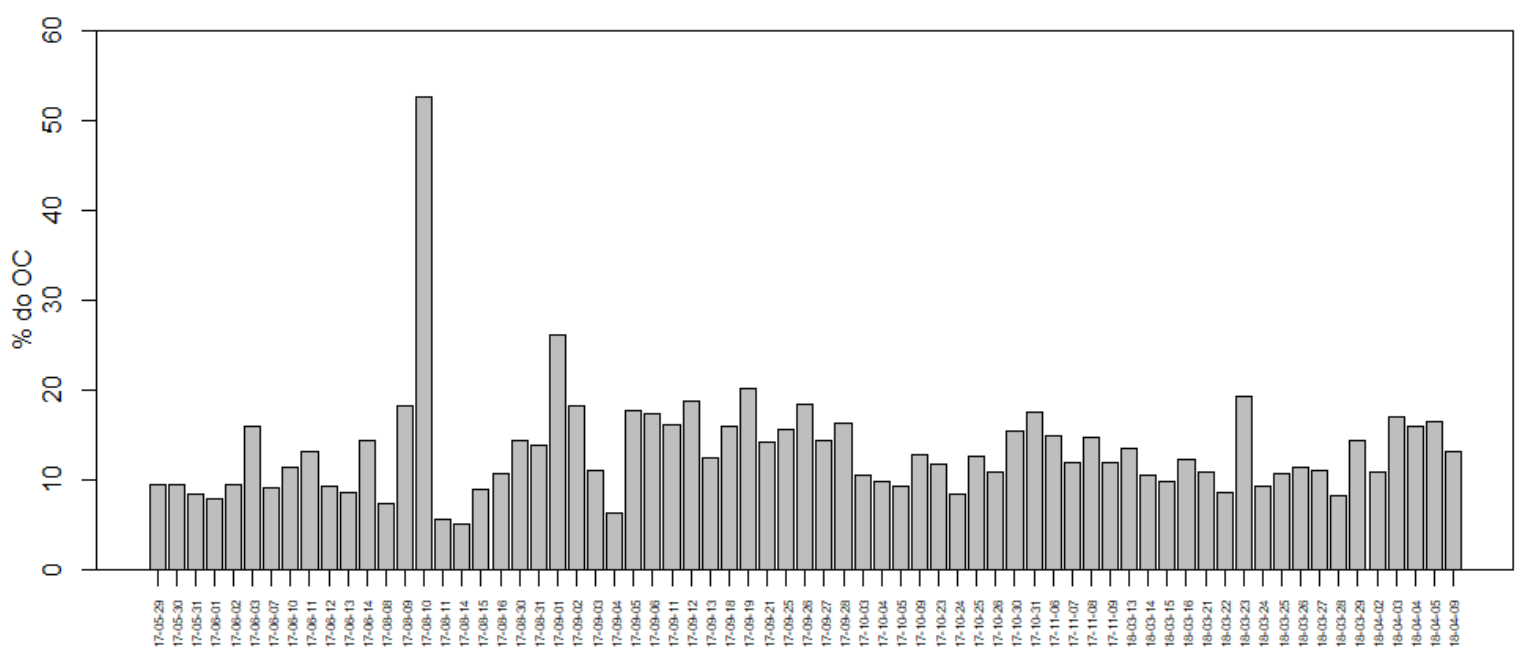

Figura 15. Porcentagem da contribuição da soma dos compostos orgânicos (acetato, formiato, succinato, maleato, MSA, oxalato, arabitol, manitol, glicose/xilose, levoglucosano, manosano) para o OC durante o período amostrado. 
Os ácidos orgânicos geralmente apresentam uma correlação de Spearman significativa entre si, levoglucosano e manosano também se correlacionam entre si, bem como o manitol, arabitol, glicose e proteínas solúveis (Figura 16). O ácido orgânico MSA também se correlaciona com os anidroaçúcares, enquanto o carbono orgânico se correlaciona significativamente com todos os compostos orgânicos menos com o maleato e glicose enquanto o EC apenas não se correlaciona com o maleato. A correlação de Pearson entre os compostos orgânicos e as frequências por dia das diferentes direções do vento, considerando todo o período amostrado, está apresentada na figura C IV.

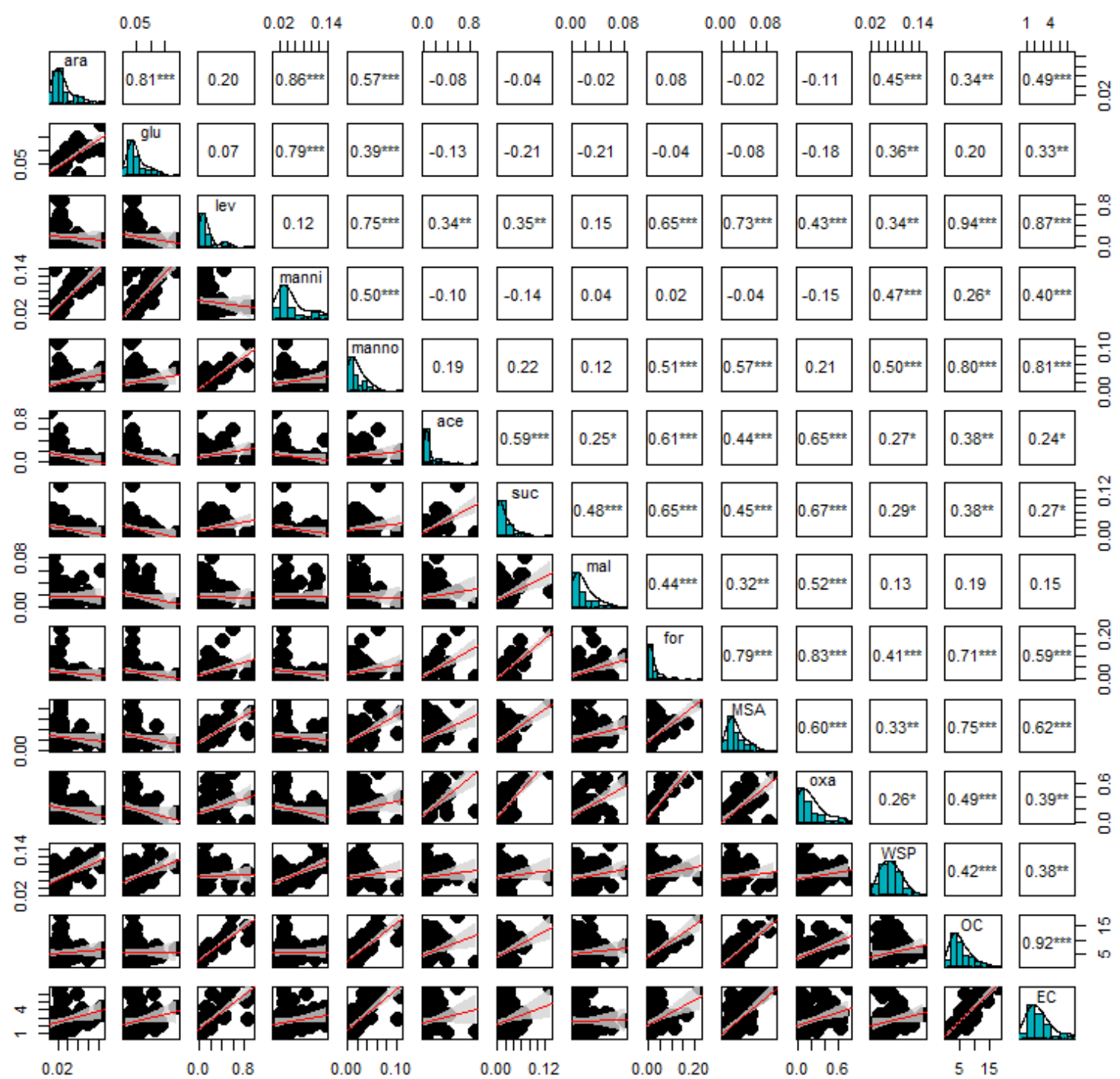

Figura 16. Correlação de Spearman entre os compostos orgânicos e o EC.

Legenda: Os valores na parte superior do gráfico indicam o coeficiente da correlação de Spearman, enquanto o gráfico de dispersão na parte inferior da figura apresenta o ajuste de regressão linear. ace (acetato), suc (succinato), mal (maleato), for (formiato), MSA (metanosulfonato), oxa (oxalato), ara (arabitol), glu (glicose/xilose), lev (levoglucosano), manni (manitol), manno (manosano), WSP (proteínas solúveis em água), OC (carbono orgânico), EC (carbono elementar).

$*$ indica $\mathrm{p}<0,05, * *$ indica $\mathrm{p}<0,01 \mathrm{e} * * *$ indica $\mathrm{p}<0,001$. 
As concentrações de cada rampa de temperatura, da análise com o analisador de carbono óptico/térmico de comprimento de onda múltiplo, para os carbonos (OC e EC) está apresentada na Tabela B. III, enquanto a correlação destes com alguns compostos orgânicos está apresentada na Figura C V. Moléculas com alto peso molecular e com vários ramos necessitam uma temperatura mais elevada para serem decompostas, quando comparado com uma molécula simples com baixo peso molecular (Alves et al., 2020). Os compostos orgânicos analisados apresentam um baixo peso molecular e são moléculas relativamente pequenas entre C5-C6. O levoglucosano e o manosano são os compostos que melhor se correlacionaram com os OC1 ao EC1. Todos os ácidos orgânicos quando se correlacionavam com as rampas de carbono, se correlacionava apenas até o EC1, e entre eles o formiato e MSA se correlacionaram melhor. O arabitol, manitol, glicose se correlacionam melhor com as rampas do EC (incluindo a EC3) do que com as do OC. Isso significa, que no geral, a maioria dos compostos orgânicos analisados se correlacionam melhor com compostos de carbono com menor peso molecular, enquanto os álcoois de açúcar - polióis (arabitol e manitol) se correlacionaram melhor com compostos de carbono com maior peso molecular. Mais estudos devem ser feitos para elucidar o porquê dessa correlação.

\subsubsection{Anidroaçúcares}

O levoglucosano é um anidroaçúcar subproduto da combustão da celulose (presente na parede celular das plantas) e como tal é emitido durante a queima de biomassa, sendo frequentemente considerado seu traçador (Simoneit et al., 1999). Manosano e galactosano são isômeros do levoglucosano e também são emitidos durante a queima de biomassa (Sullivan et al., 2011, Simoneit e Elias, 2000). Alves et al. (2020) encontraram concentrações significativas de levoglucosano em lascas de pneus triturados e nas partículas de desgaste, adicionando uma nova possível fonte de levoglucosano em ambientes urbanos.

O levoglucosano apresentou uma concentração total de $179,7 \pm 218,5 \mathrm{ng} / \mathrm{m}^{3}$ considerando todo o período amostrado e $336,7 \pm 318,1 \mathrm{ng} / \mathrm{m}^{3}, 251,1 \pm 222,7 \mathrm{ng} / \mathrm{m}^{3}, 115,3$ $\pm 147,1 \mathrm{ng} / \mathrm{m}^{3}, 57,6 \pm 39,4 \mathrm{ng} / \mathrm{m}^{3}$ para as estações de outono de 2017 (12 dias), inverno (21 dias), primavera (18 dias) e outono de 2018 (14 dias), respectivamente (Tabela 14). As menores concentrações de levoglucosano na primavera de 2017 e outono de 2018 podem ser explicadas pela maior precipitação nessas estações. No outono de 2018 choveu 3,5 vezes mais que no outono de 2017 e na primavera choveu 4,1 vezes mais do que no outono de 2017 que foi a estação mais seca considerando o período coletado, o que também explica a elevada concentração no outono de 2017. 
Em 2008, Souza et al. (2014) encontraram uma concentração média de $284 \mathrm{ng} / \mathrm{m}^{3}$ para o levoglucosano para São Paulo durante o inverno considerando o $\mathrm{MP}_{2,5}$. Para os anos de 2012 e 2013 em São Paulo durante o inverno a concentração média de levoglucosano no $\mathrm{MP}_{10}$ foi de $330 \mathrm{ng} / \mathrm{m}^{3}$ e $510 \mathrm{ng} / \mathrm{m}^{3}$, respectivamente (Caumo et al., 2016). Para o ano de 2014 também no inverno a concentração média no $\mathrm{MP}_{2,5}$ foi de $509 \mathrm{ng} / \mathrm{m}^{3}$ (Pereira et al., 2017) e para o ano de 2015, durante o outono e inverno para o $\mathrm{MP}_{10}$ a concentração média foi de $231,9 \mathrm{ng} / \mathrm{m}^{3}$ (Emygdio et al., 2018a). Urban et al. (2014) obtiveram uma concentração média de levoglucosano de $428 \mathrm{ng} / \mathrm{m}^{3}$ para Araraquara e Ourinhos entre 2010 e 2012. A tabela 14 apresenta a concentração de levoglucosano para São Paulo nos anos de 2008 (Souza et al., 2014), 2012 (Caumo et al., 2016), 2013 (Caumo et al., 2016), 2014 (Pereira et al., 2017), 2015 (Emygdio et al., 2018a) e 2017 (este trabalho).

As concentrações observadas para o levoglucosano para 2017 (este trabalho) no inverno são 50\% menores do que as observadas em 2013 para o MP M $_{10}$ (Caumo et al., 2016) e em 2014 para o $\mathrm{MP}_{2,5}$ (Pereira et al., 2017) também no inverno. Comparadas com as amostragens feitas em 2015 (Emygdio et al., 2018a) os valores encontrados nesse trabalho são bem semelhantes. Apesar das concentrações de levoglucosano observadas por Pereira et al. (2017) serem do $\mathrm{MP}_{2,5}$ e não do $\mathrm{MP}_{10}$ como realizada nesse trabalho, o autor encontrou que a maior parte do levoglucosano (> 75\%) é encontrado na parte fina do $\mathrm{MP}\left(\mathrm{MP}_{2,5}\right)$, o mesmo foi observado por outros autores (Souza et al., 2014; Urban et al., 2014). Assim sendo, entende-se que é possível fazer a comparação entre as concentrações encontradas.

Fatores meteorológicos são essenciais para explicar a diferença observada na concentração de levoglucosano, principalmente para 2014. Esse ano foi o segundo ano mais seco das últimas três décadas, com chuvas abaixo da média climatológica e uma temperatura anual 8,5\% acima da média (Boletim climatológico anual da estação do IAG/USP, 2014). A baixa precipitação não só implica menos deposição úmida dos poluentes, mas também influencia no aumento dos casos de focos de queimada. Em 2014 foram observados 585 mais focos de queimada comparado com 2017 (4490 focos de queimada em 2014 comparado com 3905 focos em 2017; INPE, 2019). Pereira et al. (2017) reportaram uma quantidade de 1364 dias com focos de queimadas durante o período amostrado no estado de São Paulo, resultando em 72 focos por dia. Durante o período de inverno neste trabalho (2017) foram observados 936 focos de queimadas (21 dias), resultando em aproximadamente 47 focos por dia (INPE, 2019).

Além dos fatores meteorológicos a diminuição da queima da palha da cana de açúcar no solo em resposta a lei $\mathrm{n}^{\mathrm{o}}$ 11.241/2002 para o Estado de São Paulo também pode ter sido um fator relevante. No Brasil é muito comum a prática de queima da palha da cana de açúcar no 
solo para facilitar a colheita da cana (Uriarte et al., 2009). Segundo Andrade et al. (2012), acredita-se que a queima de cana de açúcar em regiões no interior do estado de São Paulo, contribua para a piora na qualidade do ar nos centros urbanos do estado.

\subsection{Queima da palha da cana de açúcar}

A lei da queima da palha da cana (Lei no 11.241/2002) no Estado de São Paulo, define que até o ano de 2016 as áreas mecanizáveis (solos que permitam a mecanização - acima de 150 ha com declividade igual ou inferior a 12\%) devem eliminar $80 \%$ da queima e até 2021 toda a queima deverá ser eliminada. Em contrapartida, para as áreas não mecanizáveis (solos que não permitem a mecanização - declividade superior a 12\%) essa lei impõe que se deve eliminar 20\% da queima até 2016 e toda a queima deverá ser eliminada até 2031 (SÃO PAULO, 2002). Em 2017 também foi assinado o "Protocolo Etanol Mais Verde" para o Estado de São Paulo, que, entre diversos objetivos, também tem como diretiva técnica a antecipação da eliminação total do uso do fogo na colheita da cana-de-açúcar a partir de 2017 todas as usinas que aderiram ao protocolo (SÃO PAULO, 2017).

O CONAB (2019a) faz entrevistas com os produtores solicitando informações técnicas para fins de elaboração de um relatório com informações sobre a safra, e no último levantamento do ano é feita a consolidação dos números finais da safra de cana de açúcar. De acordo com esse levantamento, a prática da queima da palha de cana de açúcar, com o objetivo de facilitar a colheita e elevar a produtividade, tem sido substituída pela colheita mecanizável. Nas safras 2013/2014 e 2014/2015, a porcentagem de áreas com colheita manual para o estado de São Paulo foi de 18,7\% e 14,9\%, respectivamente, enquanto para a safra de 2017/2018 apenas 4,1\% da colheita no estado de São Paulo foi feita de forma manual, isto é, 95,9\% de toda a colheita no estado de São Paulo foi feita de forma mecanizada (CONAB, 2019a). No Sudeste essa mesma safra (2017/2018) teve 3,8\% da colheita feita de forma manual, enquanto no Nordeste essa porcentagem sobe para 82\%. Para a safra 2015/2016 e 2016/2017 esse valor é 5,5\% para o estado de São Paulo segundo a CONAB (2019a), enquanto segundo o IEA (2017) o índice de mecanização para a safra 2016/2017 para o estado de São Paulo é de 90\%. Apesar de um claro aumento nas áreas mecanizadas, em especial em São Paulo, vale ressaltar que a prática da queima de resíduos da lavoura, mesmo em áreas mecanizadas, pode ocorrer uma vez que a eliminação da queima beneficia o surgimento de doenças fúngicas (CONAB, 2019b; CONAB, 2017; Uriart et al., 2009). Apesar disso, a mecanização sem a queima, além de diminuir a emissão de poluentes também tem outras vantagens como aumento da fertilidade do solo em decorrência da palha, que antes era queimada, ser deixada no solo (CONAB, 2018). 
A quantidade de hectares de área colhida de cana de açúcar para o Estado de São Paulo tem aumentado. Em 2008 essa área foi de 4.530 .784 hectares, em 2012 foi de 5.150.461 hectares, em 2013 foi de 5.399.235 hectares, em 2014 foi de 5.566.084 hectares em 2015 foi de 5.527.560 hectares e em 2017 foi de 5.685.946 hectares (UNICA, 2020). Isso indica que teve um aumento de 1,25 vezes (1155162 ha) na quantidade de hectares de área colhida de cana de açúcar em São Paulo entre 2008 e 2017.

Além da queima da palha da cana de açúcar na área de plantação, há também outra fonte de queima relacionada com a cana de açúcar, que ocorre nas usinas de etanol e açúcar. Essas usinas queimam o bagaço da cana para geração de energia para abastecimento da própria usina (IBGE, 2017; Kawashima et al., 2015) e também para a cogeração. Através do novo modelo do setor energético brasileiro implantado através das Leis $\mathrm{n}^{\circ} 10.847$ e 10.848 de 15 de março de 2004 (BRASIL, 2004a,b), e Decreto n ${ }^{\circ}$ 5.163, de 30 de julho de 2004 (BRASIL, 2004c), foram criados os leilões de energia, os quais têm como objetivo a compra de energia elétrica (CCEE, 2019) por distribuidoras, incluindo termelétricas e usinas que utilizam o bagaço e outros derivados da cana de açúcar. Nesse contexto, algumas usinas além de utilizarem a energia derivada da queima do bagaço para a produção de etanol e açúcar, sendo em sua maioria autossuficientes, também cogeram energia para a rede elétrica (vendem energia elétrica para as centrais de distribuição) (IBGE, 2017b; Dantas Filho, 2009; Dantas Filho et al., 2013). Dentre as usinas analisadas pelo CONAB (2011) durante a safra 2009/2010 para a região centro-sul, $28,8 \%$ das usinas (34,1\% no estado de São Paulo) venderam sua energia para terceiros, enquanto 47,7\% (53,2\% no estado de São Paulo) da cana moída foi processada em unidades que vendem energia. Isso significa que para a região centro-sul, quase metade da cana produzida é processada em usinas que vendem a sua energia para terceiros, e isso representa quase 1/3 das usinas da região. A quantidade de bagaço queimado por hora de funcionamento na região centro-sul é de 27709,4 toneladas (para o estado de São Paulo é de 17901 toneladas) considerando todas as unidades analisadas pelo CONAB (2011) e a eficiência na queima do bagaço para a geração de energia é maior na região centro-sul do que na região norte-nordeste.

A combustão em caldeiras para a geração de energia utiliza o bagaço da cana (Castillo, 2015), bem como outras biomassas como os cavacos de madeira, cascas de amendoim e a palha da cana. Dentre as biomassas utilizadas para a produção de energia no Brasil, o bagaço da cana é o principal (EPE, 2016), sendo que dos 517 empreendimentos termelétricos que usaram biomassa no país em 2016, 394 delas utilizam o bagaço da cana ( 76\%), enquanto 49 utilizam resíduos florestais (incluindo lenha, cavaco e serragem) (Aneel, 2016 apud EPE, 2016). Com a diminuição da colheita manual a qual envolvia a queima da palha da cana, há mais biomassa 
útil para ser queimada nas caldeiras e gerar energia nas usinas (EPE, 2016). Em 2017, a queima do bagaço da cana foi o combustível mais utilizado na produção de energia a base de biomassa (85\% do total) (CCEE apud NovaCana, 2019), sendo o estado de São Paulo o maior produtor de energia derivada da queima de biomassa (48\% de toda a produção dessa fonte do SIN). Ademais, a geração de energia elétrica utilizando o bagaço da cana representou em 2015 5,9\% de toda a energia elétrica gerada no Brasil (EPE, 2016 apud IBGE, 2017). Na safra 2009/2010 a porcentagem de geração de energia pelas indústrias sucroalcooleiras foi de $4,5 \%$, enquanto o valor comercializado na rede por essas usinas representa 1,65\% do total (ONS apud CONAB, 2011). Isso indica que houve um crescimento na geração de energia elétrica por esse setor. Vale ressaltar que em 2017 houve um crescimento de 9\% na geração de energia pela queima de biomassa comparado com 2016 (CCEE apud NovaCana, 2019). Considerando as usinas termelétricas como um todo, incluindo diferentes combustíveis, elas contribuíram em 2010 com 37496,9 GWH para o abastecimento de energia no país e participaram com 7,87\% na distribuição diária de energia elétrica no país (ONS apud CONAB, 2011). Outras indústrias que fazem a cogeração de energia utilizando a biomassa são as indústrias de papéis e celulose e instalações de beneficiamento de madeira (EPE, 2016).

Segundo a EPE (2016), o bagaço da cana de açúcar é uma estrutura fibrosa, constituída de um caldo e fibras (50\% umidade e 50\% fibras lignocelulósicas), resultado da última prensagem da cana. O período de colheita e moagem da cana e, consequentemente, de produção de energia, ocorre geralmente nos meses com baixa pluviosidade, o que na região centro-sul pode significar de maio a novembro (CONAB, 2011), ou março a outubro (EPE 2016), sendo que esse período pode se estender em alguns casos. Nos outros meses do ano, os geradores são desligados interrompendo o processo de produção de energia (CONAB, 2011). O estado de São Paulo representou mais de $50 \%$ de toda a área destinada para a produção de cana de açúcar na safra 2015/2016, sendo o maior produtor dessa cultura $(55,2 \%$ do volume total de cana produzido no país) (CONAB, 2019a). No geral, 45\% da cana de açúcar produzida no Brasil é destinada a produção de açúcar, sendo 70\% da produção exportada (CONAB, 2017 apud IBGE, 2017b). Os 55\% restantes foram utilizados na produção de etanol, sendo 5\% do etanol produzido exportado (CONAB, 2017 apud IBGE, 2017b). Na safra 2015/2016 a produção de etanol no país chegou a utilizar 59,6\% de todo o volume de cana de açúcar produzido, enquanto 40,4\% foi destinado na produção de açúcar (CONAB, 2019a). A produção de etanol na safra 2017/2018 foi de 27237,7 milhões de litros (CONAB, 2019a).

O estado de São Paulo é o maior produtor de açúcar do Brasil (62\% da produção do Brasil) (IBGE, 2017 apud PIA-produto 2015), o maior produtor de etanol do Brasil (IBGE, 
2017b) e apresenta o maior número de usinas do país (2015), sendo que na safra 2009/2010 o estado processou 60,2\% da safra nacional de cana de açúcar (CONAB, 2011). Segundo a CONAB (2011) a predominância da produção em São Paulo, se deve as condições ambientais relacionadas ao solo e a meteorologia, bem como ao desenvolvimento de tecnologias e conhecimento científico. A maioria das usinas no estado de São Paulo são mistas, as quais produzem etanol e açúcar (300 de 414 usinas no Brasil em 2012 - Ministério da Agricultura, Pecuária e Abastecimento, 2012 apud Castillo, 2015).

Não há muitos trabalhos que apresentam a emissão de poluentes por usinas de etanol e açúcar, contudo Kawashima et al. (2015), CETESB (2016) e Andrade e Diniz (2007) afirmam que a principal emissão dessas usinas que utilizam o bagaço da cana de açúcar é o material particulado, seguido do $\mathrm{NO}_{\mathrm{x}}$. Existem equipamentos utilizados para diminuir a emissão desses poluentes, os quais incluem lavadores de gases, coletores mecânicos (ciclones simples, ciclones duplos, multiciclones), precipitadores e filtros-manga (CETESB 2016; Andrade e Diniz, 2007). A resolução CONAMA n ${ }^{\circ}$ 382, de 26 de dezembro de 2006, estabelece limites nos poluentes atmosféricos emitidos pelas fontes fixas, incluindo as emissões resultantes da combustão externa do bagaço da cana de açúcar (CONAMA, 2007).

Com essas informações, entende-se que no Estado de São Paulo, apesar de haver uma diminuição na porcentagem de coleta manual da cana, há um aumento nos hectares de área colhida de cana de açúcar. Além disso, o bagaço que antes era queimado no solo está sendo queimado nas caldeiras das usinas, as quais estão na sua maioria localizados no estado de São Paulo. Apesar da queima nas usinas ser mais controlada, e exigir o uso de equipamentos para diminuir a emissão de poluentes, ainda é uma fonte de poluentes. Além disso, o período de produção de energia se sobrepõe ao inverno, que é o período que geralmente apresenta maiores concentrações de poluentes primários.

\subsection{Razão Levoglucosano/Manosasno e $K^{+} /$Levoglucosano}

Para compreender melhor a fonte da queima de biomassa foi feita a razão levoglucosano para manosano (L/M), a qual pode ser usada para indicar os tipos de biomassa usados na combustão. Engling et al. (2009) fizeram uma revisão da razão L/M em vários trabalhos e observou que para madeira de conífera essa razão está entre 3 e 5, para espécies de madeira decíduas entre 15 e 23, para a queima de madeira residencial (madeira macia) de 3 a 6 , a queima de folhas apresentou um valor de L/M de 5,5, enquanto uma mistura de queima de biomassa e biocombustível apresentou um valor de 15 a 24 (no Brasil) (Engling et al. 2009). Para a queima de palha da cana de açúcar, Hall et al. (2012) realizaram um estudo em câmara e encontraram um valor de L/M de 10, enquanto Urban et al. (2014), coletando amostras ambientais para 
Araraquara e Ourinhos (Brasil), locais de elevada queima de biomassa derivada da cana de açúcar (da palha no solo e do bagaço nas usinas) encontrou uma razão L/M de 9. A razão média L/M encontrada nesse trabalho foi de 9,0 (69 dias), sendo que para o ano de 2017 a razão teve um valor de 10,5 (51 dias) e para 2018 (apenas março e abril, 18 dias) um valor de 4,5 (Tabela 14). O valor para todo o período encontrado para esse trabalho está próximo ao valor 10 observado por Hall et al. (2012) e 9 observado por Urban et al. (2014), indicando que possivelmente a principal fonte de queima de biomassa e consequentemente de levoglucosano durante o período amostrado seja a queima de cana de açúcar.

No inverno de São Paulo nos anos de 2012, 2013 e 2014 foram observados valores de 14,0, 13,9 e 11,3, respectivamente para a relação L/M (Pereira et al., 2017; Caumo et al., 2016). No presente trabalho, foi observado um valor de 13,4 para o inverno de 2017, o que está próximo aos valores observados nos anos anteriores (2012 e 2013). Se considerarmos os valores revisados por Engling et al. (2009), o valor observado no inverno está próximo ao valor observado para a mistura de queima de biomassa e biocombustível. Analisando as outras estações do ano, o outono de 2017 (maio e junho) obteve um valor da razão L/M de 10,6, a primavera de 7,2 e o outono de 2018 (março e abril) de 4,8. O outono de 2017, como apresentou um valor próximo de 10 , indica que uma possível fonte de queima de biomassa seja a da queima da cana de açúcar. A primavera e o outono de 2018 apresentaram mais chuvas do que no inverno (2,3 e 2,0 vezes mais chuva respectivamente) e outono de 2017 (4,1 e 3,5 vezes mais chuva respectivamente), o que pode explicar a diminuição na concentração de levoglucosano. Ainda, no outono de 2018 a direção predominante do vento (mais frequente) foi de nordeste, diferente do resto do ano, indicando que possivelmente nesse período a fonte de levoglucosano pode ter sido outra que não a queima da cana de açúcar (predominante na região noroeste do local de coleta).

O potássio também é um conhecido traçador de queima de biomassa (Engling et al., 2009), apesar de também apresentar outras fontes como solo e sal marinho (Andreae, 1983; Ram e Sarin, 2011). A razão $\mathrm{K}^{+} /$levoglucosano foi 2,4, semelhante ao valor de 3,1 achado anteriormente por Souza et al. (2014) para São Paulo no inverno. Durante o inverno e primavera observaram-se maiores valores dessa razão, indicando que nessas estações possivelmente há outras fontes de $\mathrm{K}^{+}$além da queima de biomassa (representada pelo levoglucosano).

Tabela 14. Concentração de levoglucosano e a razão levoglucosano/manosano para São Paulo para $\mathrm{MP}_{2,5}$ e $\mathrm{MP}_{10}$ segundo a literatura.

\begin{tabular}{|c|c|c|c|c|c|}
\hline Ano & Estação & $\begin{array}{l}\text { Período } \\
\text { amostrado }\end{array}$ & $\begin{array}{l}\text { Tamanho } \\
\text { do MP }\end{array}$ & $\begin{array}{l}\text { Método de } \\
\text { análise }\end{array}$ & $\begin{array}{l}\text { Levoglucosano L/M } \\
\left(\mathrm{ng} / \mathrm{m}^{3}\right)\end{array}$ \\
\hline
\end{tabular}




\begin{tabular}{|c|c|c|c|c|c|c|c|}
\hline $\begin{array}{l}\text { Souza et } \\
\text { al., } 2014\end{array}$ & 2008 & Inverno & & $\mathrm{MP}_{2,5}$ & HPAEC & 284 & 12,9 \\
\hline \multirow[t]{2}{*}{$\begin{array}{l}\text { Caumo et } \\
\text { al., } 2016\end{array}$} & 2012 & Inverno & $\begin{array}{l}8-23 \text { agosto } \\
(\mathrm{n}=16)\end{array}$ & $\mathrm{MP}_{10}$ & GC/MS & 330 & 14 \\
\hline & 2013 & Inverno & $\begin{array}{l}30 \text { julho a } 9 \\
\text { agosto }(n=11)\end{array}$ & $\mathrm{MP}_{10}$ & GC/MS & 510 & 13,9 \\
\hline $\begin{array}{l}\text { Pereira et } \\
\text { al., } 2017\end{array}$ & 2014 & Inverno & $\begin{array}{l}1-18 \text { de julho } \\
(\mathrm{n}=12)\end{array}$ & $\mathrm{MP}_{2,5}$ & $\begin{array}{l}\text { HPAEC- } \\
\text { MS }\end{array}$ & 509 & 11,3 \\
\hline $\begin{array}{l}\text { Emygdio et } \\
\text { al., 2018a }\end{array}$ & 2015 & Inverno & $\begin{array}{l}20 \text { junho a } 8 \\
\text { julho }(n=19)\end{array}$ & $\mathrm{MP}_{10}$ & HPAEC & 236,1 & 10,9 \\
\hline \multirow[t]{5}{*}{$\begin{array}{l}\text { Este } \\
\text { trabalho }\end{array}$} & $\begin{array}{l}2017 \text { e } \\
2018\end{array}$ & $\begin{array}{l}\text { Todo o } \\
\text { período } \\
\text { amostrado }\end{array}$ & & $\mathrm{MP}_{10}$ & IC-PAD & 179,7 & 9,0 \\
\hline & 2017 & Outono & & $\mathrm{MP}_{10}$ & IC-PAD & 336,7 & 10,6 \\
\hline & & Inverno & $\begin{array}{l}8 \text { agosto a } 21 \\
\text { setembro } \\
(\mathrm{n}=21)\end{array}$ & $\mathrm{MP}_{10}$ & IC-PAD & 251,1 & 13,4 \\
\hline & & Primavera & & $\mathrm{MP}_{10}$ & IC-PAD & 115,3 & 7,2 \\
\hline & 2018 & Outono & & $\mathrm{MP}_{10}$ & IC-PAD & 57,6 & 4,8 \\
\hline
\end{tabular}

\subsection{Focos de incêndio}

$\mathrm{Na}$ figura 17 são mostrados para os meses coletados o número de dias com focos de incêndios ativos para o Estado de São Paulo, Goiás e Amazônia obtidas através do INPE (2019). Ressalva-se que nessa figura os dados de focos de queimadas correspondem a todos os dias do mês (30 ou 31 dias) e não apenas aos dias amostrados nesse trabalho. Na figura 18 são mostradas as concentrações de levoglucosano, manosano, $\mathrm{K}^{+}$, EC e o número de dias com focos de incêndios ativos para o Estado de São Paulo, considerando apenas os dias amostrados.

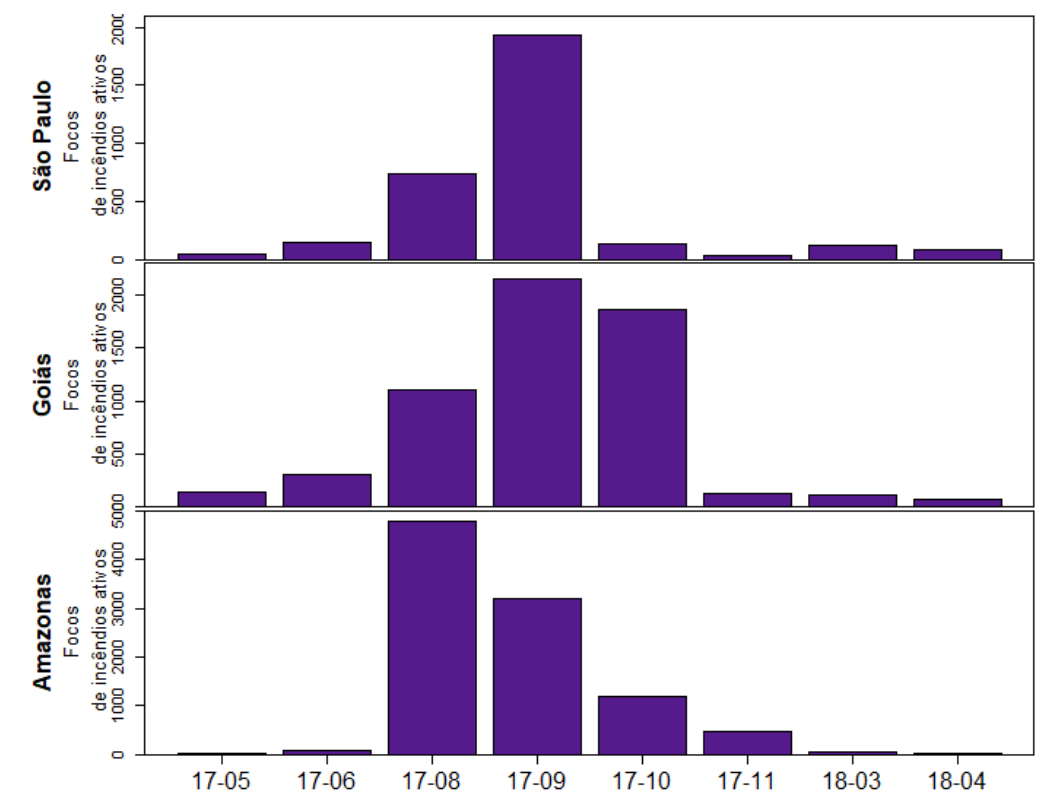

Figura 17. Número de dias com focos de incêndios ativos para os estados de São Paulo, Goiás e Amazônia considerando todos os dias do mês (30 ou 31 dias) 


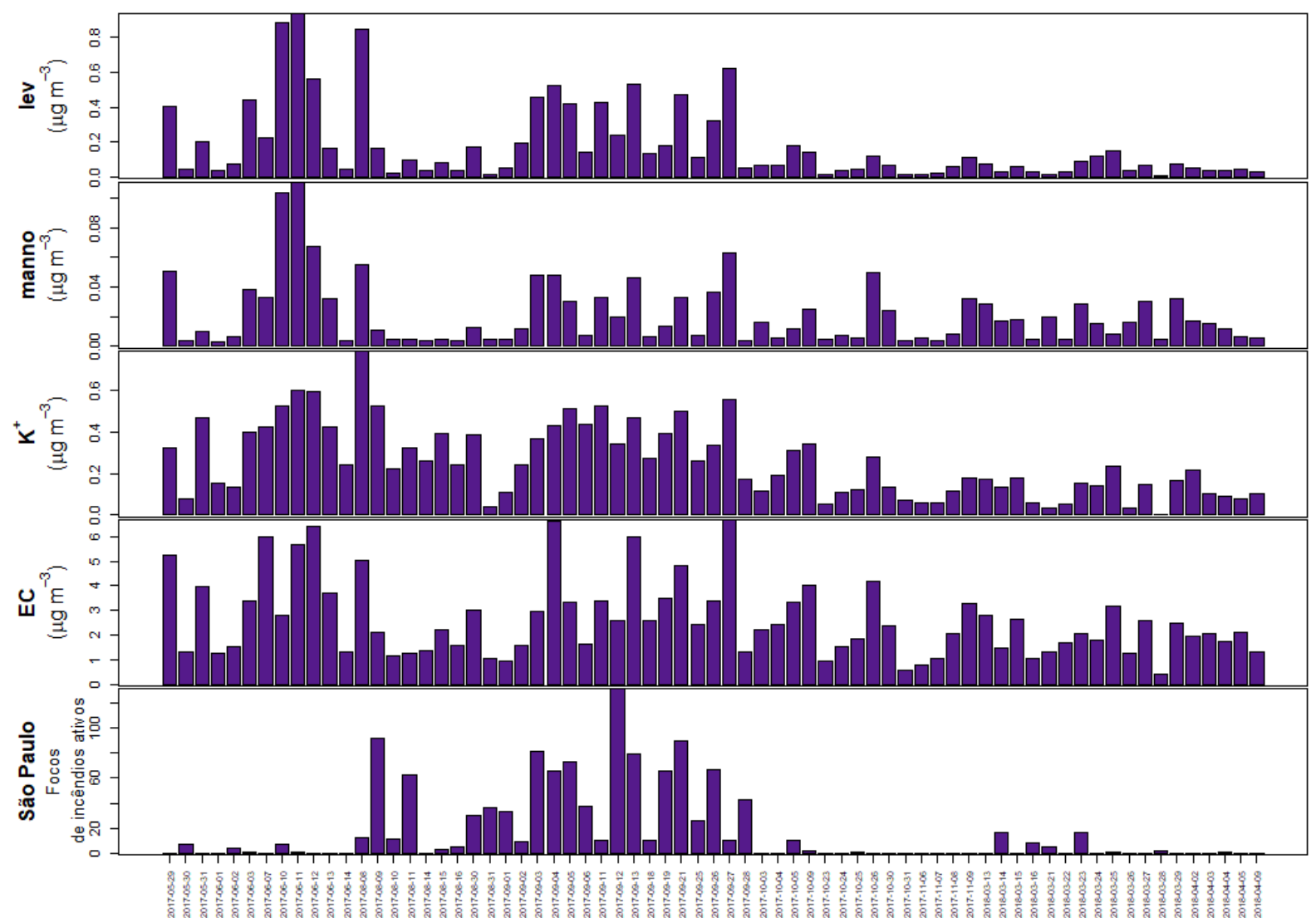

Figura 18. Concentração de levoglucosano (lev), manosano (manno), íon potássio $\left(\mathrm{K}^{+}\right)$, carbono elementar (EC) e a quantidade de focos de queimadas para o estado de São Paulo considerando o período coletado.

O mês de setembro é o mês com maior quantidade de focos de queimada, e também corresponde ao mês mais seco considerando os meses quando houve a coleta de MP. Observase que as concentrações de levoglucosano, manosano, $\mathrm{K}^{+}$, EC parecem apresentar um comportamento correlacionado com o número de dias com queimadas para o Estado de São Paulo se considerarmos apenas os dias a partir de agosto de 2017. Há uma correlação positiva e significativa $(p<0,05)$ entre a concentração de levoglucosano e o número de dias com focos de queimada para o estado de São Paulo considerando todo o período amostrado, contudo essa correlação é baixa $(r=0,28$ ou $\rho=0,39)$. Se considerarmos apenas os dias a partir de agosto de 2017, observamos que essa correlação sobe para $(r=0,49$ ou $\rho=0,55)$. Em compensação, nos meses de maio e junho as concentrações de levoglucosano, manosano, $\mathrm{K}^{+}$e EC não estão relacionadas com a ocorrência dos focos de queimada, especialmente em junho onde a concentração de levoglucosano é mais elevada do que em setembro.

Uma possível explicação para essa diferença na quantidade de dias com focos de queimada e a concentração dos conhecidos traçadores de queima de biomassa é o transporte pelo vento. As trajetórias das massas de ar obtidas com o Hysplit para o período de junho, são provenientes majoritariamente da região noroeste (Figura C VI) e as imagens de satélite 
indicam que a maioria dos focos de queimada se localizam na região central do Brasil (Figura C VII). Ademais, durante o mês de junho a relação L/M foi de 9,5 muito próxima do valor observado por Hall et al. (2012) e Urban et al. (2014) referente à queima de cana de açúcar. Esse dado fortalece ainda mais o argumento acima, ou justifica que uma possível fonte de levoglucosano seja a queima do bagaço da cana nas usinas, uma vez que o estado de São Paulo, como discutido anteriormente, apresenta o maior número de usinas do país, as quais se concentram na região noroeste do estado e a maior produção de etanol ocorre entre maio a novembro (CONAB, 2011). Outra fonte de queima de biomassa, que ocorre na própria área urbana em residências e comércio, é o uso de lenha, carvão e resíduos para geração de energia.

Segundo o IBGE o uso da lenha para a preparação de alimentos, no Estado de São Paulo aumentou de 376 mil domicílios em 2016 para 432 mil domicílios em 2017 e para 947 mil domicílios em 2018, perfazendo um aumento total de aproximadamente 571 mil domicílios a mais em 2018 comparado a 2016. Para todo o Brasil esse aumento foi de aproximadamente 3 milhões, com 11 milhões em 2016, 12 milhões em 2017 e 14 milhões em 2018. Esse aumento do uso de lenha pode ser uma explicação para a razão L/M ser 4,8 no outono de 2018, o qual é semelhante ao apresentado por Engling et al. (2009) para a queima de madeira residencial (madeira macia) (L/M entre 3 e 6). Além do uso da lenha em domicílios, também há o uso da lenha e carvão em pizzarias e churrascarias. Um estudo em pizzarias de São Paulo mostrou que há uma emissão de $6171 \mu \mathrm{g} / \mathrm{m}^{3}$ de $\mathrm{MP}_{2,5}$ na saída das chaminés (Lima et al., 2020). Por último, também há a queima de lenha em festas comemorativas, como por exemplo no mês de junho, quando ocorre a Festa Junina, a qual corresponde a um feriado religioso onde é comum a prática de acender fogueiras. Alguns estudos têm mostrado que principalmente no Nordeste do país essa prática de acender as fogueiras pode gerar diversas complicações, como problemas de saúde (Silva et al., 2017) e aumento do desmatamento da região (Souza et al., 2010).

De maneira geral, as festas com o acendimento das fogueiras ocorrem durante o final de semana. Ao remover todos os finais de semana (12 dias) da análise (figura 19) observa-se que a concentração de levoglucosano média cai expressivamente no outono de 2017, variando de uma média de $336,7 \mathrm{ng} / \mathrm{m}^{3}$ com finais de semana para $211,6 \mathrm{ng} / \mathrm{m}^{3} \mathrm{sem}$ os finais de semana. Em contrapartida, no inverno as concentrações aumentam, variando de $251,1 \mathrm{ng} / \mathrm{m}^{3}$ com finais de semana para $262,7 \mathrm{ng} / \mathrm{m}^{3}$ sem finais de semana. A diferença entre a concentração de levoglucosano no final de semana e dias da semana considerando todo o período amostral é estatisticamente significativa $(\mathrm{p}<0,05)$ de acordo com o teste de Wilcoxon. Nota-se que a concentração de OC também diminui no outono de 2017 , variando de uma média de $7,2 \mu \mathrm{g} / \mathrm{m}^{3}$ com finais de semana para $6,3 \mu \mathrm{g} / \mathrm{m}^{3}$ sem os finais de semana e aumenta no inverno variando 
de $6,95 \mu \mathrm{g} / \mathrm{m}^{3}$ com finais de semana para $7,5 \mu \mathrm{g} / \mathrm{m}^{3}$ sem finais de semana. Essa análise é mais um indicativo de que possivelmente a fonte de levoglucosano em junho (e outono de 2017) seja realmente a queima de lenha devido às festas juninas ou ainda em pizzarias e churrascarias. Em compensação no inverno, em que as concentrações são mais altas sem os finais de semana é um indicativo que a fonte de levoglucosano nesse período possa ter também a emissão por pneus como sugerido por Alves et al. (2020).

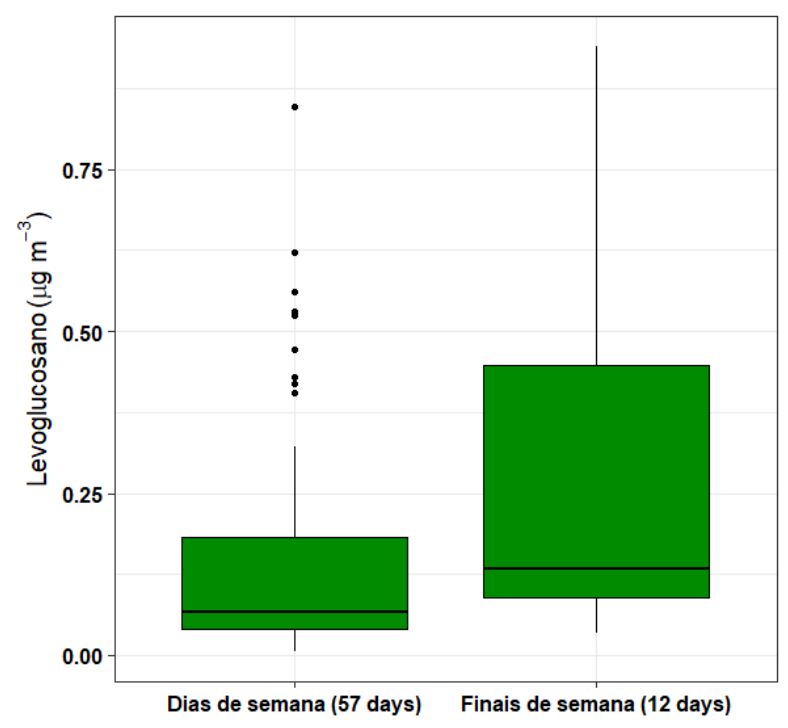

Figura 19. Concentração média de levoglucosano (lev) durante os dias de semana e finais de semana considerando todo o período coletado.

Observando a direção e velocidade do vento e a concentração de levoglucosano, notase que as maiores concentrações de levoglucosano acontecem em junho com velocidades do vento baixas ( $1^{\circ}$ e $3^{\circ}$ velocidades mais baixa de todo o período coletado) considerados períodos de calmaria (sem direção do vento predominante). Em contrapartida, considerando apenas o outono de 2017, o dia com menor concentração de levoglucosano também foi o dia com maior velocidade do vento $(11,8 \mathrm{~km} / \mathrm{h})$ e com direção predominante de $\mathrm{WNW}$. Isso indica que as maiores concentrações de levoglucosano nesse período são obtidas quando há menores velocidades do vento corroborando a hipótese de ser de uma fonte local.

\subsubsection{Acetato e formiato}

Os ácidos carboxílicos de baixo peso molecular incluem os monoácidos (apresentam apenas um terminação $\mathrm{COOH}$ ) (ácido acético, ácido fórmico e ácido metano sulfônico), os quais estão mais presentes na fase gasosa do que na fase particulada, e os diácidos (apresentam duas terminações $\mathrm{COOH}$ ) (ácido oxálico, ácido succínico e ácido maleico) que têm baixa volatilidade por apresentarem dois grupos carboxílicos e, consequentemente, estão mais presentes na fase particulada (Kawamura e Kaplan et al., 1987; Kawamura e Ikushima, 1993; 
Souza et al., 1999). Os íons dos ácidos carboxílicos, os quais foram analisados nesse trabalho são chamados e serão referidos como acetato, formiato, metanosulfonato, oxalato, succinato e maleato. Quando na forma particulada, alguns estudos mostraram que o ácido acético e ácido fórmico estão mais presentes na fração grossa do MP (Talbot et al., 1988; Souza et al., 2014), enquanto os diácidos estão mais presentes na fração fina do MP (Souza et al., 2014; Kawamura e Bikkina 2016), o que indica que estes podem ser formados pelo processo de conversão gáspartícula (Kawamura e Bikkina, 2016; Kawamura e Ikushima, 1993).

As fontes do ácido acético e ácido fórmico podem ser várias, incluindo fontes antrópicas como emissões veiculares, queima de biomassa, formação secundária fotoquímica (ex: decomposição do isopreno) e fontes biogênicas (ex: isopreno e pólen) (Talbot et al., 1988; Wang et al., 2007; Jacob e Wofsy, 1988). Talbot et al. (1988) mostraram que em Hampton (Virginia) para a estação de crescimento das plantas, a principal fonte de ambos os ácidos na fase gasosa foram as emissões biogênicas pela vegetação, enquanto na estação de nãocrescimento, as principais fontes de ácido acético na fase gasosa foram as emissões antrópicas de exaustão de veículos e queima de biomassa. Alguns autores têm proposto que o ácido acético apresenta predominantemente uma fonte primária, enquanto o ácido fórmico apresenta uma fonte secundária sendo assim, uma relação F/A maior do que 1 indicaria uma predominância de fonte secundária, e um valor de F/A menor do que 1 indicaria predominância de fonte primária (Alwe et al., 2019, Talbot et al., 1988, Souza et al., 1999, Verma et al., 2017; Wang et al., 2007). Segundo Talbot et al. (1988), a queima de biomassa, tanto na fase gasosa quanto na particulada, a emissão veicular na fase gasosa e o pólen na fase particulada apresentam uma relação ácido fórmico/acético menor do que 1 indicando uma emissão mais acentuada de acetato. Talbot et al. (1988) também sugeriram que a razão F/A na fase particulada é mais afetada pela interação entre o ácido fórmico e ácido acético na fase gasosa, do que a emissão direta pela combustão natural e de biomassa. Foi sugerido que as reações fotoquímicas e fontes biogênicas são importantes fontes do ácido fórmico durante o dia, enquanto durante à noite ambas, emissão veicular e biogênica são importantes para São Paulo (Souza et al., 1999). A conversão de gás (ácido fórmico e ácido acético) para partícula (formiato e acetato) pode ser favorecida pela baixa temperatura e alta umidade (Verma et al., 2017).

A concentração de acetato apresentou diversos valores negativos (28 dias) quando os valores foram subtraídos pelo branco, apesar desses valores serem substituídos pelo LQL (2 vezes o desvio padrão do branco), isso indica que a sua concentração deve ser considerada com reservas. $O$ acetato teve uma concentração média no período amostrado de 117,6 $\pm 154,3 \mathrm{ng} / \mathrm{m}^{3}$. Para o outono de 2017 a concentração foi de $79,7 \pm 105,9 \mathrm{ng} / \mathrm{m}^{3}$, no inverno foi de $211,2 \pm$ 
$210,2 \mathrm{ng} / \mathrm{m}^{3}$, na primavera foi de $89,8 \pm 136,6 \mathrm{ng} / \mathrm{m}^{3}$, e no outono de 2018 foi de $63,5 \pm 40,4$ $\mathrm{ng} / \mathrm{m}^{3}$. Souza et al. (2014) obteve concentrações bem mais baixas no inverno de 2008 em São Paulo, assim como Vasconcellos et al. (2011) em São Paulo no inverno (agosto) de 2008, enquanto Souza et al. (1999) encontrou uma concentração mais alta para o inverno (julho) de 1996 em São Paulo (Tabela 15).

O formiato apresentou uma concentração média durante todo o período de 26,8 $\pm 39,5$ $\mathrm{ng} / \mathrm{m}^{3}$, enquanto para o outono de 2017 a concentração foi de $14,7 \pm 14,2 \mathrm{ng} / \mathrm{m}^{3}$, no inverno foi de 45,7 $\pm 46,9 \mathrm{ng} / \mathrm{m}^{3}$, na primavera foi de $29,0 \pm 51,1 \mathrm{ng} / \mathrm{m}^{3}$, e no outono de 2018 foi de $9,0 \pm$ $8,5 \mathrm{ng} / \mathrm{m}^{3}$. No geral, as concentrações de formiato observadas nesse trabalho foram menores do que as observadas anteriormente em São Paulo no inverno (Souza et al., 2014; Souza et al., 1999; Vasconcellos et al., 2011) (Tabela 15).

Tabela 15. Comparação entre concentrações medidas dos ácidos orgânicos com outros trabalhos presentes na literatura, indicando o método usado (IC ou GC), o período coletado, local de coleta, se na fase gasosa ou fração do MP, o tempo de coleta e as concentrações.

\begin{tabular}{|c|c|c|c|c|c|c|c|c|c|c|}
\hline 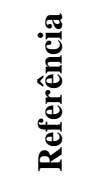 & 递 & 串 & త్రુ & 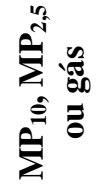 & 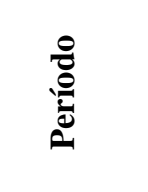 & 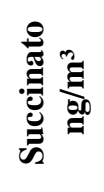 & 离 & 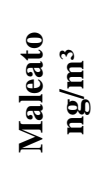 & 总 & 苞 \\
\hline 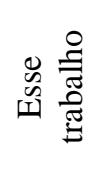 & 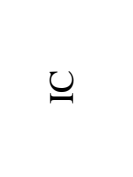 & $\begin{array}{l}0 \\
0 \\
0 \\
0 \\
0 \\
0\end{array}$ & 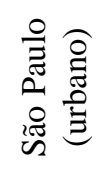 & $\stackrel{\varrho}{\sum}$ & $\underset{\sim}{\tilde{d}}$ & 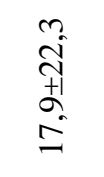 & $\begin{array}{l}\hat{a} \\
\overline{0} \\
0 \\
0 \\
8 \\
0\end{array}$ & 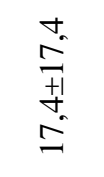 & 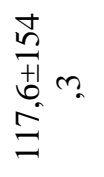 & $\begin{array}{l}n \\
\text { nे } \\
+1 \\
\infty \\
0 \\
0\end{array}$ \\
\hline 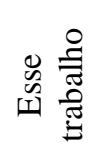 & $\varrho$ & 产 & 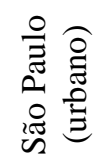 & $\stackrel{\varrho}{\sum}$ & $\underset{\sim}{\tilde{d}}$ & $\begin{array}{l}\overrightarrow{1} \\
+1 \\
+1 \\
+\end{array}$ & $\begin{array}{l}\vec{N} \\
+1 \\
\infty+\infty \\
\infty \\
\stackrel{n}{0}\end{array}$ & $\begin{array}{l}\infty \\
\infty \\
+1 \\
+ \\
0 \\
0\end{array}$ & $\begin{array}{l}\frac{1}{0} \\
+1 \\
\frac{2}{2}\end{array}$ & $\begin{array}{l}\stackrel{N}{ \pm} \\
\frac{+1}{ \pm} \\
\pm \\
\pm\end{array}$ \\
\hline 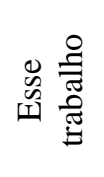 & $\varrho$ & 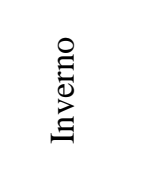 & 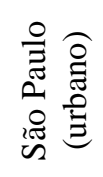 & $\stackrel{\varrho}{\stackrel{\varrho}{\Sigma}}$ & $\underset{\sim}{\tilde{d}}$ & $\begin{array}{l}\stackrel{+}{\vec{T}} \\
\stackrel{+}{a} \\
\stackrel{i}{े}\end{array}$ & 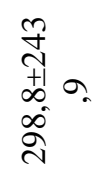 & 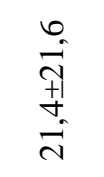 & $\begin{array}{l}\text { O } \\
\text { II } \\
\text { I } \\
\text { ज }\end{array}$ & $\begin{array}{l}a \\
0 \\
+ \\
+1 \\
\hat{\sigma} \\
\tilde{\sigma}\end{array}$ \\
\hline 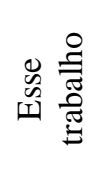 & $\varrho$ & 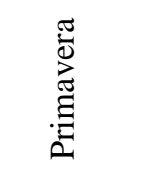 & 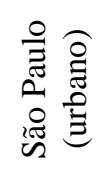 & $\stackrel{\varrho}{\stackrel{2}{\Sigma}}$ & $\underset{\sim}{\stackrel{f}{f}}$ & $\begin{array}{l}= \\
\overrightarrow{0} \\
+1 \\
0 \\
0\end{array}$ & 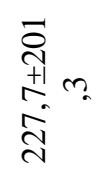 & $\begin{array}{l}n \\
\infty \\
\infty \\
+1 \\
0 \\
0\end{array}$ & $\begin{array}{l}0 \\
\infty \\
+1 \\
+1 \\
\infty \\
\infty \\
\infty\end{array}$ & $\begin{array}{l}= \\
\overrightarrow{0} \\
0 \\
0 \\
0\end{array}$ \\
\hline 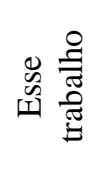 & 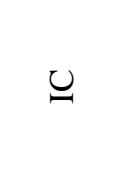 & $\stackrel{\circ}{\stackrel{0}{0}} \stackrel{\infty}{\circ}$ & 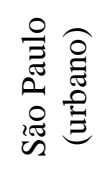 & $\stackrel{\varrho}{\Sigma}^{\varrho}$ & $\underset{\sim}{\stackrel{f}{f}}$ & 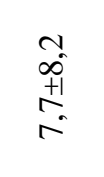 & $\begin{array}{l}m \\
0 \\
+1 \\
m \\
m \\
0 \\
0 \\
0\end{array}$ & $\frac{a}{\stackrel{a}{ \pm}}$ & 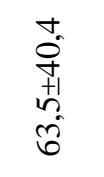 & $\begin{array}{l}n \\
\infty \\
01 \\
0 \\
0\end{array}$ \\
\hline 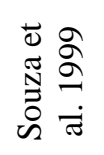 & 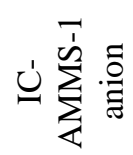 & 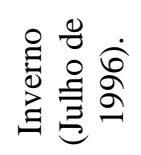 & 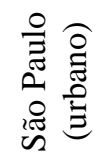 & 营 & 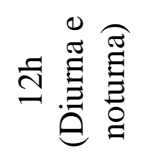 & $\overleftrightarrow{Z}$ & $\stackrel{\text { \& }}{=}$ & $\overleftrightarrow{\mathrm{z}}$ & $\underset{ণ}{\mathscr{f}}$ & $\underset{\stackrel{\infty}{+}}{\stackrel{\infty}{+}}$ \\
\hline
\end{tabular}




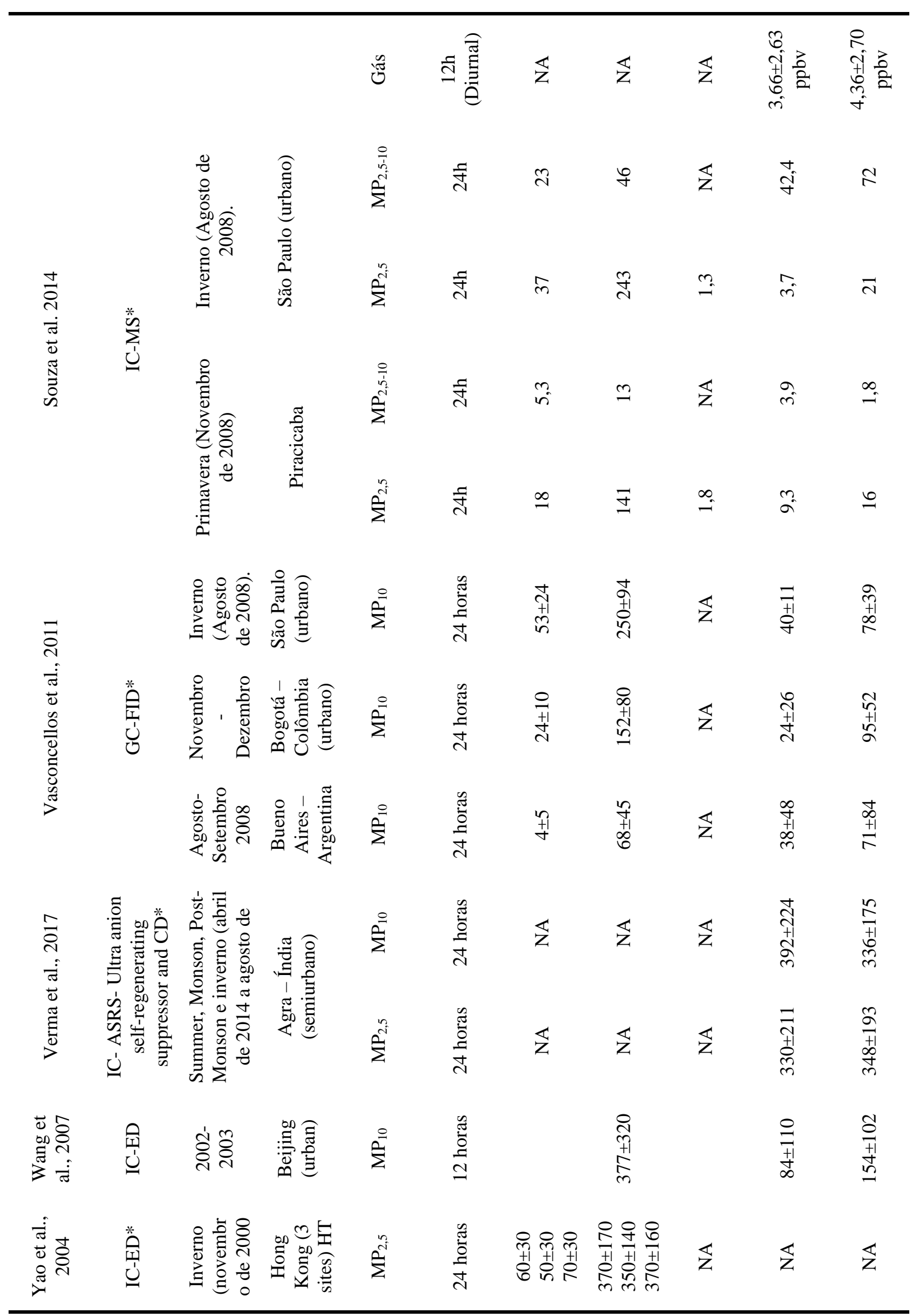




\begin{tabular}{|c|c|c|c|c|c|c|c|c|c|c|}
\hline & & 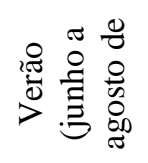 & 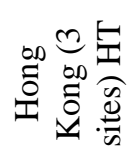 & $\stackrel{n}{i j}^{n j}$ & 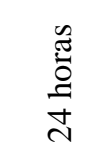 & 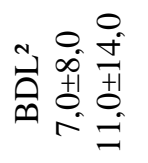 & 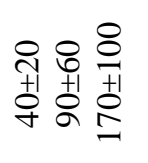 & $\overleftrightarrow{z}$ & $\mathbb{z}$ & $\overleftrightarrow{z}$ \\
\hline 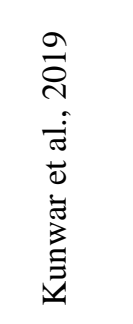 & $\sum_{0}^{\infty}$ & 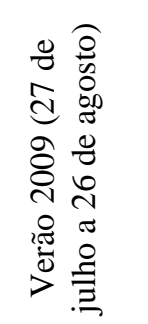 & 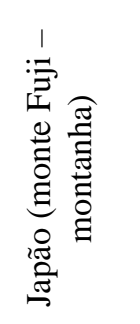 & $\stackrel{\tilde{n}}{n}$ & 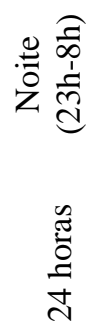 & $\begin{array}{l}\underset{+}{+} \\
+1 \\
\text { }\end{array}$ & 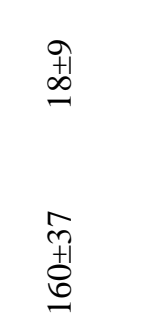 & $\begin{array}{l}0 \\
i\end{array}$ & $\mathbb{Z}$ & $\overleftrightarrow{z}$ \\
\hline 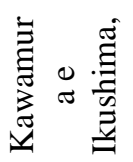 & 苛离 & 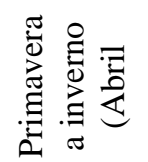 & 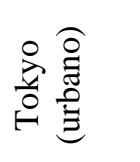 & $\begin{array}{l}\frac{\tilde{n}}{E} \\
\frac{\pi}{z}\end{array}$ & $\begin{array}{l}\tilde{n} \\
\dot{y} \\
\dot{I}\end{array}$ & 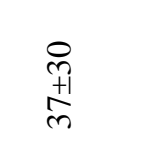 & 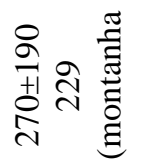 & $\begin{array}{l}+ \\
+ \\
\text { ț } \\
\text { ț } \\
\text { in }\end{array}$ & $\mathbb{Z}$ & $\overleftrightarrow{z}$ \\
\hline
\end{tabular}

*CD: detector de condutividade, ED: detector eletroquímico, MS: espectrômetro de massa, FID: detector de ionização de chama, ${ }^{1} \mathrm{NA}$ : valor não apresentado, ${ }^{2} \mathrm{BDL}$ : abaixo do limite de detecção.

Considerando os dados desse trabalho, o formiato e o acetato se correlacionam positivamente e significativamente $(\rho=0,61$ e $r=0,56)$, indicando uma possível fonte comum. A razão formiato para acetato (F/A) média foi de 0,31 . Durante todo o período amostral essa razão se manteve abaixo de 1 (mais acetato do que formiato) com apenas duas exceções (figura 20).

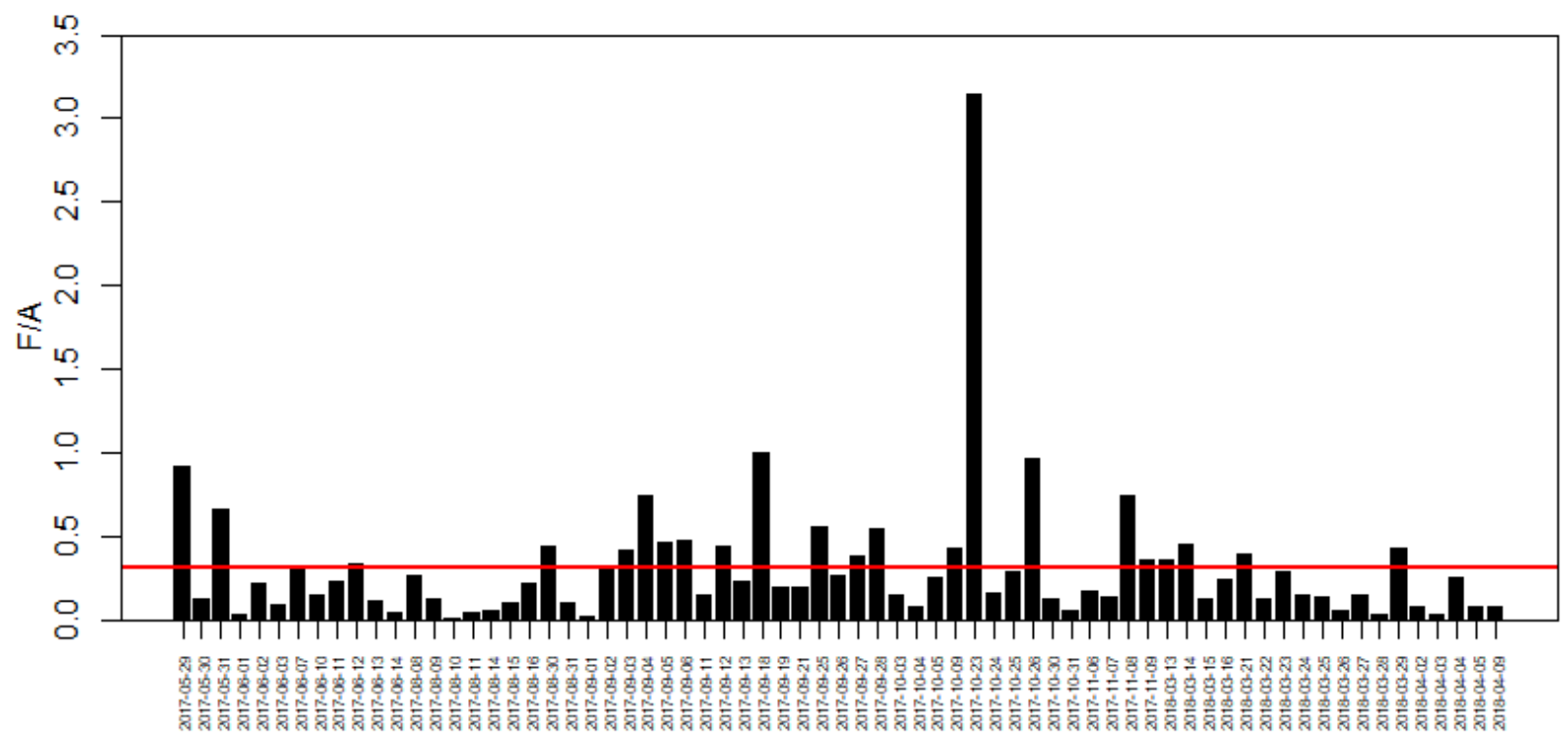

Figura 20. Razão Formiato e Acetato (F/A) durante o período amostrado. A linha horizontal vermelha indica o valor médio dessa razão $\mathrm{F} / \mathrm{A}$.

Verma et al. (2017) observaram uma concentração média na Índia entre 2014 e 2015 de $336 \mathrm{ng} / \mathrm{m}^{3}$ e $392 \mathrm{ng} / \mathrm{m}^{3}$ para o ácido fórmico e ácido acético, respectivamente no $\mathrm{MP}_{10}$, com uma correlação de 0,5 e uma razão F/A variando de 0,21 até 1,4 (média de 0,69). O autor apontou que esses valores são indicativos de que as emissões primárias são as fontes dominantes 
para ambos os ácidos para o local amostrado. Wang et al. (2007) encontraram uma concentração média de $110 \mathrm{ng} / \mathrm{m}^{3}$ e $78 \mathrm{ng} / \mathrm{m}^{3}$ de ácido fórmico e ácido acético, respectivamente e um valor de 0,71 para a relação $\mathrm{A} / \mathrm{F}$ para ácido acético e ácido fórmico para o $\mathrm{MP}_{2,5}$, isto é, há mais ácido fórmico do que ácido acético, o que os autores explicaram como a formação secundária sendo a fonte dominante para esses compostos. Vasconcellos et al. (2011) observaram um valor da razão F/A igual a 0,4 para Bogotá entre novembro e dezembro de 2008, valor semelhante ao encontrado nesse trabalho, e sugeriram que as emissões diretas, principalmente veiculares para o acetato, são mais importantes do que a reação fotoquímica na formação de acetato e formiato. Souza et al. (1999) não obtiveram uma correlação entre formiato e acetato $(r=0,4)$ e os valores de F/A para o material particulado foram semelhantes aos da fase gasosa $(1,24$ e 1,04 respectivamente) para São Paulo (inverno - julho de 1996).

Com o intuito de estimar se a fonte do acetato e formiato é primária ou secundária foi realizada uma correlação com ozônio e com o CO (Souza et al., 1999; Verma et al., 2017). O $\mathrm{O}_{3}$ é produzido fotoquimicamente, enquanto o $\mathrm{CO}$ é emitido pela ação antropogênica especialmente pela combustão incompleta de combustíveis por veículos (Souza et al., 1999; Brito et al., 2013; Perez-Martínez et al., 2014). Considerando todo o período amostrado, foi encontrada uma correlação de Spearman positiva e significativa $(\mathrm{p}<0,05)$ entre formiato, ozônio ( $\rho=0,71$ e $r=0,64)$ e $\operatorname{CO}(\rho=0,41$ e $r=0,27)$ e entre acetato e ozônio $(\rho=0,60$ e $r=0,41)$. Os dados de ozônio foram obtidos da CETESB da estação da Cidade Universitária e o CO foi obtido da estação Pinheiros ( 3,2 km do local de coleta). Souza et al. (1999), obtiveram um comportamento semelhante na primavera para o ácido fórmico, com uma correlação de $\mathrm{r}=0,50$ para com o $\mathrm{CO}$ e r=0,86 para o $\mathrm{O}_{3}$, enquanto o ácido acético apresentou uma correlação de $\mathrm{r}=0,13$ com o $\mathrm{CO}$ e $\mathrm{r}=0,84$ com o $\mathrm{O}_{3}$. A correlação positiva, significativa entre formiato e acetato com o ozônio pode indicar que os processos secundários fotoquímicos são uma fonte importante para ambos.

Talbot et al. (1988) observaram que os pólens apresentam uma elevada concentração de acetato. No presente trabalho, foi observada uma correlação de Spearman significativa apesar de baixa entre o acetato e formiato com as proteínas solúveis em água ( $\rho=0,27$ e $\rho=0,41$, respectivamente), o que pode ser um indicativo de uma possível fonte biogênica para ambos os ácidos orgânicos.

\subsubsection{Oxalato, succinato, maleato e metanosulfonato}

A origem dos ácidos dicarboxílicos (no caso, succinato, maleato e oxalato) na atmosfera são várias, incluindo emissões veiculares (exaustão do motor) que são fonte primária (Kawamura e Kaplan et al., 1987), a queima de biomassa (Kundu et al., 2010), emissão 
biogênica primária (Dutton e Evans, 1996), reações fotoquímicas (gás-para-partícula) e oxidações de hidrocarbonetos e outros precursores orgânicos (Kawamura e Ikushima,1993; Kundu et al., 2010; Kawamura e Bikkina, 2016; Yao et al., 2004).

Observa-se na tabela 15 que na literatura são encontradas duas metodologias principais de análise dos diácidos, uma utilizando o cromatógrafo de íons, de forma semelhante a esse trabalho e outra utilizando o cromatógrafo gasoso. Durante a análise de ácidos orgânicos com um cromatógrafo de íons (IC), o ácido oxálico é convertido para oxalato no eluente básico, e o resultado final é a soma do ácido oxálico com o oxalato (Kawamura e Bikkina, 2016; Kawamura et al., 2010). A análise com o IC também apresenta uma taxa de recuperação elevada ( $100 \%)$, mas tem um limite de detecção muito alto, isto é não consegue identificar os diácidos menores (Kawamura e Bikkina, 2016; Kawamura et al., 2010). Kawamura et al. (2010) analisando ácido oxálico com o método ester butil/GC e com o IC concluíram que as concentrações de ácido oxálico obtidas com o método ester butil/GC são consistentes com as obtidas com o IC (correlação entre eles de $r=0,84$ ) e podem ser comparadas. Considerando esse estudo, nesse trabalho foram feitas comparações entre os dados obtidos com IC e os dados obtidos com GC presentes na literatura.

O oxalato apresentou uma concentração média do período coletado de 200,0 \pm 197,8 $\mathrm{ng} / \mathrm{m}^{3}$. Para o outono de 2017 a concentração foi de 133,8 $\pm 121,8 \mathrm{ng} / \mathrm{m}^{3}$, no inverno foi de $298,8 \pm 243,9 \mathrm{ng} / \mathrm{m}^{3}$, na primavera foi de $227,7 \pm 201,3 \mathrm{ng} / \mathrm{m}^{3}$, e no outono de 2018 foi de 102,3 $\pm 103,3 \mathrm{ng} / \mathrm{m}^{3}$. Neste trabalho, o oxalato apresentou uma concentração no inverno semelhante à Souza et al. (2014) e à Vasconcellos et al. (2011) para São Paulo, e a Kawamura e Ikushima (1993) no Japão para o ano todo. Concentrações mais altas de oxalato foram observadas por Yao et al. (2004) para Hong Kong e concentrações mais baixas foram observadas por Kunwar et al. (2019) para o Japão (monte Fuji) no verão (Tabela 15).

O succinato apresentou vários valores abaixo de zero (34 dias) e por isso deve ser tratado com cautela. O succinato apresentou uma concentração no outono de 2017 de 7,7 $\pm 8,1 \mathrm{ng} / \mathrm{m}^{3}$, no inverno foi $29,9 \pm 21,4 \mathrm{ng} / \mathrm{m}^{3}$, na primavera de $20,0 \pm 31,1 \mathrm{ng} / \mathrm{m}^{3}$, e no outono de 2018 de $7,7 \pm 8,2 \mathrm{ng} / \mathrm{m}^{3}$, e a concentração média para todo o período coletado foi de $17,9 \pm 22,3 \mathrm{ng} / \mathrm{m}^{3}$. No inverno o succinato apresentou uma concentração mais baixa do que a encontrada no inverno em São Paulo em 2008 (Vasconcellos et al., 2011) e em Hong Kong (Yao et al., 2004), contudo semelhante a encontrada em Bogotá (Vasconcellos et al., 2011). Concentrações mais altas de succinato também foram observadas por Kunwar et al. (2019) para o TPS com uma coleta de 24 horas $\left(63 \pm 44 \mathrm{ng} / \mathrm{m}^{3}\right)$. Em contrapartida, na primavera de 2008 em São Paulo 
(Souza et al., 2014) as concentrações de succinato são bem semelhantes à primavera de 2017 (coletada nesse trabalho).

O maleato apresentou uma concentração média para todo período coletado de 17,4 \pm $17,5 \mathrm{ng} / \mathrm{m}^{3}$. Para o outono de 2017 a concentração foi de $10,4 \pm 8,8 \mathrm{ng} / \mathrm{m}^{3}$, no inverno de 21,4 $\pm 21,6 \mathrm{ng} / \mathrm{m}^{3}$, na primavera de $19,6 \pm 18,5 \mathrm{ng} / \mathrm{m}^{3}$, e no outono de $2018 \mathrm{de} 17,1 \pm 14,9 \mathrm{ng} / \mathrm{m}^{3}$. Poucos trabalhos apresentam concentração de maleato, contudo em todos os trabalhos indicados na tabela 15 (Souza et al., 2014 para MP2,5 no inverno; Kunwar et al., 2019 para TPS no verão; Kawamura e Ikushima, 1993 primavera à inverno), as concentrações são mais baixas.

Em relação às estações do ano, o succinato e o oxalato apresentaram neste trabalho maiores concentrações no inverno, sendo que o mesmo foi observado por Yao et al. (2004). Segundo esses autores (Yao et al., 2004), o motivo dessa elevada concentração no inverno comparado ao verão é devido a haver uma camada limite planetária menos profunda, nesse caso, durante o inverno a principal fonte foi a emissão veicular, enquanto no verão foram as reações secundárias. Kawamura e Ikushima (1993) observaram maiores concentrações no verão, e associaram essa elevada concentração a um aumento da produção fotoquímica. Contudo, também observaram concentrações altas no inverno, as quais foram associadas a uma produção secundária, em consequência da oxidação fotoquímica dos precursores orgânicos que foram acumulados devido à camada de inversão. Nesse trabalho, não foram coletadas amostras no verão, e a primavera foi um período com elevada precipitação (seção 3.1), o que possivelmente aumentou a cobertura de nuvens e diminuiu a produção fotoquímica. Mesmo assim, a primavera foi a segunda estação com maior concentração desses compostos. O ozônio (obtido próximo ao local de coleta), que é um composto formado através da produção fotoquímica, apresentou maiores concentrações na primavera $\left(42,0 \mu \mathrm{g} / \mathrm{m}^{3}\right)$, mas com pouca diferença do inverno $\left(38,2 \mu \mathrm{g} / \mathrm{m}^{3}\right)$. A elevada concentração de diácidos no inverno pode ser indicativa de que a produção fotoquímica é importante, mas também pode indicar que há outras fontes para os diácidos como emissão veicular direta ou queima de biomassa, por exemplo. Ademais, como apontado por Yao et al. (2004) a baixa camada limite no inverno também pode ter contribuído para essa elevada concentração, ou ainda como apontado por Kawamura e Ikushima (1993) a produção fotoquímica pode ter sido significativa devido a uma maior concentração dos precursores.

Ao dividir as concentrações dos diácidos pelo carbono total e pela massa do $\mathrm{MP}_{10} \mathrm{e}$ analisar a sua variação durante o período coletado, é possível compreender o quanto e quando os diácidos mais contribuem para a concentração de carbono total e para o aerossol urbano no geral. O oxalato é o diácido que mais contribui para a massa de TC e MP 10 (Figura 21). Apesar 
disso, a maior concentração e maior contribuição do oxalato e succinato, tanto para o TC quanto para o $\mathrm{MP}_{10}$ ocorram durante o inverno, enquanto o maleato apresentou uma maior contribuição para o TC durante a primavera de 2017 e para o MP 10 no Outono de 2018 (estação com menor concentração de $\left.\mathrm{MP}_{10}\right)$.
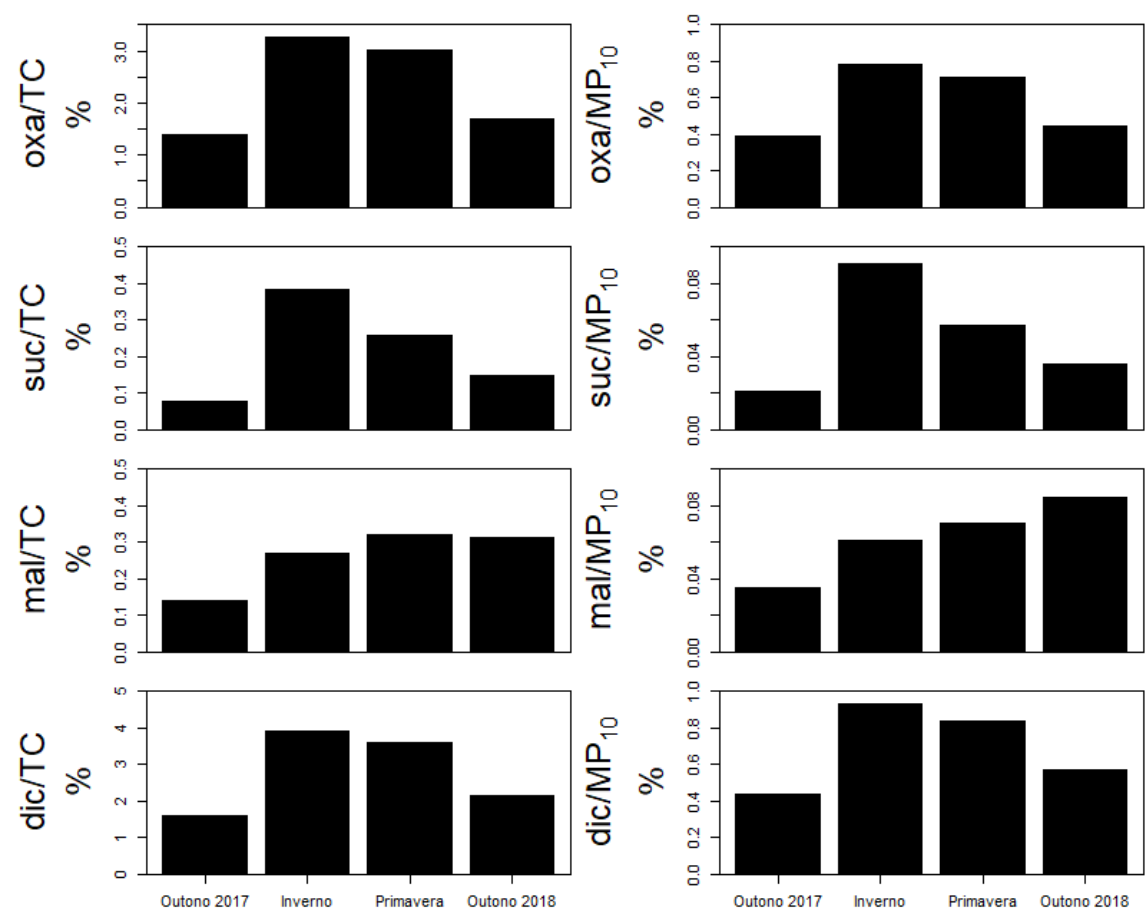

Figura 21. Concentração sazonal dos diácidos dividido pelo carbono total (TC) e $\mathrm{MP}_{10}$.

Kawamura e Ikushima (1993) observaram uma elevada correlação entre ácido oxálico e ácido succinico (porcentagem pelo TC) com um oxidante (maioria ozônio) (r=0,8 e r=0,64) e concluíram que os diácidos são amplamente produzidos na atmosfera por reações fotoquímicas secundárias. Isso também foi observado nesse trabalho, em que o oxalato, o succinato, o maleato e a soma dos três (diácidos) se correlacionaram significativamente $(\mathrm{p}<0,05)$ com o ozônio ( $\rho=0,67, \rho=0,57, \rho=0,35$ e $\rho=0,67$, respectivamente), considerando todo o período amostrado (Figura 22). Ademais, o oxalato se correlacionou melhor com o ozônio do que o succinato e o maleato, indicando que o oxalato é mais intensamente produzido na atmosfera. Vale notar que se correlacionarmos os diácidos (divididos pelo TC) com o ozônio da mesma forma que Kawamura e Ikushima (1993), também é observado uma correlação positiva e significativa, com exceção do maleato.

Compostos com uma cadeia carbônica maior do que 2 (>C2), podem ser oxidados na atmosfera e ter como resultado o ácido oxálico (C2 - menor diácido), como por exemplo a oxidação fotoquímica de hidrocarbonetos aromáticos como benzeno e tolueno (Kundu et al., 2010; Kawamura e Ikushima, 1993). O ácido oxálico nesse caso acaba se acumulando na 
atmosfera (Kundu et al., 2010; Kawamura e Ikushima, 1993). Como observado por Kawamura e Ikushima (1993) no geral compostos com menor cadeia carbônica apresentam maior concentração na atmosfera. No caso do ácido succínico (C4), foi sugerido que pode ser produzido pela oxidação de ácidos dicarboxílicos de cadeia mais longa, monocarboxílicos voláteis e semivoláteis além de oxidação de cicloalcenos, enquanto o ácido maleico pode ser produzido pela oxidação fotoquímica do benzeno (Kawamura e Ikushima, 1993). A elevada correlação entre succinato e oxalato $(\rho=0,67)$ indica que eles podem ter uma mesma origem, isto é, o ácido succínico pode ser um precursor do oxalato como sugerido por Kawamura e Ikushima (1993) e Yao et al. (2004) no verão.

Como apontado por Souza et al. (2014) a correlação entre oxalato com $\mathrm{SO}_{4}{ }^{2-}, \mathrm{NO}_{3}{ }^{-}$, $\mathrm{NH}_{4}{ }^{+}$indica formação secundária do aerossol e contribuição de emissão veicular. O oxalato, bem como os outros diácidos se correlacionam significativamente $(\mathrm{p}<0,05)$ com os íons citados, sendo que a correlação é mais alta entre $\mathrm{SO}_{4}{ }^{2-}$ e $\mathrm{NH}_{4}{ }^{+}$com o maleato, seguida do oxalato e por último o succinato (Figura 22). Isso indica que os diácidos e estes íons podem apresentar a mesma fonte, isto é, uma formação secundária e predominantemente da emissão veicular. 


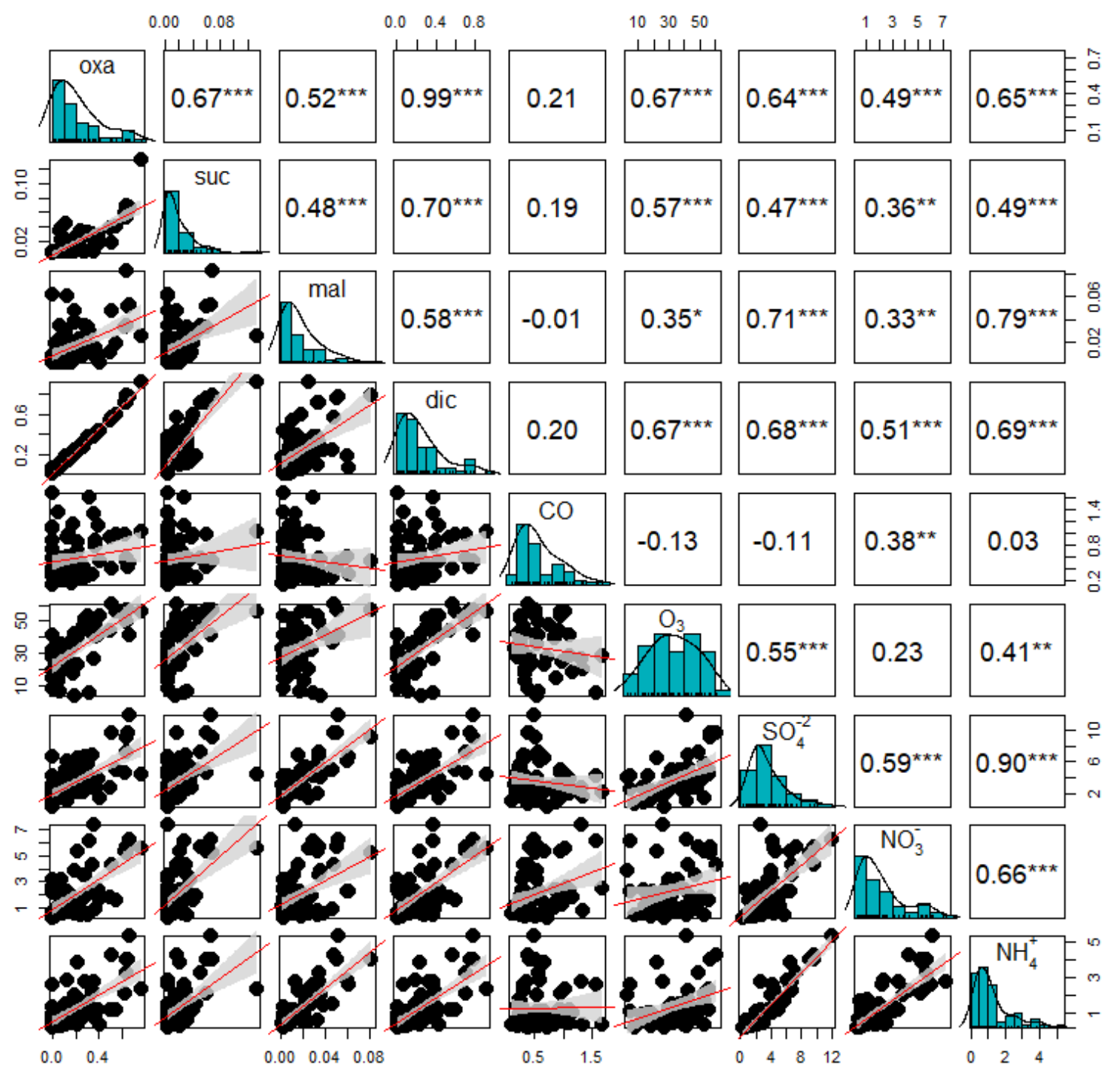

Figura 22. Correlação de Spearman entre os diácidos e alguns poluentes $\left(\mathrm{CO}, \mathrm{O}_{3}, \mathrm{SO}_{4}{ }^{2-}, \mathrm{NO}_{3}{ }^{-}, \mathrm{NH}_{4}{ }^{+}\right)$. Legenda: oxa (oxalato), suc (succinato), mal (maleato), dic (diácidos).

Segundo Davison et al. (1996), o sulfeto de dimetila (DMS) e ácido metanosulfônico (MSA) apresentam um comportamento semelhante e isso fornece evidências para o argumento de que o MSA é produzido pela oxidação do DMS na troposfera (pelo $\mathrm{OH}$ de dia e $\mathrm{NO}_{3}{ }^{-}$de noite) (Chow e Watson, 2017). Kawamura e Bikkina (2016) também apontam que o MSA é um produto da oxidação fotoquímica do DMS no oceano, e ainda Seinfeld e Pandis (2006) afirmam que a oxidação do DMS é a única fonte de MSA na atmosfera. No presente trabalho, apesar de haver uma correlação de Spearman significativa $(\mathrm{p}<0,05)$ entre MSA com o $\mathrm{SO}_{4}{ }^{2-}$ essa correlação é baixa $(\rho=0,43)$. No outono de 2018, quando há uma elevada precipitação e a maioria dos ácidos orgânicos (incluindo o MSA) e $\mathrm{o} \mathrm{SO}_{4}{ }^{2-}$, parecem ser originários da região nordeste/leste (oceano), a correlação de Spearman com o $\mathrm{SO}_{4}{ }^{2-}$ é mais elevada $(\rho=0,72)$. Isso 
pode ser um indicativo de que nas outras estações do ano, quando não há correlação entre MSA e $\mathrm{SO}_{4}{ }^{2-}$, a emissão de $\mathrm{SO}_{4}{ }^{2-}$ é bem mais acentuada localmente (veicular) e a emissão marinha se torna irrelevante. Ainda, a correlação de Spearman positiva e significativa entre o MSA e o íon $\mathrm{NO}_{3}{ }^{-}(\rho=0,59, \mathrm{p}<0,05)$, considerando todo o período amostrado, pode ser um indicativo da sua formação a partir da oxidação do DMS pelo $\mathrm{NO}_{3}{ }^{-}$.

\subsubsection{Sazonalidade}

Para compreender melhor o comportamento desses compostos durante o período coletado, foi elaborada uma correlação de Spearman entre estes e alguns importantes componentes do $\mathrm{MP}_{10}$ considerando as diferentes estações do ano. Rosas do vento e polar plot (gráficos polares bivariados condicionais - CBPF) foram elaborados para verificar a relação com velocidade e direção do vento. O CBPF (Uria-Tellaetxe e Carslaw, 2014; Jeričević et al., 2019) foi utilizado para se compreender melhor as variáveis a partir da identificação da sua direção do vento predominante considerando a velocidade do vento. Os gráficos polares usados para calcular o CBPF utilizaram um percentil de 75, um k = 10 (parâmetro de suavização), número mínimo de pontos iguais a 1 e a estatística $\mathrm{CPF}$.

Para verificar se havia uma diferença estatística das concentrações das variáveis para as estações do ano foi feito o teste de Kruskal Wallis e o post-hoc. Desse modo foi observado que dentre os compostos orgânicos, o formiato, oxalato, succinato, metanosulfonato, glicose, levoglucosano, OC apresentaram uma diferença significativa nas concentrações, considerando as estações do ano. Dentre esses compostos, a principal diferença foi entre o inverno e outono de 2018 (formiato, metanosulfonato, levoglucosano), com algumas exceções (Tabela 16). O OC e oxalato apresentaram no teste de Kruskal Wallis um $\mathrm{p}<0,05$, mas com o post-hoc não foi observada uma diferença significativa entre as estações.

Tabela 16. Post-hoc do teste de Kruskal-Wallis considerando as concentrações sazonais dos compostos orgânicos analisados, bem como alguns componentes chave do $\mathrm{MP}_{10}$ e gases presentes na atmosfera. Essa tabela indica as variáveis que apresentam uma diferença significativa considerando as estações do ano $(\mathrm{p}<0,05)$.

\begin{tabular}{llll}
\hline & Outono 2017 & Primavera & Outono 2018 \\
\hline Outono 2017 & & & levoglucosano \\
Inverno 2017 & succinato & glicose & formiato, metanosulfonato, levoglucosano \\
\hline
\end{tabular}

O outono de 2017 apresentou uma elevada concentração de levoglucosano e manosano indicando uma possível emissão significativa de queima de biomassa, comparada com as outras estações. Com a análise do CBPF (Figura C IX) observa-se que o levoglucosano e manosano parecem apresentar uma fonte mais local, o que está de acordo com o discutido na seção 3.3.4.1 a qual justifica a elevada concentração de levoglucosano em junho devido as fontes que não 
derivem de focos de queimadas distantes, como por exemplo queima de lenha em domicílios e comércio, fogueiras devido a festa junina celebrada nesse período ou queima do bagaço da cana de açúcar em usinas. A correlação entre formiato, levoglucosano, nitrato e CO (Tabela 17 e Figura C VIII), pode indicar que nessa estação a fonte de nitrato e formiato ou seus precursores pode ser a queima de biomassa (Talbot et al., 1988), além da emissão veicular (Talbot et al., 1988; Wang et al., 2007). A correlação do formiato com o CO pode indicar uma emissão primária (Souza et al., 1999; Verma et al., 2017), contudo o formiato é principalmente relacionado com a formação secundária (Alwe et al., 2019, Talbot et al., 1988, Souza et al., 1999, Verma et al., 2017; Wang et al., 2007) e apesar de ter menos irradiação solar nessa estação (IAG, 2017), os precursores desse composto podem ser em grande parte provindos da queima de biomassa, em especial se considerarmos que essa queima foi local e emitida próximo ao sítio de coleta. Esse fato explicaria as correlações e o porquê da falta de correlação desses compostos com conhecidos traçadores veiculares como $\mathrm{SO}_{4}{ }^{2-}$, uma vez que a principal fonte de MP em São Paulo é a emissão veicular (CETESB 2019b). Em contrapartida, a correlação do sulfato e amônio com o oxalato e maleato nessa estação é um indicativo que esses compostos são emitidos por veículos e, possivelmente, com uma formação secundária. Além disso, o CBPF

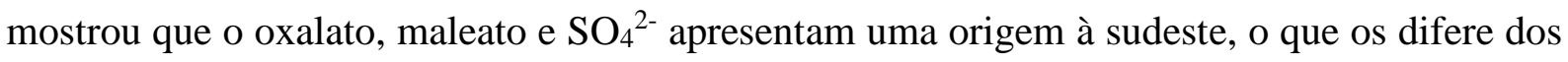
outros compostos orgânicos. A baixa temperatura e baixa irradiação solar global observadas em junho de 2017 (IAG, 2017) pode ter prejudicado a formação fotoquímica em comparação com as outras estações. Isso explicaria a falta de correlação de todos os compostos com o ozônio (é a estação com uma concentração de ozônio bem mais baixa que as outras, com 17,2 $\mu \mathrm{g} / \mathrm{m}^{3}$ ). A falta de correlação entre sulfato e nitrato, indica que nessa estação a fonte de ambos pode ser diferente. Ademais, nessa estação a concentração de nitrato é elevada, o que pode ser explicado pela diminuição da sua fotólise $\left(\mathrm{NO}_{3}+\mathrm{hv}=\mathrm{NO}+\mathrm{O}_{2}\right.$, ou $\left.\mathrm{NO}_{3}+\mathrm{hv}=\mathrm{NO}_{2}+\mathrm{O}\right)$, resultado no seu acúmulo na atmosfera, o que pode esclarecer o seu comportamento diferente do sulfato que possivelmente foi em parte neutralizado pela amônia (seção 3.3.2).

Tabela 17. Correlação de Spearman entre os ácidos orgânicos, anidroaçucares e WSP com CO, $\mathrm{O}_{3}, \mathrm{SO}_{4}{ }^{2-}, \mathrm{NH}_{4}{ }^{+}$, $\mathrm{NO}_{3}{ }^{-}, \mathrm{OC}, \mathrm{EC}, \mathrm{Al}, \mathrm{Fe}, \mathrm{Cl}, \mathrm{Cu}$ e $\mathrm{Pb}$ para o outono de 2017. Os valores mostrados indicam uma correlação significativa.

\begin{tabular}{|c|c|c|c|c|c|c|c|c|c|c|c|c|}
\hline Outono 2017 & $\mathrm{CO}$ & $\overline{\mathrm{O}_{3}}$ & $\mathrm{SO}_{4}^{2-}$ & $\mathrm{NH}_{4}^{+}$ & $\mathrm{NO}_{3}^{-}$ & $\overline{\mathrm{OC}}$ & $\overline{\mathrm{EC}}$ & $\overline{\mathrm{Al}}$ & $\mathrm{Fe}$ & $\overline{\mathrm{Cl}}$ & $\mathrm{Cu}$ & $\mathrm{Pb}$ \\
\hline Acetato & & & & & 0,60 & & & & & & & \\
\hline Formiato & 0,59 & & & 0,67 & 0,63 & 0,78 & 0,75 & & 0,69 & & & \\
\hline Oxalato & & & 0,81 & 0,83 & & & & & & & & \\
\hline Succinato & 0,68 & & & & & & 0,73 & 0,80 & 0,80 & & & \\
\hline Maleato & & & 0,84 & 0,70 & & & & & & & & \\
\hline MSA & 0,69 & & & & 0,74 & 0,90 & 0,70 & 0,61 & 0,65 & & 0,75 & \\
\hline Levoglucosano & 0,69 & & & & 0,76 & 0,97 & 0,73 & & & 0,78 & 0,73 & 0,69 \\
\hline Manosano & 0,72 & & & & 0,76 & 0,97 & 0,74 & & & 0,80 & 0,75 & 0,76 \\
\hline
\end{tabular}




\begin{tabular}{lllllllll}
\hline $\mathrm{K}^{+}$ & 0,75 & 0,67 & 0,82 & 0,72 & 0,62 & 0,64 & 0,78 & 0,72 \\
\hline
\end{tabular}

Legenda: Acetato, Formiato, Oxalato, Succinato, Maleato, Metanosulfonato, Levoglucosano, Manosano e $\mathrm{K}^{+}$.

No inverno a correlação de oxalato e succinato com $\mathrm{SO}_{4}{ }^{2-}$ e $\mathrm{NH}_{4}{ }^{+}$e $\mathrm{O}_{3}$ (Tabela 18), pode indicar uma emissão veicular seguida de reações fotoquímicas que resultam na formação secundária desses compostos (Kawamura e Ikushima, 1993; Souza et al., 2014). A correlação do formiato e acetato com o $\mathrm{O}_{3}$ também pode indicar uma formação secundária (Souza et al., 1999; Verma et al., 2017). No inverno, a inversão térmica e diminuição da camada limite resulta na diminuição na dispersão dos poluentes e como consequência há um aumento nas concentrações dos poluentes e seus precursores (Yao et al., 2004). Como no período de inverno analisado nesse trabalho, as temperaturas foram amenas, a umidade foi baixa, bem como a precipitação, a atmosfera possivelmente apresentou baixa cobertura de nuvens o que favoreceu as reações fotoquímicas, além do acúmulo de precursores. Isso é corroborado pela concentração de $\mathrm{O}_{3}$, que é a segunda maior considerando as estações analisadas. Nessa estação, a maioria dos ácidos orgânicos (com exceção do formiato) não se correlacionaram com o levoglucosano (Figura C X), indicando que a queima de biomassa não é a principal fonte destes compostos, uma vez que a fonte veicular que é local se torna muito mais relevante. Ao mesmo tempo, o levoglucosano e manosano se correlacionaram com o $\mathrm{Al}, \mathrm{Fe}, \mathrm{Pb}$ e $\mathrm{Cu}$, podendo ser um indicativo de uma possível fonte de ressuspensão do solo com a presença de pó e freio que segundo Adachi e Tainosho (2004), apresenta em sua composição o $\mathrm{Cu}$. No caso do levoglucosano este também pode ter como fonte o desgaste de pneus como proposto por Alves et al. (2020). O polar plot (Figura C XI) corrobora a ideia de que o levoglucosano e o manosano apresentam a mesma fonte uma vez que apresentam a mesma direção predominante a noroeste e relacionados com baixas velocidades do vento.

Tabela 18. Correlação de Spearman entre os ácidos orgânicos, anidroaçúcares e WSP com $\mathrm{CO}, \mathrm{O}_{3}, \mathrm{SO}_{4}{ }^{2-}, \mathrm{NH}_{4}{ }^{+}$, $\mathrm{NO}_{3}{ }^{-}, \mathrm{OC}, \mathrm{EC}, \mathrm{Al}, \mathrm{Fe}, \mathrm{Cl}, \mathrm{Cu}$ e $\mathrm{Pb}$ para o inverno de 2017.

\begin{tabular}{lllllllllllll}
\hline Inverno 2017 & $\mathrm{CO}$ & $\mathrm{O}_{3}$ & $\mathrm{SO}_{4}{ }^{2-}$ & $\mathrm{NH}_{4}{ }^{+}$ & $\mathrm{NO}_{3}{ }^{-}$ & $\mathrm{OC}$ & $\mathrm{EC}$ & $\mathrm{Al}$ & $\mathrm{Fe}$ & $\mathrm{Cl}$ & $\mathrm{Cu}$ & $\mathrm{Pb}$ \\
\hline Acetato & & 0,56 & & & & & & & & & & \\
Formiato & & 0,86 & & & & 0,59 & 0,48 & 0,56 & 0,53 & - & & \\
& & & & & & & & & & 0,50 & & \\
Oxalato & & 0,80 & 0,59 & 0,63 & & & & & & - & & \\
& & & & & & & & & & 0,59 & & \\
Succinato & & 0,50 & 0,57 & 0,62 & & & & & & - & & \\
& & & & & & & & & & 0,44 & & \\
Maleato & & & 0,71 & 0,82 & 0,56 & & & & & & & \\
MSA & 0,55 & 0,55 & & & & 0,85 & 0,72 & 0,82 & 0,80 & & 0,70 & 0,59 \\
Levoglucosano & 0,78 & & & & & 0,92 & 0,88 & 0,89 & 0,93 & & 0,68 & 0,70 \\
Manosano & 0,69 & & & & & 0,89 & 0,84 & 0,88 & 0,91 & & 0,55 & 0,70 \\
$\mathrm{~K}^{+}$ & 0,78 & & & & & 0,83 & 0,78 & 0,83 & 0,84 & & 0,64 & 0,55 \\
\hline
\end{tabular}

Legenda: Acetato, Formiato, Oxalato, Succinato, Maleato, Metanosulfonato Levoglucosano, Manosano, e $\mathrm{K}^{+}$. 
$\mathrm{Na}$ primavera, o oxalato e succinato não se correlacionaram com o maleato (Figura $\mathrm{C}$ XII), indicando que estes apresentam uma fonte diferente. Em todas as estações observa-se uma correlação do maleato com o $\mathrm{SO}_{4}{ }^{2-}$ e $\mathrm{NH}_{4}{ }^{+}$, indicando que ele possivelmente é emitido pelas mesmas fontes que esses íons. Sabe-se que a maior parte do sulfato e amônio em São Paulo são originários das emissões veiculares (Vasconcellos et al., 2007; Souza et al., 2014; Hetem et al., 2016). O oxalato e succinato parecem ser emitidos por essa fonte, mas também por outras fontes o que na primavera fica mais evidente. A primavera é a única estação em que o oxalato apresenta uma correlação significativa com o levoglucosano, enquanto o succinato e oxalato se correlacionam também com o $\mathrm{K}^{+}$. Dessa forma, nessa estação, a principal fonte de oxalato e succinato pode ser a mesma do levoglucosano e do $\mathrm{K}^{+}$. O levoglucosano e $\mathrm{K}^{+}$são traçadores de queima de biomassa, sendo a queima de biomassa também uma fonte de oxalato e succinato (Simoneit et al., 1999; Kawamura e Bikkina, 2016; Kundu et al. 2010). Esses ácidos orgânicos podem ter como fonte a queima de biomassa através de uma produção fotoquímica, uma vez que oxalato, succinato e formiato se correlacionam com o ozônio. Nessa estação, devido a velocidade do vento média elevada (5,9 m/s - maior valor comparado com as outras estações), pode-se propor que há um transporte de massas de ar de outras regiões com queima de biomassa. Ademais, nessa estação o polar plot (Figura C XIII) para os anidroaçucares, OC e EC indica que a direção predominante do vento é de noroeste e associada com elevadas velocidades, região associada à presença da queima de cana de açúcar. Em contrapartida, os ácidos orgânicos (formiato, succinato e maleato) apresentam maiores concentrações de direção sudeste, também relacionado a velocidades do vento mais altas. Além dessa fonte, os ácidos orgânicos, levoglucosano e manosano também se correlacionaram com o Al (Tabela 19), podendo indicar uma ressuspensão do solo também como fonte.

Tabela 19. Correlação de Spearman entre os ácidos orgânicos, anidroaçucares e WSP com $\mathrm{CO}, \mathrm{O}_{3}, \mathrm{SO}_{4}{ }^{2-}, \mathrm{NH}_{4}{ }^{+}$, $\mathrm{NO}_{3}^{-}, \mathrm{OC}, \mathrm{EC}, \mathrm{Al}, \mathrm{Fe}, \mathrm{Cl}, \mathrm{Cu}$ e $\mathrm{Pb}$ para a primavera de 2017.

\begin{tabular}{lllllllllllll}
\hline Primavera & $\mathrm{CO}$ & $\mathrm{O}_{3}$ & $\mathrm{SO}_{4}^{2-}$ & $\mathrm{NH}_{4}^{+}$ & $\mathrm{NO}_{3}^{-}$ & $\mathrm{OC}$ & $\mathrm{EC}$ & $\mathrm{Al}$ & $\mathrm{Fe}$ & $\mathrm{Cl}$ & $\mathrm{Cu}$ & $\mathrm{Pb}$ \\
2017 & & & & & & & & & & & & \\
\hline Acetato & 0,48 & & & & & 0,69 & 0,55 & 0,70 & & & \\
Formiato & 0,56 & 0,86 & 0,54 & 0,47 & 0,64 & 0,77 & 0,72 & 0,78 & 0,62 & & & 0,48 \\
Oxalato & 0,53 & 0,86 & 0,48 & & 0,55 & 0,71 & 0,62 & 0,73 & & & & \\
Succinato & & 0,88 & & & & & & 0,50 & & & \\
Maleato & & & 0,63 & 0,80 & 0,51 & & & & & $-0,54$ & \\
MSA & & 0,83 & 0,58 & & 0,53 & & & & & & & \\
Levoglucosano & 0,87 & & & & 0,52 & 0,93 & 0,97 & 0,87 & 0,74 & $-0,56$ & 0,69 & 0,58 \\
Manosano & 0,86 & & & & & 0,80 & 0,86 & 0,52 & 0,57 & $-0,68$ & 0,71 & \\
$\mathrm{~K}^{+}$ & 0,83 & & & & 0,52 & 0,93 & 0,92 & 0,88 & 0,64 & $-0,51$ & 0,63 & 0,59 \\
\hline
\end{tabular}

Legenda: Acetato, Formiato, Oxalato, Succinato, Maleato, Metanosulfonato, Levoglucosano, Manosano e $\mathrm{K}^{+}$.

No outono de 2018, a correlação da maioria dos ácidos orgânicos com o $\mathrm{O}_{3}$, sulfato e amônio indicam que a principal fonte destes compostos é a emissão veicular e reação 
fotoquímica, semelhante ao inverno de 2017 (Tabela 20). A falta de correlação do levoglucosano com esses compostos (Figura C XIV) indica que a queima de biomassa não é uma fonte relevante desses orgânicos nessa estação e sua correlação negativa com o Cu e falta de correlação com elementos relacionados ao solo indica que a emissão pelos pneus de veículos também não parece ser uma fonte relevante nessa estação. Ainda, a direção do vento sendo predominantemente do Nordeste difere das outras estações, e explica a baixa concentração da maioria dos compostos (com exceção dos biomarcadores de fungos), além da elevada precipitação dessa estação. As concentrações dos traçadores biogênicos são elevadas nessa estação e a correlação entre eles também é elevada indicando que a presença de esporos fúngicos e outros bioaerossóis nessa estação é mais relevante.

Tabela 20. Correlação de Spearman entre os ácidos orgânicos, anidro açúcar e WSP com CO, $\mathrm{O}_{3}, \mathrm{SO}_{4}{ }^{2-}, \mathrm{NH}_{4}{ }^{+}$, $\mathrm{NO}_{3}^{-}, \mathrm{OC}, \mathrm{EC}, \mathrm{Al}, \mathrm{Fe}, \mathrm{Cl}, \mathrm{Cu}$ e $\mathrm{Pb}$ para o outono de 2018.

\begin{tabular}{|c|c|c|c|c|c|c|c|c|c|c|c|c|}
\hline Outono 2018 & $\mathrm{CO}$ & $\mathrm{O}_{3}$ & $\mathrm{SO}_{4}^{2-}$ & $\mathrm{NH}_{4}{ }^{+}$ & $\mathrm{NO}_{3}{ }^{-}$ & $\mathrm{OC}$ & $\mathrm{EC}$ & $\overline{\mathrm{Al}}$ & $\mathrm{Fe}$ & $\mathrm{Cl}$ & $\mathrm{Cu}$ & $\mathrm{Pb}$ \\
\hline Acetato & & & & & & & & & & & & \\
\hline Formiato & & 0,78 & 0,92 & 0,86 & & 0,62 & 0,57 & & & & & \\
\hline Oxalato & & 0,76 & 0,87 & 0,84 & & 0,56 & 0,63 & & & & & \\
\hline Succinato & & 0,75 & & & & & & & & & & \\
\hline Maleato & & 0,62 & 0,75 & 0,80 & & & & & & & & \\
\hline MSA & & & 0,72 & 0,55 & 0,54 & 0,71 & 0,55 & & & & & \\
\hline Levoglucosano & & & & & & 0,91 & 0,76 & & & & $-0,69$ & \\
\hline Manosano & & & & & & & & & & & & \\
\hline $\mathrm{K}^{+}$ & & & & & & 0,90 & 0,78 & & & & $-0,79$ & \\
\hline
\end{tabular}

Legenda: Acetato, Formiato, Oxalato, Succinato, Maleato, Metanosulfonato, Levoglucosano, Manosano e $\mathrm{K}^{+}$.

Um resumo das principais fontes dos compostos orgânicos considerando as estações do ano está apresentado na Tabela B IV.

\subsubsection{Biomarcadores e esporos de fungos}

\subsection{Concentração e variação temporal dos bioaerossóis}

A média sazonal da concentração de arabitol, manitol, glicose/xilose, proteínas solúveis em água e a concentração em número de esporos fúngicos totais (TS) está apresentada na tabela 21. Como observado por muitos autores (Emygdio et al., 2018a; Nirmalkar et al., 2015; Bauer et al., 2008a; Zhang et al., 2010; Rathnayake et al., 2016; Caumo et al., 2016), a concentração medida de manitol foi maior do que a do arabitol.

Tabela 21. Concentração média ( \pm desvio padrão) em ng/m³ para arabitol, glicose/xilose, manitol, proteínas solúveis em água (WSP) e esporos totais (TS) considerando a média de todo o período amostrado ( $\mathrm{n}=66$ para TS e $n=69$ para os açucares e WSP) e as estações do ano.

\begin{tabular}{llllll}
\hline Período & $\begin{array}{l}\text { Arabitol } \\
\left(\mathrm{ng} / \mathrm{m}^{3}\right)\end{array}$ & $\begin{array}{l}\text { Glicose/xilose } \\
\left(\mathrm{ng} / \mathrm{m}^{3}\right)\end{array}$ & $\begin{array}{l}\text { Manitol } \\
\left(\mathrm{ng} / \mathrm{m}^{3}\right)\end{array}$ & $\begin{array}{l}\text { WSP } \\
\left(\mathrm{ng} / \mathrm{m}^{3}\right)\end{array}$ & $\begin{array}{l}\text { Esporos Totais } \\
\left(\mathrm{esporos} / \mathrm{m}^{3}\right)\end{array}$ \\
\hline $\begin{array}{l}\text { Média de todo o período } \\
\text { amostrado }\end{array}$ & $31,4( \pm 23,7)$ & $53,3( \pm 35,5)$ & $50,0( \pm 36,3)$ & $69,5( \pm 25,6)$ & $11204( \pm 7888)$ \\
$\begin{array}{l}\text { Outono 2017 } \\
\text { Inverno 2017 }\end{array}$ & $27,9( \pm 18,0)$ & $52,2( \pm 25,6)$ & $50,8( \pm 34,2)$ & $57,9( \pm 26,0)$ & $10774( \pm 4905)$ \\
Primavera 2017 & $\begin{array}{l}18,8( \pm 8,3) \\
30,5( \pm 9,5)\end{array}$ & $\begin{array}{l}25,0( \pm 8,3) \\
489,1( \pm 22,1)\end{array}$ & $\begin{array}{l}5551( \pm 1974) \\
12282( \pm 7201)\end{array}$ \\
\hline
\end{tabular}




\begin{tabular}{llllll}
\hline Outono 2018 & $43,5( \pm 23,6)$ & $68,2( \pm 33,4)$ & $78,5( \pm 38,9)$ & $79,8( \pm 28,4)$ & $\begin{array}{l}17176 \\
( \pm 10188)\end{array}$ \\
\hline
\end{tabular}

Tabela 22. Concentração média \pm desvio padrão (quando disponível) em ng/m³ para arabitol, glicose/xilose, manitol, proteínas solúveis em água (WSP) considerando a literatura.

\begin{tabular}{|c|c|c|c|c|c|c|c|c|}
\hline & Estação & Local & $\begin{array}{l}\text { Tamanho } \\
\text { do MP }\end{array}$ & $\begin{array}{l}\text { Arabitol } \\
\mathrm{ng} / \mathrm{m}^{3}\end{array}$ & $\begin{array}{l}\text { Manitol } \\
\mathrm{ng} / \mathrm{m}^{3}\end{array}$ & $\begin{array}{l}\text { Glicose/xilose } \\
\mathrm{ng} / \mathrm{m}^{3}\end{array}$ & $\begin{array}{l}\text { WSP } \\
\mu \mathrm{g} / \mathrm{m}^{3}\end{array}$ & $\begin{array}{l}\mathrm{TS} \\
\text { esporos } / \mathrm{m}^{3}\end{array}$ \\
\hline $\begin{array}{l}\text { Bauer et al. } \\
(2008 \mathrm{a})\end{array}$ & $\begin{array}{l}\text { Summer } \\
(2005)\end{array}$ & $\begin{array}{l}\text { Viena } \\
\text { (local de } \\
\text { tráfego } \\
\text { urbano) }\end{array}$ & $\mathrm{MP}_{10}$ & 28 & 42 & & & \\
\hline $\begin{array}{l}\text { Gosselin et } \\
\text { al. (2016) }\end{array}$ & $\begin{array}{l}\text { Chuvoso } \\
(20 \text { julho } \\
\text { a } 23 \\
\text { agosto } \\
2011)\end{array}$ & $\begin{array}{l}\text { Colorado, } \\
\text { USA } \\
\text { (região de } \\
\text { floresta de } \\
\text { pinheiros } \\
\text { semi-árida } \\
\text { montanha) }\end{array}$ & $\begin{array}{l}\text { TPS } \\
\text { (chuvoso) }\end{array}$ & $\begin{array}{l}35,2 \\
10,5\end{array}$ & $\begin{array}{l}44,9 \pm \\
13,8\end{array}$ & $73,2 \pm 50,5$ & & \\
\hline $\begin{array}{l}\text { Zhang et al. } \\
\text { (2010) }\end{array}$ & $\begin{array}{l}\text { Primavera } \\
(2004)\end{array}$ & China & $\mathrm{MP}_{10}$ & 44 & 71 & & & \\
\hline $\begin{array}{l}\text { Rathnayake } \\
\text { et al. } \\
(2016) \text {, }\end{array}$ & $\begin{array}{l}\text { Janeiro, } \\
\text { abril, } \\
\text { julho e } \\
\text { outubro } \\
(2012)\end{array}$ & $\begin{array}{l}\text { Iowa, USA } \\
\text { (urbano) }\end{array}$ & $\mathrm{MP}_{10}$ & $\begin{array}{l}19,7 \quad \pm \\
18,0\end{array}$ & $\begin{array}{l}31,8 \pm \\
34,5\end{array}$ & $32,7 \pm 32,9$ & $\begin{array}{l}1,96 \\
\pm \\
1,11\end{array}$ & \\
\hline $\begin{array}{l}\text { Urban et al. } \\
(2014)\end{array}$ & $\begin{array}{l}\text { Colheita } \\
\text { (abril a } \\
\text { novembro } \\
2010- \\
2012 \text { ) }\end{array}$ & $\begin{array}{l}\text { Araraquara, } \\
\text { Brasil }\end{array}$ & NA & $19 \pm 17$ & $7 \pm 7$ & & & \\
\hline $\begin{array}{l}\text { Caumo et } \\
\text { al. }(2016)\end{array}$ & $\begin{array}{l}\text { Inverno } \\
(2012)\end{array}$ & $\begin{array}{l}\text { São Paulo, } \\
\text { Brasil }\end{array}$ & $\mathrm{MP}_{10}$ & $\begin{array}{l}10 \\
10,7\end{array}$ & $\begin{array}{l}12,5 \\
14,4\end{array}$ & & & \\
\hline $\begin{array}{l}\text { Emygdio et } \\
\text { al. (2018a) }\end{array}$ & $\begin{array}{l}\text { Outono- } \\
\text { inverno } \\
(2015)\end{array}$ & $\begin{array}{l}\text { São Paulo, } \\
\text { Brasil }\end{array}$ & $\mathrm{MP}_{10}$ & 11,7 & 23,3 & & & 5724 \\
\hline $\begin{array}{l}\text { Emygdio et } \\
\text { al. (2018a) }\end{array}$ & $\begin{array}{l}2013 \\
2014\end{array}$ & $\begin{array}{l}\text { São Paulo, } \\
\text { Brasil }\end{array}$ & $\mathrm{MP}_{10}$ & & & & & $\begin{array}{l}5737 \\
2460\end{array}$ \\
\hline $\begin{array}{l}\text { Menetrez et } \\
\text { al. (2007a) }\end{array}$ & $\begin{array}{l}\text { Agosto } \\
2003 \quad \text { a } \\
\text { Janeiro } \\
2004\end{array}$ & $\begin{array}{l}\text { Carolina do } \\
\text { Norte } \\
\text { (EUA) }\end{array}$ & $\begin{array}{l}\mathrm{MP}_{2,5-10} \\
\mathrm{MP}_{2,5}\end{array}$ & & & & $\begin{array}{l}125 \\
111\end{array}$ & \\
\hline
\end{tabular}

*NA - não indicado

A concentração média dos álcoois de açúcar durante todo o período analisado foi similar aos obtidos por Bauer et al. (2008a) e Gosselin et al. (2016) como apresentado na tabela 2. Zhang et al. (2010) apresentaram concentrações similares, mas maiores (primavera), enquanto Rathnayake et al. (2016), Urban et al. (2014) Caumo et al. (2016) e Emygdio et al. (2018a) apresentaram concentrações menores considerando as respectivas estações do ano.

As menores concentrações de arabitol e manitol em São Paulo em 2012, 2013 (Caumo et al. 2016) e 2015 (Emygdio et al., 2018a), comparadas com as apresentadas nesse trabalho em 2017 e 2018 pode significar que houve um aumento na concentração de esporos fúngicos na 
atmosfera de São Paulo, durante o período amostrado e o local de coleta. Essa hipótese é confirmada quando analisado o número de esporos fúngicos obtidos com o amostrador Burkard (Tabela 21), que mostra maiores concentrações comparados com análises anteriores no mesmo local amostrado (Emygdio et al., 2018a; 2018b). Vale mencionar que esse comportamento é o oposto ao observado para a concentração de $\mathrm{MP}_{10}$ que diminuiu de $33 \mu \mathrm{g} / \mathrm{m}^{3}, 36 \mu \mathrm{g} / \mathrm{m}^{3}$ e 31 $\mu \mathrm{g} / \mathrm{m}^{3}$ em 2013, 2014 e 2015 para $29 \mu \mathrm{g} / \mathrm{m}^{3}$ em 2017 e 2018 na RMSP de acordo com a companhia ambiental do Estado de São Paulo (CETESB, 2019b). Comparando com a concentração de $\mathrm{MP}_{10}$ no inverno, a concentração diminuiu de $40 \mu \mathrm{g} / \mathrm{m}^{3}$ e $94 \mu \mathrm{g} / \mathrm{m}^{3}$ em 2012 e 2013, respectivamente (Caumo et al., 2016), para $37 \mu \mathrm{g} / \mathrm{m}^{3}$ em 2017.

A concentração de WSP obtidas nesse trabalho foram menores do que as concentrações de proteínas obtidas por Menetrez et al. (2007a) e o observado por Rathnayake et al. (2016). No geral, glicose/xilose acompanharam os comportamentos do arabitol e manitol e a concentração de glicose obtida nesse trabalho foi maior do que a obtida por Rathnayake et al. (2016). Os esporos totais, arabitol e manitol mostraram uma diferença significativa de aproximadamente 1,5 a 2 vezes maior em 2018, quando comparado com 2017. Em 2018, apenas 2 meses (março e abril), característicos do verão $(n=4)$ e outono $(n=14)$ foram amostrados. Em contrapartida, em 2017 a amostragem ocorreu durante os meses que perfazem o outono, inverno e primavera, trazendo um espectro maior de esporos de fungos.

A maioria dos grupos de esporos fúngicos (AS, BS e UD) também mostraram uma concentração significativamente maior em 2018 comparado com 2017, e uma diferença significativa entre o outono de 2018 e o inverno de 2017 (Tabela B V, Post Hoc). A maioria dos tipos/gêneros fúngicos do AS e BS parecem apresentar menores concentrações no inverno (Figura C XVI). O grupo BS teve um comportamento similar ao TS considerando as estações, em ordem decrescente: outono de 2018, primavera de 2017, outono de 2017 e inverno de 2017, já que representam a maior parte da concentração do TS ( 45\%). Basidiosporo hialino é o subgrupo de esporo fúngico que mais contribuiu para a concentração total de esporos (33\%) e para o seu grupo BS (75\%). Esse grupo inclui vários gêneros dentro do grupo do BS que libera esporos hialinos. As concentrações de basidiósporos não são geralmente encontradas na literatura, principalmente porque os espécimes do filo Basidiomycota, no geral, são difíceis de crescer e ser identificáveis em técnicas de cultivo. Como discutido por Fröhlich-Nowoisky et al. (2012;2009), o filo Basidiomycota é frequentemente subestimado, apesar de ser o filo mais predominante na atmosfera continental global (Fröhlich-Nowoisky et al., 2012). A maior contribuição do BS para o TS foi observada em outros trabalhos no mesmo local de coleta (Emygdio et al., 2018b; Degobbi et al., 2011). 
O grupo AS que representa apenas $\sim 17 \%$ do TS, teve maiores concentrações no outono de 2018 seguido do outono de 2017. Diatrypaceae-like (grande) é o principal tipo fúngico no grupo AS, representando $33 \%$ da concentração de AS, sendo importante para o TS também (representando 6\% do TS). O Diatrypaceae-like representa vários gêneros dentro da família Diatrypaceae ou esporos de fungos com morfologia similar.

O MS, que representa $20 \%$ do TS, mostra um comportamento bem diferente dos outros grupos, com uma concentração significativamente maior em 2017 quando comparado com 2018, e apesar de não ser significativo, apresenta maior concentração na primavera e outono de 2017, e baixa concentração no outono de 2018. Alguns tipos fúngicos pertencentes ao MS, como o Cladosporium, Epicoccum-like e Alternaria-like apresentaram um pico na primavera, enquanto outros como Curvularia-like, Drechslera-like, Periconia-like, Spegazzinia-like e Torula-like apresentaram um pico no outono de 2017 (Figura C XVI). Cladosporium sp. é o gênero que mais contribuiu para o TS (14\%) e representa $68 \%$ do grupo MS, ao qual pertence. Esse gênero está presente em todos os ecossistemas da terra (Després et al., 2012) onipresente e encontrado como o principal ou com elevada concentração em vários estudos ao redor do mundo (Burch \& Levetin, 2002; Després et al., 2012; Ščevková and Kováč, 2019; Wu et al., 2007; Ataygul et al., 2007).

Vale a pena mencionar que alguns tipos fúngicos como o Cladosporium sp. e Ganoderma-like são encontrados durante todo o ano, enquanto outros tipos fúngicos como Venturia-like, Pithomyces-like, Curvularia-like, Drechslera-like, Spegazzinia-like, Pleosporalike, entre outros, apresentam alguns períodos com uma concentração bem baixa ou mesmo nula.

\subsection{Influência das variáveis meteorológicas nos bioaerossóis}

Nas estações com elevadas concentrações de esporos fúngicos e alguns açúcares (outono 2018 e primavera de 2017$)$ foram observadas elevada temperatura média $\left(22^{\circ} \mathrm{C} \mathrm{e} 19^{\circ} \mathrm{C}\right)$ e precipitação acumulada $(49,5 \mathrm{~mm}$ e $58,9 \mathrm{~mm})$ quando comparadas com os outros períodos de experimento. Arabitol, manitol e WSP correlacionaram positivamente e significativamente com a temperatura média, máxima e mínima, enquanto o TS correlacionou com a temperatura média e mínima. Um comportamento similar foi observado por alguns autores (Zhang et al., 2010; Adhikari et al., 2006; Rathnayake et al., 2016; Rathnayake et al., 2017; Zhu et al., 2018). A temperatura é um importante fator para o desenvolvimento dos fungos, o que pode resultar em maior concentração de esporos, como apontado por alguns autores (Rathnayake et al., 2016; Grinn-Gofroń and Rapiejko, 2009). Nesse trabalho, também deve ser considerado que o período 
com maior temperatura foi também quando ocorreu maior acúmulo de precipitação e maior umidade, o que também pode ser relacionado com a liberação de esporos na atmosfera (Haines et al., 2000; Burge et al., 2006; Burch \& Levetin, 2002; Lacey, 1996; Li \& Kendrick, 1995; Fischer et al., 2010; Webster \& Weber, 2007). Essa situação é reforçada pela correlação significativa e positiva do arabitol e TS com a precipitação (Figura C XVII e Figura C XVIII).

O AS correlaciona positivamente com a precipitação e umidade (média, mínima e máxima), enquanto o BS e UD apenas se correlacionam positivamente com a temperatura (Figura C XVIII). O MS correlaciona positivamente com a temperatura máxima e negativamente com a umidade relativa média e mínima. Observa-se na figura 23 que a concentração de AS apresenta os picos coincidentes com os picos da precipitação acumulada, contudo o MS parece ser maior em períodos com baixa precipitação. Um comportamento similar foi observado por Emygdio et al. (2016), que também discutiu o comportamento de esporos em São Paulo.
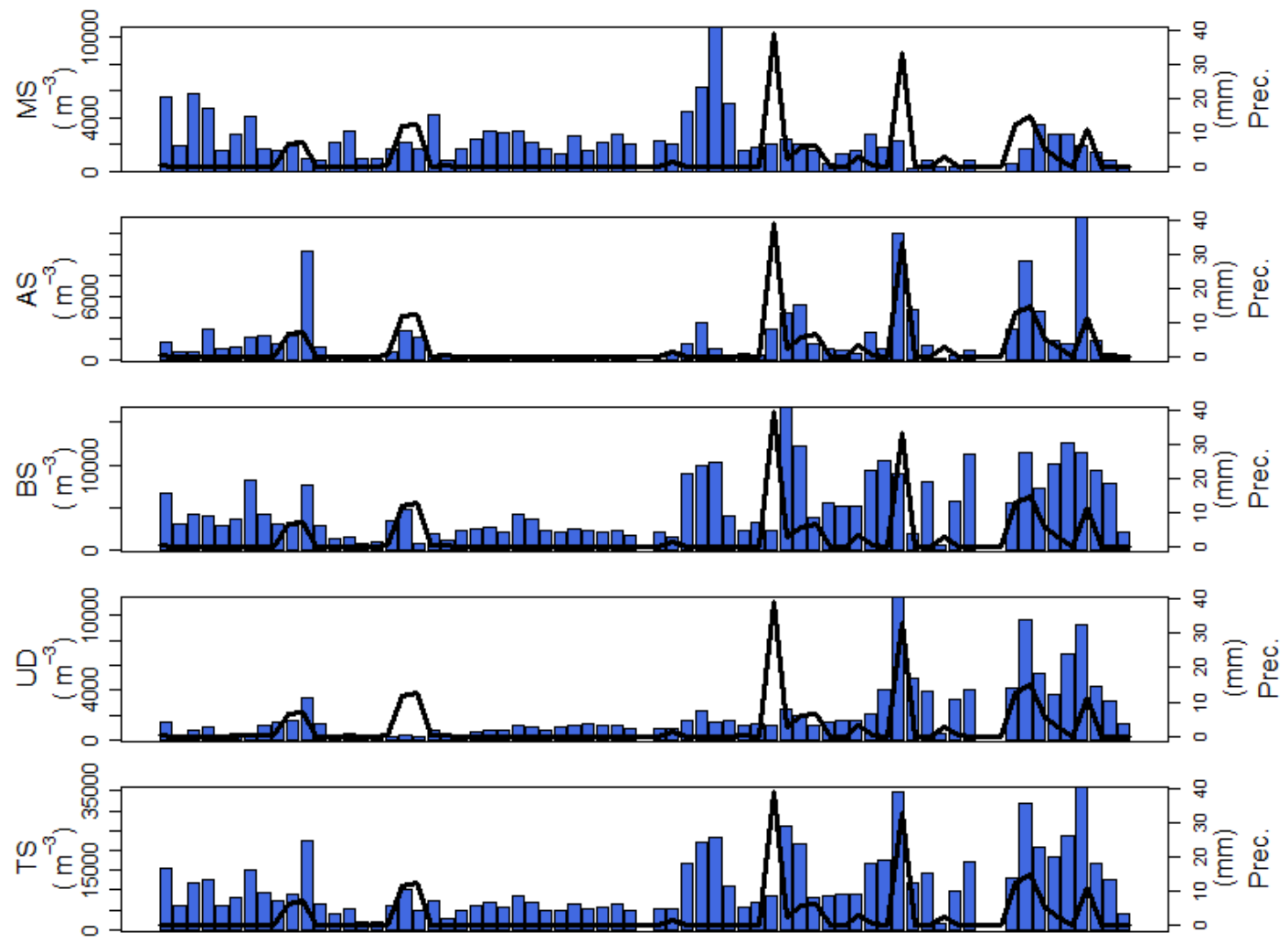


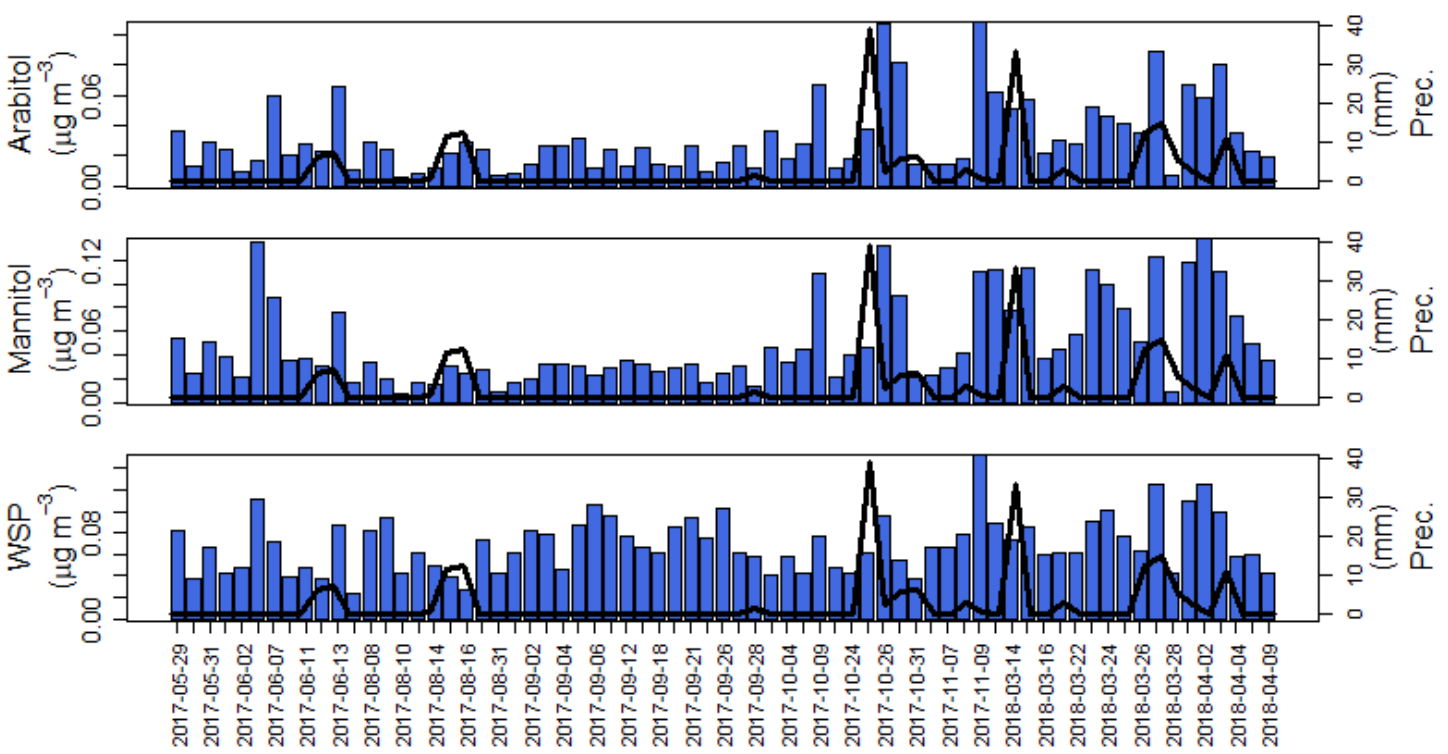

Figura 23. Concentração diária de mitósporos (MS), ascósporos (AS), basidiósporos (BS), desconhecido (UD), esporos totais (TS) em esporos $/ \mathrm{m}^{3}$ e arabitol, manitol e proteínas solúveis em água (WSP) em $\mu \mathrm{g} / \mathrm{m}^{3}$ e precipitação acumulada em mm (Prec.).

Os dias chuvosos representaram $\sim 40 \%$ de todo o período amostrado, sendo $\sim 44 \%$ dos dias amostrados na primavera de 2017, 50\% no outono de 2018 e 2017, e 24\% no inverno de 2017. Assim, apesar da precipitação acumulada ser maior na primavera de 2017, há mais dias chuvosos no outono de 2018, e essa frequência de precipitação acumulada, poderia explicar a elevada concentração de esporos fúngicos nessa estação. Arabitol e manitol tiveram maiores concentrações nos dias chuvosos, quando comparado aos dias sem chuva (1,6 e 1,2 vezes maior, respectivamente). De forma similar, TS, AS, BS e UD também apresentaram concentração maior nos dias com precipitação $(1,5 ; 3,85 ; 1,35$; e 1,66 vezes maior, respectivamente). Contudo, apenas o AS (W=206, p<0,05, r=-0,50) e TS $(\mathrm{W}=357, \mathrm{p}<0,05, \mathrm{r}=-0,26)$ apresentaram uma diferença significativa entre os dias com e sem chuva. Adicionalmente, observando a figura 23 fica claro que os esporos fúngicos e a concentração de biomarcadores é geralmente maior durante os períodos chuvosos, com a exceção do MS.

Predominantemente, maiores correlações são observadas entre os esporos de fungos (TS, AS, BS e UD) com arabitol e manitol, quando há precipitação (Figura C XIX) quando comparado com dias sem precipitação (Figura C XX) ou com todo o período amostrado (Figura C XXI). Uma maior concentração de esporos fúngicos durante períodos chuvosos, e um maior background de outras partículas contendo arabitol e manitol na sua composição durante períodos secos, poderia explicar essa diferença na correlação, como sugerido por Gosselin et al. (2016). Essa poderia ser também a explicação para a falta de correlação entre os açúcares e o MS, uma vez que o MS apresenta maiores concentrações em períodos com baixa concentração 
de esporos fúngicos. Assim, nesses períodos, poderia haver uma concentração de açúcar de outras fontes que iria "distorcer" essa correlação.

No geral, os grupos AS, BS e UD correlacionam melhor com o manitol do que com o arabitol. Em contrapartida, o MS correlaciona apenas com o arabitol quando considerado os dias sem chuva. Apenas o AS correlaciona significativamente com a precipitação quando considerado apenas os dias chuvosos $(\rho=0,64)$.

Muitos estudos sugerem que os esporos fúngicos são relacionados de alguma forma com a umidade e precipitação (Zhang et al., 2010; Huffman et al., 2013). Uma relação positiva é observada para alguns tipos fúngicos pertencentes aos grupos AS e BS, enquanto o oposto é observado para outros, como os pertencentes ao grupo MS (Emygdio et al., 2018b; Fischer et al., 2010; Grinn-Gofroń \& Rapiejko, 2009; Elbert et al., 2007; Pyrri and Kapsanaki-Gotsi, 2017; Ianovici, 2016; Webster \& Weber, 2007; Haines et al., 2000; Burch \& Levetin, 2002; Lacey, 1996; Li \& Kendrick, 1995).

Uma explicação para a elevada concentração de esporos fúngicos durante os períodos de chuva pode ser devido ao mecanismo de liberação de esporos, que para alguns Basidiomycota é relacionado com a umidade relativa (Elbert et al., 2007; Fischer et al., 2010; Webster \& Weber, 2007), enquanto alguns Ascomycota são dependentes de umidade e precipitação (Elbert et al., 2007; Haines et al., 2000; Burch \& Levetin, 2002; Lacey, 1996; Li \& Kendrick, 1995). Esse mecanismo dependente de umidade e que está presente em alguns representantes desses grupos (AS e BS) foi chamado por Elbert et al. (2007) como "descarga úmida de esporos".

Elbert et al. (2007) e outros autores (Grinn-Gofroń \& Rapiejko, 2009), também discutiram a chamada "liberação seca de esporos", a qual é geralmente relacionada com um ambiente quente, seco e com vento. Esse tipo de mecanismo é observado em alguns fungos pertencentes, nesse trabalho, ao grupo MS (Elbert et al., 2007). Esse mecanismo explica a correlação significativa e negativa entre MS com a umidade relativa média e mínima observada nesse trabalho.

\subsection{Correlação entre gases, componentes do MP10 e biomarcadores}

De maneira geral, arabitol, manitol, WSP e TS correlacionam significativamente e positivamente entre si (Figura 24). O único tipo fúngico pertencente ao grupo MS que se correlacionou com um dos açucares (arabitol) foi o Cladosporium sp., que é o gênero mais abundante (Figura C XXII). Em contrapartida, a maioria dos esporos fúngicos pertencentes ao BS, com exceção da Gliomatix, correlaciona com o arabitol e manitol, especialmente o $B S$ 
desconhecido, BS hialino e o Coprinus sp. (Figura C XXIII). Ademais, o myxomiceto e o subgrupo desconhecido também apresentam uma correlação com pelo menos um açúcar. Para o grupo do AS, os tipos fúngicos Venturia-like, Xylariaceae, 2 células colorias AS, 4 células coloridas AS e AS desconhecido, mostraram uma correlação com ambos os açucares (Figura C XXIV). Vale a pena mencionar que coincidentemente ou não, quase todos os tipos fúngicos pertencentes ao AS que se correlacionaram com os açúcares são coloridos. Especificamente, entre os tipos fúngicos classificados como AS com 2 ou 4 células, apenas os classificados como coloridos correlacionaram com os biomarcadores. Mais estudos devem ser feitos para elucidar essa questão. Geralmente quando os esporos fúngicos se correlacionam com os açucares, o manitol é o que apresenta maior correlação.

Uma correlação positiva e significativa entre arabitol e manitol também foi observada por Bauer et al. (2008a) $\left(R^{2}=0,87\right)$, Emygdio et al. (2018a) $(\sim \rho=0,9)$, Zhang et al. $(2010)\left(R^{2}=\right.$ 0,886 para o $\left.\mathrm{MP}_{10}\right)$, Gosselin et al. (2016) $\left(\mathrm{R}^{2}=0,839\right.$ amostras com chuva) e muitos outros autores (Graham et al., 2003; Rathnayake et al., 2016; Nirmalkar et al., 2015; Zhu et al., 2018). A relação entre esporos fúngicos e arabitol e manitol também foi observada em outros trabalhos (Bauer et al., 2008a; Emygdio et al., 2018a). Rathnayake et al. (2016) também observaram uma elevada correlação entre arabitol e manitol com WSP. A correlação média entre arabitol, manitol e TS com WSP encontrada nesse trabalho (Figura 24) é esperada, já que o WSP representa todos os tipos de bioaerossóis no MP, incluindo pólen, bactérias e outros que podem ter um padrão diferente na atmosfera. 

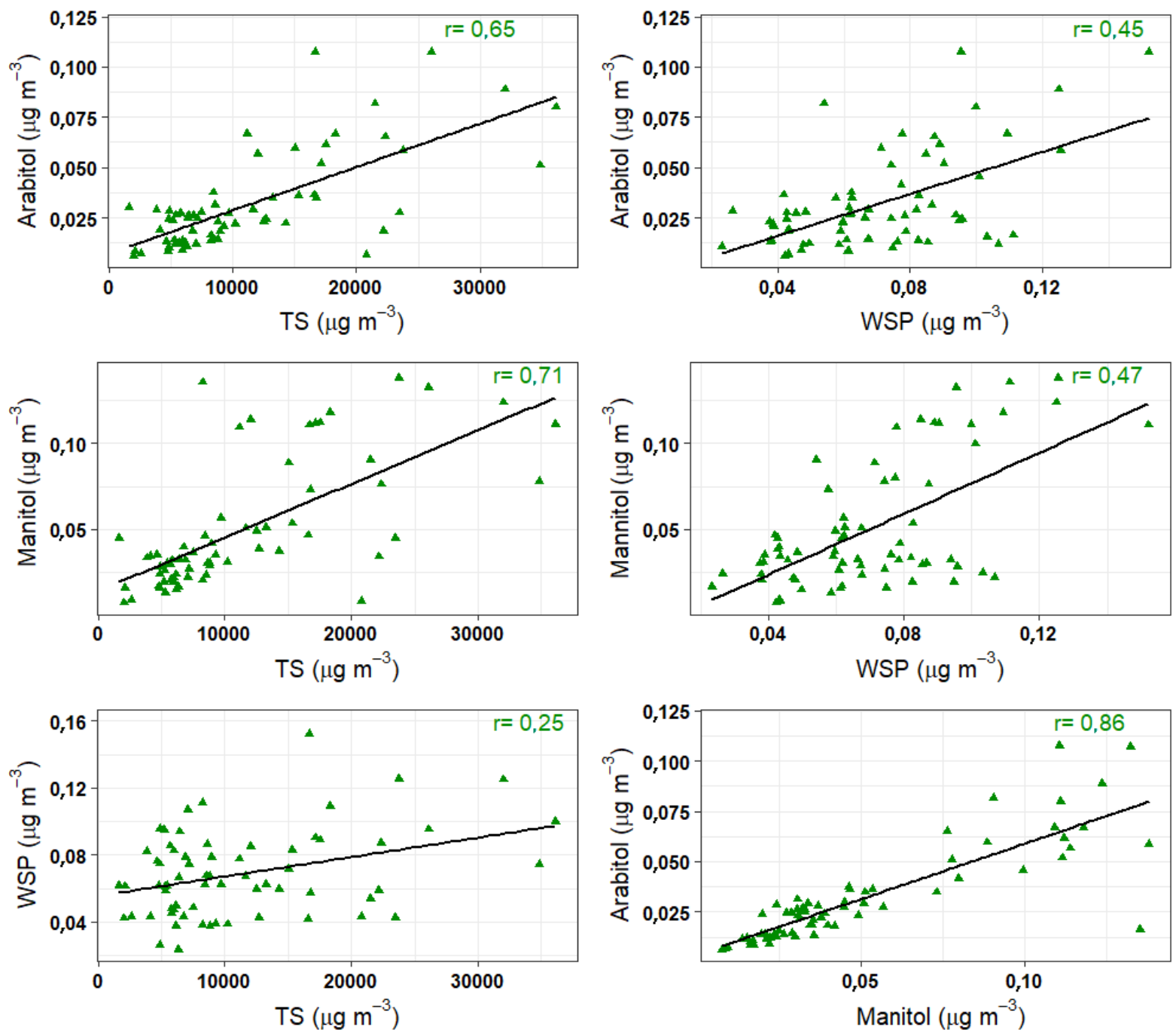

Figura 24. Correlação de Spearman ( $<<0,05)$ entre açucares (arabitol e manitol), WSP e TS (esporos totais).

Destacando as principais correlações entre esses traçadores e elementos e íons do $\mathrm{MP}_{10}$, é observada uma correlação negativa e significativa entre arabitol, manitol, TS e WSP com o elemento $\mathrm{Cl}$; arabitol, manitol e TS também se correlacionam negativamente com $\mathrm{Mg}^{+2}, \mathrm{Na}^{+}$, $\mathrm{Cl}^{-}$, e $\mathrm{NO}_{3}{ }^{-}$, enquanto o arabitol e TS com $\mathrm{SO}_{4}{ }^{2-}$ e $\mathrm{NH}_{4}{ }^{+}$. WSP correlaciona positivamente com $\mathrm{Al}, \mathrm{Si}, \mathrm{P}, \mathrm{K}, \mathrm{Ca}, \mathrm{Ti}, \mathrm{V}, \mathrm{Mn}, \mathrm{Fe}, \mathrm{Ca}^{+}, \mathrm{K}^{+}$e a massa do $\mathrm{MP}_{10}$. Considerando os poluentes gasosos medidos pela estação automática da CETESB em Pinheiros, o ozônio correlaciona negativamente com o manitol, arabitol e esporos fúngicos, enquanto o $\mathrm{NO}_{\mathrm{x}}$ correlaciona positivamente com esses compostos. O ozônio é conhecido por inativar microrganismos e também há relatos apontando a sua habilidade em inibir o crescimento de fungos (Whangchai et al., 2006). Nesse caso, a diminuição da concentração de esporos e açúcares pode ser devido à redução no crescimento dos fungos. Em contrapartida, a correlação positiva com o $\mathrm{NO}_{\mathrm{x}}$ poderia indicar períodos em que há uma baixa formação de ozônio. Além disso, pode-se considerar que os períodos com elevado $\mathrm{NO}_{\mathrm{x}}$ pode coincidir com os períodos de alta 
concentração de esporos. Outro fator que deve ser considerado, é que nos dias chuvosos e úmidos, os quais parecem favorecer a presença de esporos fúngicos na atmosfera, não é favorável para a formação de ozônio. Nesse caso, os fatores meteorológicos são os fatores importantes afetando a concentração dos esporos fúngicos, e não os poluentes. Ainda, como apontado por Grinn-Gofroń et al., (2011) a correlação entre esporos fúngicos e ozônio pode ser inconsistente e os poluentes não são um fator real influenciando a concentração de esporos fúngicos. A ressuspensão do solo é uma importante fonte de bioaerossol (Miguel et al., 1999; Rathnayake et al., 2016) e a correlação positiva e significativa entre WSP e os elementos geralmente associados com a ressuspensão do solo (Hetem et al., 2016) é um forte indicativo da importância dessa fonte para a concentração de WSP na atmosfera.

Kang et al. (2012) indicaram que a correlação positiva entre proteínas com o $\mathrm{NO}_{3}{ }^{-} \mathrm{e} \mathrm{K}^{+}$ é um indicativo da sua fonte antropogênica comum e da queima de biomassa da palha do arroz na estação seca. No presente trabalho, não foi encontrada uma correlação entre as WSP e o $\mathrm{NO}_{3}{ }^{-}$, mas há uma correlação baixa, mas positiva entre WSP, $\mathrm{K}^{+}$e levoglucosano, o que poderia indicar que a queima de biomassa é a uma fonte de bioaerossóis, i.e. queima de biomassa de palha de cana de açúcar ao invés de arroz (Andrade et al., 2012) ou os incêndios florestais ou queima de resíduos vegetais. Ademais, Kobziar et al., (2018) mostraram que na Florida (EUA) há um transporte de microrganismos quando há fumaça da queima de biomassa. Contudo a falta de correlação entre arabitol e manitol com levoglucosano (traçador de queima de biomassa) observada nesse estudo, está em concordância com a baixa correlação observada por Zhang et al. (2010) e Urban et al. (2014). O TS também não se correlacionou com o levoglucosano. Isso indica que não há uma fonte comum entre os álcoois de açúcares e os esporos fúngicos com o levoglucosano no local de coleta durante o período coletado. Nesse caso, a queima de biomassa parece não emitir quantidades significativas desses compostos (relacionada com fungos) na maioria do período amostrado. Em contrapartida, outros microrganismos ou bioaerossóis podem ser emitidos através da queima de biomassa, o que poderia contribuir para o WSP (i.e., bactérias, pólen).

\subsection{Limiar para o surgimento de sintomas alérgicos para alguns fungos}

O limiar de 3000 esporos $/ \mathrm{m}^{3}$ para o Cladosporium spp., proposto por Gravesen (1979) e 50 esporos $/ \mathrm{m}^{3}$ para a Alternaria sp. usada por Sadys et al. (2016) na Europa foi usado para estimar quantos dias, esses tipos fúngicos excederam esse limiar o que poderia causar sintomas alérgicos na população em São Paulo. 
Durante o período estudado nesse trabalho da concentração diária (amostra de 24 horas), a Alternaria-like não excedeu o limiar de (50 esporos $\left./ \mathrm{m}^{3}\right)$ em nenhum dia (Figura 25). Alternaria-like mostrou um pico na concentração em outubro de aproximadamente 36 esporos $/ \mathrm{m}^{3}$. Em contrapartida, houve 7 dias em que a concentração de Cladosporium sp. excedeu o limiar de 3000 esporos $/ \mathrm{m}^{3}$, representando aproximadamente 10,6\% dos dias amostrados (66 dias). Esse excesso ocorreu principalmente em outubro (4 dias - primavera), mas também em março (2 dias), e agosto (1 dia).

Sadys et al. (2016) observaram que 25 a $45 \%$ do período de 5 anos amostrados tiveram dias com uma elevada contagem de esporos, excedendo o limiar, para Alternaria sp., enquanto esse valor foi de 32 a 74\% para o Cladosporium sp.. Grinn-Gofroń e Rapiejko (2009) reportaram que em 2006, na Szczecin, Warszawa e Olsztyn a Alternaria spp. ultrapassou o limiar em 42, 49 e 56 dias, respectivamente, enquanto que para o Cladosporium spp. foram 43, 55 e 62 dias, respectivamente.

O baixo número de dias em que houve ultrapassagens no limiar para a Alternaria e Cladosporium observado nesse trabalho comparado com a literatura pode estar relacionado ao número de amostras (as quais são apenas 66 dias, e não o ano todo), fatores meteorológicos e climatológicos e muitos outros motivos. E ainda, o limiar para a ocorrência de sintomas alérgicos em áreas tropicais, como o Brasil, provavelmente é diferente do Europeu.
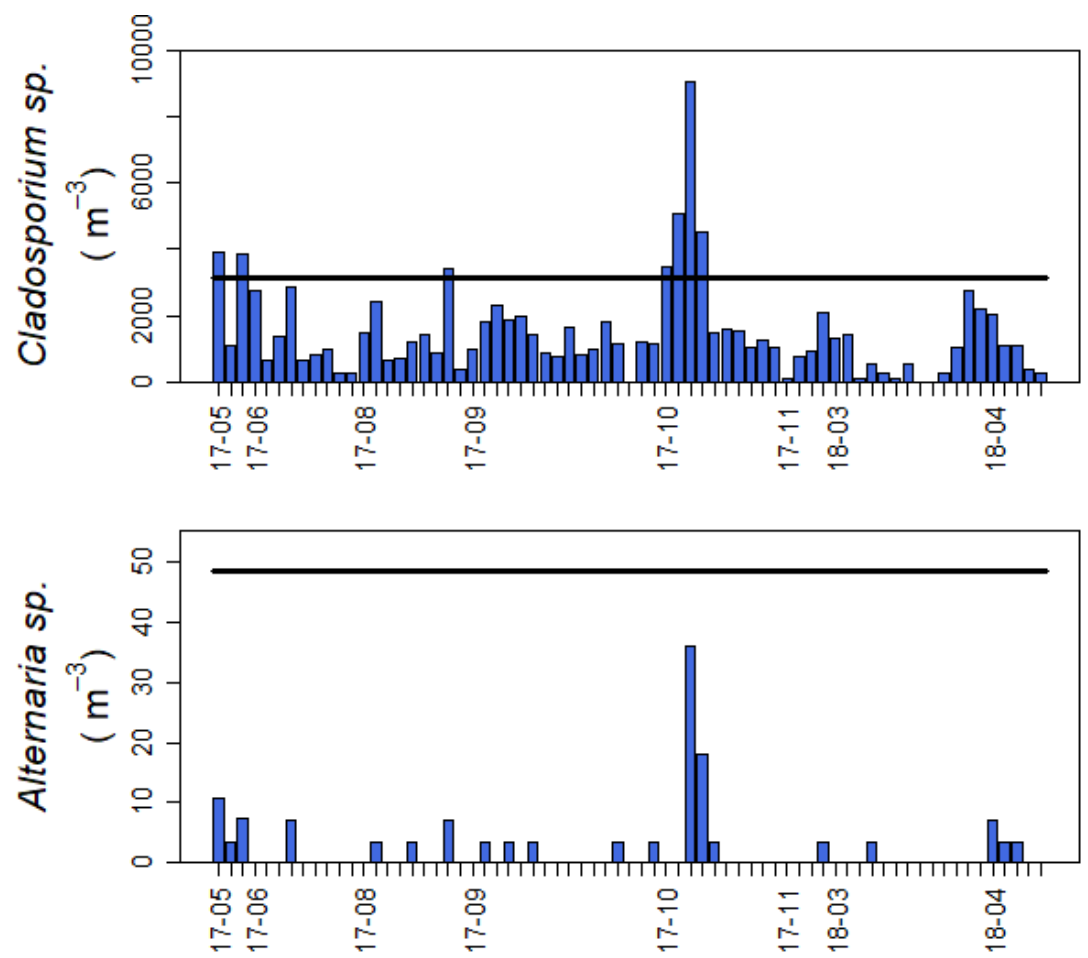

Figura 25. Série temporal da concentração de Cladosporium sp. e Alternaria sp.. Legenda: A linha reta representa o limiar de 3000 esporos $/ \mathrm{m}^{3}$ para o Cladosporium sp. e 50 esporos $/ \mathrm{m}^{3}$ para a Alternaria sp., onde pode ocorrer um agravamento de reações alérgicas. 


\subsection{Relação entre os carboidratos e os esporos de fungos}

Assumindo que o arabitol e manitol estão presentes na atmosfera devido principalmente aos esporos fúngicos, e que a concentração em número de esporos obtidas pelo Burkard e microscópio óptico representa todos os esporos fúngicos presentes na atmosfera, é possível obter um fator de conversão que relaciona ambos, os esporos fúngicos e os açúcares. Considerando que na média há aproximadamente 3,0 pg de arabitol por esporo e aproximadamente $4,5 \mathrm{pg}$ de manitol por esporo, encontramos uma concentração variando de 0,3-7,5 pg arabitol/esporos e 0,4-9,8 pg de manitol/esporos considerando todo o período amostrado. Para se obter esses valores, um outlier (concentração elevada) foi removido da concentração de arabitol e dois outliers foram removidos da concentração de manitol.

Apesar de ambos os açúcares (arabitol e manitol) serem usados como traçadores de esporos fúngicos na atmosfera (Bauer et al., 2008a; Zhang et al., 2010), esse tipo de fator de conversão tem algumas ressalvas e essa suposição deve ser feita com cautela. Sabe-se que ambos, arabitol e manitol não são apenas substâncias de armazenamento (reserva de energia) para fungos, mas também são encontrados em plantas (i.e., pólen), algas e bactérias (Loescher et al., 1992; Burshtein et al., 2011; Webster et al.,1995; Fu et al., 2012; Rathnayake et al., 2017). Adicionalmente, é sabido que o amostrador Burkard e a análise no microscópio óptico apresentam várias incertezas associadas e não representam com acurácia a concentração total de partículas (fungos e pólen) na atmosfera (Gottardini et al., 2009; Oteros et al., 2017). Além disso, a concentração de ambos os açúcares nas estruturas fúngicas pode variar entre as espécies e até entre espécimes da mesma espécie (Zhang et al., 2010). Ademais, os tipos fúngicos, e os bioaerossóis no geral, também podem variar dependendo da localização geográfica, uso do solo, bioma, estação do ano, fatores meteorológicos e climatológicos, poluição do ar e outras influências antropogênicas (Matthias-Maser, 2000; Després et al., 2012; Fröhlich-Nowoisky et al., 2016; Gong et al., 2020; Bauer et al., 2008a). Portanto, o uso de fatores de conversão proposto para uma localização e período deve ser cuidadosamente avaliado ao ser usado em outros locais, pois pode envolver muitas incertezas (Zhang et al., 2010).

Em contrapartida, sabe-se que a distribuição de esporos fúngicos, especialmente os principais tipos fúngicos observados na atmosfera (Cladosporium, Alternaria, Aspergillus, Penicillium), são considerados cosmopolitas, o que significa que muitas dessas espécies estão presentes no mundo todo (Ogórek et al., 2012; Després et al., 2012; Fröhlich-Nowoisky et al., 2012; Bensch et al., 2012; Lucca et al., 2007). Isso indica que apesar dos fatores que influenciam a concentração de arabitol e manitol nos fungos e na atmosfera, eles podem apresentar alguns 
padrões. Os outros fatores de conversão, como para a glicose, frutose e sucrose que estimam a concentração de pólen na atmosfera, apresentam uma incerteza ainda maior quando são consideradas diferentes localizações, especialmente em diferentes hemisférios. Isso ocorre porque a flora varia substancialmente dependendo da localização, condição climática, condição do solo e fatores abióticos e bióticos presentes. Assim, muitas espécies e gêneros presentes em países tropicais como o Brasil, não estão presentes ou não são relevantes nos países do hemisfério norte, e vice versa. Um exemplo disso é que algumas espécies usadas por Rathnayake et al. (2017) e Fu et al. (2012) para estimar a concentração de glicose, frutose e sucrose no pólen, os quais são tipicamente de regiões temperadas, não são tão relevantes para o Brasil. Portanto, os valores observados por Rathnayake et al. (2017) para estimar a massa de pólen na atmosfera provavelmente não deveriam ser usados em amostras no Brasil.

Um fator de conversão que é frequentemente usado para os esporos fúngicos, arabitol e manitol é o proposto por Bauer et al. (2008a; 2002b) em Viena. Vários autores têm usado esse fator para obter a concentração em número e massa de esporos fúngicos na atmosfera (Zhang et al., 2010; Emygdio et al., 2018a; Bauer et al., 2008b; Gosselin et al., 2016). Na tabela 23 são apresentados os fatores de conversão propostos nesse trabalho em Emygdio et al. (2016; 2018a), e por Bauer et al. (2008a. Emygdio et al. (2016; 2018a) fizeram o mesmo tipo de cálculo usando a concentração em número de esporos obtidas com o Burkard e coletou no mesmo local desse trabalho (São Paulo), enquanto Bauer et al. (2008a) usou uma análise de epifluorescência em Viena, Áustria.

Valores mais altos do fator de conversão bem como a concentração de arabitol e manitol foram observados nesse trabalho comparado com Bauer et al. (2008a) e Emygdio et al. (2016; 2018a). Da mesma forma, a concentração em número de esporos fúngicos foi mais alta do que a observada por Emygdio et al. (2016; 2018a; 2018b), contudo, menor do que a observada por Bauer et al. (2008a). O uso da epifluorescência por Bauer et al. (2008a) poderia explicar essa diferença. Vale apontar que essa diferença no fator de conversão também pode ser um resultado da variação da quantidade de arabitol e manitol em diferentes espécies de fungos, que também varia com o período e local amostrado, além de outros fatores.

A proporção entre o fator de conversão do arabitol e manitol é similar entre o presente trabalho ( 66,7\%) e Bauer et al. (2008a), com o fator de conversão do arabitol representando aproximadamente $70 \%$ do fator do manitol, mas é diferente da proporção observada em Emygdio et al. (2016;2018a) de aproximadamente 47,5\%. Uma diferença muito pequena foi observada quando se comparou o fator de conversão proposto nesse trabalho durante o período sem chuva e com chuva (2,9 para o arabitol para o período úmido e 3,0 para o arabitol no 
período seco; 4,0 para o manitol para o período úmido e 4,8 para o manitol para o período seco). Esse fator de conversão provavelmente representa mais os esporos fúngicos do AS e BS do que do MS, uma vez que o MS não é tão bem correlacionado com os açúcares.

Tabela 23. Concentração de arabitol, manitol e esporos fúngicos, e o fator de conversão obtidos nesse trabalho, por Emygdio et al (2016; 2018a) e por Bauer et al. (2008a).

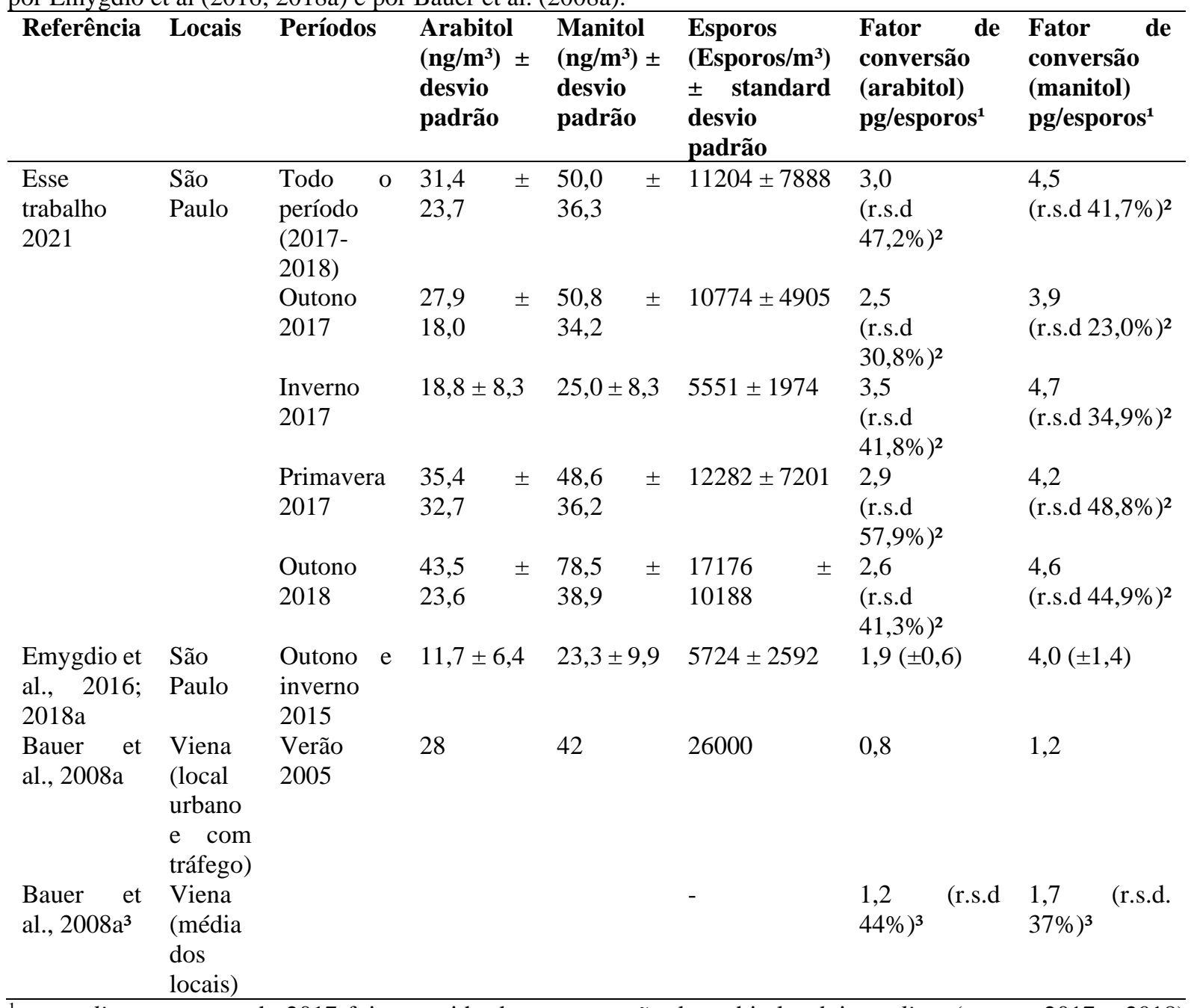

${ }^{1}$ um outlier no outono de 2017 foi removido da concentração de arabitol e dois outliers (outono 2017 e 2018) foram removidos da concentração de manitol para fazer esses cálculos.

${ }^{2}$ r.s.d (desvio padrão relativo ou coeficiente de variação - CV): desvio padrão dividido pela metade e multiplicado por 100 .

${ }^{3}$ média de diferentes locais de coleta e estações

Usando o fator de conversão proposto por Bauer et al. (2002b) é possível converter a concentração em número de esporos fúngicos para a massa de OC (13 pg de OC por esporo) e massa de MP (33 pg de massa fresca por esporo) e obter a o balaço de massa para o MP 10 e OC (Bauer et al., 2008a; 2008b). Assim, observa-se que os esporos fúngicos contribuem com 1,5\% da concentração de $\mathrm{MP}_{10}$ (2\% durante os dias chuvosos e 1,2\% durante os dias secos) e 3,7\% ( $5 \%$ durante os dias chuvosos e $2,7 \%$ durante os dias secos) da massa de OC.

Tabela 24. Contribuição dos esporos fúngicos para a concentração em massa de $\mathrm{MP}_{10} \mathrm{e}$ OC em porcentagem usando os dados desse trabalho e os fatores de conversão (arabitol e manitol para esporos) propostos nesse trabalho, 
no trabalho de Emygdio et al. $\left(2016 ; 2018\right.$ a) e de Bauer et al. $\left(2008 a^{3}\right)$ considerando as estações do ano e todo o período amostrado.

\begin{tabular}{lllllll}
\hline $\mathrm{MP}_{10}$ & \multicolumn{2}{l}{ Esse trabalho } & \multicolumn{2}{l}{ Emygdio et al. (2016; 2018a) } & \multicolumn{2}{l}{ Bauer et al. (2008a $\left.{ }^{3}\right)$} \\
\hline & Arabitol & Manitol & Arabitol & Manitol & Arabitol & Manitol \\
Todo o período & $1,4 \%$ & $1,4 \%$ & $2,1 \%$ & $1,6 \%$ & $3,4 \%$ & $3,8 \%$ \\
Outono2017 & $0,8 \%$ & $0,9 \%$ & $1,3 \%$ & $1,0 \%$ & $2,0 \%$ & $2,5 \%$ \\
Inverno 2017 & $0,6 \%$ & $0,5 \%$ & $1,0 \%$ & $0,6 \%$ & $1,6 \%$ & $1,4 \%$ \\
Primavera 2017 & $1,5 \%$ & $1,4 \%$ & $2,4 \%$ & $1,5 \%$ & $3,7 \%$ & $3,6 \%$ \\
Outono 2018 & $2,5 \%$ & $2,9 \%$ & $3,9 \%$ & $3,3 \%$ & $6,2 \%$ & $7,8 \%$ \\
\hline OC & Esse trabalho & Emygdio et al. $(2016 ; 2018 \mathrm{a})$ & Bauer et al. (2008a $\left.{ }^{3}\right)$ \\
\hline & Arabitol & Manitol & Arabitol & Manitol & Arabitol & Manitol \\
Todo o período & $2,9 \%$ & $3,1 \%$ & $4,6 \%$ & $3,5 \%$ & $7,2 \%$ & $8,2 \%$ \\
Outono2017 & $2,0 \%$ & $2,2 \%$ & $3,2 \%$ & $2,5 \%$ & $5,1 \%$ & $5,9 \%$ \\
Inverno 2017 & $1,4 \%$ & $1,2 \%$ & $2,2 \%$ & $1,4 \%$ & $3,4 \%$ & $3,2 \%$ \\
Primavera 2017 & $3,3 \%$ & $3,1 \%$ & $5,2 \%$ & $3,5 \%$ & $8,2 \%$ & $8,3 \%$ \\
Outono 2018 & $5,0 \%$ & $6,0 \%$ & $7,9 \%$ & $6,7 \%$ & $12,6 \%$ & $15,8 \%$ \\
\hline
\end{tabular}

${ }^{3}$ Média de diferentes locais de coleta e estações do ano

A contribuição em porcentagem da massa de esporos fúngicos para o $\mathrm{MP}_{10}$ e $\mathrm{OC}$ é muito maior usando o fator de conversão proposto por Bauer et al. (2008a) comparado com os outros fatores (Tabela 24). O outono de 2018 foi a estação com maior contribuição dos esporos fúngicos para o $\mathrm{OC}$ e $\mathrm{MP}_{10}$ considerando todos os fatores de conversão, o que é relacionado com a maior concentração de arabitol e manitol e número de esporos fúngicos e menor concentração de $\mathrm{MP}_{10}$ e OC.

Tabela 25. Contribuição em porcentagem dos esporos fúngicos para o $\mathrm{OC}$ e $\mathrm{MP}_{10}$ considerando a literatura*.

\begin{tabular}{|c|c|c|c|c|}
\hline Referência & Local & Estação & $\mathrm{OC}$ & $\mathrm{MP}_{10}$ \\
\hline Bauer et al. (2008b) & Viena (Urbano) & Primavera e verão & $\begin{array}{lll}4,3 \% & (2 \% & \mathrm{e} \\
8 \%) & & \end{array}$ & $\begin{array}{l}2,3 \% \quad(1 \% \\
4 \%)\end{array}$ \\
\hline et al. (2010) & China & Pril & $12,1 \%$ & $7,9 \%$ \\
\hline $\begin{array}{l}\text { Emygdio et al. (2016; } \\
\text { 2018a) }\end{array}$ & $\begin{array}{l}\text { São } \\
\text { (Urbano) }\end{array}$ & $\begin{array}{l}\text { Outono e inverno } \\
2015\end{array}$ & $8 \%$ & $2 \%$ \\
\hline
\end{tabular}

*Esses trabalhos utilizaram o fator de conversão proposto por Bauer et al. (2008a).

Como observado na tabela 25, comparando esse trabalho com estação do ano similar e usando o fator de conversão proposto por Bauer et al. (2008a) é observada uma contribuição muito maior na Floresta tropical da China (Zhang et al., 2010) na primavera, e menores contribuições em Viena (também na primavera) (Bauer et al., 2008b). Em contrapartida, usando o fator de conversão proposto nesse trabalho, uma concentração ainda maior é observada na China (Zhang et al., 2010), mas uma contribuição similar é observada em Viena (Bauer et al., 2008b), ambos na primavera. A contribuição de São Paulo em 2017 (média do inverno e outono) foi menor do que a média do inverno e outono de 2015 (Emygdio et al., 2016; 2018a), independente do fator de conversão usado. Em contraste, o outono de 2018 mostrou maiores porcentagens para o $\mathrm{MP}_{10}$ para todos os fatores de conversão quando comparados com a média do inverno e outono de 2015 (Emygdio et al., 2016; 2018a). Isso indica a variabilidade da concentração de esporos fúngicos na atmosfera. 
O fator de conversão proposto nesse trabalho, teoricamente seria a melhor estimativa a ser usado em trabalhos realizados no mesmo local e período amostrado. Contudo, o método de amostragem e outros fatores que devem ser levados em consideração. Em contrapartida, quando comparando com outros trabalhos ao redor do mundo, talvez seja melhor utilizar um fator de conversão mais globalmente usado, como o proposto por Bauer et al. (2008a), para que os valores possam ser comparados de forma equivalente.

\subsection{Variação sazonal}

As concentrações de arabitol e manitol foram baixas no outono de 2017, provavelmente devido à baixa precipitação e temperatura do período, uma vez que são traçadores de bioaerossóis que estão sujeitos a esses fatores ambientais. Apesar disso, nessa estação ambos se correlacionam bem entre si, com a glicose e com as proteínas (Figura C VIII), indicando uma fonte em comum para esses biomarcadores de bioaerossóis. A correlação de manitol, arabitol e glicose com o Al e Fe pode indicar que esses traçadores apresentam como fonte nessa estação, a ressuspensão do solo (Nirmalkar et al., 2015). O arabitol e glicose também se correlacionaram com o $\mathrm{Cu}$ e com o $\mathrm{CO}$, podendo indicar que a ressuspensão do solo relacionada com a emissão veicular pode ser uma fonte desses biomarcadores, como por exemplo a ressuspensão do solo com a presença de pó e freio que segundo Adachi e Tainosho (2004), apresenta em sua composição o Cu. No polar plot (Figura C IX) é possível verificar que o arabitol e manitol tem uma origem a noroeste, mas relacionado com baixa velocidade do vento, indicando uma fonte local.

No inverno, a correlação entre levoglucosano, $\mathrm{K}^{+}$e manosano com o arabitol, manitol, glicose e WSP (Figura C X) é um indicativo que nessa estação que tem as menores concentrações dos álcoois de açúcar uma possível fonte para os esporos fúngicos seja a queima de biomassa, como indicado por Kang et al. (2012) e exemplificado por Kobziar et al. (2018). O polar plot (Figura C XI) corrobora a ideia de que o arabitol e manitol apresentam a mesma fonte uma vez que apresentam a mesma direção predominante a noroeste e relacionado com baixas velocidades do vento.

As concentrações de arabitol, manitol e glicose são elevados na primavera e estes correlacionam entre si indicando uma fonte em comum, contudo estes não se correlacionam com o WSP, indicando que a fonte fúngica não é a mais importante para a concentração total de proteínas na atmosfera nessa região e nessa estação. 
No outono de 2018, tem-se as maiores concentrações dos álcoois de açucares, e esses se correlacionam bem entre si e com a glicose e WSP bem como com o levoglucosano, manosano e $\mathrm{K}^{+}$, indicando novamente uma possível fonte da queima de biomassa.

\subsection{Variação diária dos esporos fúngicos}

Os esporos fúngicos foram quantificados considerando os quatro períodos do dia (manhã - 6h-12h, tarde - 12h-18h, noite - 18h-00h e madrugada - 00h-6h). O TS, AS, BS e UD apresentaram maiores concentrações médias no período da madrugada (Figura 26), da mesma forma que o observado por Emygdio et al. (2018b). Contudo, apenas o BS apresentou uma diferença significativa considerando os períodos do dia, que foi entre a tarde e a madrugada (Kruskal Wallis com post-hoc).

Entende-se que normalmente o período da madrugada apresenta condições atmosféricas mais estáveis e menos favoráveis a dispersão dos poluentes, apesar de poder haver mais deposição para as partículas maiores. Em condições estáveis ao nível da superfície é possível esperar uma temperatura mais baixa, umidade mais elevada e baixas velocidades do vento. Deve-se considerar que a umidade elevada, nesse caso, pode ser um importante fator para a maioria dos esporos, como já explicado na seção 4.3.4.5.2. Em contrapartida, no período da tarde espera-se uma atmosfera mais turbulenta e instável, com maior velocidade do vento, temperatura e menor umidade, facilitando a dispersão dos poluentes. Como já observado quando comparado as estações do ano (seção 4.3.5.1.), a concentração média de MS foi diferente dos outros grupos, com elevadas concentrações no período da tarde, seguida da manhã, noite e por último na madrugada. O'connor et al. (2014) também observaram maiores concentrações de gêneros aqui classificados como MS (Cladosporium e Alternaria) no período da tarde, enquanto o Ganoderma, aqui classificado como BS, foi observado com maiores concentrações na madrugada. 


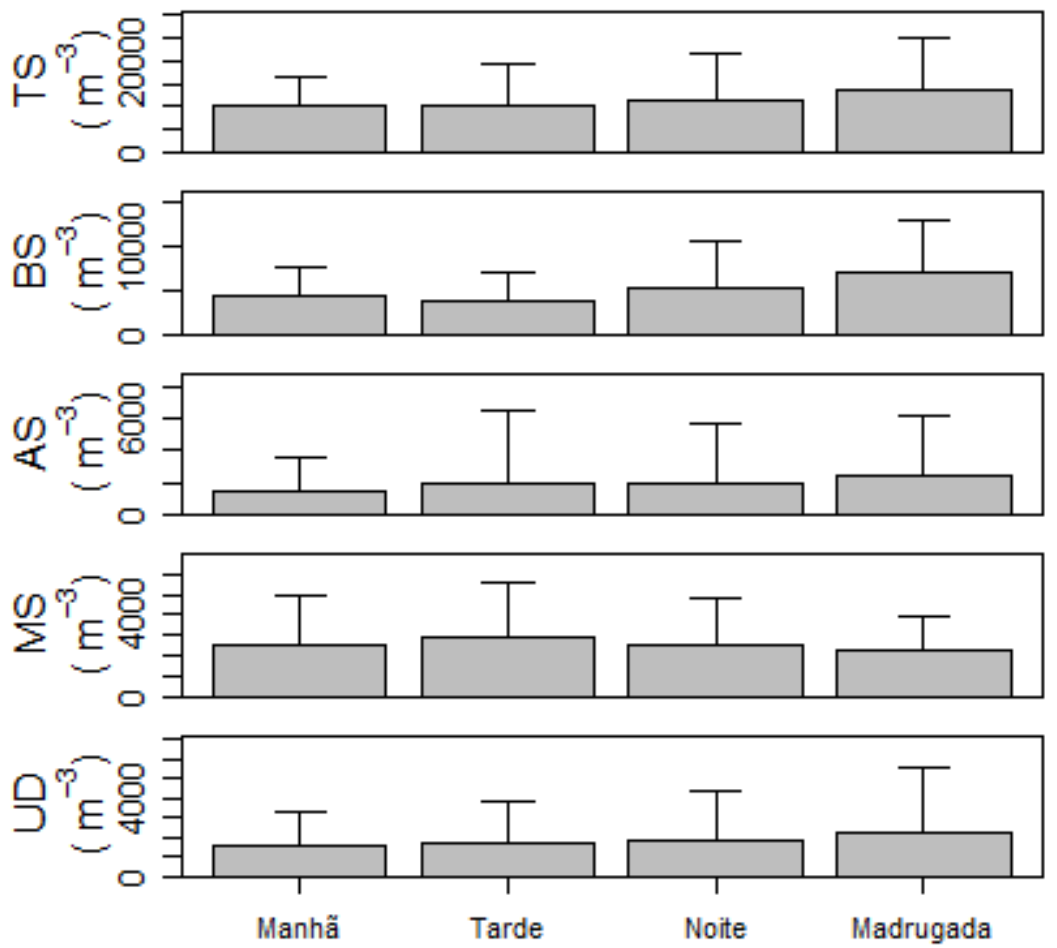

Figura 26. Concentração média dos principais grupos de esporos (MS, AS, BS e UD) e os esporos totais (TS) considerando os períodos do dia (manhã, tarde, noite e madrugada) de todo o período amostrado.

\subsubsection{Quantificação e caracterização das fontes de MP10}

\subsubsection{Fontes identificadas com o PMF}

$\mathrm{O}$ modelo PMF foi aplicado à base de dados para estimar as principais fontes do $\mathrm{MP}_{10}$ no local de estudo, atenção especial sendo dada aos compostos orgânicos. A contribuição das fontes e a sua direção de origem constituem uma importante questão não apenas com propósito científico, mas também para ajudar os tomadores de decisão a entender como enfrentar o problema das elevadas concentrações de $\mathrm{MP}_{10}$ e seus efeitos. As variáveis usadas no PMF estão presentes na Tabela B VI, enquanto as configurações usadas no PMF estão apresentadas na tabela 26 e o resumo do diagnóstico na tabela 27.

Tabela 26. Configurações utilizadas na aplicação da Fatoração de Matriz Positiva (PMF).

\begin{tabular}{ll}
\hline Parâmetros & \\
\hline N de espécies & 47 (13 “strong”, 16 “weak", 18 “bad”) \\
N de amostras & 69 (63 usadas) \\
N de fatores & $5-8$ \\
Tratamento dos dados faltantes & Removidas (6 amostras) \\
Tratamento dos dados BDL $(\leq 0)$ & Substituído pelo LQL/2; MDL/2 \\
N de corridas & 100 \\
Constraints (restrições) & Nenhuma \\
Valor do "Seed" & Aleatório \\
N de BS iterações & 50 \\
r para o BS & 0,6 \\
Tamanho do bloco do BS & 5 \\
Incerteza extra do modelo & $15 \%$ \\
Espécies ativas no DISP & Todos as espécies não “weak" \\
Espécies ativas no BS-DISP & $\mathrm{SO}_{4}^{-2}$, levoglucosano, WSP, Al, Pb \\
\hline
\end{tabular}


BDL - abaixo do limite de detecção; MDL - limite de deteç̧ão mínimo; LQL - menor limite quantificável; BS bootstrap (mapping); DISP - displacement; BS-DISP - bootstrapping displacement; WSP - Proteína solúvel em água.

Índices baseados em Brown et al. (2015). 
Tabela 27. Resumo do diagnóstico da Fatoração de Matriz Positiva (PMF) com rodadas com diferentes números de fatores.

\begin{tabular}{|c|c|c|c|c|}
\hline Corrida com/ diagnóstico & 5 fatores & 6 fatores & 7 fatores & 8 fatores \\
\hline $\mathrm{Q}_{\text {robust }}$ & 874,387 & 668,215 & 533,713 & 436,489 \\
\hline $\mathrm{Q}_{\text {true }}$ & 874,386 & 668,210 & 533,712 & 436,489 \\
\hline $\mathrm{N}$ residuais $> \pm 3$ & $\begin{array}{l}1 \text { (1 amostra e } 1 \\
\text { espécie }[\mathrm{Pb}])\end{array}$ & 0 & 0 & 0 \\
\hline Espécies com uma razão $\mathrm{Q} / \mathrm{Q}_{\exp }>2$ & $\begin{array}{l}\mathrm{NO}_{3}{ }^{-}, \\
\text {manosano, } \mathrm{Sb} \text { e } \\
\mathrm{Pb}\end{array}$ & $\begin{array}{l}\mathrm{K}^{+}, \mathrm{Cl}^{-}, \mathrm{NO}_{3}{ }^{-} \\
\mathrm{Zn} \text { e } \mathrm{Sb}\end{array}$ & $\begin{array}{l}\mathrm{K}^{+}, \mathrm{NO}_{3}^{-}, \mathrm{EC} \\
\mathrm{P}, \mathrm{Mn}, \mathrm{Fe}, \mathrm{Zn} \mathrm{e} \\
\mathrm{Sb}\end{array}$ & $\begin{array}{l}\mathrm{K}^{+}, \mathrm{Cl}^{-}, \mathrm{NO}_{3}^{-}, \\
\mathrm{Ca}^{+}, \text {manosano, } \\
\mathrm{EC}, \mathrm{Al}, \mathrm{P}, \mathrm{Mn}, \\
\mathrm{Fe}, \mathrm{Zn}, \mathrm{As} \text { e } \\
\text { esporos } \\
\text { fúngicos }\end{array}$ \\
\hline \multirow{8}{*}{$\begin{array}{l}\text { BS (o número do fator não representa a } \\
\text { mesma fonte nas diferentes corridas) }\end{array}$} & F1: $100 \%$ & F1: $98 \%$ & F1: $64 \%$ & F1: $74 \%$ \\
\hline & $\mathrm{F} 2: 100 \%$ & F2: $100 \%$ & F2: $96 \%$ & F2: $98 \%$ \\
\hline & F3: $96 \%$ & F3: $100 \%$ & F3: $100 \%$ & F3: $100 \%$ \\
\hline & F4: $92 \%$ & F4: $86 \%$ & F4: $90 \%$ & F4: $80 \%$ \\
\hline & F5: $100 \%$ & F5: $92 \%$ & F5: $96 \%$ & F5: $84 \%$ \\
\hline & & F6: $100 \%$ & F6: $94 \%$ & F6: $100 \%$ \\
\hline & & & F7: $100 \%$ & F7: $98 \%$ \\
\hline & & & & F8: $88 \%$ \\
\hline $\begin{array}{l}\mathrm{N} \text { de fatores com mapeamento } \mathrm{BS}< \\
100 \%\end{array}$ & 2 & 3 & 5 & 6 \\
\hline BS não mapeado & 0 & 0 & 0 & $\begin{array}{l}\text { F1:1 } \\
\text { F5:1 }\end{array}$ \\
\hline DISP \%dQ & 0 & 0 & 0 & 0 \\
\hline Maior diminuição em Q DISP & 0 & 0 & 0 & 0 \\
\hline DISP swaps (trocas) & 0 & 0 & 0 & 0 \\
\hline Maior diminuição em Q BS-DISP & $-6,458000183$ & $-3,498$ & $-4,59100008$ & $-5,501999855$ \\
\hline BS-DISP \%dQ (mudança em Q) & $-0,738574588$ & $-0,523484$ & $-0,86020016$ & $-1,260512832$ \\
\hline $\mathrm{N}$ de diminuições em Q BS-DISP & 0 & 0 & 0 & 0 \\
\hline$\%$ de casos aceitos BS-DISP & $96 \%$ & $78 \%$ & $48 \%$ & $22 \%$ \\
\hline
\end{tabular}

BS - bootstrap (mapping); DISP - displacement; BS-DISP - bootstrapping displacement; WSP - Proteína solúvel em água; $\mathrm{N}$ - número.

Índices baseados em Brown et al. (2015).

No geral as espécies com uma razão sinal -ruído $(\mathrm{S} / \mathrm{N})$ maior do que 0,5 foram categorizados como "bad", enquanto aqueles com a razão $\mathrm{S} / \mathrm{N}$ de $0,5-1,0$ foram categorizadas como "weak" e aqueles com a razão $\mathrm{S} / \mathrm{N}$ maior do que 1,0 foram categorizados como "strong" (Norris et al., 2014). Adicionalmente, algumas espécies também foram categorizadas como "weak" devido ao número de dias com concentrações abaixo do limite de detecção, relevância para a distribuição de fontes e o quão bem eles se ajustavam ao modelo. As espécies "weak" foram $\mathrm{Na}^{+}, \mathrm{K}^{+}, \mathrm{Cl}^{-}, \mathrm{NO}_{3}{ }^{-}, \mathrm{Br}^{-}$, arabitol, glicose/xilose, manitol, Ti, $\mathrm{Si}, \mathrm{Cu}, \mathrm{Zn}, \mathrm{As}, \mathrm{Sb}$ e massa de esporos fúngicos (obtidas através da conversão proposta na seção 3.2.3.5.5). Os elementos com concentração abaixo do limite de detecção em um número elevado de dias foram categorizadas como "bad", como também outras espécies como, por exemplo, as espécies redundantes (i.e., $\mathrm{S}$ e $\mathrm{SO}_{4}^{-2}$ ). Uma incerteza extra de $15 \%$ foi adicionada ao banco de dados para evitar uma 
sobreponderação de algumas variáveis que podem ter sua incerteza subestimada (Paatero and Hopke, 2003).

Como mostrado na tabela 27 apenas a corrida com 5 fatores alcançou um resíduo maior do que \pm 3 . Espécies com a razão $Q / Q_{\exp }$ maior do que 2 e o número de fatores com o mapeamento BS menor do que $100 \%$ aumentaram com a consideração de um número maior de fatores na corrida. Em contraste, a proporção de casos aceitos no BS-DISP diminuiu conforme o número de fatores aumentou. O BS-DISP \%dQ e maior diminuição no BS-DISP Q foi maior para a corrida com seis fatores (menos negativa). Contudo, o \%dQ foi $<1 \%$ para todas as corridas com exceção da corrida com oito fatores. Apenas as corridas com 5 e 6 fatores apresentaram um mapeamento BS maior do que $80 \%$ para todos os fatores. Portanto, a solução obtida com a corrida com seis fatores melhor explica as espécies e considerando o já é conhecido sobre as fontes de MP na região metropolitana de São Paulo, foi a mais apropriada.

O perfil de cada fator da corrida com seis fatores do PMF e a contribuição em massa de cada fator para a massa do $\mathrm{MP}_{10}$ é mostrada na figura 27 . A série temporal para os fatores do PMF, considerando a corrida com seis fatores, durante o período amostrado é mostrado na Figura C XXV. 


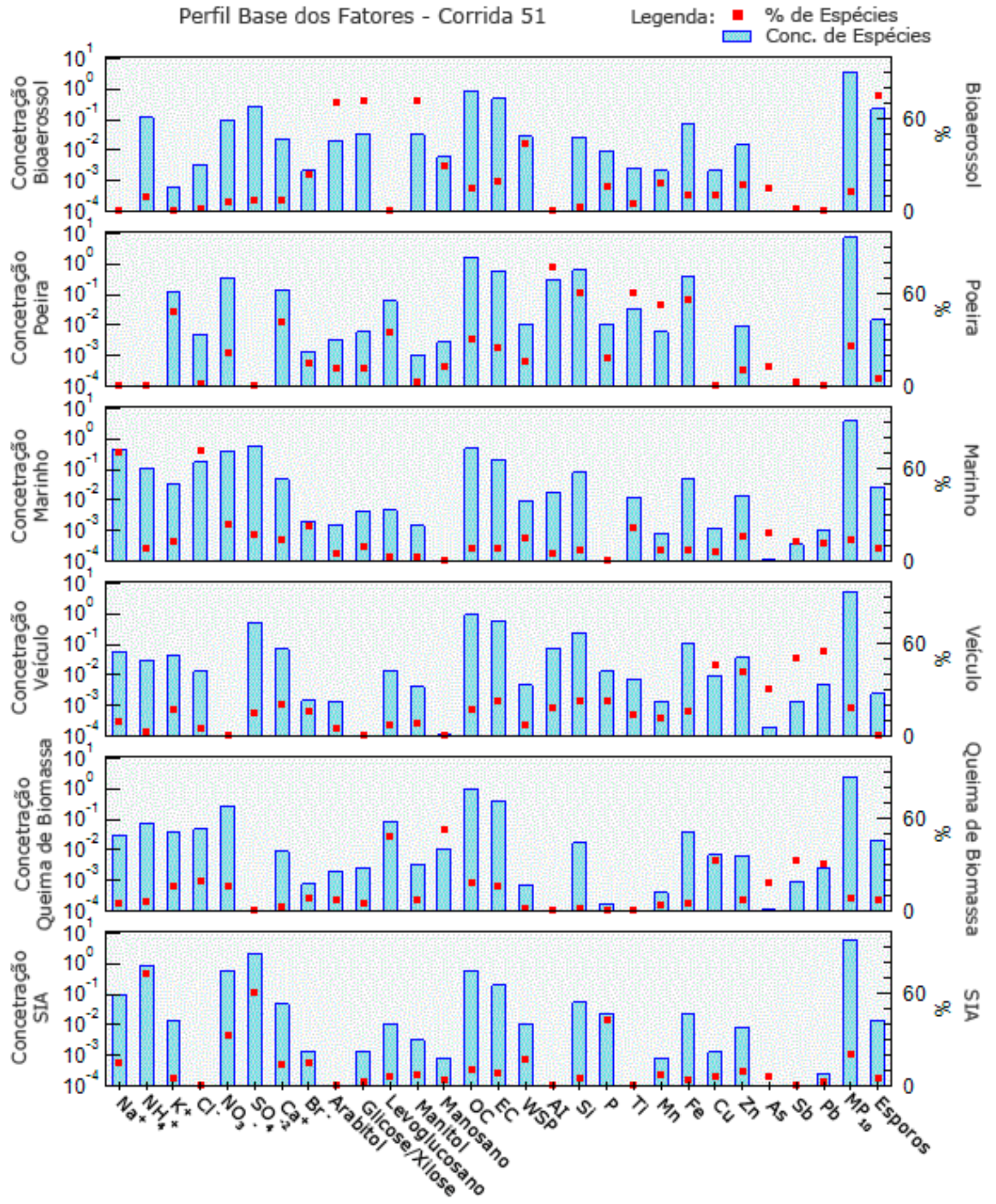




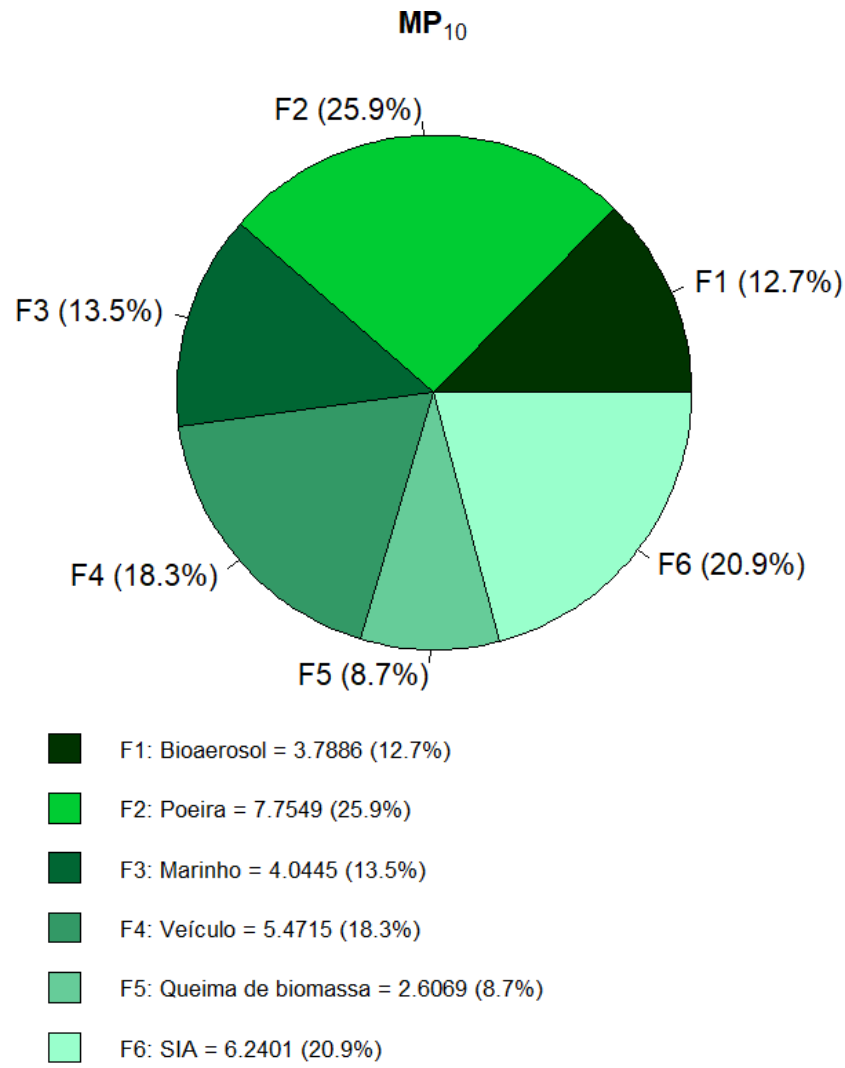

Figura 27. Fontes identificadas com a Fatoração de Matriz Positiva (PMF) e porcentagem da contribuição dos seis fatores para a massa do $\mathrm{MP}_{10}$.

Legenda: Fator 1: Bioaerossol; Fator 2: Poeira (ressuspensão do solo/ poeira de rua); Fator 3: Marinho (aerossol marinho); Fator 4: Veículos (emissão veículos); Fator 5: queima de biomassa (BB); Fator 6: Aerossol inorgânico secundário (SIA). Conc. - concentração.

A fonte majoritária para $\mathrm{o} \mathrm{MP}_{10}$ foi a ressuspensão do solo/pavimento seguida pela fonte veicular e aerossóis inorgânicos secundários. Para a análise da direção de onde a fonte pode estar sendo transportada foi aplicada a metodologia CBPF (função de probabilidade bivariada condicional), que apresenta a probabilidade de cada fonte se originar de uma determinada direção. Na Figura 28 estão apresentadas os CBPF aplicados às fontes identificadas com o PMF.

O CBPF considera a direção e velocidade local do vento a uma altura de $10 \mathrm{~m}$. É valido informar que a estação climatológica, onde a direção e velocidade do vento foram obtidas está localizada a aproximadamente $15 \mathrm{~km}$ do local de coleta. 

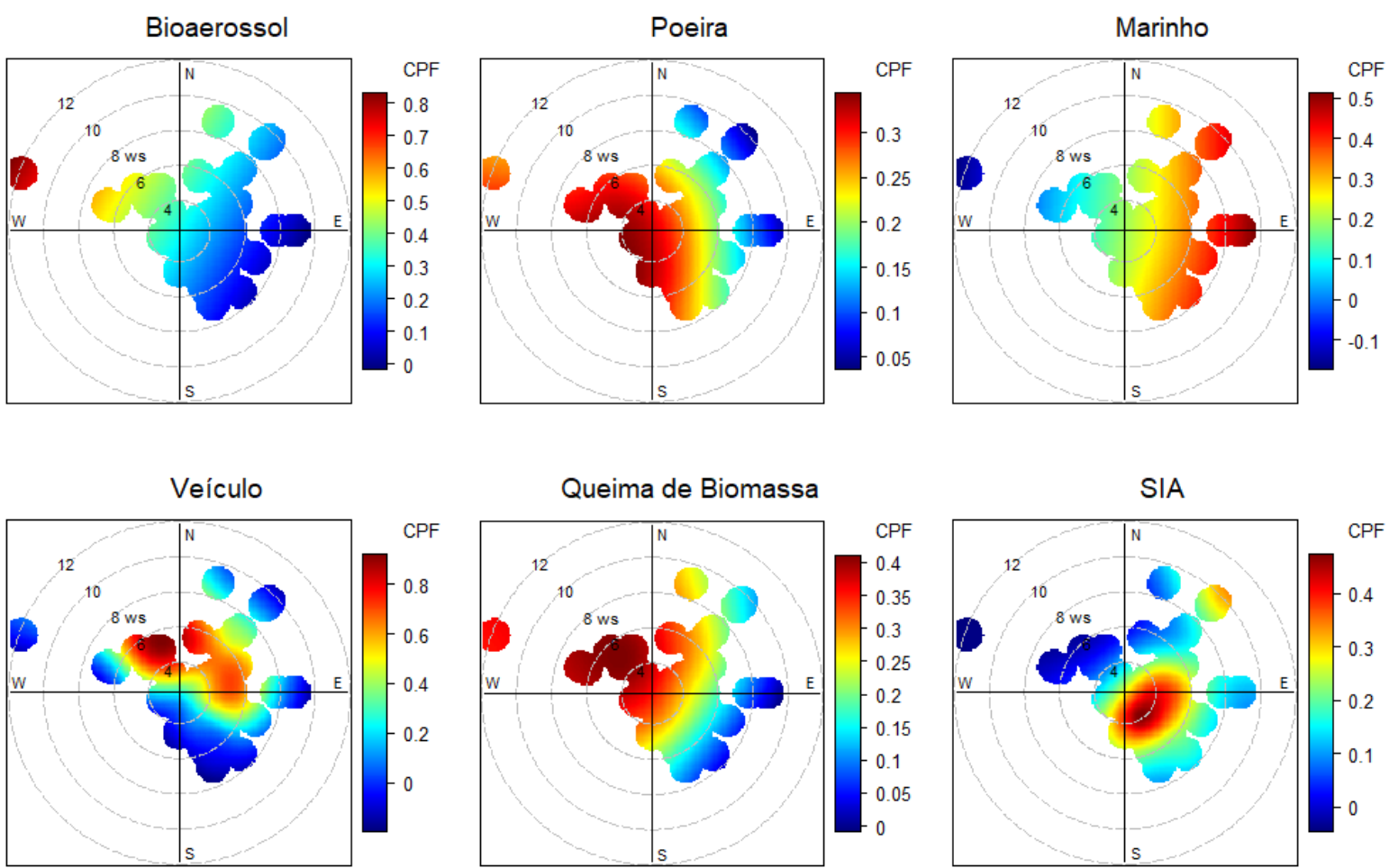

Figura 28. Gráficos polares da função de probabilidade bivariada condicional (CBPF) para os fatores obtidos com a Fatoração de Matriz Positiva (PMF).

Legenda: Fator 1: Bioaerossol - CPF no $75^{\circ}$ percentil (=6); Fator 2: Poeira (ressuspensão do solo/poeira de rua) CPF no $75^{\circ}$ percentil (= 12); Factor 3: Marinho (aerossol marinho) - CPF no $75^{\circ}$ percentil $(=7,2)$; Fator 4: Veículo (emissão veicular) - CPF no $75^{\circ}$ percentil $(=7,8)$; Fator 5: Queima de biomassa $(\mathrm{BB})-\mathrm{CPF}$ no $75^{\circ}$ percentil $(=$ 1,8); Fator 6: Aerossol inorgânico secundário (SIA) - CPF no $75^{\circ}$ percentil $(=7,8)$. ws - velocidade do vento. CPF: Função de probabilidade condicional.

Como observado na Figura 27, o fator 1 mostrou uma elevada contribuição dos traçadores de bioaerossol, como o arabitol, manitol, glicose/xilose, proteínas solúveis em água, e esporos fúngicos, indicando uma fonte biogênica (Menetrez et al., 2007; Bauer et al., 2008a; Zhang et al., 2010; Kang et al., 2012; Rathnayake et al., 2016). A presença do EC poderia indicar uma contribuição de emissão veicular misturada na fonte. Fator 1 contabilizou 12,7\% e uma média BS-DISP na Porcentagem da Soma das Espécies de $\pm 15,7 \%$ da massa do $\mathrm{MP}_{10}$. Adicionalmente, teve uma origem a noroeste do local de coleta, associado com uma elevada velocidade do vento. A aproximadamente $11 \mathrm{~km}$ do noroeste do local de coleta, existe uma área vegetada, que poderia ser a uma fonte de bioaerossóis na RMSP. Os açúcares, esporos fúngicos e proteínas solúveis em água individualmente também mostraram uma origem à noroeste. Essa fonte, junto com os seus principais componentes tiveram sua maior concentração no outono de 2018 (Figura C XXVI), quando a maior umidade relativa e temperatura foram observadas, bem como a segunda maior precipitação acumulada. Existe um fragmento florestal a aproximadamente $450 \mathrm{~m}$ a sudeste do local de coleta, o que poderia também ser uma fonte de bioaerossol. Em um estudo, conduzido no mesmo local de coleta, apesar de ter sido em períodos 
diferentes, e usando o PCA, Emygdio et al. (2018a) encontraram que a fonte biogênica contribuiu para $11 \%$ da massa do $\mathrm{MP}_{10}$, uma proporção similar a observada nesse trabalho. Zhang et al. (2015) também usaram o PCA para determinar as fontes do $\mathrm{MP}_{10}$, incluindo os traçadores de esporos de fungos como arabitol e manitol em uma região tropical da China. Esses autores também observaram um fator com elevada contribuição de arabitol, manitol, $\mathrm{K}^{+}$, OC e EC.

O Fator 2 explica a maior contribuição para a massa total de $\mathrm{MP}_{10}(25,9 \% \pm 24,9 \%$ - média BS-DISP) e foi caracterizada por grande participação de $\mathrm{Al}, \mathrm{Si}, \mathrm{Ti}, \mathrm{Mn}, \mathrm{Fe}, \mathrm{K}^{+}$e $\mathrm{Ca}^{+}$, elementos característicos do solo/poeira, ressuspensão da poeira de rua e ressuspensão da poeira do pavimento, como descrito por Hetem et al. (2016), que analisaram a composição do pavimento na RMSP. A presença de levoglucosano nesse fator, o qual explica $35 \%$ da concentração de levoglucosano (Figura C XXVII) poderia indicar que tem uma deposição do composto no solo e que se junta com os outros elementos quando a ressuspensão do solo ocorre. O levoglucosano presente na atmosfera pode ter originado do desgaste do pneu (Alves et al., 2020) ou da fonte mais comumente reportada, queima de biomassa (Simoneit et al., 1999), a qual por sua vez poderia ser originada da queima de lenha ou carvão em residências ou restaurantes, bem como de queimadas de florestas e de agricultura. De acordo com Alves et al. (2020), a presença do levoglucosano no pneu pode ser devido a vulcanização da borracha, na qual as fibras de celulose são usadas como um material de reforço. Outra explicação poderia ser um aumento na temperatura causada pela fricção entre o pneu e o pavimento, o que resulta na conversão da celulose em açúcar, incluindo levoglucosano. Ademais, incêndios (que ocorrem naturalmente ou devido a ação humana) são comuns em diversas áreas do Brasil. Por exemplo, quando esses incêndios ocorrem no cerrado brasileiro (savana) eles podem ser associados às características do clima e bioma local, bem como ao desflorestamento, que ocorre devido a abertura de novos campos de lavoura ou devido à falta de manejo do fogo (Schmidt and Eloy, 2020). Adicionalmente, acredita-se que a queima de cana de açúcar no interior do estado de São Paulo, contribui para a piora na qualidade do ar nas áreas urbanas do estado (Andrade et al., 2012). A concentração da Fonte 2 foi maior no inverno (Figura C XXVI) e foi primariamente associada com ventos de oeste, noroeste com uma velocidade do vento baixa a mediana ( 0,3 de probabilidade no CBPF).

O Fator 3 teve uma elevada carga de $\mathrm{Na}^{+}, \mathrm{Cl}^{-}$e $\mathrm{Br}^{-}$, o que sugere uma fonte de aerossol marinho(Belis et al., 2013). A presença de $\mathrm{NO}_{3}{ }^{-}$nesse fator, poderia indicar uma contribuição de combustíveis nessa fonte (Belis et al., 2013; EEA, 2020) ou estar associado com partículas de sal marinho envelhecidas sofrendo de depleção de cloro. Em um inventário da União 
europeia de emissões em 2018 (EEA, 2020), óxidos de nitrogênio estavam associados, em ordem decrescente de importância com o transporte rodoviário, produção de energia e distribuição de energia; combustão de combustíveis comercial institucional e residencial; e energia usada em indústria e transporte não rodoviário. Esse fator contribuiu com 13,5 $\pm 11,6$ $\%$ (média $\mathrm{BS}-\mathrm{DISP}$ ) da massa do $\mathrm{MP}_{10}$. $\mathrm{O}$ fator 3 mostrou maiores concentrações no inverno (Figura C XXVI) e se originou na região leste/sudeste ( 0,5 probabilidade no CBPF). No leste/sudeste do local de amostragem há, respectivamente, a área conhecida como a região do $\mathrm{ABC}$ paulista, compreendendo um grupo de cidades industrializadas na RMSP, o complexo petroquímico de Cubatão, o porto de Santos e o oceano atlântico. Assim, as brisas marítimas são esperadas de virem dessa direção e a presença de $\mathrm{NO}_{3}{ }^{-}$poderia indicar uma contribuição de emissões veiculares (transporte rodoviário) e emissão industrial (Souto-Oliveira et al., 2016).

O Fator 4 mostrou elevada contribuição de $\mathrm{Zn}, \mathrm{Cu}, \mathrm{As}$, Sb e Pb, bem como de 22,9\% da concentração de EC, sugerindo uma contribuição de emissão veicular dos elementos que estão associados ao freio e ao desgaste de pneu (Adachi e Tainosho, 2004; Alves et al., 2020; Hopke et al., 2020). Esse fator explicou 18,3\% $\pm 13,1 \%$ (média BS-DISP) da massa do MP 10 e é provavelmente relacionado à frota veicular local. O local de coleta é rodeado por grandes avenidas e muito movimentadas, principalmente à norte, sul e nordeste. O CBPF mostrou uma probabilidade de aproximadamente 0,8 desse fator ter se originado ao norte do local de coleta, onde a avenida Marginal Pinheiros está localizada, e está associado a uma velocidade do vento lenta (4 e $6 \mathrm{~km} / \mathrm{h}$ ). A contribuição desse fator foi maior no outono de 2018, apesar de, como esperado, ter uma pouca diferença entre as estações (Figura C XXVI).

A Fonte 5 foi a que menos contribuiu para a massa do $\mathrm{MP}_{10}$, representando 8,7\% $\pm 15,9 \%$ (média BS-DISP), e é caracterizada por altas contribuições de $\mathrm{Cu}, \mathrm{As}, \mathrm{Sb}, \mathrm{Pb}$, levoglucosano e manosano, junto com menores contribuições de $\mathrm{K}^{+}, \mathrm{Cl}^{-}, \mathrm{NO}_{3}{ }^{-}$, OC e EC. Os elementos sugerem uma emissão por freios e desgaste de pneu como mostrado por Adachi e Tainosho, (2004). Levoglucosano e manosano são geralmente associados com queima de biomassa (Simoneit et al., 1999). Algumas das outras variáveis presentes nesse fator, como $\mathrm{K}^{+}, \mathrm{NO}_{3}^{-}$, OC e EC, sugerem combustão e queima de biomassa. O CBPF mostrou que a fonte do fator 5 é originaria da região noroeste do local de coleta e foi principalmente relacionada com velocidades do vento médias (apesar de que elevadas velocidades do vento também foram observadas). O fator de queima de biomassa pode incluir uma emissão local ou devido a um transporte e com maiores no outono de 2017.

Fator 6 teve uma alta contribuição de P, junto com altas contribuições de espécies do aerossol secundário, como $\mathrm{SO}_{4}{ }^{-2}, \mathrm{NH}_{4}{ }^{+}, \mathrm{NO}_{3}{ }^{-}$, e podem ser emitidos pela exaustão de veículos 
(Sánchez-Ccoyllo et al., 2008). Esse fator contribui com 20,9\% $\pm 23,1 \%$ (média BS-DISP) da massa total do $\mathrm{MP}_{10}$. Embora o dióxido de enxofre $\left(\mathrm{SO}_{2}\right)$ e os óxidos de nitrogênio $\left(\mathrm{NO}_{\mathrm{x}}\right)$ possam ser originados principalmente de processos industriais, grande parte da amônia $\left(\mathrm{NH}_{3}\right)$ pode ser proveniente de práticas agrícolas e pecuárias. SIA também podem ser associados às emissões veiculares no geral, incluindo combustão para o $\mathrm{NO}_{3}{ }^{-}$, gasolina para $\mathrm{o}_{\mathrm{NH}_{4}}{ }^{+}$, ou queima de combustível como gasolina ou óleo lubrificante para o $\mathrm{SO}_{4}{ }^{-2}$ e $\mathrm{P}$ (Maricq, 2007; Silva et al., 2010; Belis et al., 2013). Esse fator apresentou maiores concentrações no inverno (Figura C XXVI). Duas direções do vento foram associadas com esse fator, o principal vindo de sudeste, sendo local e associado com baixas velocidades do vento ( 4 km/h), enquanto a segunda foi de nordeste e foi associada com elevadas velocidades do vento $(\sim 10 \mathrm{~km} / \mathrm{h})$. Como mencionado anteriormente, na região sudeste do local de coleta tem o porto de santos, o complexo de Cubatão e mais próximo a região do $\mathrm{ABC}$ paulista. Isso poderia significar que além das emissões locais, uma emissão veicular ou industrial pode estar sendo transportada para o local de coleta, considerando que essa fonte compreende aerossol secundário, que geralmente se caracteriza por tamanho pequeno de partícula. A nordeste do local de coleta há o estado do Rio de Janeiro e Espírito Santo, que tem grande área metropolitana com elevada emissão de poluentes (Godoy et al., 2009; Sousa et al., 2012).

A regressão múltipla mostrou que o formiato, succinato e oxalato foram associados com o fator 2 (poeira) e fator 6 (SIA), enquanto o maleato foi associado apenas com o fator 6 (SIA). Metanosulfonato foi associado com o fator 2 (Poeira), fator 4 (Veículo), fator 5 (Queima de biomassa) e fator 6 (SIA). Os ácidos monocarboxílicos e dicarboxílicos podem ser originários de diversas fontes, incluindo emissão veicular, queima de biomassa, formação secundária fotoquímica e fonte biogênica (Kawamura e Kaplan, 1987; Jacob e Wofsy, 1988; Talbot et al., 1988; Kawamura e Ikushima, 1993; Dutton e Evans, 1996; Yao et al., 2004; Wang et al., 2007; Kundu et al., 2010; Kawamura e Bikkina, 2016). A associação dos ácidos orgânicos com o fator 2 (Poeira) poderia ser explicada pela deposição e ressuspensão junto com outros componentes da poeira, enquanto a sua associação com o fator 6 (SIA) poderia ser explicada pelo fato de ambos compreenderem compostos que podem ser formados de forma secundária.

Como esperado, a massa do $\mathrm{MP}_{10}$ mostrou uma elevada concentração no inverno, semelhante ao observado pelas fontes Poeira, SIA e a fonte marinha (Figura C XXVI). O gráfico do CBPF para a massa de $\mathrm{MP}_{10}$ é mostrada na figura 29, e a origem é similar ao das fontes Poeira e queima de biomassa, de noroeste e associada com velocidades do vento baixas a médias. 


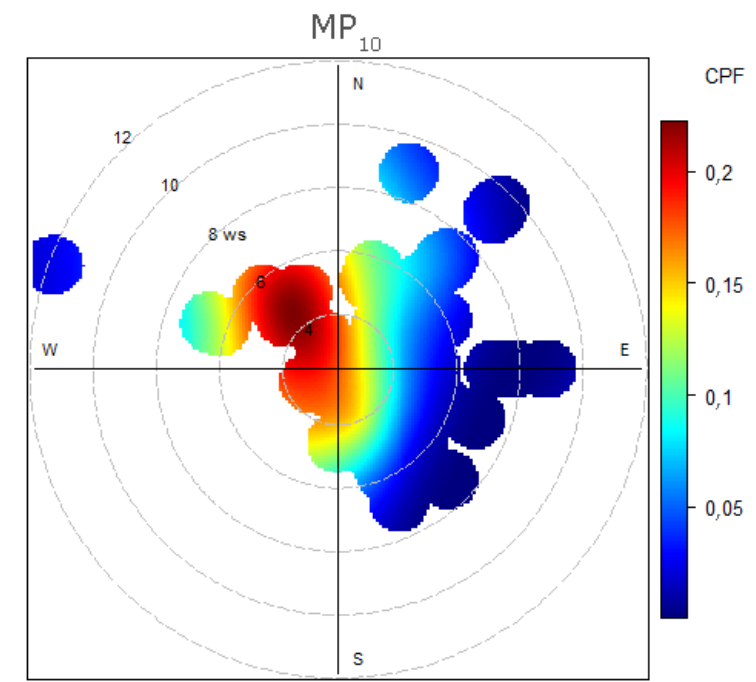

Figura 29. Gráficos polares da função de probabilidade bivariada condicional (CBPF) para a massa do MP 10 (ws - velocidade do vento).

Legenda: CPF no $75^{\circ}$ percentil (=37).

\subsection{Potencial de alguns fungos como núcleadores de gelo}

$\mathrm{Na}$ maioria dos ensaios foram testadas 32 gotas de $10 \mu \mathrm{l}$ considerando três diferentes diluições para cada um dos 12 gêneros/espécies de fungo. Entre as espécies analisadas estão: Aspergillus niger, Aspergillus sp., Trichoderma sp., Fusarium sp., Henningsia brasiliensis, Macrolepiota sp., Ganoderma australe, Dichomitus setulosus, Flaviporus liebmanii, Pycnoporus sanguineus, Hidnoide, Antrodiella liebmannii, Ceriporia xylostromatoides, Abortiporus fractipes. Em todos os testes a água ultrapura Milli-Q congelou em uma temperatura igual ou abaixo de $-20^{\circ} \mathrm{C}$. O volume total de esporos suspensos para as três diluições foi no geral (i) $10^{+6} / 10^{+7}$ esporos $/ \mathrm{ml}$, (ii) $10^{+5} / 10^{+6}$ esporos $/ \mathrm{ml} \mathrm{e} \mathrm{(iii)} 10^{+4} / 10^{+5}$ esporos $/ \mathrm{ml}$. Apenas para o Ganoderma australe o fator de diluição foi (i) $10^{+4}$ esporos $/ \mathrm{ml}$, (ii) $10^{+3}$ esporos $/ \mathrm{ml}$ e (iii) $10^{+2}$ esporos $/ \mathrm{ml}$. Vale ressaltar que em alguns testes houve problemas com a bandeja e algumas gotas foram perdidas devido ao agrupamento de gotas, de modo que esse experimento foi considerado apenas como um piloto para futuras análises.

Utilizando os dados de concentração de esporos por diluição e o número de gotas congeladas por espécie, foi possível estimar o número cumulativo de núcleos de gelo por esporos de acordo com o cálculo (Equação 10) proposto por Vali (1971) e aplicado em diversos artigos (Pouleur et al., 1992; Cochet e Widehem, 2000; Bowers et al., 2009; Conen et al., 2012; Morris et al., 2012). Na figura 30 é apresentada para cada diluição, congelamento e gênero/espécie de fungo, o espectro de núcleos cumulativos em log, obtidos através da fórmula de Vali (1971), considerando a temperatura de congelamento. 

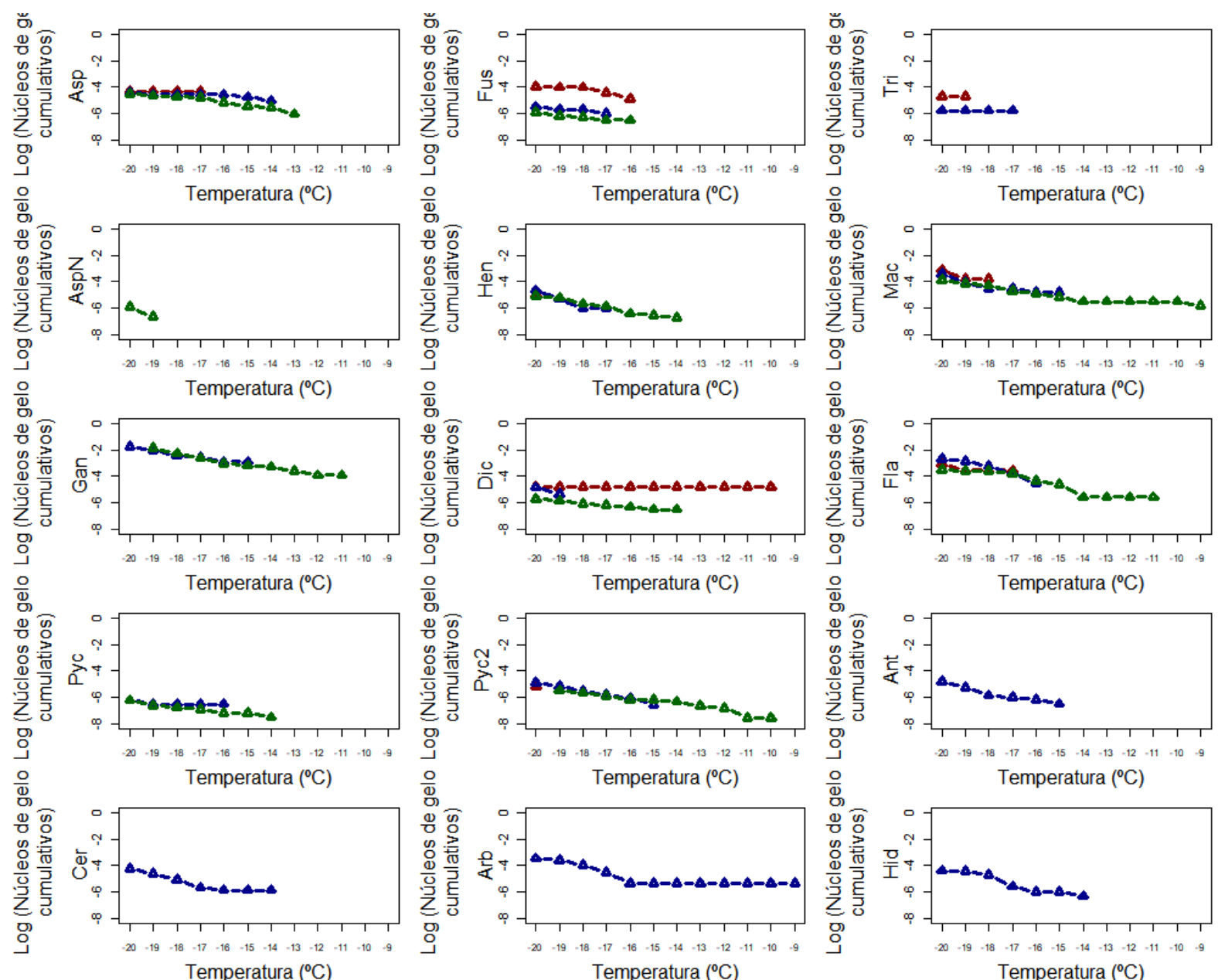

Figura 30. Número cumulativo de núcleos de gelos por tipo de fungo por temperatura de acordo com o cálculo proposto por Vali (1971).

Legenda: As linhas vermelhas indicam uma concentração de $10^{+4} / 10^{+5}$ esporos $/ \mathrm{ml}$ (no geral, diluição 1:100), as linhas azuis indicam de $10^{+5} / 10^{+6}$ esporos $/ \mathrm{ml}$ (no geral, diluição 1:10), as linhas verdes indicam uma concentração $10^{+6} / 10^{+7}$ esporos /ml (no geral, sem diluição). A exceção foi o Ganoderma (Gan) que apresentou uma concentração menor considerando as diluições. Aspergillus sp. (Asp), Fusarium sp. (Fus), Trichoderma sp. (Tri), Aspergillus niger (AspN), Henningsia brasiliensis (Hen), Macrolepiota sp. (Mac), Ganoderma australe (Gan), Dichomitus setulosus (Dic), Flaviporus liebmanii (Fla), Pycnoporus sanguineus (Pyc), Antrodiella liebmannii (Ant), Ceriporia xylostromatoides (Cer), Abortiporus fractipes (Arb) Hidnoide (Hid).

A maior temperatura inicial de congelamento para todos os esporos testados foi de $-9^{\circ} \mathrm{C}$ para a Macrolepiota sp. e a temperatura mais baixa inicial de congelamento foi de $-22^{\circ} \mathrm{C}$. A temperatura de congelamento inicial aumentou quanto maior a concentração da solução na maioria dos casos. A temperatura de congelamento para todos os esporos testados indica que eles podem contribuir para uma formação de uma nuvem gelada heterogênea, já que a maioria dos esporos congelaram em uma temperatura superior a $-19^{\circ} \mathrm{C}$ e a água Milli-Q ultrapura congelou em uma temperatura mais baixa que $-20^{\circ} \mathrm{C}$. Contudo, apenas a Macrolepiota e a Abortiporus sp. apresentaram atividade significativa como núcleo de gelo considerando o desenho desse experimento. Devem ser considerados outros fatores além da temperatura para uma formação heterogênea de nuvem de gelo, como o tamanho do esporo e a altura da nuvem necessária para alcançar a temperatura requerida para o congelamento. 
Apesar da temperatura da atividade como núcleo de gelo (INA) desses fungos não serem comparáveis às bactérias (Pseudomonas syringae $-3^{\circ} \mathrm{C}$ : Araujo et al., 2019) ou a alguns outros fungos (Rust $-4^{\circ} \mathrm{C} /-6^{\circ} \mathrm{C}$ : Morris et al., 2012; Fusarium $-2,5^{\circ} \mathrm{C} /-5^{\circ} \mathrm{C}$ : Pouleur et al., 1992), ainda apresentam uma temperatura de INA mais alta do que de muitos fungos estudados anteriormente (Cladosporium $-28^{\circ} \mathrm{C} / 30^{\circ} \mathrm{C}$ : Iannone et al., 2011 ; Agaricomycetes $-17^{\circ} \mathrm{C} /-25^{\circ} \mathrm{C}$ : Haga et al., 2014; Eurotiomycetes $-25^{\circ} \mathrm{C} /-29^{\circ} \mathrm{C}$ : Haga et al., 2014). Ainda deve-se considerar que dependendo do tratamento dado aos esporos antes da análise, o esporo pode perder sua atividade como INA, devido a algum fator ambiental (temperatura, umidade, radiação, etc.).

\section{Conclusão}

Este trabalho trouxe contribuições significativas para o conhecimento da composição do material particulado em São Paulo. Diferentes compostos orgânicos e inorgânicos do $\mathrm{MP}_{10}$ foram examinados com o objetivo de descrever mais detalhadamente a concentração, importância e as fontes das partículas biogênicas primárias e outros compostos presentes na atmosfera da RMSP. Especial enfoque foi dado à caracterização da contribuição de esporos de fungos para o $\mathrm{MP}_{10}$. Esse conhecimento é importante, tanto do ponto de vista de impactos à saúde quanto aos processos climáticos.

Com a ajuda de ferramentas estatísticas (PMF) e polar plots, foi possível propor uma distribuição de fontes e sua origem, incluindo aquelas que no geral não são consideradas, como bioaerossóis, queima de biomassa e aerossol marinho. As contribuições dessas fontes para a massa do $\mathrm{MP}_{10}$ não estão entre as maiores, mas ainda assim são significativas e devem ser consideradas em pesquisas futuras. A estimativa média da contribuição dos esporos fúngicos de $1,5 \%$ e $3,7 \%$ para a massa de $\mathrm{MP}_{10}$ e OC, respectivamente, mostra que a contribuição é significativa e reforça a sua importância.

Dentre os vários resultados obtidos pode-se destacar a elaboração do fator que converte a massa de biomarcadores (arabitol e manitol) para número de esporos fúngicos para São Paulo no período amostrado. Esse fator permitirá que outros trabalhos estimem, de forma mais fácil, a massa de esporos fúngicos na atmosfera, ampliando assim o conhecimento sobre fungos na atmosfera de São Paulo. Além disso, também se obteve como resultado desse trabalho que os esporos de fungos Macrolepiota e a Abortiporus sp. apresentaram uma temperatura inicial de congelamento de $-9{ }^{\circ} \mathrm{C}$. Isso demonstra que não só os fungos contribuem para a massa do material particulado, como também têm potencial de serem nucleadores de gelo influenciando os processos atmosféricos como na formação de nuvem e precipitação, indicando mais ainda a sua relevância. 
Além da distribuição de fontes, foi possível propor diversas origens para os compostos orgânicos, através da análise da sua variabilidade temporal, em especial as estações do ano, e relação com outros poluentes. Em particular, a queima de biomassa e a ressuspensão do solo foram observadas como possíveis fontes para os bioaerossóis. Dentre as origens propostas para o levoglucosano e também para a queima de biomassa durante o período amostrado estão as emissões locais por residências, comércio e atividades festivas (como fogueiras de festa junina), e o transporte de outras regiões derivados da queima de florestas e queima do bagaço da cana de açúcar no solo ou nas usinas. Muitos fatores influenciaram a concentração do levoglucosano e a queima de biomassa durante o período amostrado. A meteorologia tem um importante papel na variação das concentrações e no aumento de queimadas. Contudo, outros fatores como políticas públicas e melhora na tecnologia da agricultura, em especial sucroalcooleira, podem ter sido essenciais para a variação na concentração de levoglucosano durante o período amostrado.

Esse estudo forneceu uma especiação química e biológica abrangente e uma reflexão sobre a contribuição e relevância dos compostos biogênicos e outros compostos orgânicos para o material particulado. Além disso, foram elaboradas ferramentas que poderão ser utilizadas em análises futuras e que facilitarão no avanço do conhecimento sobre bioaerossóis na atmosfera.

Um avanço no entendimento dos bioaerossóis é essencial, uma vez que, de modo geral os bioaerossóis tem um impacto muito importante para a saúde, sendo responsáveis ou relacionados a diversos problemas respiratórios, especialmente as doenças alérgicas. Ademais, a importância dos bioaerossóis também se destaca do ponto de vista ambiental e climático, pois podem ser núcleos de condensação de nuvem e núcleos de gelo, influenciando tanto o balanço radiativo e o ciclo hidrológico da Terra, como impactando na agricultura. Deste modo, com esse trabalho pode-se compreender melhor a presença desses bioaerossóis na RMSP e com isso proporcionar embasamento para políticas públicas e para medidas de controle ou prevenção, como por exemplo, no combate a crises alérgicas e perdas na agricultura.

Além disso, nossas descobertas trazem novos esclarecimentos para as fontes de $\mathrm{MP}_{10}$ na RMSP. Trabalhos anteriores sobre fontes na RMSP focaram, principalmente, na fração inorgânica do aerossol. Consequentemente, obtinha-se um entendimento deficiente sobre a real contribuição de cada composto para as fontes e da contribuição desta para a massa do $\mathrm{MP}_{10}$. Nossas descobertas revelam novas fontes de $\mathrm{MP}_{10}$ e podem ser usadas por autoridades ambientais para reavaliar as contribuições de fontes na RMSP. 


\section{Sugestões para trabalhos futuros}

Os resultados obtidos elucidaram diversas questões sobre a composição do material particulado. Contudo, deve-se estar ciente das limitações envolvidas. Assim sugere-se que para estudos futuros sejam realizadas mais amostragens e análises com maior resolução temporal das coletas. Recomenda-se também uma comparação entre anos, para que assim, os resultados sejam mais consistentes e reprodutíveis.

Há também uma necessidade em calcular a contribuição de outros bioaerossóis, como bactérias e pólens, os quais podem ser estimados através de outros biomarcadores (e.g., ácido graxo 3-hidroxi) ou mesmo através de outras metodologias. Além disso, a utilização de outros biomarcadores de esporos fúngicos, como o ergosterol, podem trazer informações relevantes e um melhor entendimento da variabilidade fúngica e de sua composição.

Por último sugere-se que essas análises também sejam feitas com o $\mathrm{MP}_{2.5}$, para assim compreender qual o impacto dos bioaerossóis nessas partículas menores. 


\section{Referências ${ }^{1}$}

ABNT. Associação Brasileira de Normas Técnicas. Material particulado em suspensão no ar ambiente Determinação da concentração total pelo método do amostrador de grande volume. vol. NBR 9547, p. 14, 1997. Disponível em : http://www.esaat.com.br/docs/met_abnt/9547.pdf.

ADACHI, K.; TAINOSHO, Y. Characterization of heavy metal particles embedded in tire dust. Environment International, vol. 30, no. 8, p. 1009-1017, 2004. Disponível em: https://doi.org/10.1016/j.envint.2004.04.004.

ADACHI, K.; TAINOSHO, Y. Characterization of heavy metal particles embedded in tire dust. Environment International, v. 30, n. 8, p. 1009-1017, 2004.

ADHIKARI, A.; REPONEN, T.; GRINSHPUN, S. A.; MARTUZEVICIUS, D.; LEMASTERS, G. Correlation of ambient inhalable bioaerosols with particulate matter and ozone: A two-year study. Environmental Pollution, vol. 140, no. 1, p. 16-28, 2006. Disponível em: https://doi.org/10.1016/j.envpol.2005.07.004.

AGUIAR, G. F. M. Avaliação de métodos empregando a espectrometria de massas com plasma acoplado (ICP-MS) para determinação de impurezas elementares e especiação química de arsênio e mercúrio em fármacos e excipientes. 2017. 118f. Tese (Doutorado). Faculdade de Ciências Farmacêuticas de Ribeirão Preto Universidade de São Paulo, Ribeirão, 2017.

ALBUQUERQUE, T. T. A.; ANDRADE, M. F.; YNOUE, R. Y. Characterization of atmospheric aerosols in the city of São Paulo, Brazil: Comparisons between polluted and unpolluted periods. Environmental Monitoring and Assessment, vol. 184, no. 2, p. 969-984, 2012. Disponível em: https://doi.org/10.1007/s10661-011-2013-y.

ALVES, C. A.; VICENTE, A. M. P.; CALVO, A. I.; et al. Physical and chemical properties of non-exhaust particles generated from wear between pavements and tyres. Atmospheric Environment, v. 224, n. July 2019, p. 117252, 2020. Elsevier Ltd. Disponível em: https://doi.org/10.1016/j.atmosenv.2019.117252>.

ALWE, H. D.; MILlET, D. B.; CHEN, X.; RAFF, J. D.; PAYNE, Z. C.; FLEDDERMAN, K. Oxidation of Volatile Organic Compounds as the Major Source of Formic Acid in a Mixed Forest Canopy. Geophysical Research Letters, vol. 46, no. 5, p. 2940-2948, 2019. Disponível em: https://doi.org/10.1029/2018GL081526.

ANDRADE, J. M. F., DINIZ, K. M. Impactos Ambientais da Agroindústria da Cana-de-açúcar: Subsídios para a Gestão, 2007, 131p. Monografia de especialista em Gerenciamento Ambiental - Escola Superior de Agricultura "Luiz de Queiroz", Universidade de São Paulo.

ANDRADE, M. D. F.; MIRANDA, R. M. DE; FORNARO, A.; et al. Vehicle emissions and PM(2.5) mass concentrations in six Brazilian cities. Air quality, Atmosphere, \& Health, v. 5, n. 1, p. 79-88, 2012.

ANDRADE, M. DE F.; KUMAR, P.; FREITAS, E. D. DE; et al. Air quality in the megacity of São Paulo: Evolution over the last 30 years and future perspectives. Atmospheric Environment, 2017. Elsevier Ltd. Disponível em: http://linkinghub.elsevier.com/retrieve/pii/S1352231017302212>.

ANDRADE, M. F.; FORNARO, A.; FREITAS, E.D.; MAZZOLI, C. R.; MARTINS, L. D.; BOIAN, C.; OLIVEIRA, M. G. L.; PERES, J.; CARBONE, S.; ALVAlÁ, P.; LEME, N. P. Ozone sounding in the Metropolitan Area of São Paulo, Brazil: Wet and dry season campaigns. Atmospheric Environment, v.61 , p.627640, 2012.

ANDREAE, M. O. Soot Carbon and Excess Fine Potassium: Long-Range Transport of Combustion-Derived Aerosols. Science, vol. 220, p. 1148-1151, 1983. Disponível em: http://www.sciencemag.org/content/220/4602/1148.short.

ANDREÃO, W. L.; PINTO, J. A.; PEDRUZZI, R.; KUMAR, P.; ALBUQUERQUE, T. T. DE A. Quantifying the impact of particle matter on mortality and hospitalizations in four Brazilian metropolitan areas. Journal of Environmental Management, v. 270, 2020.

APTE, J. S.; BRAUER, M.; COHEN, A. J.; EZZATI, M.; POPE, C. A. Ambient PM2.5 Reduces Global and Regional Life Expectancy. Environmental Science and Technology Letters, v. 5, n. 9, p. 546-551, 2018.

ARAUJO, G. G.; RODRIGUES, F.; GONÇALVES, F. L. T.; GALANTE, D. Survival and ice nucleation activity of Pseudomonas syringae strains exposed to simulated high-altitude atmospheric conditions. Scientific Reports, vol. 9, no. 1, p. 1-11, 2019. Disponível em: https://doi.org/10.1038/s41598-019-44283-3.

ATAYGUL, E.; CELENK, S.; CANITEZ, Y.; BICAKCI, A.; MALYER, H.; SAPAN, N. Allergenic Fungal Spore Concentrations in the Atmosphere of Bursa, Turkey. Journal of Biological \& Environmental Sciences., vol. 1, no. 2, p. 73-79, 2007.

${ }^{1}$ De acordo com a Associação Brasileira de Normas Técnicas (ABNT NBR 6023). 
AUGUIE, B. gridExtra: Miscellaneous Functions for "Grid" Graphics. R package version 2.3, 2017. Disponível em: https://CRAN.R-project.org/package=gridExtra

BACHE, S. M. AND WICKHAM, H. magrittr: A Forward-Pipe Operator for R. R package version 1.5, 2014. https://CRAN.R-project.org/package=magrittr

BANERJEE, T.; MURARI, V.; KUMAR, M.; RAJU, M. P. Source apportionment of airborne particulates through receptor modeling: Indian scenario. Atmospheric Research, v. 164-165, p. 167-187, 2015.

BARKER, K.; CAMBI, F.; CATCOTT, E. J.; CHAMBERS, L. A.; HALLIDAY, E. C.; HASEGAWA, A.; HEIMANN, H.; JAMMET, H. P.; KATZ, M.; LECLERC, E.; MCCABE, L. C.; MACFARLANE, W. A.; PARKER, A.; ROSE, A. H.; STENBURG, R. L.; STEPHAN, D. G.; TAYLOR, J. R.; THOMAS, M. D.; WEXLER, H. Air Pollution. World Health Organization, no. 46, 1961.

BAUER, H.; CLAEYS, M.; VERMEYLEN, R.; SCHUELLER, E.; WEINKE, G.; BERGER, A.; PUXBAUM, H. Arabitol and mannitol as tracers for the quantification of airborne fungal spores. Atmospheric Environment, vol. 42, no. 3, p. 588-593, 2008a. Disponível em: https://doi.org/10.1016/j.atmosenv.2007.10.013.

BAUER, H.; KASPER-GIEBL, A.; LÖFLUND, M.; GIEBL, H.; HITZENBERGER, R.; ZIBUSCHKA, F.; PUXBAUM, H. The contribution of bacteria and fungal spores to the organic carbon content of cloud water, precipitation and aerosols. Atmospheric Research, vol. 64, no. 1-4, p. 109-119, 2002a. Disponível em: https://doi.org/10.1016/S0169-8095(02)00084-4.

BAUER, H.; KASPER-GIEBL, A.; ZIBUSCHKA, F.; HITZENBERGER, R.; KRAUS, G. F.; PUXBAUM, H. Determination of the carbon content of airborne fungal spores. Analytical Chemistry, vol. 74, no. 1, p. 91-95, 2002b. Disponível em: https://doi.org/10.1021/ac010331.

BAUER, H.; SCHUELLER, E.; WEINKE, G.; BERGER, A.; HITZENBERGER, R.; MARR, I. L.; PUXBAUM, H. Significant contributions of fungal spores to the organic carbon and to the aerosol mass balance of the urban atmospheric aerosol. Atmospheric Environment, vol. 42, no. 22, p. 5542-5549, 2008b. Disponível em: https://doi.org/10.1016/j.atmosenv.2008.03.019.

BELIS, C. A.; KARAGULIAN, F.; LARSEN, B. R.; HOPKE, P. K. Critical review and meta-analysis of ambient particulate matter source apportionment using receptor models in Europe. Atmospheric Environment, v. 69, p. 94-108, 2013.

BENSCH, K.; BRAUN, U.; GROENEWALD, J. Z.; CROUS, P. W. The genus Cladosporium. Studies in Mycology, vol. 72, p. 1-401, 2012. DOI 10.3114/sim0003. Disponível em: http://dx.doi.org/10.3114/sim0003

BIOTIUM. PRODUCT INFORMATION: AccuOrange ${ }^{\mathrm{TM}}$ Protein Quantitation Kit. 2016. Disponível em: https://biotium.com/wp-content/uploads/2013/07/PI-30071.pdf.

BOND, T. C.; DOHERTY, S. J.; FAHEY, D. W.; FORSTER, P. M.; BERNTSEN, T.; DEANGELO, B. J.; FLANNER, M. G.; GHAN, S.; KÄRCHER, B.; KOCH, D.; KINNE, S.; KONDO, Y.; QUINN, P. K.; SAROFIM, M. C.; SCHULTZ, M. G.; SCHULZ, M.; VENKATARAMAN, C.; ZHANG, H.; ZHANG, S.; ... ZENDER, C. S. Bounding the role of black carbon in the climate system: A scientific assessment. Journal of Geophysical Research Atmospheres, vol. 118, no. 11, p. 5380-5552, 2013. Disponível em: https://doi.org/10.1002/jgrd.50171.

BOWERS, R. M.; LAUBER, C. L.; WIEDINMYER, C.; HAMADY, M.; HALLAR, A. G.; FALL, R.; KNIGHT, R.; FIERER, N. Characterization of Airborne Microbial Communities at a High-Elevation Site and Their Potential To Act as Atmospheric Ice Nuclei. Applied and Environmental Microbiology, vol. 75, no. 15, p. 5121-5130, 2009. Disponível em: https://doi.org/10.1128/AEM.00447-09.

BRASIL. Decreto $\mathbf{N}^{\circ} 5.163$ de 30 de julho de 2004. Regulamenta a comercialização de energia elétrica, o processo de outorga de concessões e de autorizações de geração de energia elétrica, e dá outras providências. Diário oficial da união, 2004c. Disponível em: http://www.planalto.gov.br/ccivil_03/_Ato20042006/2004/Decreto/D5163.htm. Acesso em: 29/10/2019.

BRASIL. Lei No 10.847, de 15 de março de 2004. Autoriza a criação da Empresa de Pesquisa Energética - EPE e dá outras providências. Diário oficial da união, 2004a. Disponível em: http://www.planalto.gov.br/ccivil_03/_Ato2004-2006/2004/Lei/L10.847.htm. Acesso em: 29/10/2019.

BRASIL. Lei No 10.848, de 15 de março de 2004. Dispõe sobre a comercialização de energia elétrica, altera as Leis $n^{\circ} \mathrm{s} 5.655$, de 20 de maio de 1971, 8.631, de 4 de março de 1993, 9.074, de 7 de julho de 1995, 9.427, de 26 de dezembro de 1996, 9.478, de 6 de agosto de 1997, 9.648, de 27 de maio de 1998, 9.991, de 24 de julho de 2000, 10.438, de 26 de abril de 2002, e dá outras providências. Diário oficial da união, 2004b. Disponível em: http://www.planalto.gov.br/ccivil_03/_Ato2004-2006/2004/Lei/L10.848.htm. Acesso em: 29/10/2019. 
BRASIL. Lei $\mathbf{n}^{\circ}$ 11.241, de 19 de setembro de 2002. Dispõe sobre a eliminação gradativa da queima da palha da cana-de-açúcar e dá providências correlatas, Assembleia legislativa do estado de São Paulo, 2002. Disponível em: https://www.al.sp.gov.br/repositorio/legislacao/lei/2002/lei-11241-19.09.2002.html. Acesso em: 26/02/2021.

BRASIL. Lei no 9.985, de 18 de julho de 2000. Esta Lei institui o Sistema Nacional de Unidades de Conservação da Natureza - SNUC, estabelece critérios e normas para a criação, implantação e gestão das unidades de conservação. Diário oficial da união, 2000. Disponível em: http://www.planalto.gov.br/ccivil_03/leis/19985.htm. Acesso em: 26/02/2021.

BRITO, J.; RIZZO, L. V.; HERCKES, P.; et al. Physical-chemical characterisation of the particulate matter inside two road tunnels in the São Paulo Metropolitan Area. Atmospheric Chemistry and Physics, v. 13, n. 24, p. 12199-12213, 2013. Disponível em: http://www.atmos-chem-phys.net/13/12199/2013/.

BROWN, S. G.; EBERLY, S.; PAATERO, P.; NORRIS, G. A. Methods for estimating uncertainty in PMF solutions: Examples with ambient air and water quality data and guidance on reporting PMF results, Science of the Total Environment, v. 518-519, p. 626-635, 2015.

BURCH, M.; LEVETIN, E. Effects of meteorological conditions on spore plumes. International Journal of Biometeorology, vol. 46, no. 3, p. 107-17, Aug. 2002. DOI 10.1007/s00484-002-0127-1. Disponível em: http://www.ncbi.nlm.nih.gov/pubmed/12194003.

BURGE, H. A., MUILENBERG, M. L., ROGERS, C., \& HOYER, M. Spore Identification. In:Introductory fungal spore identification and bioaerosol sampler workshop, Boston - Massachusetts. Boston: Aerobiology Instruction and research, p. 75-112, 2006.

BURGE, H. A.; ROGERS, C. A. Outdoor Allergens. Environmental Health Perspectives, vol. 108, p. 653-659, 2000 .

BURNETT, R.; CHEN, H.; SZYSZKOWICZ, M.; et al. Global estimates of mortality associated with longterm exposure to outdoor fine particulate matter. Proceedings of the National Academy of Sciences of the United States of America, v. 115, n. 38, p. 9592-9597, 2018.

BURROWS, S. M.; ELBERT, W.; LAWRENCE, M. G.; PÖSCHL, U. Bacteria in the global atmosphere - Part 1: Review and synthesis of literature data for different ecosystems. Atmospheric Chemistry and Physics., vol. 9, p. 9263-9280, 2009.

BURSHTEIN, N.; LANG-YONA, N.; RUDICH, Y. Ergosterol, arabitol and mannitol as tracers for biogenic aerosols in the eastern Mediterranean. Atmospheric Chemistry and Physics, vol. 11, no. 2, p. 829-839, 31 Jan. 2011. DOI 10.5194/acp-11-829-2011. Disponível em: http://www.atmos-chem-phys.net/11/829/2011/.

BUTINAR, L.; SPENCER-MARTINS, I.; GUNDE-CIMERMAN, N. Yeasts in high Arctic glaciers: the discovery of a new habitat for eukaryotic microorganisms. Antonie van Leeuwenhoek, vol. 91, p. 277-289, 2007. Disponível em: https://doi.org/10.1007/s10482-006-9117-3.

CAPOTE, R., LÓPEZ, E., MAINEGRA, E. WinQXAS Manual (Quantitative X-Ray Analysis System for Widows) Version 1.2, 2000.

CARSLAW, D. C. AND K. ROPKINS. openair --- an R package for air quality data analysis. Environmental Modelling \& Software. Volume 27-28, 52-61, 2012.

CASTANHO, A. D. A.; ARTAXO, P. Wintertime and summertime São Paulo aerosol source apportionment study. Atmospheric Environment, v. 35, n. 29, p. 4889-4902, 2001.

CASTILLO, R. Dinâmicas recentes do setor sucroenergético no Brasil: competitividade regional para o bioma Cerrado. GEOgraphia, dossiê, v. 17, n. 35, p. 95, 2015.

CASTRO, L. M.; PIO, C. a.; HARRISON, R. M.; SMITH, D. J. T. Carbonaceous aerosol in urban and rural European atmospheres: Estimation of secondary organic carbon concentrations. Atmospheric Environment, vol. 33, no. 17, p. 2771-2781, 1999. Disponível em: https://doi.org/10.1016/S1352-2310(98)00331-8.

CAUMO, S. E. S.; CLAEYS, M.; MAENHAUT, W.; VERMEYLEN, R.; BEHROUZI, S.; SAFI SHALAMZARI, M.; VASCONCELLOS, P. C. Physicochemical characterization of winter PM10 aerosol impacted by sugarcane burning from S??o Paulo city, Brazil. Atmospheric Environment, vol. 145, p. 272-279, 2016. Disponível em: https://doi.org/10.1016/j.atmosenv.2016.09.046.

CCEE, Câmara de comercialização de energia elétrica. Disponível em: http://www.ccee.org.br/portal/faces/pages_publico/onde$\underline{\text { atuamos/setor_eletrico? afrLoop }=527845936648312 \& \text { adf.ctrl- }}$ 
state=lf38em5vd_1\#!\%40\%40\%3F_afrLoop\%3D527845936648312\%26_adf.ctrl-state\%3Dlf38em5vd_5. Acesso em: 29/10/2019.

CETESB, 2019a. Emissões veiculares no estado de São Paulo 2018. Secretaria do Meio Ambiente, São Paulo (ISSN 0103-4103), 2019a. Disponível em: http://www.CETESB.sp.gov.br/ ar/emissao-veicular/48-relatoriosepublicacoes.

CETESB, 2019b. Qualidade do ar no estado de São Paulo 2018. Secretaria do Meio Ambiente, São Paulo (ISSN 0103-4103), 2019b. Disponível em: https://cetesb.sp.gov.br/ar/wpcontent/uploads/sites/28/2019/07/Relat\%C3\%B3rio-de-Qualidade-do-Ar-2018.pdf.

CETESB, 2020. Qualidade do ar no estado de São Paulo 2019. Secretaria do Meio Ambiente, São Paulo (ISSN 0103-4103), 2020. Disponível em: https://cetesb.sp.gov.br/ar/wpcontent/uploads/sites/28/2020/07/Relat\%C3\%B3rio-de-Qualidade-do-Ar-2019.pdf.

CETESB. Plano de redução de emissões de fontes estacionárias. Guia de melhor tecnologia prática disponível, capítulo 2 - fontes de combustão, 2016. Disponível em: https://cetesb.sp.gov.br/ar/wpcontent/uploads/sites/28/2016/06/Cap\%C3\%ADtulo-2-MTPD-Combust\%C3\%A3o.pdf. Acesso em: 29/10/2019.

CHEN, L. W. A.; CHOW, J. C.; WANG, X. L.; ROBLES, J. A.; SUMLIN, B. J.; LOWENTHAL, D. H.; ZIMMERMANN, R.; WATSON, J. G. Multi-wavelength optical measurement to enhance thermal/optical analysis for carbonaceous aerosol. Atmospheric Measurement Techniques, vol. 8, no. 1, p. 451-461, 2015. Disponível em: https://doi.org/10.5194/amt-8-451-2015.

CHOW, J. C. Measurement methods to determine compliance with ambient air quality standards for suspended particles. Journal of the Air and Waste Management Association, vol. 45, no. 5, p. 320-382, 1995. Disponível em: https://doi.org/10.1080/10473289.1995.10467369.

CHOW, J. C.; LOWENTHAL, D. H.; CHEN, L. A.; WANG, X.; WATSON, J. G. Mass reconstruction methods for PM 2.5: a review. Air Quality, Atmosphere \& Health, v. 8, p. 243-263, 2015. Disponível em: https://doi.org/10.1007/s11869-015-0338-3.

CHOW, J. C.; WANG, X.; SUMLIN, B. J.; GRONSTAL, S. B.; ANTONY CHEN, L. W.; TRIMBLE, D. L.; KOHL, S. D.; MAYORGA, S. R.; RIGGIO, G.; HURBAIN, P. R.; JOHNSON, M.; ZIMMERMANN, R.; WATSON, J. G. Optical calibration and equivalence of a multiwavelength thermal/optical carbon analyzer. Aerosol and Air Quality Research, vol. 15, no. 4, p. 1145-1159, 2015. Disponível em: https://doi.org/10.4209/aaqr.2015.02.0106.

CHOW, J. C.; WATSON, J. G. Enhanced Ion Chromatographic Speciation of Water-Soluble PM 2.5 to Improve Aerosol Source Apportionment. Aerosol Science and Engineering, vol. 1, no. 1, p. 7-24, 2017. Disponível em: https://doi.org/10.1007/s41810-017-0002-4.

CHOW, J. C.; WATSON, J. G.; CHEN, L. W. A.; CHANG, M. C. O.; ROBINSON, N. F.; TRIMBLE, D.; KOHL, S. The IMPROVE_A temperature protocol for thermal/optical carbon analysis: Maintaining consistency with a long-term database. Journal of the Air and Waste Management Association, vol. 57, no. 9, p. 1014-1023, 2007. Disponível em: https://doi.org/10.3155/1047-3289.57.9.1014.

CHOW, J. C.; WATSON, J. G.; LU, Z.; LOWENTHAL, D. H.; FRAZIER, C. a.; SOLOMON, P. a.; THUILLIER, R. H.; MAGLIANO, K. Descriptive analysis of PM2.5 and PM10 at regionally representative locations during SJVAQS/AUSPEX. Atmospheric Environment, vol. 30, no. 12, p. 2079-2112, 1996. Disponível em: https://doi.org/10.1016/1352-2310(95)00402-5.

CHOW, J. C.; WATSON, J. G.; PRITCHETT, L. C.; PIERSON, W. R.; FRAZER, C. A.; PURCELL, R. G. The DRI thermal/optical reflectance carbon analysis system: description, evaluation and applications in u.s. air quality studies. Atmospheric Environment, vol. 27, no. 8, p. 1185-1201, 1993.

COCHET, M. N. Ice crystallization by Pseudomonas syringae. Applied Microbiology and Biotechnology, vol. 54, p. 153-161, 2000.

CONAB - Companhia Nacional de Abastecimento. A Geração Termoelétrica com a Queima do Bagaço de Cana-de-Açúcar no Brasil. p. 1-160, 2011.

CONAB - Companhia Nacional de Abastecimento. Acompanhamento da safra brasileira de cana-de-açúcar. v. 5, n.4, 2019a.

CONAB - Companhia Nacional de Abastecimento. Acompanhamento da safra brasileira de cana-de-açúcar. v. 4, n.1, 2017. 
CONAB - Companhia Nacional de Abastecimento. Acompanhamento da safra brasileira de cana-de-açúcar. v. 4, n.4, 2018.

CONAB - Companhia Nacional de Abastecimento. Perfil do Setor do Açúcar e do Etanol no Brasil, 2019 b.

CONAMA. Resolução CONAMA No 382/2006. Estabelece os limites máximos de emissão de poluentes atmosféricos para fontes fixas. Diário oficial da união, 2007. Disponível em: http://www2.mma.gov.br/port/conama/legiabre.cfm?codlegi=520. Acesso em: 29/10/2019.

CONEN, F.; HENNE, S.; MORRIS, C. E.; ALEWELL, C. Atmospheric ice nucleators active $\geq-12 \circ \mathrm{C}$ can be quantified on PM 10 filters. Atmospheric Measurement Techniques., p. 321-327, 2012. Disponível em: https://doi.org/10.5194/amt-5-321-2012.

DANTAS FILHO, P.L. Análise de custos na geração de energia com bagaço de cana-de- açúcar: um estudo de caso em quatro usinas de São Paulo, 2009, 175p. Dissertação de mestrado - Programa de Pós-Graduação em Energia, Universidade de São Paulo.

DANTAS, G. A.; LEGEY, L. F. L.; MAZZONE, A. Energy from sugarcane bagasse in Brazil: An assessment of the productivity and cost of different technological routes. Renewable and Sustainable Energy Reviews, v. 21, p. 356-364, 2013. Elsevier. Disponível em: http://dx.doi.org/10.1016/j.rser.2012.11.080.

DAVISON, B.; HEWITT, C. N.; O’DOWD, C. D.; LOWE, J. A.; SMITH, M. H.; SCHWIKOWSKI, M.; BALTENSPERGER, U.; HARRISON, R. M. Dimethyl sulfide, methane sulfonic acid and physicochemical aerosol properties in Atlantic air from the United Kingdom to Halley Bay. Journal of Geophysical Research Atmospheres, vol. 101, no. 17, p. 22855-22867, 1996.

DEGOBBI, C. Análise dos contaminantes biológicos presentes no material particulado (PM2,5) de amostras da região metropolitana de São Paulo. 2010. 151 f. Tese (Doutorado em Ciência) - Programa de Pós- Graduação em Patologia. Faculdade de medicina da Universidade de São Paulo, São Paulo.

DEGOBBI, C.; LOPES, F. D. T. Q. S.; CARVALHO-OLIVEIRA, R.; MUÑOZ, J. E.; SALDIVA, P. H. N. Correlation of fungi and endotoxin with PM2.5 and meteorological parameters in atmosphere of Sao Paulo, Brazil. Atmospheric Environment, vol. 45, no. 13, p. 2277-2283, Apr. 2011. DOI 10.1016/j.atmosenv.2010.12.005. Disponível em: http://linkinghub.elsevier.com/retrieve/pii/S1352231010010307.

DENG, Q.; DENG, L.; MIAO, Y.; GUO, X.; LI, Y. Particle deposition in the human lung: Health implications of particulate matter from different sources. Environmental Research, v. 169, p. 237-245, 2019. Elsevier Inc. Disponível em: https://doi.org/10.1016/j.envres.2018.11.014.

DESPRÉS, V. R.; ALEX HUFFMAN, J.; BURROWS, S. M.; HOOSE, C.; SAFATOV, A. S.; BURYAK, G.; FRÖHLICH-NOWOISKY, J.; ELBERT, W.; ANDREAE, M. O.; PÖSCHL, U.; JAENICKE, R. Primary biological aerosol particles in the atmosphere: A review. Tellus, Series B: Chemical and Physical Meteorology, vol. 64, no. 1, 2012. Disponível em: https://doi.org/10.3402/tellusb.v64i0.15598.

DI DOMENICO, M.; BENEVENUTO, S. G. M.; TOMASINI, P. P.; et al. Concentrated ambient fine particulate matter (PM2.5) exposure induce brain damage in pre and postnatal exposed mice. NeuroToxicology, v. 79, p. 127$141,2020$.

DIEHL, K.; QUICK, C.; MATTHIAS-MASER, S.; MITRA, S. K., JAENICKE, R The ice nucleating ability of pollen Part I : Laboratory studies in deposition and condensation freezing modes. Atmospheric Research, vol. 58, p. 75-87, 2001.

DOUWES, J.; THORNE, P.; PEARCE, N.; HEEDERIK, D. Bioaerosol health effects and exposure assessment: Progress and prospects. Annals of Occupational Hygiene, vol. 47, no. 3, p. 187-200, 2003. Disponível em: https://doi.org/10.1093/annhyg/meg032.

DUTTON, M. V.; EVANS, C. S. Oxalate production by fungi: Its role in pathogenicity and ecology in the soil environment. Canadian Journal of Microbiology, v. 42, n. 9, p. 881-895, 1996.

EEA, 2020. In: E. E. Agency (Ed.), European Union Emission Inventory Report 1990 - 2018 Under the UNECE Convention on Long-range Transboundary Air Pollution (LRTAP). Publications Office of the European Union, Copenhagen.

ELBERT, W.; TAYLOR, P. E.; ANDREAE, M. O.; PÖSCHL, U. Contribution of fungi to primary biogenic aerosols in the atmosphere: wet and dry discharged spores, carbohydrates, and inorganic ions. Atmospheric Chemistry and Physics, vol. 7, no. 17, p. 4569-4588, 7 Sep. 2007. DOI 10.5194/acp-7-4569-2007. Disponível em: http://www.atmos-chem-phys.net/7/4569/2007/ 
EMYGDIO, A. P. M. Identificação de bioaerossóis de origem fúngica na cidade de São Paulo. 2016.164 f. Dissertação (Mestrado em Ciências) - Escola de artes, ciências e humanidades, Universidade de São Paulo, São Paulo, 2016.

EMYGDIO, A. P. M.; ANDRADE, M. de F.; GONÇALVES, F. L. T.; ENGLING, G.; ZANETTI, R. H. de S.; KUMAR, P. Biomarkers as indicators of fungal biomass in the atmosphere of São Paulo, Brazil. Science of the Total Environment, 2018a. Disponível em: https://doi.org/10.1016/j.scitotenv.2017.08.153.

EMYGDIO, A. P. M.; DEGOBBI, C.; GONÇALVES, F. L. T.; ANDRADE, M. de F. One year of temporal characterization of fungal spore concentration in São Paulo metropolitan area, Brazil. Journal of Aerosol Science, vol. 115, no. July 2017, p. 121-132, 2018b. DOI 10.1016/j.jaerosci.2017.07.003. Disponível em: https://doi.org/10.1016/j.jaerosci.2017.07.003.

ENGLING, G.; LEE, J. J.; TSAI, Y. W.; et al. Size-resolved anhydrosugar composition in smoke aerosol from controlled field burning of rice straw. Aerosol Science and Technology, v. 43, n. 7, p. 662-672, 2009.

EPA (United States Environmental Protection Agency). Ecosystems and Air Quality. Disponível em: https://www.epa.gov/eco-research/ecosystems-and-air-

quality\#: :text=Research\%20shows\%20that\%20air\%20pollution,when\%20deposited $\% 20$ on $\% 20$ surface $\% 20$ wat ers. Acesso em: 30/10/2020.

EPE. TOLMASQUIM, MAURICIO TIOMNO. Energia Termelétrica: Gás Natural, Biomassa, Carvão, Nuclear. Empresa de Pesquisa Energética (EPE): Rio de Janeiro, 2016.

FIELD, A. MILES J.; FIELD, Z. Discovering statistics using R. SAGE, 2012.

FIRKE, S. janitor: Simple Tools for Examining and Cleaning Dirty Data. R package version 2.0.1., 2020. https://CRAN.R-project.org/package=janitor

FISCHER, M. W. F.; STOLZE-RYBCZYNSKI, J. L.; CUI, Y.; MONEY, N. P. How far and how fast can mushroom spores fly? Physical limits on ballistospore size and discharge distance in the Basidiomycota. Fungal Biology, vol. 114, no. 8, p. 669-75, Aug. 2010. DOI 10.1016/j.funbio.2010.06.002. Disponível em: http://www.pubmedcentral.nih.gov/articlerender.fcgi?artid=2936274\&tool=pmcentrez\&rendertype=abstract.

FRÖHLICH-NOWOISKY, J. PICKERSGILL, D. A. DESPRES, V. R. PÖSCHEL, U. High diversity of fungi in air particulate matter. PNAS, vol. 106, no. 31, p. 12814-12819, 2009. Disponível em: http://www.pnas.org/content/106/31/12814.short.

FRÖHLICH-NOWOISKY, J.; BURROWS, S. M.; XIE, Z.; ENGLING, G.; SOLOMON, P. a.; FRASER, M. P.; MAYOL-BRACERO, O. L.; ARTAXO, P.; BEGEROW, D.; CONRAD, R.; ANDREAE, M. O.; DESPRÉS, V. R.; PÖSCHL, U. Biogeography in the air: fungal diversity over land and oceans. Biogeosciences, vol. 9, no. 3, p. 1125-1136, 27 Mar. 2012. DOI 10.5194/bg-9-1125-2012. Disponível em: http://www.biogeosciences.net/9/1125/2012/.

FRÖHLICH-NOWOISKY, J.; KAMPF, C. J.; WEBER, B.; HUFFMAN, J. A.; PÖHLKER, C.; ANDREAE, M. O.; LANG-YONA, N.; BURROWS, S. M.; GUNTHE, S. S.; ELBERT, W.; SU, H.; HOOR, P.; THINES, E.; HOFFMANN, T.; DESPRÉS, V. R.; PÖSCHL, U. Bioaerosols in the Earth system: Climate, health, and ecosystem interactions. Atmospheric Research, vol. 182, p. 346-376, 2016. DOI 10.1016/j.atmosres.2016.07.018. Disponível em: http://dx.doi.org/10.1016/j.atmosres.2016.07.018.

FU, P.; KAWAMURA, K.; KOBAYASHI, M.; SIMONEIT, B. R. T. Seasonal variations of sugars in atmospheric particulate matter from Gosan, Jeju Island: Significant contributions of airborne pollen and Asian dust in spring. Atmospheric Environment, v. 55, p. 234-239, 2012. Elsevier Ltd. Disponível em: http://dx.doi.org/10.1016/j.atmosenv.2012.02.061.

GIMENES, L. J.; PROF, O.; ROBERTO, D. FUNGOS BASIDIOMICETOS Técnicas de coleta, isolamento e subsídios para processos biotecnológicos. 2010. Curso de Capacitação de Monitores e Educadores - Programa de Pós Graduação em Biodiversidade Vegetal e Meio Ambiente, Instituto de botânica, São Paulo, 2010

GIRAUDOUX, P. pgirmess: Spatial Analysis and Data Mining for Field Ecologists. R package version 1.6.9, 2018. Disponível em: https://CRAN.R-project.org/package=pgirmess

GLIKSON, M.; RUTHERFORD, S.; SIMPSON, R. W.; MITCHELL, C. A.; YAGO, A. Microscopic and submicron components of atmospheric particulate matter during high asthma periods in Brisbane, Queensland, Australia. Atmospheric Environment, vol. 29, no. 4, p. 549-562, 1995 . Disponível em: https://doi.org/10.1016/1352-2310(94)00278-S.

GODISH, T. Air Quality. 2. ed. Florida: Lewis publishers, 2004. 
GODOY, M. L. D. P.; GODOY, J. M.; ROLDÃO, L. A.; SOLURI, D. S.; DONAGEMMA, R. A. Coarse and fine aerosol source apportionment in Rio de Janeiro, Brazil. Atmospheric Environment, vol. 43, no. 14, p. 23662374, 2009. Disponível em: https://doi.org/10.1016/j.atmosenv.2008.12.046.

GONG, J.; QI, J.; E, B.; YIN, Y.; GAO, D. Concentration, viability and size distribution of bacteria in atmospheric bioaerosols under different types of pollution. Environmental Pollution, vol. 257, p. 113485, 2020. DOI 10.1016/j.envpol.2019.113485. Disponível em: https://doi.org/10.1016/j.envpol.2019.113485.

GOSSELIN, M. I.; RATHNAYAKE, C. M.; CRAWFORD, I.; PÖHLKER, C.; FRÖHLICH-NOWOISKY, J.; SCHMER, B.; DESPRÉS, V. R.; ENGLING, G.; GALLAGHER, M.; STONE, E.; PÖSCHL, U.; HUFFMAN, J. A. Fluorescent Bioaerosol Particle, Molecular Tracer, and Fungal Spore Concentrations during Dry and Rainy Periods in a Semi-Arid Forest. Atmospheric Chemistry and Physics Discussions, no. September, p. 1-33, 2016. DOI 10.5194/acp-2016-743. Disponível em: http://www.atmos-chem-phys-discuss.net/acp-2016-743/.

GOTTARDINI, E.; CRISTOFOLINI, F.; CRISTOFORI, A.; VANNINI, A.; FERRETTI, M. Sampling bias and sampling errors in pollen counting in aerobiological monitoring in Italy. Journal of Environmental Monitoring, v. 11, n. 4, p. 751-755, 2009.

GRAHAM, B.; GUYON, P.; TAYLOR, P. E.; ARTAXO, P.; MAENHAUT, W.; GLOVSKY, M. M.; FLAGAN, R. C.; ANDREAE, M. O. Organic compounds present in the natural Amazonian aerosol: Characterization by gas chromatography-mass spectrometry. Journal of Geophysical Research: Atmospheres, vol. 108, no. D24, p. n/an/a, 2003. DOI 10.1029/2003JD003990. Disponível em: http://doi.wiley.com/10.1029/2003JD003990.

GRAVESEN, S. FUNGI AS A CAUSE OF ALLERGIC DISEASE. Allergy, vol. 34, no. 1, p. 135-154, 1979. Disponível em: https://doi.org/10.1001/jama.1995.03520250039026.

GRINN-GOFROŃ, A.; RAPIEJKO, P. Occurrence of Cladosporium spp. and Alternaria spp. spores in Western, Northern and Central-Eastern Poland in 2004-2006 and relation to some meteorological factors. Atmospheric
n. $\quad 4, \quad \mathrm{p}$
p. $\quad 747-758, \quad 2009$.
Disponível
em:

http://linkinghub.elsevier.com/retrieve/pii/S0169809509000696. Acesso em: 26/11/2014.

GRINN-GOFROŃ, A.; STRZELCZAK, A.; WOLSKI, T. The relationships between air pollutants, meteorological parameters and concentration of airborne fungal spores. Environmental Pollution, vol. 159, no. 2, p. 602-608, 2011. Disponível em: https://doi.org/10.1016/j.envpol.2010.10.002.

GROSJEAN, P. and IBANEZ, F. pastecs: Package for Analysis of Space-Time Ecological Series. R package version 1.3.21. 2018. https://CRAN.R-project.org/package=pastecs

HAGA, D. I.; BURROWS, S. M.; IANNONE, R.; WHEELER, M. J.; MASON, R. H.; CHEN, J.; POLISHCHUK, E. A.; PÖSCHL, U.; BERTRAM, A. K. Ice nucleation by fungal spores from the classes agaricomycetes, ustilaginomycetes, and eurotiomycetes, and the effect on the atmospheric transport of these spores. Atmospheric Chemistry and Physics, vol. 14, no. 16, p. 8611-8630, 2014. Disponível em: https://doi.org/10.5194/acp-148611-2014.

HAineS, J., ESCAMILlA, B., MUILENBERG, M. L., GALLUP, J., LEVETIN, E. Mycology of the air. An introduction to the sampling and identification of airborne fungus spores. Tucson, Arizona, 2000.

HALL, D.; WU, C.-Y.; HSU, Y.-M.; et al. PAHs, carbonyls, VOCs and PM2.5 emission factors for pre-harvest burning of Florida sugarcane. Atmospheric Environment, v. 55, p. 164-172, 2012. Elsevier Ltd. Disponível em: http://linkinghub.elsevier.com/retrieve/pii/S1352231012002750. Acesso em: 25/11/2014.

HASSETT, M. O.; FISCHER, M. W. F.; MONEY, N. P. Mushrooms as Rainmakers : How Spores Act as Nuclei for Raindrops. PLoS ONE, p. 1-10, 2015. Disponível em: https://doi.org/10.1371/journal.pone.0140407.

HETEM, I. G. Quantificação da contribuição veicular para as concentrações atmosféricas de material particulado fino e black carbon em São Paulo. 2014. 80f. Dissertação (Mestrado em ciências) - Instituto de Astronomia, Geofísica e Ciências Atmosféricas, Universidade de São Paulo, São Paulo, 2014.

HETEM, I. G.; DE FATIMA ANDRADE, M. Characterization of fine particulate matter emitted from the resuspension of road and pavement dust in the Metropolitan Area of São Paulo, Brazil. Atmosphere, vol. 7, no. 3, 2016. Disponível em: https://doi.org/10.3390/atmos7030031.

HOPKE, P. K.; DAI, Q.; LI, L.; FENG, Y. Global review of recent source apportionments for airborne particulate matter. Science of the Total Environment, vol. 740, p. 140091, 2020. DOI 10.1016/j.scitotenv.2020.140091. Disponível em: https://www.sciencedirect.com/science/article/pii/S0048969720336111?dgcid=rss_sd_all\&utm_source=research er_app\&utm_medium=referral\&utm_campaign=RESR_MRKT_Researcher_inbound . 
HUFFMAN, J. A.; PRENNI, A. J.; DEMOTT, P. J.; PÖHLKER, C.; MASON, R. H.; ROBINSON, N. H.; FRÖHLICH-NOWOISKY, J.; TOBO, Y.; DESPRÉS, V. R.; GARCIA, E.; GOCHIS, D. J.; HARRIS, E.; MÜLLER-GERMANN, I.; RUZENE, C.; SCHMER, B.; SINHA, B.; DAY, D. A.; ANDREAE, M. O.; JIMENEZ, J. L.; GALLAGHER, M.; KREIDENWEIS, S. M.; BERTRAM, A. K.; PÖSCHL, U. High concentrations of biological aerosol particles and ice nuclei during and after rain. Atmospheric Chemistry and Physics, vol. 13, no. 13, p. 6151-6164, 2013. Disponível em: https://doi.org/10.5194/acp-13-6151-2013.

IAG - Boletim Climatológico Anual da Estação Meteorológica do IAG/USP, 2017. Instituto de Astronomia, Geofísica e Ciências Atmosféricas da Universidade de São Paulo, v.20, 2017. Disponível em: http://www.estacao.iag.usp.br/Boletins/2017.pdf. Acesso em: 17/12/2020.

IAG - Boletim Climatológico Anual da Estação Meteorológica do IAG/USP, 2014. Instituto de Astronomia, Geofísica e Ciências Atmosféricas da Universidade de São Paulo, v.17, 2014. Disponível em: http://www.estacao.iag.usp.br/Boletins/2014.pdf, Acesso em: 25/02/2021.

IAG - Estação Meteorológica do IAG-USP. Resumo mensal, abril de 2018. Instituto de Astronomia, Geofísica e Ciências Atmosféricas da Universidade de São Paulo, 2018b. Disponível em: http://www.estacao.iag.usp.br/Mensais/Abril2018.pdf. Acesso em: 17/12/2020.

IAG - Estação Meteorológica do IAG-USP. Resumo mensal, março de 2018. Instituto de Astronomia, Geofísica e Ciências Atmosféricas da Universidade de São Paulo, 2018a. Disponível em: http://www.estacao.iag.usp.br/Mensais/Mar\%C3\%A7o2018.pdf. Acesso em: 17/12/ 2020.

IANNONE, R.; CHERNOFF, D. I.; PRINGLE, A.; MARTIN, S. T.; BERTRAM, A. K. The ice nucleation ability of one of the most abundant types of fungal spores found in the atmosphere. Atmospheric Chemistry and Physics., vol. 11, p. 1191-1201, 2011. Disponível em: https://doi.org/10.5194/acp-11-1191-2011.

IANOVICI, N. Atmospheric concentrations of selected allergenic fungal spores in relation to some meteorological factors, in Timişoara (Romania). Aerobiologia, vol. 32, no. 1, p. 139-156, 2016. Disponível em: https://doi.org/10.1007/s10453-016-9427-5.

IBGE - Instituto Brasileiro de Geografia e Estatística (2010). Sinopse do Censo demográfico 2010. Rio de Janeiro, 2011.

IBGE - Instituto Brasileiro de Geografia e Estatística (2017). A Geografia da cana-de-açúcar. Dinâmica territorial da produção agropecuária, Rio de Janeiro, 2017b.

IBGE - Instituto Brasileiro de Geografia e Estatística (2017). Estimativas da população residente no Brasil e unidades da federação com data de referência em $\mathbf{1}^{\mathbf{0}}$ de julho de 2017, Rio de Janeiro, 2017a.

IEA - Instituto de Economia Agrícola. Mecanização da Colheita da Cana-de-açúcar Atinge 90\% na Safra 2016/17. Análises e Indicadores do Agronegócio, v.12, n.6, junho 2017.

INPE: INPE (Instituto Nacional de Pesquisa Espaciais). Portal do Monitoramento de Queimadas. Programa Queimadas. Disponível em: http://queimadas.dgi.inpe.br/queimadas/bdqueimadas. Acesso em: 26/11/2019.

IPCC, 2007: Climate Change 2007: Synthesis Report. Contribution of Working Groups I, II and III to the Fourth Assess- ment Report of the Intergovernmental Panel on Climate Change [Core Writing Team, Pachauri, R.K and Reisinger, A. (eds.)]. IPCC, Geneva, Switzerland, 104 pp

IPCC, 2014: Climate Change 2014: Synthesis Report. Contribution of Working Groups I, II and III to the Fifth Assessment Report of the Intergovernmental Panel on Climate Change [Core Writing Team, R.K. Pachauri and L.A. Meyer (eds.)]. IPCC, Geneva, Switzerland, 151 pp.

JACOB, D. J.; WOFSY, S. C. Photochemistry of biogenic emissions over the Amazon forest. Journal of Geophysical Research, v. 93, n. D2, p. 1477-1486, 1988.

JERIČEVIĆ, A.; GAŠPARAC, G.; MIKULEC, M. M.; KUMAR, P.; PRTENJAK, M. T. Identification of diverse air pollution sources in a complex urban area of Croatia. Journal of Environmental Management, v. 243, n. March, p. 67-77, 2019. Disponível em: https://linkinghub.elsevier.com/retrieve/pii/S0301479719304815.

JOHANSSON, S. G. O.; BIEBER, T.; DAHL, R.; FRIEDMANN, P. S.; LANIER, B. Q.; LOCKEY, R. F.; MOTAlA, C.; ORTEGA MARTELL, J. A.; PlATTS-MILlS, T. A. E.; RING, J.; THIEN, F.; VAN CAUWENBERGE, P.; WILLIAMS, H. C. Revised nomenclature for allergy for global use: Report of the Nomenclature Review Committee of the World Allergy Organization, October 2003. Journal of Allergy and Clinical Immunology, vol. 113, no. 5, p. 832-836, 2004. Disponível em: https://doi.org/10.1016/j.jaci.2003.12.591. 
KANEDA, T. Seasonal Population Changes and Characterization of Ice-Nucleating Bacteria in Farm Fields of Central Albertat. Applied and Environmental Microbiology, vol. 52, no. 1, p. 173-178, 1986.

KANG, H.; XIE, Z.; HU, Q. Ambient protein concentration in PM10 in Hefei, central China. Atmospheric Environment, vol. 54, p. 73-79, 2012. DOI 10.1016/j.atmosenv.2012.03.003.

KASPRZYK, I.; RODINKOVA, V.; ŠAULIENĖ, I.; RITENBERGA, O.; GRINN-GOFRON, A.; NOWAK, M.; SULBORSKA, A.; KACZMAREK, J.; WERYSZKO-CHMIELEWSKA, E.; BILOUS, E.; JEDRYCZKA, M. Air pollution by allergenic spores of the genus Alternaria in the air of central and eastern Europe. Environmental Science and Pollution Research, vol. 22, no. 12, p. 9260-9274, 2015. Disponível em: https://doi.org/10.1007/s11356-014-4070-6.

KAWAMURA, K.; BARRIE, L. A.; TOOM-SAUNTRY, D. Intercomparison of the measurements of oxalic acid in aerosols by gas chromatography and ion chromatography. Atmospheric Environment, vol. 44, no. 39, p. 53165319, 2010. Disponível em: https://doi.org/10.1016/j.atmosenv.2010.08.051.

KAWAMURA, K.; BIKKINA, S. A review of dicarboxylic acids and related compounds in atmospheric aerosols: Molecular distributions, sources and transformation. Atmospheric Research, v. 170, p. 140-160, 2016. Elsevier B.V. Disponível em: http://dx.doi.org/10.1016/j.atmosres.2015.11.018.

KAWAMURA, K.; IKUSHIMA, K. Seasonal changes in the distribution of dicarboxylic acids in the urban atmosphere. Environmental Science \& Technology, v. 27, n. 10, p. 2227-2235, 1993. Disponível em: http://pubs.acs.org/doi/pdf/10.1021/es00047a033.

KAWAMURA, K.; KAPLAN, I. R. Motor exhaust emission as a primary source for dicarboxylic acids in Los Angeles Ambient Air. Environ. Sci. Techn., v. 21, n. 1, p. 105-110, 1987.

KAWASHIMA, A.B., DE MORAIS, M.V.B., MARTINS, L.D., URBINA, V., RAFEE, S.A.A., CAPUCIM, M.N. AND MARTINS, J.A. Estimates and Spatial Distribution of Emissions from Sugar Cane Bagasse Fired Thermal Power Plants in Brazil. Journal of Geoscience and Environment Protection, v. 03, n. 06, p. 72-76, 2015.

KIEFT, T. L.; RUSCETTIT, T. Characterization of Biological Ice Nuclei from a Lichen. Journal of Bacteriology, vol. 172, no. 6, p. 3519-3523, 1990.

KIM, H.; ORSER, C.; LINDOW, S.; SANDS, D. Xanthomonas campestris pv. translucens strains active in ice nucleation. Plant Disease, vol. 71, p. 994-997, 1987. Disponível em: https://doi.org/10.1094/PD-71-0994.

KOBZIAR, L. N.; PINGREE, M. R. A.; LARSON, H.; DREADEN, T. J.; GREEN, S.; SMITH, J. A. Pyroaerobiology:the aerosolization and transport of viable microbial life by wildland fire. Ecosphere, vol. 9, no. November, 2018. Disponível em: https://doi.org/10.1002/ecs2.2507.

KUNDU, S.; KAWAMURA, K.; ANDREAE, T. W.; HOFFER, A.; ANDREAE, M. O. Molecular distributions of dicarboxylic acids, ketocarboxylic acids and $\alpha$-dicarbonyls in biomass burning aerosols: Implications for photochemical production and degradation in smoke layers. Atmospheric Chemistry and Physics, v. 10, n. 5, p. 2209-2225, 2010.

KUNWAR, B.; KAWAMURA, K.; FUJIWARA, S.; FU, P.; MIYAZAKI, Y.; POKHREL, A. Dicarboxylic acids, oxocarboxylic acids and $\alpha$-dicarbonyls in atmospheric aerosols from Mt. Fuji, Japan: Implication for primary emission versus secondary formation. Atmospheric Research, vol. 221, no. January, p. 58-71, 2019. DOI 10.1016/j.atmosres.2019.01.021. Disponível em: https://doi.org/10.1016/j.atmosres.2019.01.021.

KUSTRZEBA-WÓJCICKA, I.; SIWAK, E.; TERLECKI, G.; WOLAŃCZYK-MĘDRALA, A.; MĘDRALA, W. Alternaria alternata and Its Allergens: a Comprehensive Review. Clinical Reviews in Allergy and Immunology, vol. 47, no. 3, p. 354-365, 2014. Disponível em: https://doi.org/10.1007/s12016-014-8447-6.

LACEY, J. Spore dispersal - its role in ecology and disease: the British contribution to fungal aerobiology. Mycological Research, vol. 100, no. 6, p. 641-660, Jun. 1996. DOI 10.1016/S0953-7562(96)80194-8. Disponível em: http://linkinghub.elsevier.com/retrieve/pii/S0953756296801948.

LAU, A. P. S.; LEE, A. K. Y.; CHAN, C. K.; FANG, M. Ergosterol as a biomarker for the quantification of the fungal biomass in atmospheric aerosols. Atmospheric Environment, vol. 40, no. 2, p. 249-259, Jan. 2006. DOI 10.1016/j.atmosenv.2005.09.048. http://linkinghub.elsevier.com/retrieve/pii/S1352231005008988. Disponível

em:

LEE, A. K. Y.; CHAN, C. K.; FANG, M.; LAU, A. P. S. The 3-hydroxy fatty acids as biomarkers for quantification and characterization of endotoxins and Gram-negative bacteria in atmospheric aerosols in Hong Kong. Atmospheric Environment, vol. 38, no. 37, p. 6307-6317, 2004. Disponível em: https://doi.org/10.1016/j.atmosenv.2004.08.013. 
LEVETIN, E. Methods for aeroallergen sampling. Current Allergy and Asthma Reports, vol. 4, no. 5, p. 37683, 2004. DOI 10.1007/s11882-004-0088-z. Disponível em: http://www.ncbi.nlm.nih.gov/pubmed/15283878.

LI, D. W.; KENDRICK, B. A year-round study on functional relationships of airborne fungi with meteorological factors. International Journal of Biometeorology, vol. 39, no. 2, p. 74-80, 1995. Disponível em: https://doi.org/10.1007/BF01212584.

LIMA, F. D. M.; PÉREZ-MARTÍNEZ, P. J.; ANDRADE, M. D. F.; KUMAR, P.; MIRANDA, R. M. Characterization of particles emitted by pizzerias burning wood and briquettes: a case study at Sao Paulo, Brazil. Environmental Science and Pollution Research, 2020. Disponível em: https://doi.org/10.1007/s11356-019-075086\%0AURBAN.

LIN, W.-H.; LI, C.-S. Associations of Fungal Aerosols, Air Pollutants, and Meteorological Factors. Aerosol Science and Technology, vol. 32, no. 4, p. 359-368, Apr. 2000. DOI 10.1080/027868200303678. Disponível em: http://www.tandfonline.com/doi/abs/10.1080/027868200303678.

LINDOW, S. E.; ARNY, D. C.; UPPER, C. D. Erwinia herbicola : A Bacterial Ice Nucleus Active in Increasing Frost Injury to Corn. Phytopathology, vol. 68, p. 523-527, 1978.

LOESCHER, W. H.; TYSON, R. H.; EVERARD, J. D.; REDGWELL, R. J.; BIELESKI, R. L. Mannitol Synthesis in Higher Plants 1. Plant Physiology, vol. 98, no. 4, p. 1396-1402, 1992. Disponível em: http://www.pubmedcentral.nih.gov/articlerender.fcgi?artid=1080363\&tool=pmcentrez\&rendertype=abstract.

LUCCA, A. J. Harmful fungi in both agriculture and medicine. Revista Iberoamericana de Micologia, vol. 24, no. 1, p. 3-13, 2007. DOI 10.1016/s1130-1406(07)70002-5. Disponível em: http://dx.doi.org/10.1016/S11301406(07)70002-5.

MARCO, A. et al. Impacts of air pollution on human and ecosystem health, and implications for the National Emission Ceilings Directive: Insights from Italy. Environment International, v. 125, n. February, p. 320-333, 2019.

MARICQ, M. M. Chemical characterization of particulate emissions from diesel engines: A review. Journal of Aerosol Science, v. 38, n. 11, p. 1079-1118, 2007.

MATTHIAS-MASER, S.; JAENICKE, R. The size distribution of primary biological aerosol particles in the multiphase atmosphere. Aerobiologia, v.16, p. 207-210, 2000a.

MATTHIAS-MASER, S.; OBOLKIN, V.; KHODZER, T.; JAENICKE, R. Seasonal variation of primary biological aerosol particles in the remote continental region of Lake Baikal/Siberia. Atmospheric Environment, v.34, p.3805-3811, 2000b.

MENETREZ, M. Y.; FOARDE, K. K.; DEAN, T. R.; BETANCOURT, D. A.; MOORE, S. A. An evaluation of the protein mass of particulate matter. Atmospheric Environment, vol. 41, no. 37, p. 8264-8274, 2007 a. Disponível em: https://doi.org/10.1016/j.atmosenv.2007.06.021.

MENETREZ, M. Y.; FOARDE, K. K.; ESCH, R. K.; et al. The measurement of ambient bioaerosol exposure. Aerosol Science and Technology, v. 41, n. 9, p. 884-893, 2007a.

MIGUEL, A. G.; CASS, G. R.; GLOVSKY, M. M.; WEISS, J. Allergens in Paved Road Dust and Airborne Particles. Environmental Science \& Technologyvol. 33, no. 23, p. 4159-4168, 1999. Disponível em: https://doi.org/10.1021/es9904890.

MIRANDA, R. M. DE; FÁTIMA ANDRADE, M. DE; WOROBIEC, A.; GRIEKEN, R. VAN. Characterisation of aerosol particles in the São Paulo Metropolitan Area. Atmospheric Environment, v. 36, p. 345-352, 2002.

MIRANDA, R. M.; ANDRADE, M. F. Physicochemical characteristics of atmospheric aerosol during winter in the São Paulo Metropolitan area in Brazil. Atmospheric Environment, vol. 39, no. 33, p. 6188-6193, 2005. Disponível em: https://doi.org/10.1016/j.atmosenv.2005.06.055.

MÖHLER, O.; DEMOTT, P. J.; VALI, G.; LEVIN, Z. Microbiology and atmospheric processes: the role of biological particles in cloud physics. Biogeosciences Discussions, vol. 4, no. 4, p. 2559-2591, 2007. Disponível em: https://doi.org/10.5194/bgd-4-2559-2007.

MORRIS, C. E.; SANDS, D. C.; BARDIN, M.; JAENICKE, R.; VOGEL, B.; LEYRONAS, C.; ARIYA, P. A.; PSENNER, R. Microbiology and atmospheric processes : research challenges concerning the impact of airborne micro-organisms on the atmosphere and climate. Biogeosciences, vol. 8, p. 17-25, 2011. Disponível em: https://doi.org/10.5194/bg-8-17-2011. 
MORRIS, C. E.; SANDS, D. C.; BARDIN, M.; JAENICKE, R.; VOGEL, B.; LEYRONAS, C.; ARIYA, P.A.; PSENNER, R. Microbiology e atmospheric processes: an upcoming era of research on bio-meteorology. Biogeosciences Discussions, v. 5, p. 191-212, 2008.

MORRIS, C. E.; SANDS, D. C.; GLAUX, C.; SAMSATLY, J.; ASAAD, S.; MOUKAHEL, A. R; GONÇALVES, F. L. T. ; BIGG, E. K. Urediospores of rust fungi are ice nucleation active at $-10^{\circ} \mathrm{C}$ e harbor ice nucleation active bacteria. Atmospheric Chemistry e Physics, v. 13, p. 4223-4233, 2012.

NA, K.; SAWANT, A. a.; SONG, C.; COCKER, D. R. Primary and secondary carbonaceous species in the atmosphere of Western Riverside County, California. Atmospheric Environment, vol. 38, no. 9, p. 1345-1355, 2004. DOI 10.1016/j.atmosenv.2003.11.023. Disponível em: http://linkinghub.elsevier.com/retrieve/pii/S135223100301046X.

NASCIMENTO FILHO, V. F. e SIMABUCO, S. M. Uso da fluorescência de raios X com dispersão de energia e da reflexão total na análise de amostras ambientais. In: II WORKSHOP DO PROJETO PIRACENA: A BACIA HIDROGRÁFICA COMO UNIDADE DE ESTUDO, ESTRUTURA E PROCESSOS, 1996. Nazaré Paulista, SP. Anais... Nazaré Paulista: 1996. p. 140-145.

NAYEBARE, S. R.; ABURIZAIZA, O. S.; KHWAJA, H. A.; SIDDIQUE, A.; HUSSAIN, M. M.; ZEB, J.; KHATIB, F.; CARPENTER, D. O.; BLAKE, D. R. Chemical characterization and source apportionment of PM2.5 in Rabigh, Saudi Arabia. Aerosol and Air Quality Research, vol. 16, no. 12, p. 3114-3129, 2016. Disponível em: https://doi.org/10.4209/aaqr.2015.11.0658.

NELMS, S. Crash! Bang! Wallop! How Does an ICP-MS Collision Cell Work? Part 1. Disponível em: https://analyteguru.com/crash-bang-wallop-how-does-an-icp-ms-collision-cell-work-part-1/. Acesso em: 25/02/2021.

NIRMALKAR, J.; DEB, M. K.; TSAI, Y. I.; DESHMUKH, D. K. Arabitol and Mannitol as Tracer for Fungal Contribution to Size-Differentiated Particulate Matter of Rural Atmospheric Aerosols. International Journal of Environmental Science and Development, vol. 6, no. 6, p. 460-463, 2015. DOI 10.7763/IJESD.2015.V6.637. Disponível em: http://www.ijesd.org/index.php?m=content\&c=index\&a=show\&catid=60\&id=986.

NORRIS, G.; DUVALL, R.; BROWN, S.; BAI, S. EPA Positive Matrix Factorization (PMF) 5.0 Fundamentals and User Guide; U.S. Environmental Protection Agency, National Exposure Research Laboratory: Washington, DC, 2014

NOVACANA - Disponível em: https://www.novacana.com/n/cogeracao/geracao-energia-biomassa-cresce-92017-ccee-221117. Acesso em: 29/10/2019

NOVAKOV, T.; MENON, S.; KIRCHSTETTER, T. W.; KOCH, D.; HANSEN, J. E. Aerosol organic carbon to black carbon ratios: Analysis of published data and implications for climate forcing. Journal of Geophysical Research, vol. 110, 2005. DOI 10.1029/2005JD005977. Disponível em: http://doi.wiley.com/10.1029/2005JD005977.

O’CONNOR, D. J.; SADYŚ, M.; SKJØTH, C. a.; HEALY, D. a.; KENNEDY, R.; SODEAU, J. R. Atmospheric concentrations of Alternaria, Cladosporium, Ganoderma and Didymella spores monitored in Cork (Ireland) and Worcester (England) during the summer of 2010. Aerobiologia, vol. 30, no. 4, p. 397-411, 2014. DOI 10.1007/s10453-014-9337-3. Disponível em: http://link.springer.com/10.1007/s10453-014-9337-3.

OGÓREK, R.; LEJMAN, A.; PUSZ, W.; MIŁUCH, A.; MIODYŃSKA, P. Characteristics and taxonomy of Cladosporium fungi Characteristics and taxonomy of Cladosporium fungi. Mikologia Lekarska, vol. 19, no. June, p. 80-85, 2012.

OTEROS, J.; BUTERS, J.; LAVEN, G.; et al. Errors in determining the flow rate of Hirst-type pollen traps. Aerobiologia, v. 33, n. 2, p. 201-210, 2017.

OYAMA, B. S.; ANDRADE, M. D. F.; HERCKES, P.; DUSEK, U.; RÖCKMANN, T.; HOLZINGER, R. Chemical characterization of organic particulate matter from on-road traffic in São Paulo, Brazil. Atmospheric Chemistry and Physics, vol. 16, no. 22, p. 14397-14408, 2016. Disponível em: https://doi.org/10.5194/acp-1614397-2016.

OYAMA, B. S.; ANDRADE, M. F.; HERCKES, P.; et al. Vehicular emissions of organic particulate matter in Sao Paulo, Brazil. Atmospheric Chemistry and Physics Discussions, v. 15, n. 23, p. 33755-33788, 2015. Disponível em: http://www.atmos-chem-phys-discuss.net/15/33755/2015/.

PAATERO, P.; HOPKE, P. K. Discarding or downweighting high-noise variables in factor analytic models. Analytica Chimica Acta, vol. 490, no. 1-2, p. 277-289, 2003. Disponível em: https://doi.org/10.1016/S00032670(02)01643-4. 
PAL, M.; YIRGALEM, M.; ANBERBER, M.; GIRO, B.; DASGUPTA, R. Impact of environmental pollution on animal health. Journal of Natural History, v. 11, n. 1, 2015.

PAWANKAR, R. Allergic diseases and asthma: A global public health concern and a call to action. World Allergy Organization Journal, vol. 7, p. 1-3, 2014. Disponível em: https://doi.org/10.1186/1939-4551-7-12.

PAWANKAR, R. S.; SÁNCHEZ-BORGES, M.; BONINI, S.; KALINER, M. A. Section 2.1. Allergic Rhinitis, Allergic Conjunctivitis, and Rhinosinusitis. In: Pawankar, R.; Canonica, G. W.; Holgate, S. T.; Lockey, R. F.; Blaiss, M. S. WAO White book on allergy: update 2013. World Allergy Organization, 2013.

PEREIRA, G. M.; OLIVEIRA ALVES, N. DE; CAUMO, S. E. S.; et al. Chemical composition of aerosol in São Paulo, Brazil: influence of the transport of pollutants. Air Quality, Atmosphere and Health, v. 10, n. 4, p. 457468, 2017. Air Quality, Atmosphere \& Health. Disponível em: http://dx.doi.org/10.1007/s11869-016-0437-9.

PEREZ-MARTÍNEZ, P. J.; MIRANDA, R. M.; NOGUEIRA, T.; et al. Emission factors of air pollutants from vehicles measured inside road tunnels in São Paulo: case study comparison. International Journal of Environmental Science and Technology, v. 11, n. 8, p. 2155-2168, 2014.

PIO, C.; CERQUEIRA, M.; HARRISON, R. M.; NUNES, T.; MIRANTE, F.; ALVES, C.; OLIVEIRA, C.; SANCHEZ DE LA CAMPA, A.; ARTÍÑANO, B.; MATOS, M. OC/EC ratio observations in Europe: Re-thinking the approach for apportionment between primary and secondary organic carbon. Atmospheric Environment, vol. 45, no. 34, p. 6121-6132, 2011. DOI 10.1016/j.atmosenv.2011.08.045. Disponível em: http://dx.doi.org/10.1016/j.atmosenv.2011.08.045.

PLATTS-MILLS, T.A.E.; LEE, B. W.; ARRUDA, L. K.; CHEW, F. T. Section 3.2. Allergens as Risk Factors for Allergic Disease. In: Pawankar, R.; Canonica, G. W.; Holgate, S. T.; Lockey, R. F.; Blaiss, M. S. WAO White book on allergy: update 2013. World Allergy Organization, 2013.

POULEUR, S.; RICHARD, C.; MARTIN, J. G.; ANTOUN, H. Ice Nucleation Activity in Fusarium acuminatum and Fusarium avenaceum. Applied and Environmental Microbiology, vol. 58, no. 9, p. 2960-2964, 1992. Disponível em: http://ukpmc.ac.uk/abstract/MED/16348770.

PYRRI, I.; KAPSANAKI-GOTSI, E. Functional relations of airborne fungi to meteorological and pollution factors in a Mediterranean urban environment. Fungal Ecology, vol. 30, p. 48-54, 2017. DOI 10.1016/j.funeco.2017.08.007. Disponível em: https://doi.org/10.1016/j.funeco.2017.08.007.

R CORE TEAM. R: A language and environment for statistical computing. R Foundation for Statistical Computing, Vienna, Austria, 2020. URL https://www.R-project.org/.

RAM, K.; SARIN, M. M. Day-night variability of EC, OC, WSOC and inorganic ions in urban environment of Indo-Gangetic Plain: Implications to secondary aerosol formation. Atmospheric Environment, vol. 45, no. 2, p. 460-468, 2011. DOI 10.1016/j.atmosenv.2010.09.055. Disponível em: http://linkinghub.elsevier.com/retrieve/pii/S1352231010008411.

RAM, K.; SARIN, M. M. Spatio-temporal variability in atmospheric abundances of EC, OC and WSOC over Northern India. Journal of Aerosol Science, vol. 41, no. 1, p. 88-98, 2010. DOI 10.1016/j.jaerosci.2009.11.004. Disponível em: http://dx.doi.org/10.1016/j.jaerosci.2009.11.004.

RAPIEJKO, P.; STANKIEWICZ, W.; SZCZYGIELSKI, K.; JURKIEWICZ, D. Progowe stężenie pyłku roślin niezbędne do wywołania objawów alergicznych (Threshold pollen count necessary to evoke allergic symptoms). Otolaryngologia Polska, vol. 61, no. 4, p. 591-594, 2007. DOI 10.1016/s0030-6657(07)70491-2. Disponível em: http://dx.doi.org/10.1016/S0030-6657(07)70491-2.

RATHNAYAKE, C. M.; METWALI, N.; BAKER, Z.; JAYARATHNE, T.; KOSTLE, P. A.; THORNE, P. S.; O'SHAUGHNESSY, P. T.; STONE, E. A. Urban enhancement of PM10 bioaerosol tracers relative to background locations in the Midwestern United States. Journal of Geophysical Research: Atmospheres, vol. 121, no. 9, p. 5071-5089, 2016. https://doi.org/10.1002/2015JD024538.

RATHNAYAKE, C. M.; METWALI, N.; JAYARATHNE, T.; KETTLER, J.; HUANG, Y.; THORNE, P. S.; O'SHAUGHNESSY, P. T.; STONE, E. A. Influence of rain on the abundance of bioaerosols in fine and coarse particles. Atmospheric Chemistry and Physics, vol. 17, no. 3, p. 2459-2475, 2017. https://doi.org/10.5194/acp17-2459-2017.

RENGARAJAN, R.; SUDHEER, a. K.; SARIN, M. M. Wintertime PM2.5 and PM10 carbonaceous and inorganic constituents from urban site in western India. Atmospheric Research, vol. 102, no. 4, p. 420-431, 2011. DOI 10.1016/j.atmosres.2011.09.005.

http://linkinghub.elsevier.com/retrieve/pii/S0169809511002900. Disponível

em: 
REVELLE, W. psych: Procedures for Personality and Psychological Research, Northwestern University, Evanston, Illinois, USA, 2020. https://CRAN.R-project.org/package=psych Version = 2.0.8,

ROGERS, C., MUILENBERG, M. L. Comprehensive guidelines for the operation of hirst-type suction bioaerossol samplers. Pan-American Aerobiology Association, Standardized Protocols, 2001.

SADYŚ, M.; ADAMS-GROOM, B.; HERBERT, R. J.; KENNEDY, R. Comparisons of fungal spore distributions using air sampling at Worcester, England (2006-2010). Aerobiologia, vol. 32, no. 4, p. 619-634, 2016. https://doi.org/10.1007/s10453-016-9436-4.

SAGAN, C. The demon-haunted world. London: Headline book publishing, 1997.

SALAKO, G. O.; HOPKE, P. K.; COHEN, D. D.; BEGUM, B. A.; BISWAS, S. K.; PANDIT, G. G.; CHUNG, Y. S.; RAHMAN, S. A.; HAMZAH, M. S.; DAVY, P.; MARKWITZ, A.; SHAGJJAMBA, D.; LODOYSAMBA, S.; WIMOLWATTANAPUN, W.; BUNPRAPOB, S. Exploring the variation between EC and BC in a variety of locations. Aerosol and Air Quality Research, vol. 12, no. 1, p. 1-7, 2012. Disponível em: https://doi.org/10.4209/aaqr.2011.09.0150.

SÁNCHEZ-CCOYLLO, O. R.; YNOUE, R. Y.; MARTINS, L. D.; ASTOLFO, R.; MIRANDA, R. M.; FREITAS, E. D.; BORGES, A. S.; FORNARO, A.; FREITAS, H.; MOREIRA, A.; ANDRADE, M. F. Vehicular particulate matter emissions in road tunnels in Sao Paulo, Brazil. Environmental Monitoring and Assessment, vol. 149, no. 1-4, p. 241-9, Feb. 2008. DOI 10.1007/s10661-008-0198-5. Disponível em: http://www.ncbi.nlm.nih.gov/pubmed/18228152. Accessed on: 25 Nov. 2014.

SÁNCHEZ-CCOYLLO, O. R.; YNOUE, R. Y.; MARTINS, L. D.; et al. Vehicular particulate matter emissions in road tunnels in Sao Paulo, Brazil. Environmental Monitoring and Assessment, v. 149, n. 1-4, p. 241-9, 2008. Disponível em: http://www.ncbi.nlm.nih.gov/pubmed/18228152. Acesso em: 25/11/2014.

SANDRADEWI, J, et al. Using Aerosol Light Absorption Measurements for the Quantitative Determination of Wood Burning and Traffic Emission Contributions to Particulate Matter. Environmental Science and Technology, vol. 42, no. 9, p. 3316-3323, 2008.

SANDRADEWI, J.; PRÉVÔT, A. S. H.; SZIDAT, S.; PERRON, N.; ALFARRA, M. R.; LANZ, V. A.; WEINGARTNER, E.; BALTENSPERGER, U. R. S. Using aerosol light abosrption measurements for the quantitative determination of wood burning and traffic emission contribution to particulate matter. Environmental Science and Technology, vol. 42, no. 9, p. 3316-3323, 2008. https://doi.org/10.1021/es702253m.

SÃO PAULO (Estado). Lei $\mathbf{N}^{\mathbf{0}} \mathbf{1 1 . 2 4 1}$, de 19 de setembro de 2002. Dispõe sobre a eliminação gradativa da queima da palha da cana-de-açúcar e dá providências correlatas. Diário oficial Estado de São Paulo, 2002. Disponível

em: http://dobuscadireta.imprensaoficial.com.br/default.aspx?DataPublicacao=20020920\&Caderno=EXECUTIVO\% 20SECAO\%20I\&NumeroPagina=2. Acesso em: 26/11/0219.

SÃO PAUlO (Estado). Protocolo Etanol Mais Verde. Protocolo de intenções que celebram entre si o estado de São Paulo, por intermédio de suas secretarias de estado da agricultura e abastecimento, e do meio ambiente; a CETESB - companhia ambiental do Estado de São Paulo; a Organização de Plantadores de Cana da Região Centro-Sul do Brasil, e a União da Agroindústria Canavieira do Estado de São Paulo, para a superação dos desafios advindos da mecanização da colheita da cana-de-açucar, e a adoção de ações destinadas a consolidar o desenvolvimento sustentável do setor sucroenergético no estado de São Paulo. Estado de São Paulo, 2017. Disponível em: https://smastr16.blob.core.windows.net/etanolverde/2011/10/protocolo-etanol-mais-verde-2017assinado.pdf. Acesso em: 26/11/0219.

ŠČEVKOVÁ, J.; KOVÁČ, J. First fungal spore calendar for the atmosphere of Bratislava, Slovakia. Aerobiologia, vol. 35, no. 2, p. 343-356, 2019. https://doi.org/10.1007/s10453-019-09564-4.

SCHAUER, J. J.; ROGGE, W. F.; HILDEMANN, L. M.; MAZUREK, M. A.; CASS, G. R.; SIMONEIT, B. R. T. Source apportionment of airborne particulate matter using organic compounds as tracers. Atmospheric Environment, v. 30, p. 3837-3855, 1996.

SCHMIDT, I. B.; ELOY, L. Fire regime in the Brazilian Savanna: Recent changes, policy and management. Flora, v. 268, 2020.

SEINFELD, J. H.; PANDIS, S. N. Atmospheric Chemistry and Physics: From Air Pollution to Climate Change. 2ed. New Jersey: John Wiley \& Sons, Inc., 2006.

SHEN, Z.; ARIMOTO, R.; CAO, J.; ZHANG, R.; LI, X.; DU, N.; OKUDA, T.; NAKAO, S.; TANAKA, S. Seasonal variations and evidence for the effectiveness of pollution controls on water-soluble inorganic species in total suspended particulates and fine particulate matter from Xi'an, China. Journal of the Air and Waste 
Management Association, vol. 58, no. 12, p. 1560-1570, 2008. Disponível em: https://doi.org/10.3155/10473289.58.12.1560.

SILVA, J. C. D. S.; CAMPOS, F. S.; ARAUJO, N. C. F. Incidence of Respiratory Problems in the Population of Santana do Ipanema, Brazil, with the Burning of Biomass. Current Trends in Biomedical Engineering \& Biosciences, v. 5, n. 1, 2017.

SILVA, M. F. DA; ASSUNÇÃO, J. V. DE; FÁTIMA ANDRADE, M. DE; PESQUERO, C. R. Characterization of metal and trace element contents of particulate matter (PM10) emitted by vehicles running on Brazilian fuels $\backslash-$ hydrated ethanol and gasoline with $22 \%$ of anhydrous ethanol. Journal of Toxicology and Environmental Health - Part A: Current Issues, v. 73, n. 13-14, p. 901-909, 2010.

SIMONEIT, B. R. T.; ELIAS, V. O. Organic tracers from biomass burning in atmospheric particulate matter over the ocean. Marine Chemistry, v. 69, n. 3-4, p. 301-312, 2000.

SIMONEIT, B. R. T.; SCHAUER, J. J.; NOLTE, C. G.; et al. Levoglucosan, a tracer for cellulose in biomass burning and atmospheric particles. Atmospheric Environment, v. 33, n. 2, p. 173-182, 1999.

SINDT, C.; BESANCENOT, J. P.; THIBAUDON, M. Airborne Cladosporium fungal spores and climate change in France. Aerobiologia, vol. 32, no. 1, p. 53-68, 2016. https://doi.org/10.1007/s10453-016-9422-X.

SOUSA, S. I. V.; PIRES, J. C. M.; MARTINS, E. M.; FORTES, J. D. N.; ALVIM-FERRAZ, M. C. M.; MARTINS, F. G. Short-term effects of air pollution on respiratory morbidity at Rio de Janeiro - PART I: Air Pollution Assessment. Environment International, vol. 44, no. 1, p. 18-25, $2012 . \quad$ DOI 10.1016/j.envint.2012.01.005. Disponível em: http://dx.doi.org/10.1016/j.envint.2012.01.005.

SOUTO-OLIVEIRA, C. E.; ANDRADE, M. DE F.; KUMAR, P.; et al. Effect of local and remote sources and new particle formation events on the activation properties of cloud condensation nuclei in the Brazilian megacity of São Paulo. Atmospheric Chemistry and Physics Discussions, n. April, p. 1-35, 2016. Available in: http://www.atmos-chem-phys-discuss.net/acp-2016-241/.

SOUZA, D. Z.; VASCONCELlOS, P. C.; LEE, H.; AURELA, M.; SAARNIO, K.; TEINILÄ, K.; HILLAMO, R. Composition of PM2.5 and PM10 Collected at Urban Sites in Brazil. Aerosol and Air Quality Research, p. 168-176, 2014. DOI 10.4209/aaqr.2013.03.0071. Available at: http://www.aaqr.org/Doi.php?id=15_AAQR-13$03-\mathrm{OA}-0071 \& \mathrm{v}=14 \& \mathrm{i}=1 \& \mathrm{~m}=2 \& \mathrm{y}=2014$.

SOUZA, P. F. DE; LIMA, J. R. DE; OLIVEIRA, H. M. Campanha de sensibilização sobre o desmatamento causado pela queima da madeira nas festas juninas. CCNExt, Santa Maria, v. 1, n. 1, jan-jun. 2010.

SOUZA, S. R.; VASCONCELLOS, P. C.; CARVALHO, L. R. F. Low molecular weight carboxylic acids in an urban atmosphere: Winter measurements in Sao Paulo City, Brazil. Atmospheric Environment, v. 33, n. 16, p. 2563-2574, 1999.

SQUIZZATO, S.; MASIOL, M.; RICH, D. Q.; HOPKE, P. K. A long-term source apportionment of PM2.5 in New York State during 2005-2016. Atmospheric Environment, v. 192, n. April, p. 35-47, 2018.

STEIN, A. F.; DRAXLER, R. R.; ROLPH, G. D.; STUNDER, B. J. B.; COHEN, M. D.; NGAN, F. Noaa's hysplit atmospheric transport and dispersion modeling system. Bulletin of the American Meteorological Society, vol. 96, no. 12, p. 2059-2077, 2015. https://doi.org/10.1175/BAMS-D-14-00110.1.

SUlliVAN, a. P.; FRANK, N.; KENSKI, D. M.; COLLETT, J. L. Application of high-performance anionexchange chromatography-pulsed amperometric detection for measuring carbohydrates in routine daily filter samples collected by a national network: 2. Examination of sugar alcohols/polyols, sugars, and anhydrosugars in. Journal of Geophysical Research, vol. 116, no. D8, p. D08303, 2011. DOI 10.1029/2010JD014169. Disponível em: http://doi.wiley.com/10.1029/2010JD014169.

TALBOT, R. W.; BEECHER, K. M.; HARRISS, R. C.; COFER, W. R. Atmospheric geochemistry of formic and acetic acids at a mid- latitude temperate site. Journal of Geophysical Research, vol. 93, no. D2, p. 1638-1652, 1988. Disponível em: https://doi.org/10.1029/JD093iD02p01638.

THOMAS, R. Practical guide to ICP-MS. New York: Marcel Dekker, Inc.,2004.

TURPIN, B. J.; HUNTZICKER, J. J. Identification of secondary organic aerosol episodes and quantitation of primary and secondary organic aerosol concentrations during SCAQS. Atmospheric Environment, v. 29, n. 23, p. 3527-3544, 1995.

UNICA - União da Indústria de Cana-de-Açúcar. Área cultivada com cana-de-açúcar - Área colhida com cana-de-açúcar 2003-2018. UNICADATA. Disponível em: http://www.unicadata.com.br/historico-de-area- 
ibge.php?idMn=33\& tipoHistorico $=5 \&$ acao $=$ visualizar $\&$ idTabela $=2381 \&$ produto $=\% \mathrm{C} 3 \% 81 \mathrm{rea}+$ colhida $\&$ anoIni $=2003 \&$ anoFim $=2018 \&$ estado=SP. Acesso em: 30/01/2020.

URBAN, R. C.; ALVES, C. A.; ALlEN, A. G.; CARDOSO, A. A.; QUEIROZ, M. E. C.; CAMPOS, M. L. A. M. Sugar markers in aerosol particles from an agro-industrial region in Brazil. Atmospheric Environment, vol. 90, no. 2014, p. 106-112, 2014. DOI 10.1016/j.atmosenv.2014.03.034. Disponível em: http://dx.doi.org/10.1016/j.atmosenv.2014.03.034.

URIARTE, M.; YACKULIC, C. B.; COOPER, T.; et al. Expansion of sugarcane production in São Paulo, Brazil: Implications for fire occurrence and respiratory health. Agriculture, Ecosystems and Environment, v. 132, n. $1-2$, p. 48-56, 2009.

URIA-TELLAETXE, I.; CARSLAW, D. C. Conditional bivariate probability function for source identification. Environmental Modelling and Software, vol. 59, p. 1-9, 2014. DOI 10.1016/j.envsoft.2014.05.002. Disponível em: http://dx.doi.org/10.1016/j.envsoft.2014.05.002.

Vali, G. Quantitative Evaluation of Experimental Results on Heterogeneous Freezing Nucleation of Supercooled Liquids. J Atmos Sci, v. 28, n. 402-409, 1971. Disponível em: https://doi.org/10.1175/15200469(1971)028<0402:Qeoera>2.0.Co;2 (1971).

VASCONCELLOS, P. C.; BALASUBRAMANIAN, R.; BRUNS, R. E.; SANCHEZ-CCOYLlO, O.; ANDRADE, M. F.; FLUES, M. Water-soluble ions and trace metals in airborne particles over urban areas of the state of São Paulo, Brazil: Influences of local sources and long range transport. Water, Air, and Soil Pollution, vol. 186, no. 1-4, p. 63-73, 2007. Disponível em: https://doi.org/10.1007/s11270-007-9465-2.

VASCONCELlOS, P. C.; SOUZA, D. Z.; ÁVILA, S. G.; ARAÚJO, M. P.; NAOTO, E.; NASCIMENTO, K. H.; CAVALCANTE, F. S.; DOS SANTOS, M.; SMICHOWSKI, P.; BEHRENTZ, E. Comparative study of the atmospheric chemical composition of three South American cities. Atmospheric Environment, vol. 45, no. 32, p. 5770-5777, 2011. DOI 10.1016/j.atmosenv.2011.07.018. Disponível em: http://dx.doi.org/10.1016/j.atmosenv.2011.07.018.

VERÍSSIMO, T., G. Análise do Aerossol Atmosférico em Acra, Capital de Gana. 2016150 p. Dissertação (Mestrado em Física) - Instituto de Física, Universidade de São Paulo, São Paulo, 2016.

VERMA, N.; SATSANGI, A.; LAKHANI, A.; KUMARI, K. M. Low molecular weight monocarboxylic acids in PM2.5 and PM10: Quantification, seasonal variation and source apportionment. Aerosol and Air Quality Research, vol. 17, no. 2, p. 485-498, 2017. https://doi.org/10.4209/aaqr.2016.05.0183.

VIEIRA, S. Bioestatística: Tópicos avançados. 2 ed. Rio de Janeiro: Elsevier, 2004

VOS, T.; ABAJOBIR, A. A.; ABBAFATI, C.; et al. Global, regional, and national incidence, prevalence, and years lived with disability for 328 diseases and injuries for 195 countries, 1990-2016: A systematic analysis for the Global Burden of Disease Study 2016. The Lancet, v. 390, n. 10100, p. 1211-1259, 2017. https://doi.org/10.1016/S0140-6736(17)32154-2.

WANG, Q.; CAO, J.; TAO, J.; LI, N.; SU, X.; CHEN, L. W. A.; WANG, P.; SHEN, Z.; LIU, S.; DAI, W. LongTerm Trends in Visibility and at Chengdu, China. PLoS ONE, vol. 8, no. 7, 2013. https://doi.org/10.1371/journal.pone.0068894.

WANG, Y.; ZHUANG, G.; CHEN, S.; AN, Z.; ZHENG, A. Characteristics and sources of formic, acetic and oxalic acids in PM 2.5 and PM 10 aerosols in Beijing, China. Atmospheric Research, v. 84, n. 2, p. 169-181, 2007.

WATSON, J. G.; LIOY, P. J.; MUELLER, P. K. The measurement process: Precision, accuracy and validity. Air Sampling Instruments for Evaluation of Atmospheric Contaminants, 9th Edition, 2001.

WEBSTER, J. E., \& WEBER, R. Introduction to fungi (3 ed.). New York: Cambridge University Press, 2007. http://dx.doi.org/10.2307/2806321

WEBSTER, J.; DAVEY, R. a.; SMIRNOFF, N.; FRICKE, W.; HINDE, P.; TOMOS, D.; TURNER, J. C. R. Mannitol and hexoses are components of Buller's drop. Mycological Research, vol. 99, no. 7, p. 833-838, 1995. DOI 10.1016/S0953-7562(09)80737-5. Disponível

em: http://linkinghub.elsevier.com/retrieve/pii/S0953756209807375.

WEI, T. AND SIMKO, V. R package "corrplot": Visualization of a Correlation Matrix (Version 0.84). 2017. Disponível em: https://github.com/taiyun/corrplot project.org/web/packages/corrplot/vignettes/corrplot-intro.html)

(https://cran.r- 
WHANGCHAI, K.; SAENGNIL, K.; UTHAIBUTRA, J. Effect of ozone in combination with some organic acids on the control of postharvest decay and pericarp browning of longan fruit. Crop Protection, vol. 25, no. 8, p. 821825, 2006. https://doi.org/10.1016/j.cropro.2005.11.003.

WHO (World Health Organization). Ambient (outdoor) air quality and health. 2018b. Disponível em: https://www.who.int/news-room/fact-sheets/detail/ambient-(outdoor)-air-quality-and-health. Acesso em: $27 / 06 / 2020$

WHO (World Health Organization). Ambient air pollution: Pollutants, 2020c. Disponível em: https://www.who.int/airpollution/ambient/pollutants/en/. Acesso em: 30/10/2020.

WHO (World Health Organization). Exposure to ambient air pollution from particulate matter for 2016. 2018a. Disponível em: https://www.who.int/airpollution/data/AAP_exposure_Apr2018_final.pdf. Acesso em: $27 / 06 / 2020$

WHO (World Health Organization). WHO Air quality guidelines for particulate matter, ozone, nitrogen dioxide and sulfur dioxide. Summary of risk assessment, 2005. Disponível em: https://apps.who.int/iris/bitstream/handle/10665/69477/WHO_SDE_PHE_OEH_06.02_eng.pdf. Acesso em: $16 / 02 / 2021$.

WICKHAM, H. and BRYAN, J. readxl: Read Excel Files. R package version 1.3.1, 2019 Disponível em: https://CRAN.R-project.org/package=readxl

WICKHAM, H. ggplot2: Elegant Graphics for Data Analysis. Springer-Verlag New York, 2016. Disponível em: https://cran.r-project.org/web/packages/ggplot2/ggplot2.pdf

WICKHAM, H. httr: Tools for Working with URLs and HTTP. R package version 1.4.2, 2020. Disponível em: https://CRAN.R-project.org/package=httr

WICKHAM, H. The Split-Apply-Combine Strategy for Data Analysis. Journal of Statistical Software, 40(1), 1 29, 2011. URL http://www.jstatsoft.org/v40/i01/. Disponível em: https://cran.rproject.org/web/packages/plyr/index.html

WICKHAM, H.; FRANÇOIS, R.; HENRY, L. and MÜLLER, K. dplyr: A Grammar of Data Manipulation. R package version 1.0.2, 2020. Disponível em: https://CRAN.R-project.org/package=dplyr

WOMILOJU, T. O.; MILlER, J. D.; MAYER, P. M.; BROOK, J. R. Methods to determine the biological composition of particulate matter collected from outdoor air. Atmospheric Environment, vol. 37, no. 31, p. 43354344, Oct. 2003. DOI 10.1016/S1352-2310(03)00577-6. Disponível em: http://linkinghub.elsevier.com/retrieve/pii/S1352231003005776.

WU, Y. H.; CHAN, C. C.; RAO, C. Y.; LEE, C. Te; HSU, H. H.; CHIU, Y. H.; CHAO, H. J. Characteristics, determinants, and spatial variations of ambient fungal levels in the subtropical Taipei metropolis. Atmospheric Environment, vol. 41, no. 12, p. 2500-2509, 2007. Disponível em: https://doi.org/10.1016/j.atmosenv.2006.11.035.

YAO, X.; FANG, M.; CHAN, C. K.; HO, K. F.; LEE, S. C. Characterization of dicarboxylic acids in PM2.5 in Hong Kong. Atmospheric Environment, v. 38, n. 7, p. 963-970, 2004.

YNOUE, R. Y.; ANDRADE, M. F.; YNOUE, R. Y.; F, M. De. Size-Resolved Mass Balance of Aerosol Particles over the São Paulo Metropolitan Area of Brazil. Aerosol Science and Technology, v. 38, p. 52-62, 2004.

ZHANG, T.; ENGLING, G.; CHAN, C. Y.; ZHANG, Y. N.; ZHANG, Z. S.; LIN, M.; SANG, X. F.; LI, Y. D.; LI, Y. S. Contribution of fungal spores to particulate matter in a tropical rainforest. Environmental Research Letters, vol. 5, no. 2, 2010. Disponível em: https://doi.org/10.1088/1748-9326/5/2/024010.

ZHANG, Y.; CAI, J.; WANG, S.; HE, K.; ZHENG, M. Review of receptor-based source apportionment research of fine particulate matter and its challenges in China. Science of the Total Environment, v. 586, p. 917-929, 2017.

ZHANG, Z.; ENGLING, G.; ZHANG, L.; KAWAMURA, K.; YANG, Y.; TAO, J.; ZHANG, R.; CHAN, C.; LI, Y. Significant influence of fungi on coarse carbonaceous and potassium aerosols in a tropical rainforest. Environmental Research Letters, vol. 10, no. 3, p. 034015, 2015. DOI 10.1088/1748-9326/10/3/034015.

ZHU, W.; CHENG, Z.; LUO, L.; LOU, S.; MA, Y.; YAN, N. Investigation of fungal spore characteristics in PM2.5 through organic tracers in Shanghai, China. Atmospheric Pollution Research, vol. 9, no. 5, p. 894-900, 2018. DOI 10.1016/j.apr.2018.01.009. Disponível em: https://doi.org/10.1016/j.apr.2018.01.009. 
ZOPPAS, B. C. D. A.; VALENCIA-BARRERA, R. M.; DUSO, S. M. V.; FERNÁNDEZ-GONZÁLEZ. Fungal spores prevalent in the aerosol of the city of Caxias do Sul, Rio Grande do Sul, Brazil , over a 2-year period ( 2001 - 2002 ). Aerobiologia (2006), vol. 22, p. 119-126, 2006. https://doi.org/10.1007/s10453-006-9022-2. 


\section{APÊNDICE}

\section{APÊNDICE A - Comparação entre dados de diferentes equipamentos}

APÊNDICE Aa - Comparação entre os equipamentos para a determinação da concentração de massa obtida com diferentes arranjos experimentais

\section{APÊNDICE Aaa - Equipamentos}

Foram coletadas amostras com três equipamentos MiniVol (AIRmetrics, Springfield, OR, USA) e um Partisol 2025i (Thermo Fisher Scientific, Franklin, MA, EUA). O objetivo desse primeiro teste foi verificar se os três MiniVol apresentavam massa equivalente entre si e com o equipamento de referência (Partisol 2025i). Nos três MiniVol foi utilizado o filtro de

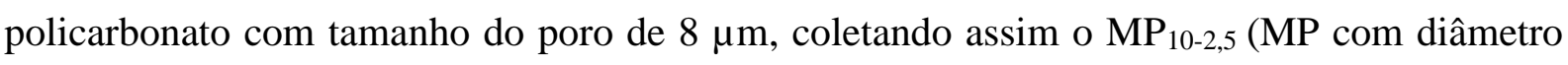
aerodinâmico entre 2,5 e $10 \mu \mathrm{m}$ - MP grosso). No Partisol 2025i foi utilizado filtro de teflon (2 $\mu \mathrm{m}$ ) e o suporte escolhido foi para a coleta de $\mathrm{MP}_{10}$ (MP com diâmetro aerodinâmico menor do que $10 \mu \mathrm{m})$. A concentração obtida durante essa coleta está apresentada na figura A I.
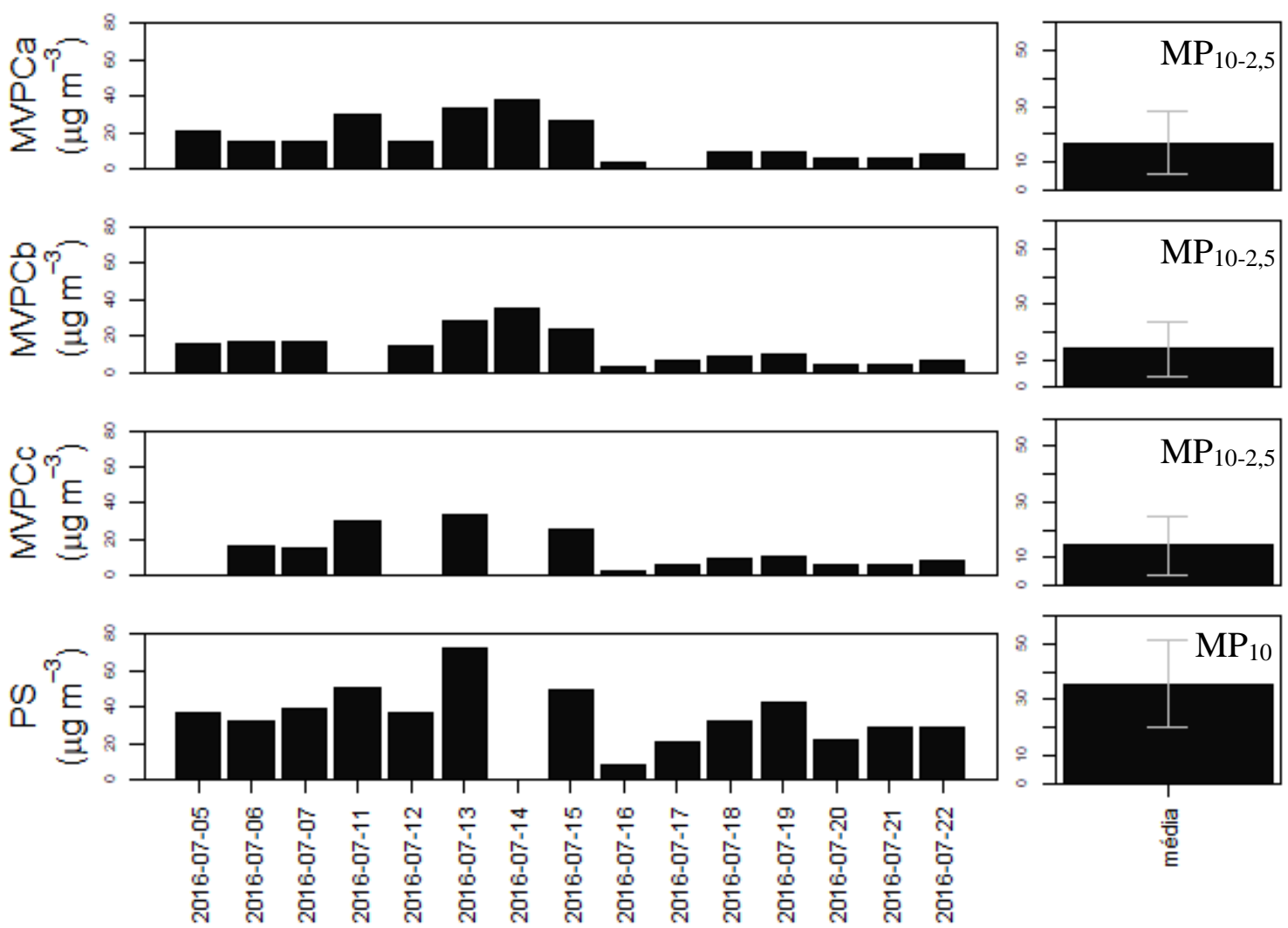

Figura A I. Concentração da massa $\left(\mu \mathrm{g} / \mathrm{m}^{3}\right)$ obtida com os três equipamentos MiniVol (MVPCa, MVPCb, MVPCc) e o Partisol 2025i (PS), considerando o período coletado.

Como podemos observar, as concentrações dos três MiniVol estão equivalentes entre si. No equipamento MVPCa é $\sim 1,22$ vezes maior do que o MVPCb e 1,18 vezes maior do que o MVPCc, enquanto o equipamento MVPCc é apenas $\sim 1,03$ vezes maior do que o equipamento 
MVPCb. Se considerarmos o desvio padrão essa diferença não é significativa. A correlação entre os 4 equipamentos (três MiniVol e Partisol 2025i) foi elevada $(r=\sim 0,9)$ como indicado na figura A II, indicando que as concentrações apresentam a mesma variabilidade.

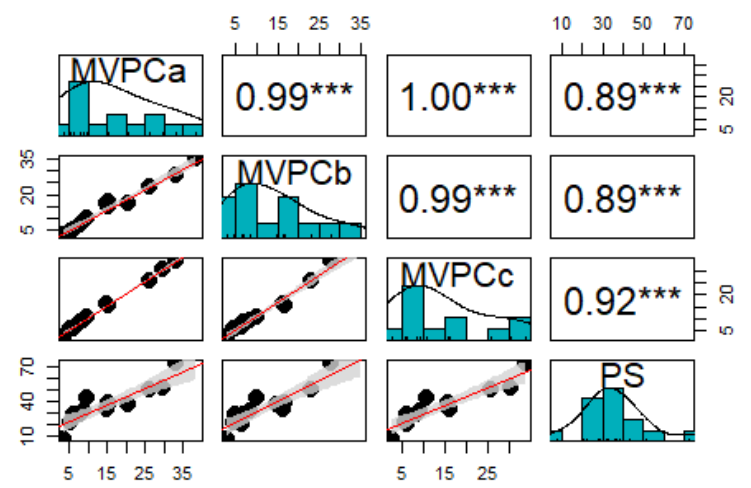

Figura A II. Correlação de Pearson entre os três MiniVol (MVPCa, MVPCb, MVPCc) e o Partisol 2025i (PS).

Apesar das concentrações estarem muito bem correlacionadas, as concentrações obtidas com o MiniVol são de 1,7 a 5,9 vezes menor do que as do Partisol 2025i. Uma análise um pouco mais detalhada permite observar que quando as concentrações de MP obtidas são mais altas (do dia 5 ao dia 15 de julho de 2016) a diferença entre a concentração do MiniVol e do Partisol 2025i varia de 1,7 a 2,6 vezes e quando as concentrações são mais baixas (do dia 16 ao dia 22 de julho de 2016) a diferença entre a concentração do MiniVol e do Partisol 2025i varia de 2,2 a 5,9 vezes. Essa variação é explicada pela quantidade de partículas coletadas em cada equipamento. No MiniVol foram coletadas partículas com diâmetro entre 10 e 2,5 $\mu \mathrm{m}$ e no Partisol 2025 i foram coletadas todas as partículas inferiores a $10 \mu \mathrm{m}$. Nesse caso, toda a massa do chamado $\mathrm{MP}_{2,5}$ é desconsiderada das coletas com o MiniVol. Com isso entende-se que nessa situação, quando ocorreu menor concentração de $\mathrm{MP}_{10}$ na atmosfera foi devido a uma diminuição do $\mathrm{MP}_{10-2,5}$, partículas maiores que sofrem maior deposição, e o $\mathrm{MP}_{2,5}$ se manteve elevado (Tabela A I).

Observa-se que na média o $\mathrm{MP}_{2,5}$ (obtido através da subtração entre $\mathrm{MP}_{10-2,5}$ e $\mathrm{MP}_{10}$ ) apresenta uma concentração mais elevada do que o $\mathrm{MP}_{10-2,5}$ (Tabela A I) indicando que mesmo que as partículas com diâmetro menor tenham menos massa individualmente, estas estão em maior quantidade na atmosfera de São Paulo, sendo assim no total, elas representam uma fração maior do $\mathrm{MP}_{10}$, o que está de acordo com o observado nas estações de qualidade do ar da CETESB (2020)

Através da regressão linear, a correlação entre concentração média obtida com os três MiniVol e a concentração obtida com o Partisol 2520i foi $r=0,9$ e a equação que representa os dados é $\mathrm{y}=0,533 \mathrm{x}-4,731$ (Figura A III.). 


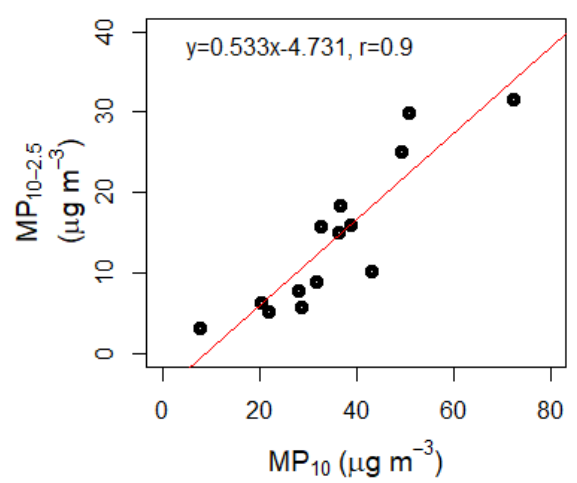

Figura A III. Regressão linear entre a concentração da média dos três MiniVol e do Partisol 2520i.

Essa reta pode ser utilizada como uma importante ferramenta para se obter a concentração de $\mathrm{MP}_{10}$ considerando apenas a concentração de $\mathrm{MP}_{10-2,5}$ ou vice versa. Considerando essa curva, a concentração média obtida com o MiniVol (MP10-2,5) pode ser convertida para a concentração em $\mathrm{MP}_{10}$ (tabela A I).

Tabela A I. Concentração da massa $\left(\mu \mathrm{g} / \mathrm{m}^{3}\right)$ do $\mathrm{MP}_{10}$ obtido com o Partisol 2025i, $\mathrm{MP}_{10-2,5}$ obtido através da média dos três MiniVol, $\mathrm{MP}_{2,5}$ obtido através da subtração entre $\mathrm{MP}_{10-2,5}$ e $\mathrm{MP}_{10}$, e a concentração de $\mathrm{MP}_{10}$ obtida com a equação da reta.

\begin{tabular}{lllll}
\hline Data & $\begin{array}{l}\mathrm{MP}_{10} \\
\left(\mu \mathrm{g} / \mathrm{m}^{3}\right)\end{array}$ & $\begin{array}{l}\mathrm{MP}_{2,5} \\
\left(\mu \mathrm{g} / \mathrm{m}^{3}\right)\end{array}$ & $\begin{array}{l}\mathrm{MP}_{10-2,5} \\
\left(\mu \mathrm{g} / \mathrm{m}^{3}\right)\end{array}$ & $\begin{array}{l}\mathrm{MP}_{10} \text { (equação da reta) } \\
\left(\mu \mathrm{g} / \mathrm{m}^{3}\right)\end{array}$ \\
\hline $05 / 07 / 2016$ & 36,66 & 18,31 & 18,35 & 43,26 \\
$06 / 07 / 2016$ & 32,60 & 16,81 & 15,79 & 38,47 \\
$07 / 07 / 2016$ & 38,71 & 22,68 & 16,03 & 38,92 \\
$11 / 07 / 2016$ & 50,82 & 20,84 & 29,98 & 65,07 \\
$12 / 07 / 2016$ & 36,24 & 21,16 & 15,08 & 37,13 \\
$13 / 07 / 2016$ & 72,27 & 40,64 & 31,63 & 68,16 \\
$14 / 07 / 2016$ & & & & 77,79 \\
$15 / 07 / 2016$ & 49,26 & 24,18 & 25,08 & 55,88 \\
$16 / 07 / 2016$ & 7,65 & 4,56 & 3,09 & 14,67 \\
$17 / 07 / 2016$ & 20,44 & 14,07 & 6,37 & 20,81 \\
$18 / 07 / 2016$ & 31,65 & 22,68 & 8,97 & 25,68 \\
$19 / 07 / 2016$ & 42,98 & 32,79 & 10,19 & 27,97 \\
$20 / 07 / 2016$ & 22,00 & 16,72 & 5,28 & 18,76 \\
$21 / 07 / 2016$ & 28,55 & 22,81 & 5,74 & 19,62 \\
$22 / 07 / 2016$ & 28,09 & 20,30 & 7,79 & 23,47 \\
Média (desvio padrão) & $35,57( \pm 15,58)$ & $21,32( \pm 8,34)$ & $15,74( \pm 10,65)$ & $38,38( \pm 19,97)$ \\
\hline
\end{tabular}

\section{APÊNDICE Aab - Análise dos filtros utilizados}

Foram feitos testes para verificar a validade do filtro. Nesse caso, foram utilizados dois MiniVol, um com filtro de policarbonato de poro de $8 \mu \mathrm{m}$, coletando assim $\mathrm{MP}_{10-2,5}$ (MVPC), e outro com filtro de quartzo coletando $\mathrm{MP}_{10}(\mathrm{MVQ})$. Em conjunto com o MiniVol também foi 
utilizado o Partisol 2025i com filtro de teflon coletando MP ${ }_{10}$ (PS). A concentração da massa $\left(\mu \mathrm{g} / \mathrm{m}^{3}\right)$ obtida durante essa coleta está apresentada na figura A IV.
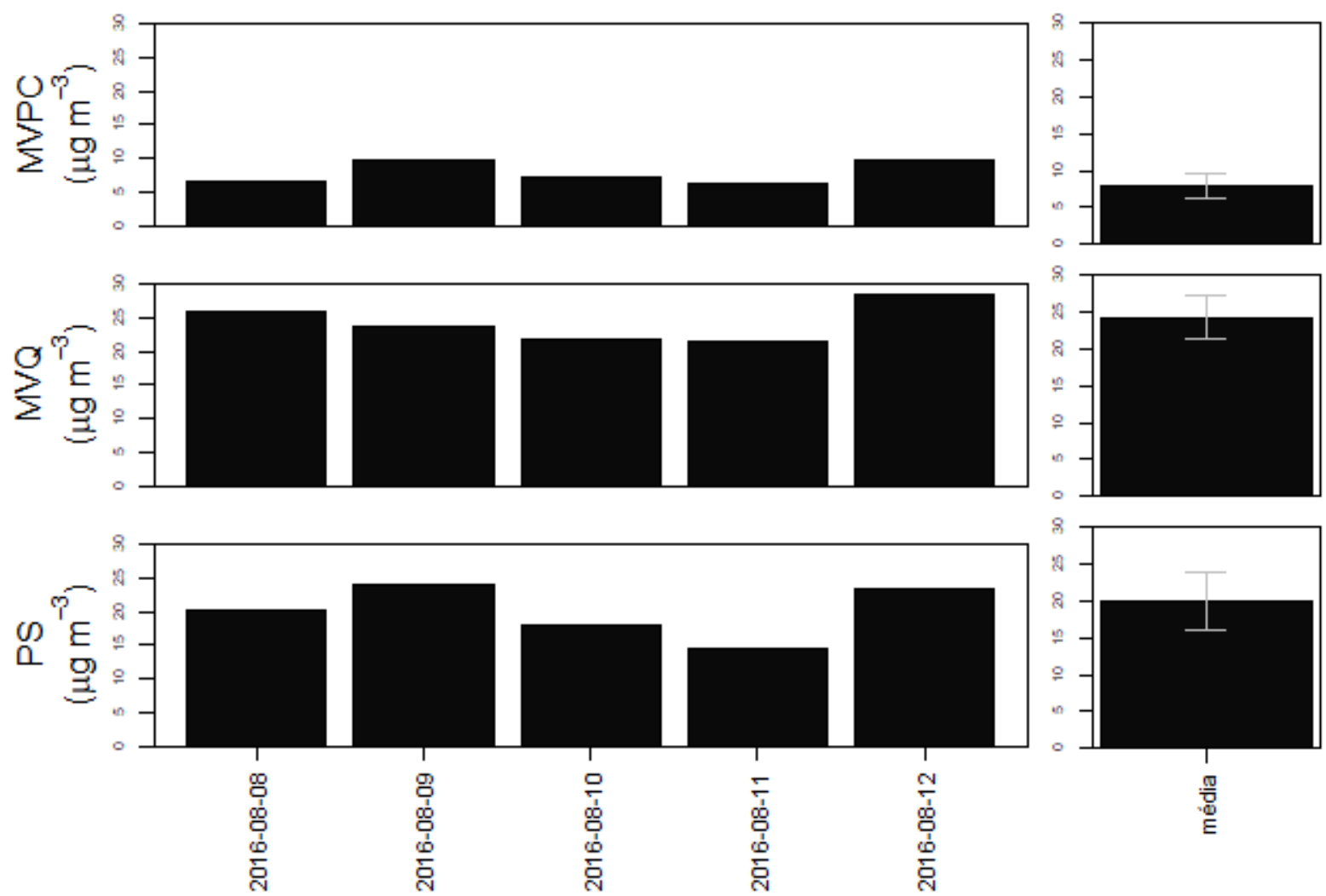

Figura A IV. Concentração da massa $\left(\mu \mathrm{g} / \mathrm{m}^{3}\right)$ obtida com o MiniVol com filtro de policarbonato (MVPC - MP 10 2,5), MiniVol com filtro de quartzo (MVQ - MP10) e o Partisol $2025 \mathrm{i}$ (PS - MP 10 ), considerando o período coletado.

Apesar das concentrações obtidas com o MiniVol com filtro de policarbonato $\left(\mathrm{MP}_{2,5-10}\right)$ serem menores do que com o Partisol $2025 \mathrm{i}$ com filtro de teflon $\left(\mathrm{MP}_{10}\right)$, como esperado, estes se correlacionam bem (Figura A V), de forma semelhante à análise anterior.

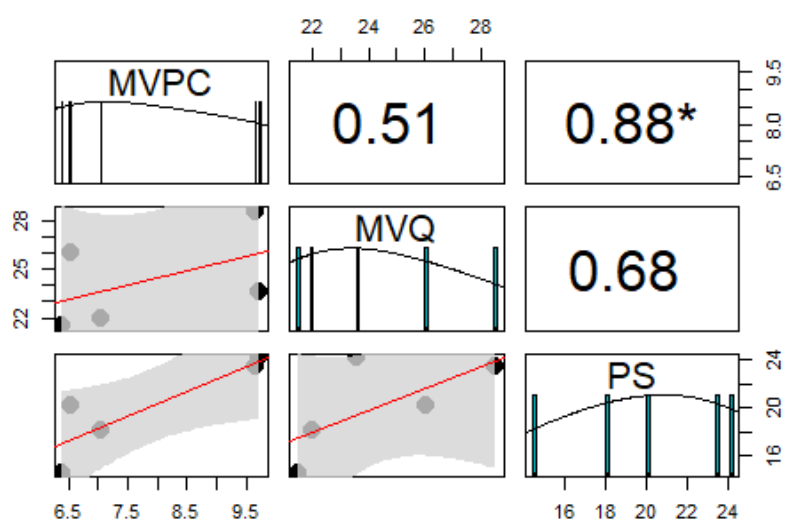

Figura A V. Correlação entre MVPC (filtro de policarbonato com MiniVol - MP $10-2,5$ ), MVQ (filtro de quartzo com MiniVol - MP 10 ) e PS (Filtro de teflon com Partisol 2025i - MP 10 ). 
Considerando as concentrações obtidas com o filtro de quartzo é possível observar que elas são da mesma ordem de grandeza das concentrações obtidas com o Partisol, contudo no geral apresentam uma concentração mais elevada e não estão correlacionadas significativamente. A mesma falta de correlação observa-se entre o filtro de quartzo e o filtro de policarbonato. Como ambos os filtros de quartzo (MiniVol) e filtro de teflon (Partisol 2025i) coletaram $\mathrm{MP}_{10}$ era esperado que houvesse uma correlação entre eles. A diferença observada na variabilidade pode ser explicada principalmente devido ao baixo número amostral (5 dias), o qual não permitiu uma análise estatística significativa. Ademais, como apontado anteriormente, cada filtro e equipamento apresenta diversas características que podem os diferir e que podem resultar em concentrações distintas. Somado a isso há muitos artefatos e fatores que podem interferir no valor real da massa como absorção/adsorção e perda de umidade e compostos voláteis (Chow et al., 2015), ou ainda devido a diferença na eficiência de coleta de partículas, a qual é maior no filtro de quartzo comparada ao filtro de policarbonato (Chow et al., 1995).

\section{APÊNDICE Aac - Análise da concentração de MP2,5 obtidas por diferentes equipamentos}

Os filtros e equipamentos também foram comparados em relação à coleta do $\mathrm{MP}_{2,5}$. Nesse caso, foram utilizados dois MiniVol, um com filtro de policarbonato e outro com filtro de quartzo em conjunto com o Partisol 2025i com filtro de teflon, todos coletando $\mathrm{MP}_{2,5}$. A concentração obtida durante essa coleta está apresentada na figura A VI. 

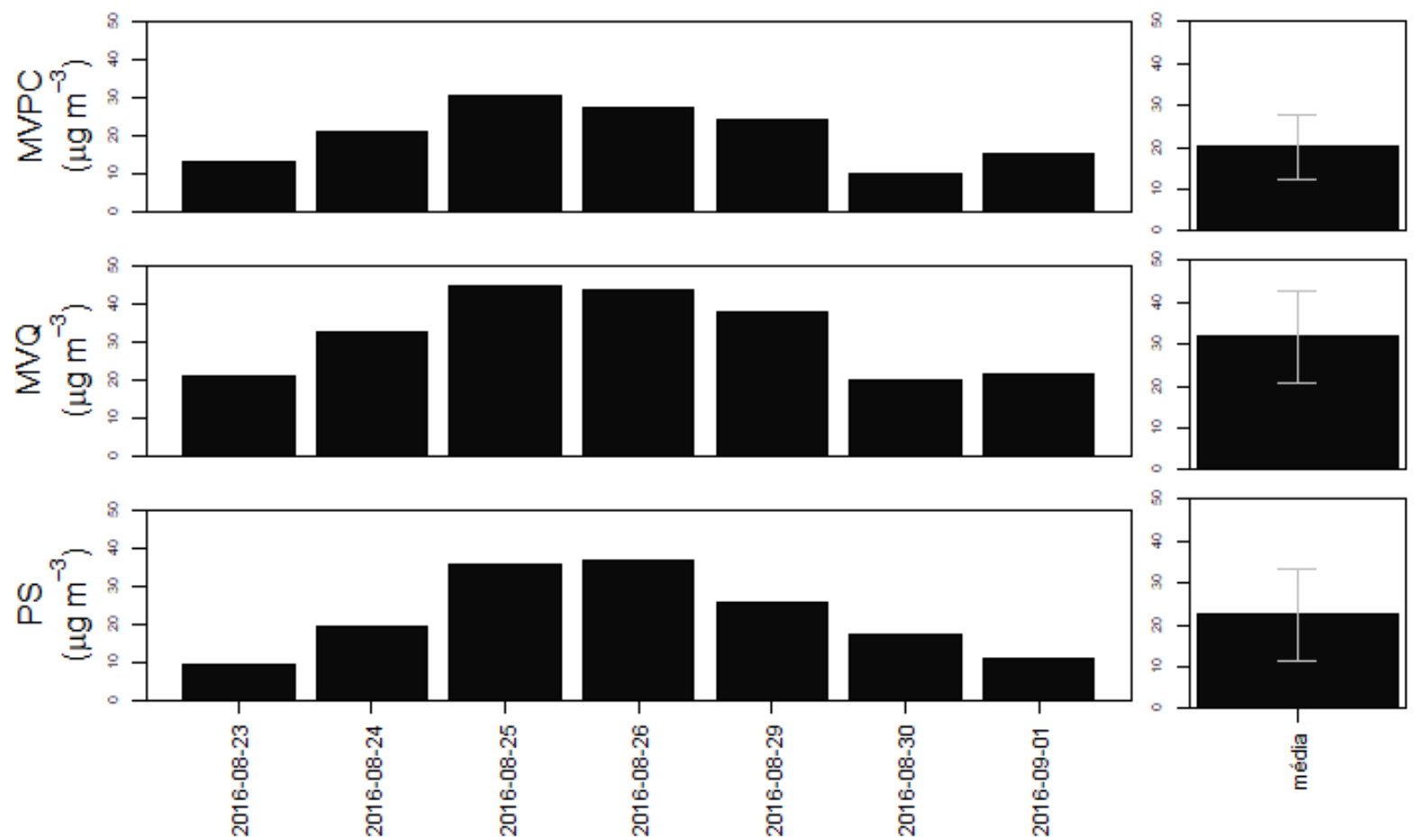

Figura A VI. Concentração da massa $\left(\mu \mathrm{g} / \mathrm{m}^{3}\right)$ de $\mathrm{MP}_{2,5}$ obtida com o MiniVol com filtro de policarbonato (MVPC), com o MiniVol com filtro de quartzo (MVQ) e com o Partisol 2025i com filtro de teflon (PS), considerando o período coletado.

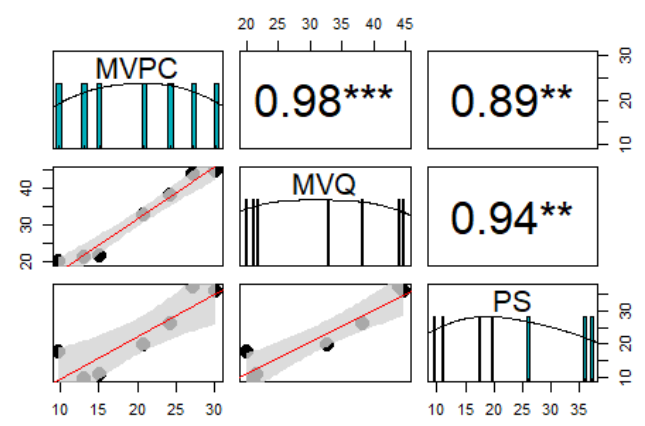

Figura A VII. Correlação entre MVPC (filtro de policarbonato com minivol), MVQ (filtro de quartzo com Minivol) e PS (Filtro de teflon com Partisol 2025i) para o $\mathrm{MP}_{2,5}$.

As concentrações obtidas com o filtro de quartzo (MVQ) são 1,58 vezes maior do que as obtidas com o filtro de policarbonato (MVPC) e $\sim 1,42$ vezes maior do que as obtidas com o filtro de teflon (PS), enquanto o filtro de teflon (PS) é $\sim 1,11$ vezes maior do que as concentrações obtidas com o filtro de policarbonato (MVPQ). Apesar disso, as concentrações obtidas com os diferentes filtros se correlacionam muito bem entre si $(r>0,9)$ como observado na figura A VII. Essa análise indica que para o $\mathrm{MP}_{2,5}$ os filtros e equipamentos estão consistentes e apesar de as concentrações serem um pouco diferentes, a variabilidade temporal é semelhante. Da mesma forma que na análise anterior, a concentração do filtro de quartzo foi maior do que dos outros filtros, possivelmente devido aos fatores já mencionados como absorção de água, 
adsorção de vapores orgânicos e eficiência na coleta de partículas (Chow et al., 2015; Chow et al., 1995).

\section{APÊNDICE Aad - Análise da concentração de MP10 obtidas por diferentes equipamentos}

Foram coletadas amostras de $\mathrm{MP}_{10}$ com os equipamentos Minivol com filtro de policarbonato (MVPC) e com filtro de quartzo (MVQ) e o equipamento HiVol com filtro de quartzo (HVQ). As concentrações obtidas foram comparadas com as fornecidas pela CETESB monitoradas automaticamente com método de medição por atenuação da radiação $\beta$ (Beta), na estação Pinheiros localizada a aproximadamente $3,2 \mathrm{~km}$ do local de coleta. Na figura A VIII estão apresentadas as concentrações em massa $\left(\mu \mathrm{g} / \mathrm{m}^{3}\right)$ obtidas com os quatro métodos (MVPC, MVQ, HVQ, CETESB) considerando o período de coleta de 29 de maio a 22 de agosto de 2017.
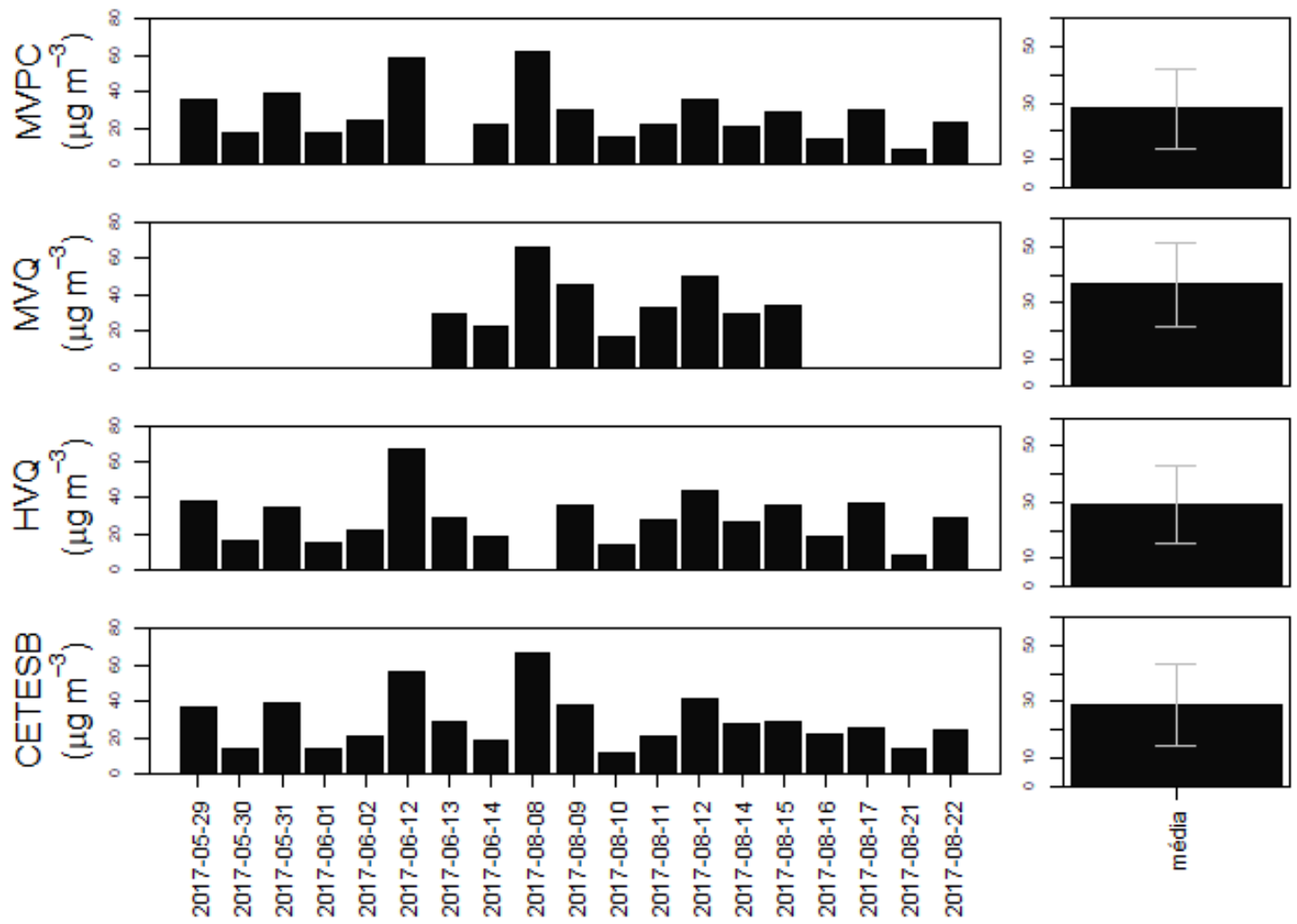

몸

Figura A VIII. Concentração em massa $\left(\mu \mathrm{g} / \mathrm{m}^{3}\right)$ para $\mathrm{MP}_{10}$ obtida com o MiniVol com filtro de policarbonato (MVPC), MiniVol com filtro de quartzo (MVQ) HiVol com filtro de quartzo (HVQ) e dados da CETESB, considerando o período coletado.

Da mesma forma que as outras análises, as concentrações do MVQ são maiores do que as dos outros equipamentos e da CETESB. Assim, o MVQ é 1,30 vezes maior do que o MVPC, 1,26 vezes maior do que o HVQ, e 1,27 vezes maior do que o da CETESB. Os outros equipamentos apresentaram uma concentração muito próxima, com o HVQ apresentando maiores concentrações do que o MVPC e o da CETESB, mas essa diferença é muito baixa $(1,03$ e 1,01 vezes maior, respectivamente). Esse comportamento em que o MVQ e o HVQ apresentam concentrações maiores do que os outros equipamentos provavelmente se deve ao 
filtro de quartzo, que como discutido acima (Chow et al., 2015; Chow et al., 1995). A correlação entre os equipamentos e com a CETESB é elevada $\left(r^{\sim}<0,9\right)$, indicando que todos apresentam uma variabilidade semelhante (Figura A. IX).

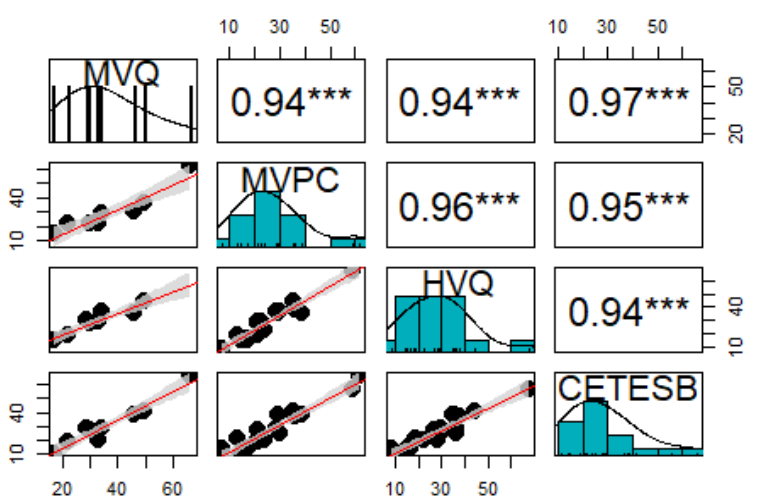

Figura A IX. Correlação entre o MVPC (MiniVol com filtro de policarbonato), MVQ (MiniVol com filtro de quartzo), HVQ (HiVol com filtro de quartzo) e os dados da CETESB, considerando o período coletado para MP ${ }_{10}$.

Como conclusão, observa-se que os três equipamentos MiniVol aparentam estar coletando de forma equivalente. Para o $\mathrm{MP}_{2,5}$, tanto os filtros quando os equipamentos apresentaram uma correlação elevada, bem como para o $\mathrm{MP}_{10}$ quando comparadas as concentrações obtidas com o MiniVol, HiVol e a CETESB. As concentrações obtidas com o MiniVol se correlacionam melhor com o Partisol 2025i, que é o instrumento de referência para a coleta de MP, quando utilizado o filtro de policarbonato. No geral, as concentrações obtidas com o filtro de quartzo com o MiniVol se mostraram ser as mais destoantes (maiores) entre os filtros e equipamentos comparados. Contudo, para algumas análises, como as dos compostos orgânicos por exemplo, o filtro de quartzo é mais recomendado, nesse caso, deve-se estar ciente das limitações.

\section{APÊNDICE Ab - Comparação entre as concentrações elementar obtidas com} (ICP e EDX) com diferentes equipamentos e filtros

Os dados da composição elementar do $\mathrm{MP}_{10}$ foram obtidos de dois métodos diferentes, utilizando dois filtros diferentes. Um espectrômetro de fluorescência de raio X por energia dispersiva (EDX) no LAPAt foi utilizado para analisar os filtros de policarbonato coletados com o MiniVol. Um Espectrômetro de massas com plasma acoplado indutivamente (ICP) no DRI foi utilizado para analisar os filtros de quartzos coletados com o HiVol. Para comparar os dois métodos e determinar o mais adequado para realizar as análises requeridas nesse trabalho, foram feitas correlações e análise de erro percentual relativo. Os elementos utilizados nessa análise foram aqueles que eram comuns entre o ICP e o EDX. Foram analisados apenas 57 
dados, uma vez que alguns dados (12 dias) alguns elementos do ICP apresentavam valores muito discrepantes (muito elevados) e por isso foram removidos. As concentrações dos elementos $\left(\mu \mathrm{g} / \mathrm{m}^{3}\right)$ obtidos com o EDX e com o ICP estão apresentadas na figura $\mathrm{A} X$, enquanto na tabela A II são apresentadas as concentrações médias $\left(\mu \mathrm{g} / \mathrm{m}^{3}\right)$ dos elementos em ambas as metodologias e a o erro percentual relativo da média (Erro $(\%)={ }^{c_{1}-c_{2}} / c_{2}$, sendo $\mathrm{C}_{1}$ a concentração média medida e $\mathrm{C}_{2}$ a concentração média verdadeira).

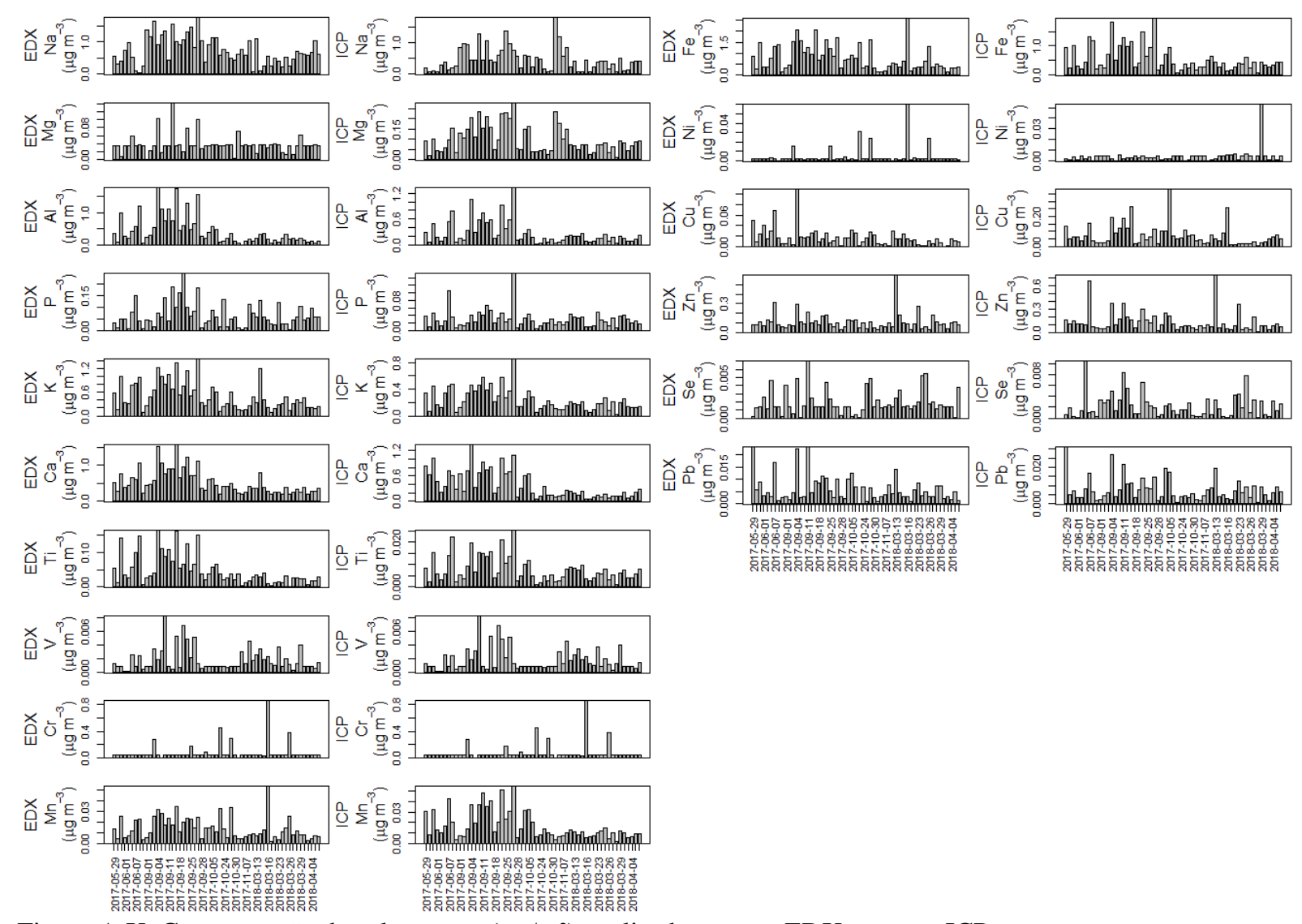

Figura A X. Concentração dos elementos $\left(\mu \mathrm{g} / \mathrm{m}^{3}\right)$ analisados com o EDX e com o ICP.

Tabela A II. Concentração média ( \pm desvio padrão) dos elementos e erro percentual relativo da média (\%) dos elementos analisados no ICP e no EDX. A coluna do erro percentual relativo (ICP, \%) indica o erro quando os dados do ICP são considerados $c_{2}$ (a concentração média verdadeira), enquanto erro percentual relativo (EDX, \%) indica o erro quando os dados do EDX são considerados $c_{2}$.

\begin{tabular}{lllll}
\hline Elementos & $\begin{array}{l}\text { EDX } \\
\left(\mu \mathrm{g} / \mathrm{m}^{3}\right)\end{array}$ & $\begin{array}{l}\mathrm{ICP} \\
\left(\mu \mathrm{g} / \mathrm{m}^{3}\right)\end{array}$ & $\begin{array}{l}\text { Erro percentual } \\
\text { relativo (EDX, \%) }\end{array}$ & $\begin{array}{l}\text { Erro percentual } \\
\text { relativo }(\mathrm{ICP}, \%)\end{array}$ \\
\hline $\mathrm{Na}$ & $0,74( \pm 0,42)$ & $0,46( \pm 0,38)$ & $-37,32$ & 59,55 \\
$\mathrm{Mg}$ & $0,04( \pm 0,02)$ & $0,10( \pm 0,07)$ & 166,97 & $-62,54$ \\
$\mathrm{Al}$ & $0,42( \pm 0,43)$ & $0,27( \pm 0,27)$ & $-35,96$ & 56,15 \\
$\mathrm{P}$ & $0,07( \pm 0,05)$ & $0,03( \pm 0,02)$ & $-53,48$ & 114,98 \\
$\mathrm{~K}$ & $0,50( \pm 0,35)$ & $0,24( \pm 0,16)$ & $-52,00$ & 108,35 \\
$\mathrm{Ca}$ & $0,52( \pm 0,33)$ & $0,38( \pm 0,32)$ & $-27,73$ & 38,36 \\
$\mathrm{Ti}$ & $0,05( \pm 0,04)$ & $0,01( \pm 0,01)$ & $-83,77$ & 516,26 \\
\hline
\end{tabular}




\begin{tabular}{lllll}
\hline $\mathrm{V}$ & $0,00( \pm 0,00)$ & $0,00( \pm 0,00)$ & 58,94 & $-37,08$ \\
$\mathrm{Cr}$ & $0,08( \pm 0,13)$ & $0,00( \pm 0,00)$ & $-96,19$ & 2527,73 \\
$\mathrm{Mn}$ & $0,01( \pm 0,01)$ & $0,02( \pm 0,01)$ & 21,01 & $-17,36$ \\
$\mathrm{Fe}$ & $0,77( \pm 0,58)$ & $0,55( \pm 0,43)$ & $-28,43$ & 39,71 \\
$\mathrm{Ni}$ & $0,00( \pm 0,01)$ & $0,00( \pm 0,01)$ & $-16,26$ & 19,42 \\
$\mathrm{Cu}$ & $0,02( \pm 0,02)$ & $0,07( \pm 0,07)$ & 330,00 & $-76,74$ \\
$\mathrm{Zn}$ & $0,11( \pm 0,09)$ & $0,13( \pm 0,14)$ & 23,19 & $-18,83$ \\
$\mathrm{Se}$ & $0,00( \pm 0,00)$ & $0,00( \pm 0,00)$ & 15,10 & $-13,12$ \\
$\mathrm{~Pb}$ & $0,01( \pm 0,01)$ & $0,01( \pm 0,01)$ & 30,52 & $-23,38$ \\
\hline
\end{tabular}

As concentrações dos elementos obtidas com as duas metodologias não aparentam ser equivalentes, uma vez que o erro percentual relativo foi bem alto para a maioria dos elementos analisados. Há várias possíveis explicações para essa diferença, incluindo o tipo de filtro e equipamento utilizado na coleta, que foram diferentes nesses dois casos. Essa diferença no tipo do filtro implica em diferentes características como diferentes níveis de absorção/adsorção de umidade e compostos voláteis e eficácia na coleta de partículas (Chow et al., 2015; Chow et al., 1995). A diferença decorrente do tipo de equipamentos implica em volumes (o de quartzo teve um volume bem maior do que o de policarbonato) e suporte diferentes, que poderiam de alguma forma interferir na concentração final. Além disso, o modo de análise do filtro para o EDX envolve a leitura direta no filtro, sem a necessidade de nenhum tipo de extração, enquanto a análise de filtro pelo ICP requer uma laboriosa extração, o que implica em possíveis perda de material devido a uma extração não $100 \%$ eficiente. Apesar do erro ser relativamente elevado para alguns dos elementos, é possível observar na figura A XI, que alguns elementos se correlacionam bem, como o $\mathrm{Al}(\sim 0,9), \mathrm{K}(\sim 0,9), \mathrm{Ca}(\sim 0,8), \mathrm{Ti}(\sim 0,9), \mathrm{Zn}(\sim 0,9), \mathrm{Pb}(\sim 0,9)$. Isso indica que apesar de talvez não apresentarem o mesmo valor, variam de forma semelhante. 


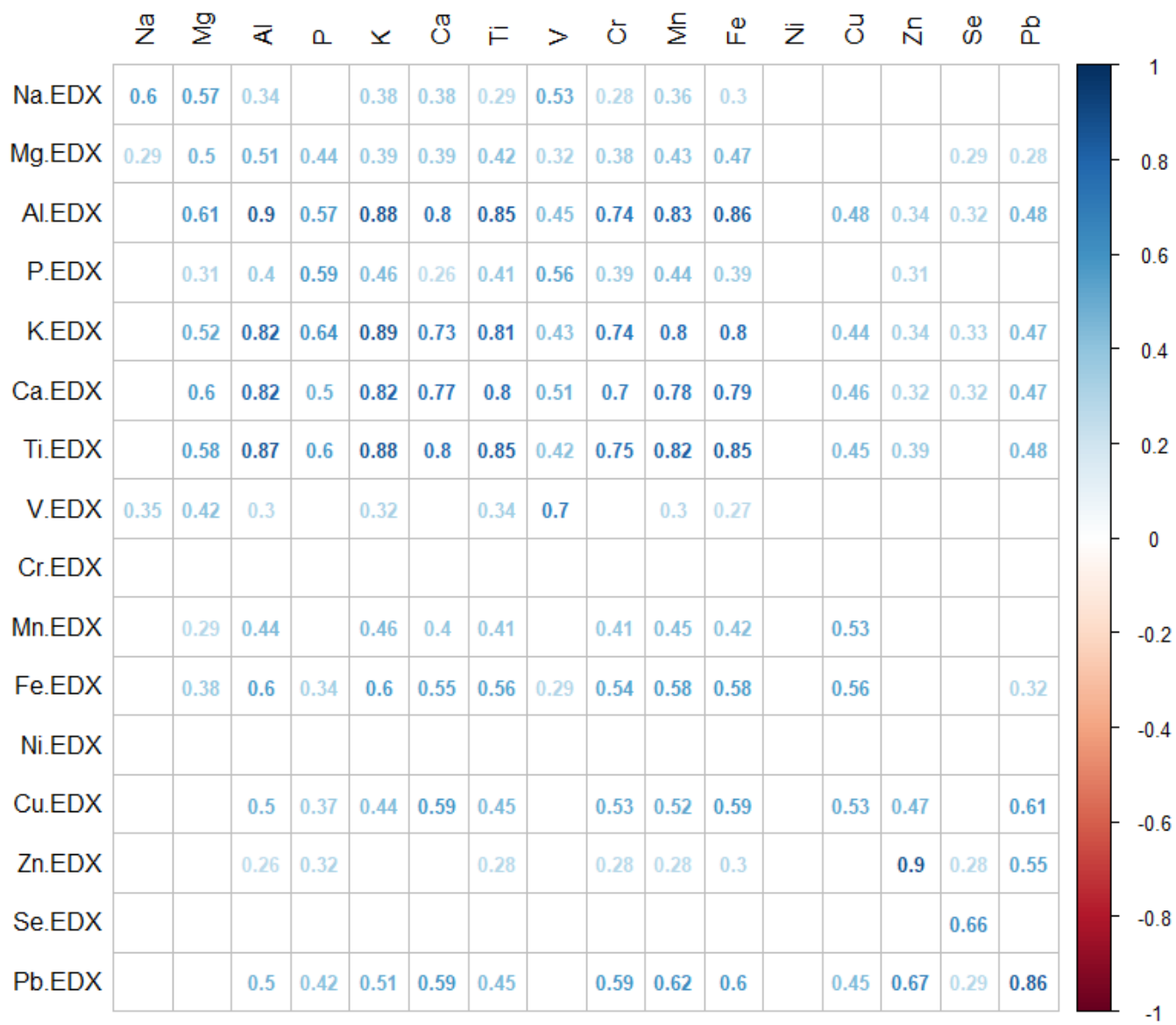

Figura A XI. Matriz de correlação (Pearson) significativa ( $\mathrm{p}<0,05)$ entre os elementos do EDX e ICP. Legenda: Os elementos do EDX estão indicados com ".EDX”. Espaços em branco indicam uma correlação não significativa $(\mathrm{p}>0,05)$.

A maioria das análises feitas neste trabalho (ex.: compostos orgânicos) utilizaram o filtro de quartzo. Considerando a análise feita no tópico anterior (seção 3.2.1) seria ideal utilizar o máximo de análises com o mesmo filtro para evitar possíveis discrepâncias. Apesar disso, alguns fatores depõem contra utilizar os elementos analisados com o ICP, entre eles estão: o ICP apresenta 12 dias com valores discrepantes (concentrações muito elevadas) para alguns dos elementos; a análise com ICP exige a extração dos elementos do filtro o que aumenta as incertezas; a massa do $\mathrm{MP}_{10}$ foi obtida utilizando o filtro de policarbonato, o mesmo no qual foi feita a análise de EDX. Assim neste trabalho, os elementos analisados com o método EDX foram os escolhidos para as análises posteriores. Vale notar que em alguns casos, como na análise com o PMF, também foram utilizados alguns elementos analisados com o ICP, aqueles que não foram identificados com o EDX.

\section{APÊNDICE Ac - Comparação da concentração de íons e elementos obtidas por} diferentes equipamentos e filtros 
Os íons também foram analisados em dois equipamentos e filtros diferentes. Com o filtro de policarbonato coletado com o MiniVol foi realizada a análise de íons no LAPAt com um cromatógrafo de íons (IC) da marca "Metrohm", enquanto para o filtro de quartzo coletado com o HiVol a análise de íons foi realizada no DRI com um cromatógrafo de íons (IC) da marca "Dionex". Para verificar se as concentrações obtidas com os dois filtros coletados e analisados em equipamentos diferentes podem ser consideradas equivalentes, foi realizada uma comparação entre ambos. Na figura A XII estão apresentadas as concentrações diárias e totais (médias) dos íons $\left(\mu \mathrm{g} / \mathrm{m}^{3}\right.$ ) analisados no LAPAt (Filtro de policarbonato - MiniVol) e no DRI (Filtro de quartzo - HiVol) coletados em 2017.
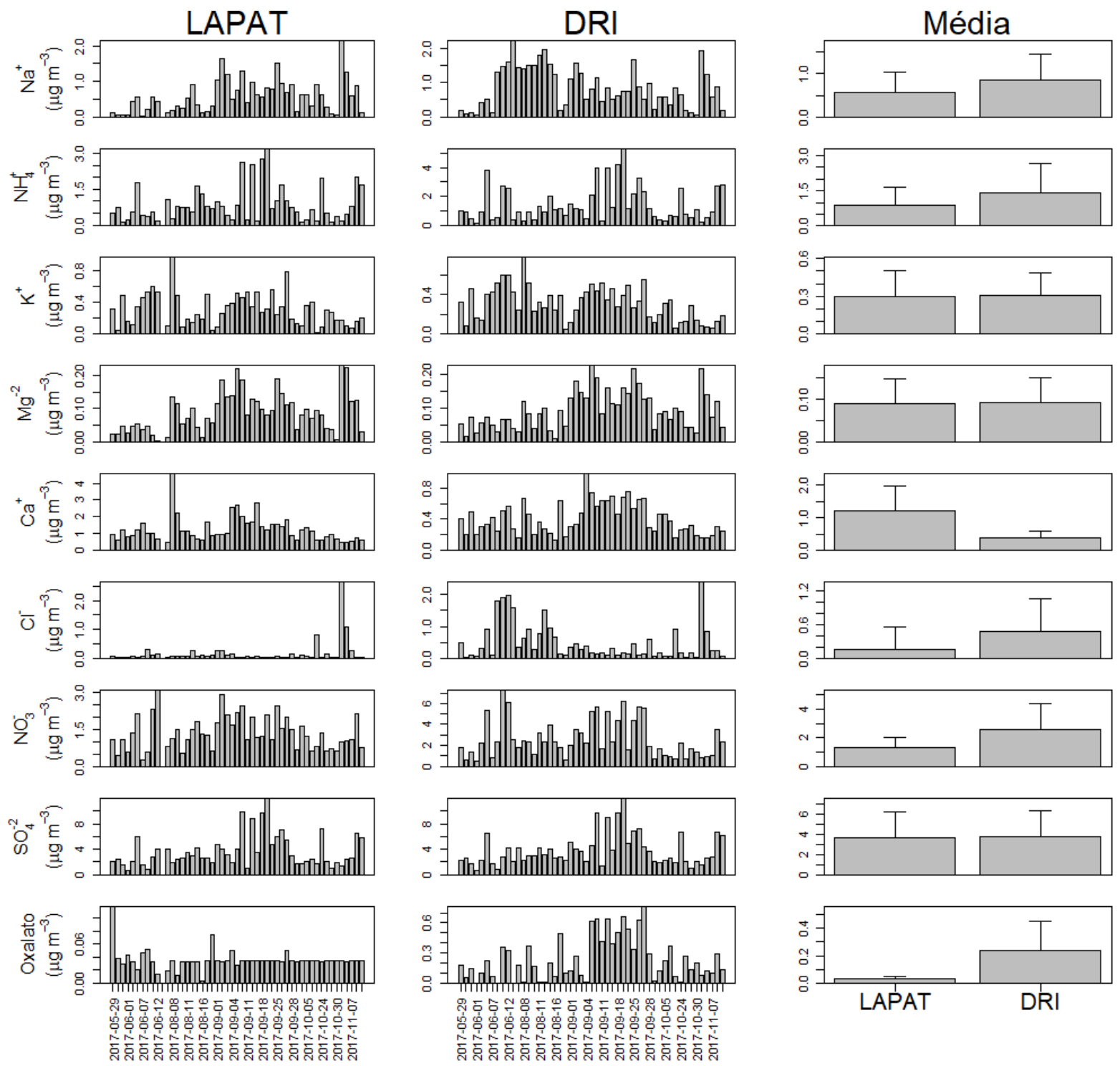

Figura A XII. Concentração diária e total (média) dos íons $\left(\mu \mathrm{g} / \mathrm{m}^{3}\right)$ analisados no LAPAt e no DRI em 2017. 
Com exceção do $\mathrm{Ca}^{+}$, todos os íons apresentam maiores concentrações na análise realizado no DRI do que no LAPAt. Esse fato pode ser uma evidência que a extração de íons do filtro de quartzo é mais eficiente do que do filtro de policarbonato. Ademais, com a exceção do oxalato todos os íons do LAPAt apresentaram uma correlação elevada e significativa com seus respectivos íons do DRI. A concentração média dos íons $\mathrm{K}^{+}, \mathrm{Mg}^{-2} \mathrm{e} \mathrm{SO}_{4}{ }^{2-}$ são semelhantes em ambas as análises, o que difere dos íons $\mathrm{NH}_{4}{ }^{+}, \mathrm{NO}_{3}{ }^{-}$e $\mathrm{Ca}^{+}$, os quais apresentam uma diferença elevada na concentração média comparando as duas metodologias. As concentrações médias dos íons $\mathrm{NH}_{4}{ }^{+}$e $\mathrm{NO}_{3}{ }^{-}$no DRI são 1,6 e 1,9 vezes maiores do que as do LAPAt, respectivamente, enquanto a do $\mathrm{Ca}^{+}$é 3 vezes maior no LAPAt comparado ao DRI.

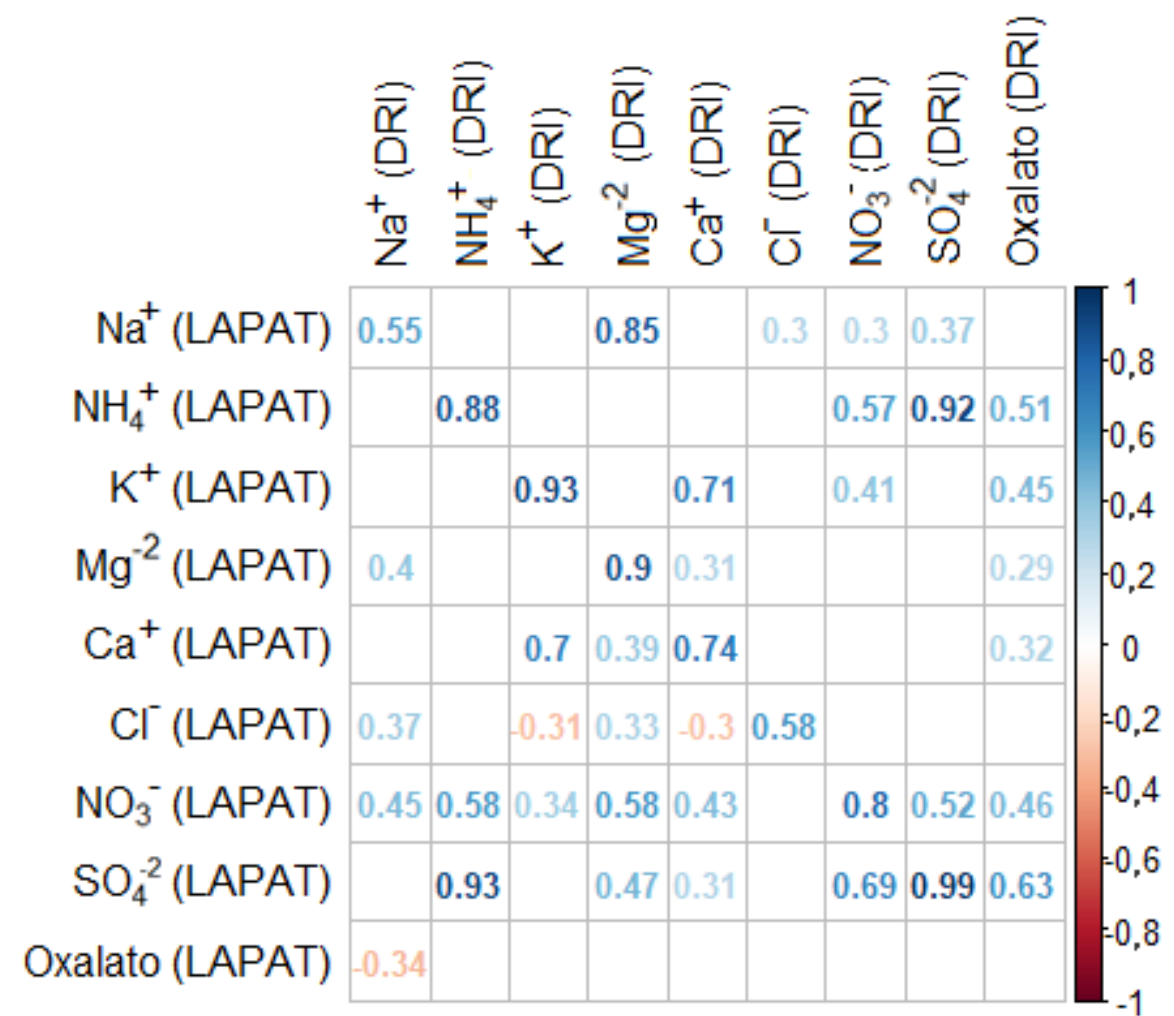

Figura A XIII. Matriz de correlação (Pearson) significativa $(\mathrm{p}<0,05)$ entre os íons analisados no DRI e LAPAt. Legenda: Espaços em branco indicam uma correlação não significativa $(p>0,05)$.

Os íons $\mathrm{NH}_{4}{ }^{+} \mathrm{e} \mathrm{SO}_{4}{ }^{2-}$ se correlacionam bem entre si considerando ambas as análises, $\mathrm{o}$ mesmo observa-se para os íons $\mathrm{Ca}^{+}$e o $\mathrm{K}^{+}$(Figura A XIII). O oxalato medido no LAPAt apresenta uma concentração muito mais baixa do que no DRI e não se correlaciona significativamente com nenhum íon, apenas negativamente com o $\mathrm{Na}^{+}$. O oxalato $\left(\mathrm{C}_{2} \mathrm{O}_{4}{ }^{-2}\right)$ é um ácido orgânico que pode ser medido no cromatógrafo de íons, mas geralmente seu pico no cromatógrafo surge entre 90 e 95 minutos (Chow et al., 2015). Como os íons analisados no LAPAt levaram de 20 minutos para os cátions e 27 minutos para os ânions para serem analisados, é provável que esse pico que foi chamado de oxalato, na verdade seja algum outro 
composto, ou contaminantes. Sabe-se que esse tempo de corrida de uma amostra pode variar dependendo do cromatógrafo, eluente, coluna, detector e amostra, contudo para os outros íons, Chow et al. (2015) reportaram que o tempo de análise é de $\sim 20$ minutos, tempo esse semelhante ao do LAPAt, o que indica que provavelmente o tempo de análise do oxalato deve ser semelhante ao reportado por Chow et al. (2015).

$\mathrm{O} \mathrm{Cl}^{-}, \mathrm{Ca}^{+}, \mathrm{NO}_{3}{ }^{-}$e oxalato são os íons que apresentam maior erro percentual relativo da média (Figura A. I. 14), indicando que a diferença entre esses íons nas duas análises é grande.

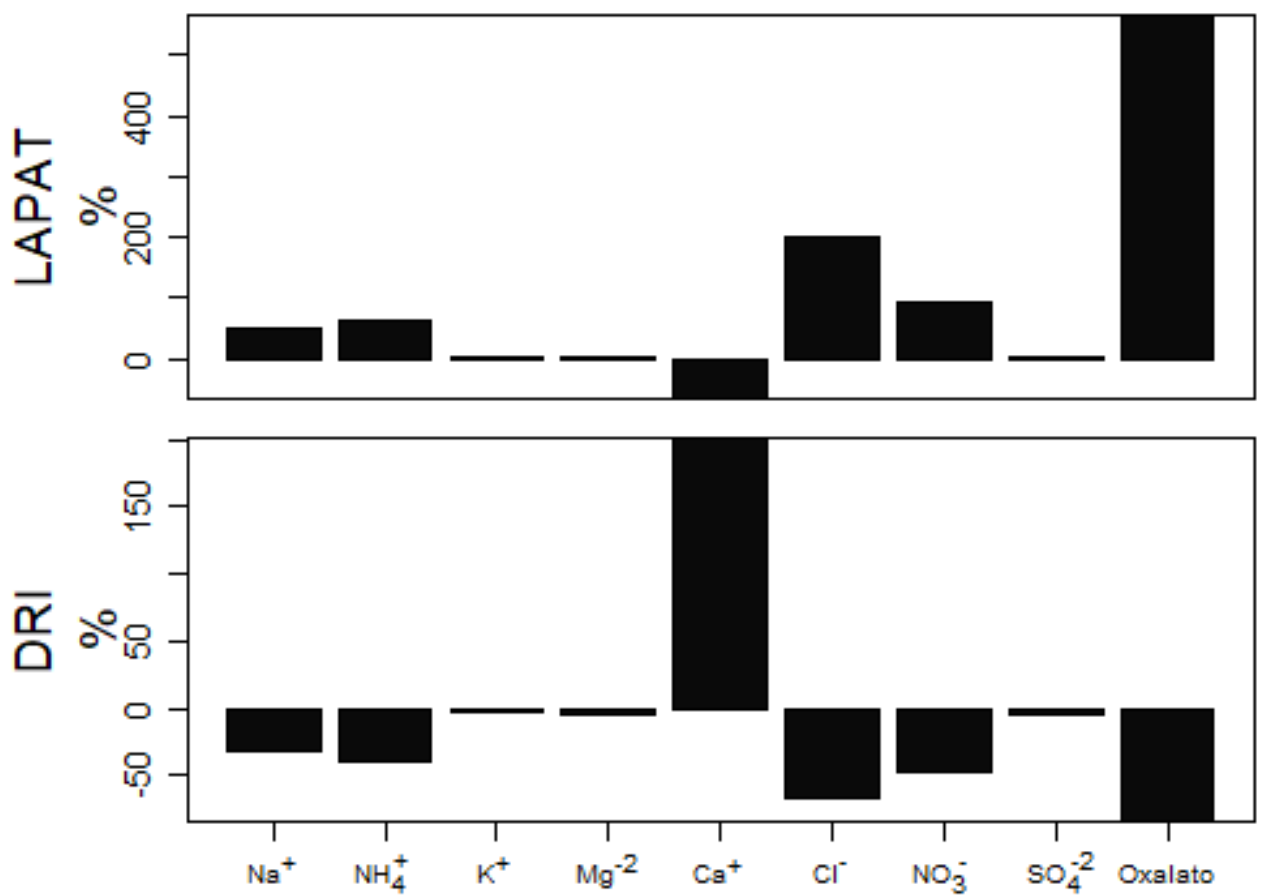

Figura A XIV. Erro percentual relativo da média (\%) considerando os íons analisados no DRI e LAPAt. Legenda: O gráfico LAPAt indica o erro quando os dados do LAPAt são considerados $c_{2}$ (a concentração média verdadeira), enquanto o gráfico DRI indica o erro quando os dados do DRI são considerados $\mathrm{c}_{2}$.

$\mathrm{O}$ íon $\mathrm{Mg}^{+2}$ da análise do DRI e do LAPAt se correlaciona com o elemento $\mathrm{Mg}$ na análise do ICP (DRI), mas não com o elemento da análise do EDX (LAPAt) (Figura A. I. 15). $\mathrm{O}$ mesmo vale para o $\mathrm{Na}^{+}$, o qual se correlaciona com o elemento $\mathrm{Na}$ do DRI, e apenas o íon $\mathrm{Na}^{+}$do LAPAt apresenta uma correlação fraca com o elemento Na do LAPAt. Isso indica que provavelmente esses elementos ( $\mathrm{Mg}$ e $\mathrm{Na}$ ) no EDX (LAPAt) não são bem medidos. Os íons $\mathrm{K}^{+}$ e $\mathrm{Ca}^{+}$se correlacionam bem com os elementos $\mathrm{K}$ e Ca de ambas as análises (ICP - DRI e EDX - LAPAt). $\mathrm{O}$ íon $\mathrm{Cl}^{-}$se correlacionou com o elemento $\mathrm{Cl}$ analisado no EDX (LAPAt), enquanto o $\mathrm{SO}_{4}{ }^{2-}$ se correlacionou com o elemento $\mathrm{S}$ também na análise do EDX (LAPAt). Vale notar que ambos os elementos não foram medidos no ICP (DRI). 


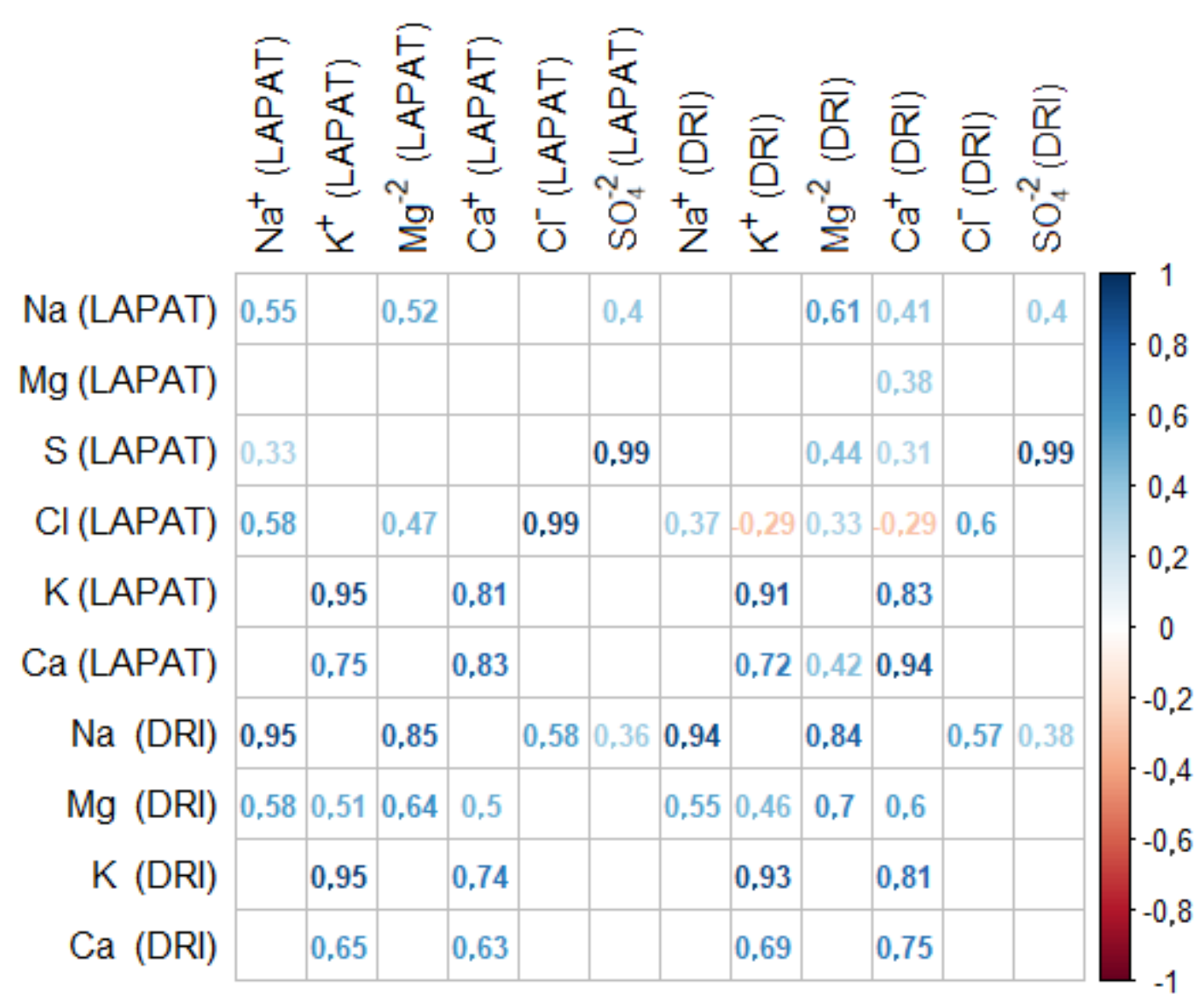

Figura A XV. Matriz de correlação (Pearson) significativa $(\mathrm{p}<0,05)$ entre alguns íons e elementos analisados no DRI e LAPAt incluindo todos os dados de 2017.

Legenda: Espaços em branco indicam uma correlação não significativa $(p>0,05)$.

Vários fatores devem ser levados em conta na hora de escolher qual análise de íons é a mais adequada para ser utilizada. Considerando as comparações realizadas, ambas as análises parecem estar adequadas. Segundo Chow et al. (1995) o filtro de quartzo é adequado para fazer análise de íons com um cromatógrafo de íons, enquanto o filtro de policarbonato não é recomendado para essa análise sendo mais adequado para análises ao microscópio, EDX, entre outras. Outro fator que se deve considerar é que íons analisados no LAPAt foram somente para o ano de 2017, enquanto as outras variáveis consideradas nesse trabalho foram analisadas em 2017 e em 2018. E por fim, a maioria das análises que foram utilizadas nesse trabalho (ex.:compostos orgânicos) foram realizadas com o mesmo filtro de quartzo analisado no DRI, com exceção da massa do $\mathrm{MP}_{10}$ e dos elementos. Nesse caso, seria mais adequado utilizar o máximo de análises com o mesmo filtro para evitar possíveis discrepâncias. Considerando todos esses pontos, os íons utilizados nesse trabalho foram os analisados no DRI utilizando o filtro de quartzo coletado com o HiVol. 


\section{Tabelas}

Tabela B I. Resumo da metodologia de coleta e analítica para a comparação entre equipamentos, filtros e suportes.

\begin{tabular}{|c|c|c|c|c|c|}
\hline Equipamento & Substrato & Instrumento(s) & $\begin{array}{l}\text { Parâmetro } \\
\text { medido(s) }\end{array}$ & $\begin{array}{l}\text { Local de } \\
\text { análise }\end{array}$ & $\begin{array}{l}\text { Dias } \\
\text { amostrados }\end{array}$ \\
\hline \multirow{2}{*}{ MiniVol } & $\begin{array}{l}\text { Filtro de } \\
\text { quartzo }\end{array}$ & $\begin{array}{l}\text { Balança } \\
\text { microanalítica }\end{array}$ & $\begin{array}{l}\mathrm{MP}_{10,} \mathrm{MP}_{2,5} \\
\mathrm{em} \mu \mathrm{g} / \mathrm{m}^{3}\end{array}$ & $\mathrm{IAG}^{1}$ (USP) & 27 \\
\hline & $\begin{array}{l}\text { Filtro de } \\
\text { policarbonato }\end{array}$ & $\begin{array}{l}\text { Balança } \\
\text { microanalítica }\end{array}$ & $\begin{array}{l}\mathrm{MP}_{10}, \mathrm{MP}_{2,5-} \\
{ }_{10} \mathrm{e} \mathrm{MP}_{2,5} \mathrm{em} \\
\mu \mathrm{g} / \mathrm{m}^{3}\end{array}$ & $\mathrm{IAG}^{1}$ (USP) & 27 \\
\hline $\begin{array}{l}\text { Partisol } \\
2025 i\end{array}$ & $\begin{array}{l}\text { Filtro de } \\
\text { teflon }\end{array}$ & $\begin{array}{l}\text { Balança } \\
\text { microanalítica }\end{array}$ & $\begin{array}{l}\mathrm{MP}_{10} \text { e } \mathrm{MP}_{2,5} \\
\mathrm{em} \mu \mathrm{g} / \mathrm{m}^{3}\end{array}$ & $\mathrm{IAG}^{1}$ (USP) & 27 \\
\hline
\end{tabular}

Tabela B II. Inclinação (a2), interceptação (b2) fator de correlação (r2) e vazão de operação para cada verificação da calibração realizada no Hivol.

\begin{tabular}{lllll}
\hline & $\mathrm{a} 2$ & $\mathrm{~b} 2$ & $\mathrm{r} 2$ & Operation flow rate \\
\hline $10-05-2017$ & 7,7680 & 0,4204 & 0,9831 & 1,1847 \\
$11-05-2017$ & 7,7680 & 0,4194 & 0,9831 & 1,1929 \\
$16-05-2017$ & 6,3622 & 0,5248 & 0,9678 & 1,1609 \\
$26-05-2017$ & 7,0826 & 0,4778 & 0,9784 & 1,1886 \\
$08-08-2017$ & 8,6875 & 0,3673 & 0,9576 & 1,1724 \\
$20-09-2017$ & 8,0778 & 0,4072 & 0,9976 & 1,1681 \\
$13-03-2017$ & 8,3177 & 0,3892 & 0,9890 & 1,1756 \\
$21-03-2017$ & 9,6684 & 0,3042 & 0,9809 & 1,1666 \\
$16-04-2017$ & 9,2184 & 0,3304 & 0,9308 & 1,1593 \\
$17-04-2017(1)$ & 6,7871 & 0,4946 & 0,9172 & 1,1623 \\
$17-04-2017(2)$ & 9,2985 & 0,3223 & 0,9935 & 1,1338 \\
\hline
\end{tabular}

Legenda: Observe que os valores reais utilizados para obter a vazão das amostras foram obtidos nos dias: 26-052017, 08-08-2017, 20-09-2017, 13-03-2017, 21-03-2017 e 17 -04-2017 (2).

Tabela B III.Concentração média \pm desvio padrão $\left(\mu \mathrm{g} / \mathrm{m}^{3}\right)$ do $\mathrm{OC}$ e EC em cada rampa de temperatura.

\begin{tabular}{ll}
\hline Rampas & $\begin{array}{l}\text { Média } \pm \text { desvio padrão } \\
\left(\mu \mathrm{g} / \mathrm{m}^{3}\right)\end{array}$ \\
\hline O1TC & $0,40 \pm 0,40$ \\
O2TC & $1,35 \pm 0,89$ \\
O3TC & $2,23 \pm 1,38$ \\
O4TC & $1,55 \pm 1,01$ \\
E1TC & $2,62 \pm 1,56$ \\
E2TC & $0,15 \pm 0,13$ \\
E3TC & $0,00 \pm 0,00$ \\
\hline
\end{tabular}

Tabela B IV. Resumo das possíveis fontes dos compostos orgânicos

\section{Levoglucosano e manosano}

Outono 2017 Fontes locais queima de lenha em domicílios e comércio (poucos focos de incêndio e maior [] em finais de semana), fogueiras devido a festa junina (maior [] em finais de semana) ou queima do bagaço da cana de açúcar em usinas ( $\mathrm{L} / \mathrm{M}=10$; Hysplit de noroeste, poucos focos de incêndio) 
Inverno 2017 Mistura de queima de biomassa e biocombustível (L/M = 13,4); Queimadas externas (muitos focos de incêndio - INPE); ressuspensão do solo e desgaste de pneu (maior [] em dias de semana; correlação com elementos do solo e $\mathrm{Cu}, \mathrm{Pb}$ e baixa velocidade do vento)

Primavera 2017 Queima de cana de açúcar de áreas mais distantes (elevada velocidade do vento e polar plot do Noroeste); ressuspensão do solo (correlação com Al)

Outono 2018 Queima de biomassa não muito relevante (direção de nordeste, baixa concentração de lev., elevada precipitação); queima de madeira residencial $(\mathrm{L} / \mathrm{M}=4,5)$;

Geral Queima de Cana de açúcar $(\mathrm{L} / \mathrm{M}=9)$

\begin{tabular}{ll}
\hline & Acetato \\
\hline Outono 2017 & NA \\
Inverno 2017 & $\begin{array}{l}\text { Formação secundária de precursores } \\
\text { emitidos por veículos (correlação com } \\
\text { O3, acúmulo de precursores pela } \\
\text { inversão térmica; baixa cobertura de } \\
\text { nuvens - baixa precipitação e umidade, } \\
\text { elevada concentração de } \mathrm{O}_{3} \text { ) }\end{array}$
\end{tabular}

Primavera 2017 Queima de Biomassa de áreas mais distantes (velocidade do vento alta; correlação com levoglucosan e $\mathrm{K}^{+}$); ressuspensão do solo (correlação com Al)

Outono $2018 \quad$ NA

Geral Fonte comum com o Formiato (correlação F e A); Emissão primária dominante possivelmente veicular (F/A $<1)$; Processos secundários fotoquímicos importante (correlação Formiato

Queima de biomassa local (correlação com lev., nitrato e $\mathrm{CO}$; sem correlação com $\mathrm{SO}_{4}{ }^{2-}$ ); Emissão primária (baixa irradiação solar, correlação com $\mathrm{CO}$ );

Formação secundária de precursores emitidos por veículos (correlação com $\mathrm{O}_{3}$, acúmulo de precursores pela inversão térmica; baixa cobertura de nuvens - baixa precipitação e umidade, elevada concentração de $\mathrm{O}_{3}$ )

Formação secundária de precursores emitidos pela queima de biomassa (velocidade do vento alta; correlação com levoglucosan, $\mathrm{K}^{+}$e $\mathrm{O}_{3}$ ); Formação secundária de precursores emitidos por emissão veicular (correlação com $\mathrm{SO}_{4}{ }^{2-}, \mathrm{NH}_{4}{ }^{-} \mathrm{e}$ $\mathrm{O}_{3}$ ); ressuspensão do solo (correlação com $\mathrm{Al}$ ) Formação secundária de precursores emitidos por veículos (correlação com $\mathrm{SO}_{4}{ }^{2-}, \mathrm{NH}_{4}{ }^{-}, \mathrm{O}_{3}$ )

Fonte comum com o Formiato (correlação F e A); Emissão primária dominante possivelmente veicular (F/A <1); Processos secundários fotoquímicos importante (correlação com O3) com O3)

\begin{tabular}{|c|c|c|c|}
\hline & Oxalato & $\begin{array}{l}\text { Succin } \\
\text { ato }\end{array}$ & Maleato \\
\hline Outono 2017 & $\begin{array}{l}\text { Formação secundária de precursores } \\
\text { emitidos por veículos (correlação com } \\
\mathrm{SO}_{4}^{2-} \text { e } \mathrm{NH}_{4}^{-} \text {; direção de sudeste com o } \\
\mathrm{SO}_{4}^{2-} \text { ) }\end{array}$ & $\mathrm{NA}$ & $\begin{array}{l}\text { Formação secundária de precursores } \\
\text { emitidos por veículos (correlação } \\
\text { com } \mathrm{SO}_{4}^{2-} \text { e } \mathrm{NH}_{4}^{-} \text {; direção de } \\
\text { sudeste com o } \mathrm{SO}_{4}^{2-} \text { ) }\end{array}$ \\
\hline Inverno 2017 & $\begin{array}{l}\text { Formação secundária de precursores } \\
\text { emitidos por veículos (correlação com } \\
\mathrm{SO}_{4}^{2-}, \mathrm{NH}_{4}^{-}, \mathrm{O}_{3} \text { ) }\end{array}$ & $\begin{array}{l}\text { Forma } \\
\text { ção } \\
\text { secun } \\
\text { dária } \\
\text { de } \\
\text { precur } \\
\text { sores } \\
\text { emitid } \\
\text { os por } \\
\text { veícul } \\
\text { os } \\
\text { (correl } \\
\text { ação } \\
\text { com } \\
\mathrm{SO}_{4}^{2-} \text {, } \\
\mathrm{NH}_{4}^{-}, \\
\mathrm{O}_{3} \text { ) }\end{array}$ & $\begin{array}{l}\text { Formação secundária de precursores } \\
\text { emitidos por veículos (correlação } \\
\text { com } \mathrm{SO}_{4}^{2-} \text { e } \mathrm{NH}_{4}^{-} \text {) }\end{array}$ \\
\hline Primavera 2017 & $\begin{array}{l}\text { Formação secundária de precursores } \\
\text { emitidos pela queima de biomassa } \\
\text { (correlação com levoglucosan, } \mathrm{K}^{+} \mathrm{e} \mathrm{O}_{3} \text { ); }\end{array}$ & $\begin{array}{l}\text { Forma } \\
\text { ção } \\
\text { secun }\end{array}$ & $\begin{array}{l}\text { Formação secundária de precursores } \\
\text { emitidos por veículos (correlação } \\
\text { com } \mathrm{SO}_{4}^{2-} \text { e } \mathrm{NH}_{4}^{-} \text {) }\end{array}$ \\
\hline
\end{tabular}




\begin{tabular}{|c|c|c|c|}
\hline & $\begin{array}{l}\text { ressuspensão do solo (correlação com } \\
\mathrm{Al} \text { ) }\end{array}$ & $\begin{array}{l}\text { dária } \\
\text { de } \\
\text { precur } \\
\text { sores } \\
\text { emitid } \\
\text { os } \\
\text { pela } \\
\text { queim } \\
\text { a de } \\
\text { bioma } \\
\text { ssa } \\
\text { (correl } \\
\text { ação } \\
\text { com } \\
\mathrm{K}^{+} \text {e } \\
\mathrm{O}_{3} \text { ); } \\
\text { ressus } \\
\text { pensã } \\
\text { o do } \\
\text { solo } \\
\text { (correl } \\
\text { ação } \\
\text { com } \\
\text { Al) }\end{array}$ & \\
\hline Outono 2018 & $\begin{array}{l}\text { Formação secundária de precursores } \\
\text { emitidos por veículos (correlação com } \\
\mathrm{SO}_{4}^{2-}, \mathrm{NH}_{4}^{-}, \mathrm{O}_{3} \text { ) }\end{array}$ & $\begin{array}{l}\text { Reaçã } \\
\text { o } \\
\text { fotoqu } \\
\text { ímica } \\
\text { (correl } \\
\text { ação } \\
\text { com } \\
\mathrm{O}_{3} \text { ) }\end{array}$ & $\begin{array}{l}\text { Formação secundária de precursores } \\
\text { emitidos por veículos (correlação } \\
\text { com } \mathrm{SO}_{4}^{2-} \text { e } \mathrm{NH}_{4}^{-} \text {) }\end{array}$ \\
\hline Geral & $\begin{array}{l}\text { Formação secundária de precursores } \\
\text { emitidos por veículos (correlação com } \\
\mathrm{SO}_{4}^{2-}, \mathrm{NH}_{4}^{-} \text {e } \mathrm{O}_{3} \text { ) }\end{array}$ & $\begin{array}{l}\text { Forma } \\
\text { ção } \\
\text { secun } \\
\text { dária } \\
\text { de } \\
\text { precur } \\
\text { sores } \\
\text { emitid } \\
\text { os por } \\
\text { veícul } \\
\text { os } \\
\text { (correl } \\
\text { ação } \\
\text { com } \\
\mathrm{SO}_{4}{ }^{2-}, \\
\mathrm{NH}_{4}{ }^{-} \text {e } \\
\mathrm{O}_{3} \text { ) }\end{array}$ & $\begin{array}{l}\text { Formação secundária de precursores } \\
\text { emitidos por veículos (correlação } \\
\text { com } \mathrm{SO}_{4}^{2-}, \mathrm{NH}_{4}^{-} \mathrm{e} \mathrm{O}_{3} \text { ) }\end{array}$ \\
\hline
\end{tabular}

Tabela B V. Post-hoc do teste de Kruskal-Wallis, considerando as concentrações sazonais dos principais grupos fúngicos (AS - Ascósporos, BS - Basidiósporos e UD - desconhecido) e TS (Esporos totais). Essa tabela indica as variáveis que mostraram diferença significativa considerando a estação respectiva $(\mathrm{p}<0,05)$.

\begin{tabular}{llll}
\hline & Outono 2017 & Inverno 2017 & Outono 2018 \\
\hline Outono 2017 & & TS, AS, BS & UD \\
Inverno 2017 & TS, AS, BS & & TS, AS, BS, UD \\
Primavera & & TS, AS, BS, UD & \\
2017 & & & \\
\hline
\end{tabular}


Tabela B VI. Variáveis utilizadas na Fatoração de Matriz Positiva (PMF) e metodologia analítica usada.

\begin{tabular}{|c|c|}
\hline Método & Variáveis \\
\hline Cromatografia de íons & $\begin{array}{l}\mathrm{Na}^{+}, \mathrm{NH}_{4}^{-}, \mathrm{K}^{+}, \mathrm{Cl}^{-}, \mathrm{NO}_{3}^{-}, \mathrm{SO}_{4}^{-2}, \mathrm{Ca}^{+}, \mathrm{Br}^{-} \\
\text {Arabitol, glicose, levoglucosano, manitol, } \\
\text { manosano }\end{array}$ \\
\hline $\begin{array}{l}\text { Analisador de carbono óptico/térmico de } \\
\text { comprimento de onda múltiplo (Modelo DRI 2015) }\end{array}$ & $\mathrm{OC}$ e EC \\
\hline Quantificação de Proteína (AccuOrange kit) & Proteínas solúveis em água \\
\hline $\begin{array}{l}\text { Espectrômetro de fluorescência de raio X por energia } \\
\text { dispersiva (EDX) }\end{array}$ & $\mathrm{Al}, \mathrm{Si}, \mathrm{P}, \mathrm{Ti}, \mathrm{Mn}, \mathrm{Fe}, \mathrm{Cu}, \mathrm{Zn}$ \\
\hline $\begin{array}{l}\text { Espectrometria de massas com fonte de plasma } \\
\text { indutivamente acoplado (ICP-MS) }\end{array}$ & $\mathrm{As}, \mathrm{Sb}, \mathrm{Pb}$ \\
\hline Microscópio e fator de conversão & Massa dos esporos fúngicos \\
\hline Gravimetria & Massa do $\mathrm{MP}_{10}$ \\
\hline
\end{tabular}

$\overline{\mathrm{OC}}$ - Carbono orgânico; EC - carbono elementar; $\mathrm{MP}_{10}$ - material particulado com aerodiâmetro abaixo de 10 $\mu \mathrm{m}$. 


\section{Figuras}
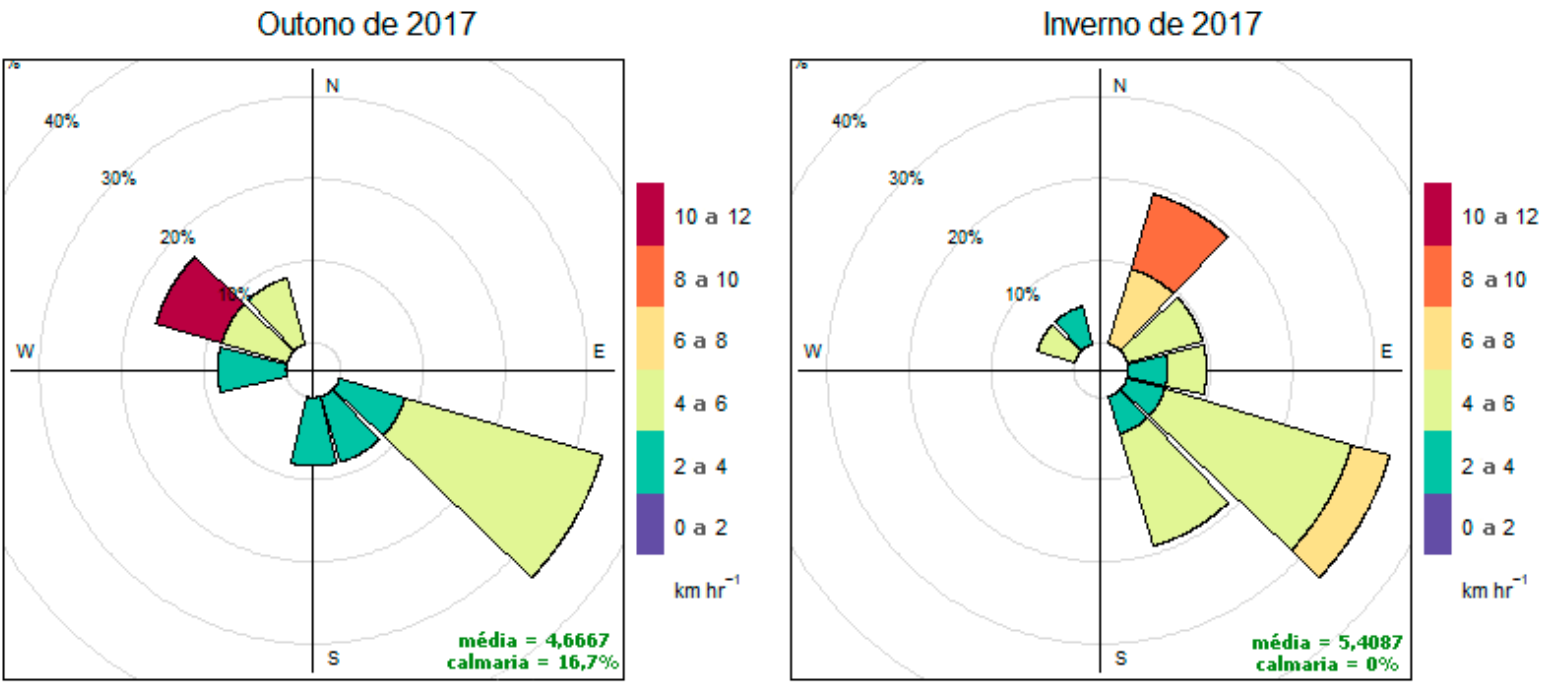

Primavera de 2017
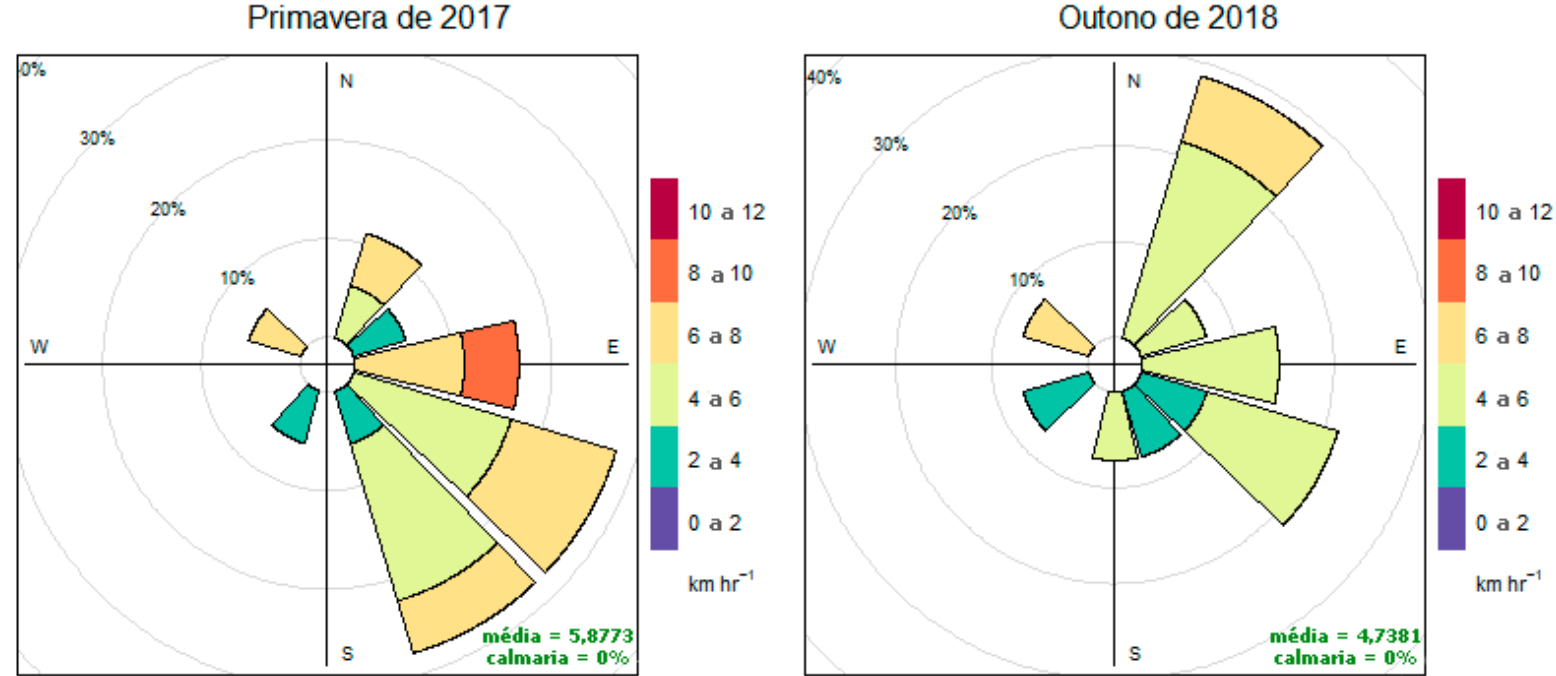

Figura C I. Rosa dos ventos sazonal para o período amostrado (Frequência de contagens por direção do vento (\%)).
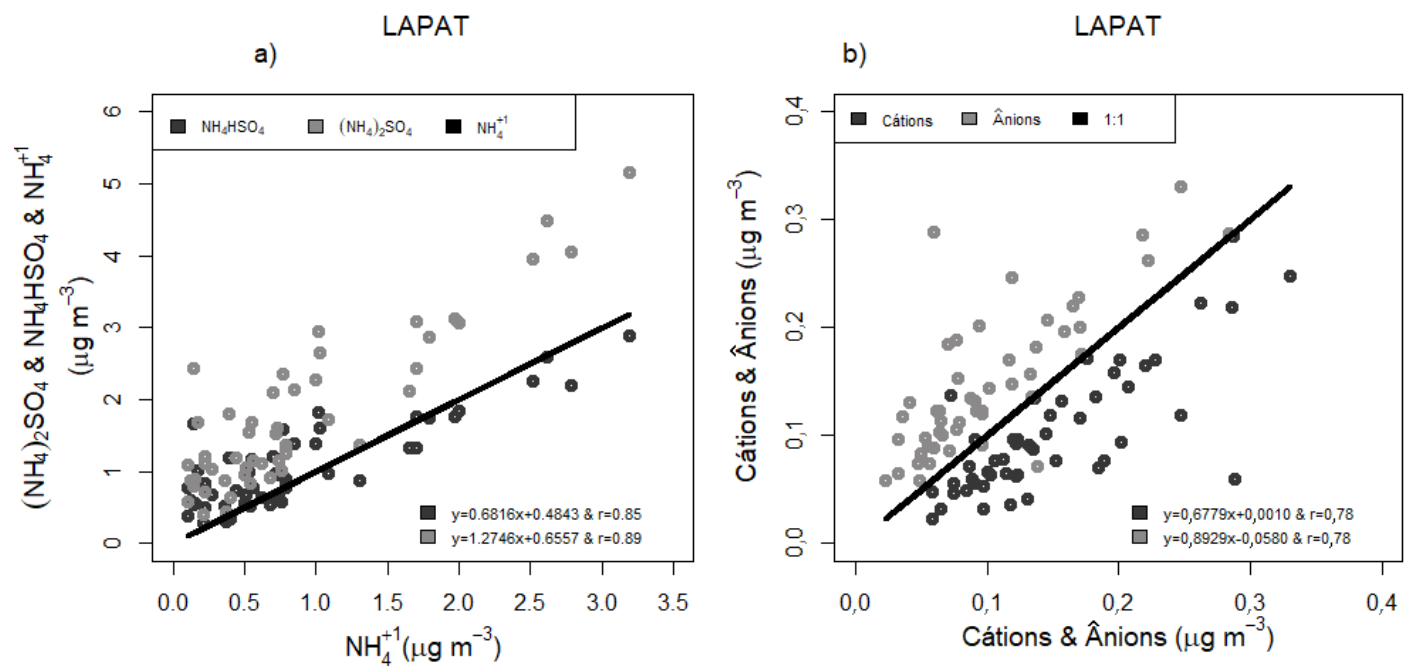
Figura C II. Balanço dos íons analisados no LAPAt entre a) $\mathrm{NH}_{4} \mathrm{HSO}_{4},\left(\mathrm{NH}_{4}\right)_{2} \mathrm{SO}_{4} \mathrm{e} \mathrm{NH}_{4}^{+}$; b) Íons (cátions e ânions).

LAPAT

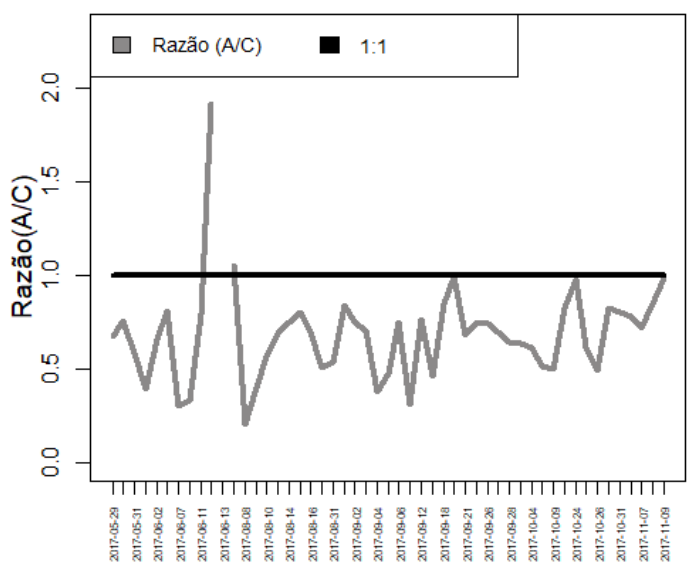

Figura C III. Razão entre a concentração em massa dos ânions (A) e os cátions (C) dos íons analisados no LAPAt, considerando todo o período amostrado.

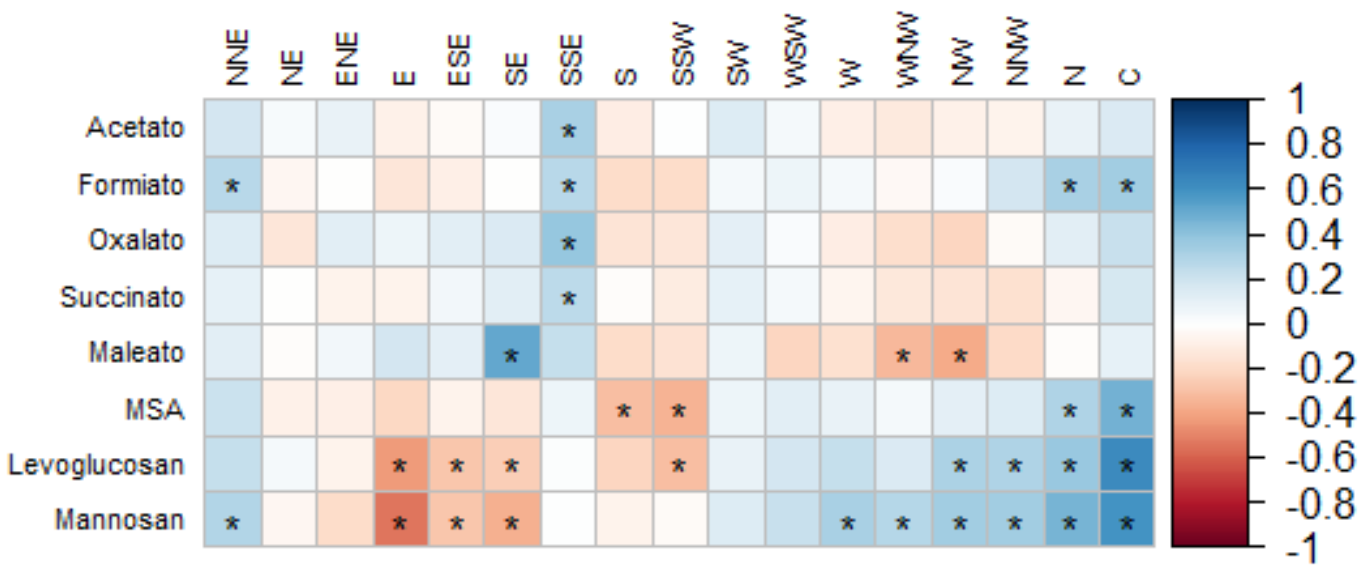

Figura C IV. Correlação de Pearson entre os compostos orgânicos com a frequências por dia das diferentes direções do vento considerando todo o período amostrado. 


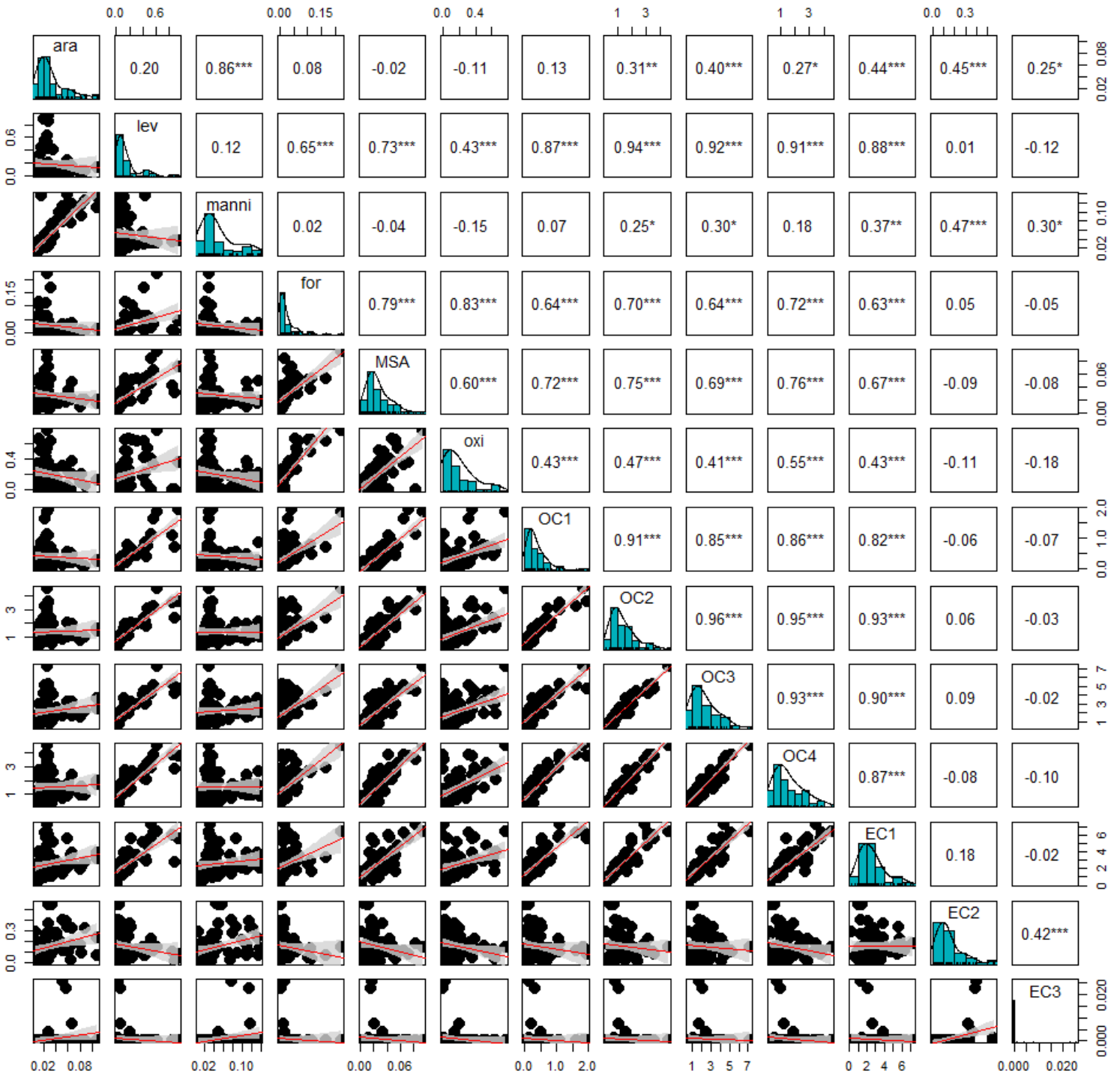

Figura C V. Correlação entre as concentrações de OC e EC em diferentes rampas de temperatura e alguns componentes orgânicos.

Legenda: Arabitol - ara, Levoglucosano - lev, Manitol - manni, Formiato - for, Metanosulfonato - MSA, Oxalato - oxi. 
NOAA HYSPLIT MODEL

Backward trajedories ending at 1200 UTC 02 Jun 17

GDAS Meteorological Data

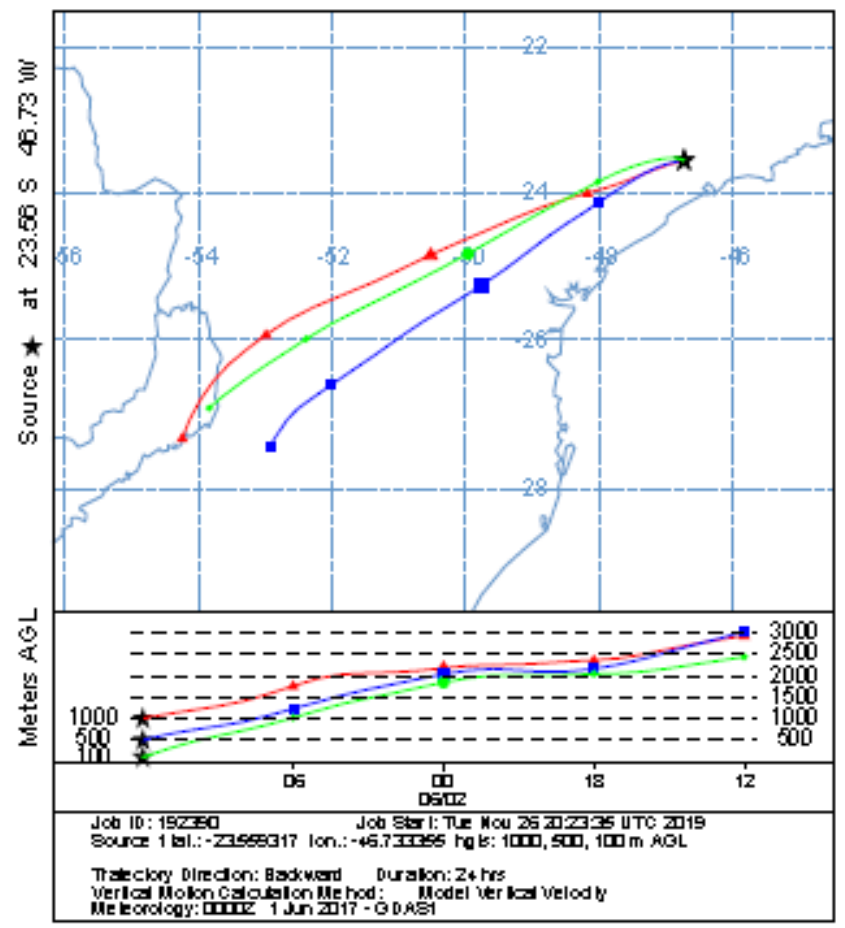


NOAA HYSPLIT MODEL

Backward trajedories ending at 1200 UTC 03 Jun 17

GDAS Meteorological Data

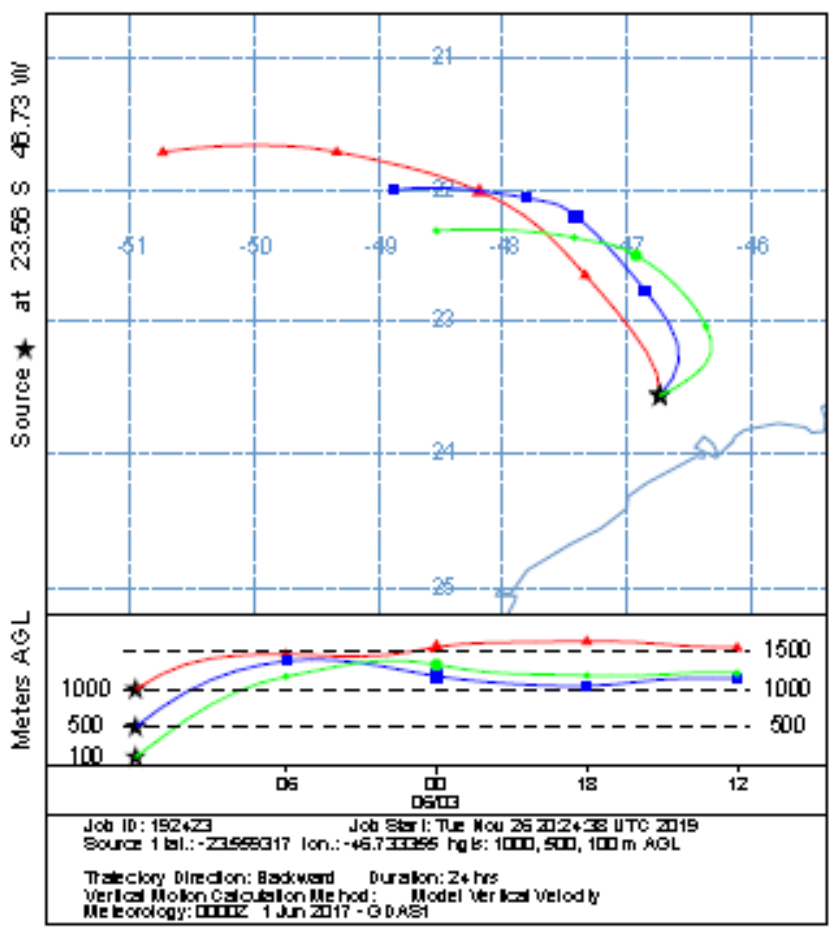

NOAA HYSPLIT MODEL

Backward trajectoriesending at 1200 UTC 04 Jun 17 GDAS Meteorological Data

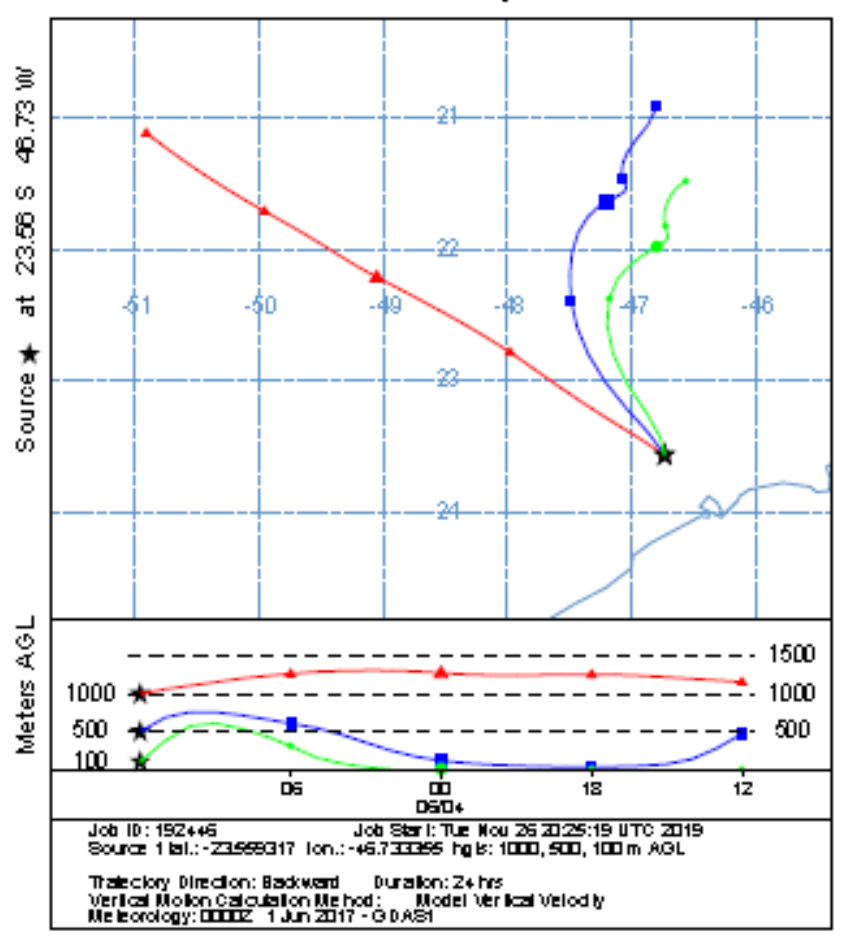


NOAA HYSPLIT MODEL

Backward trajedoriesending at 1200 UTC 08 Jun 17 GDAS Meteorological Data

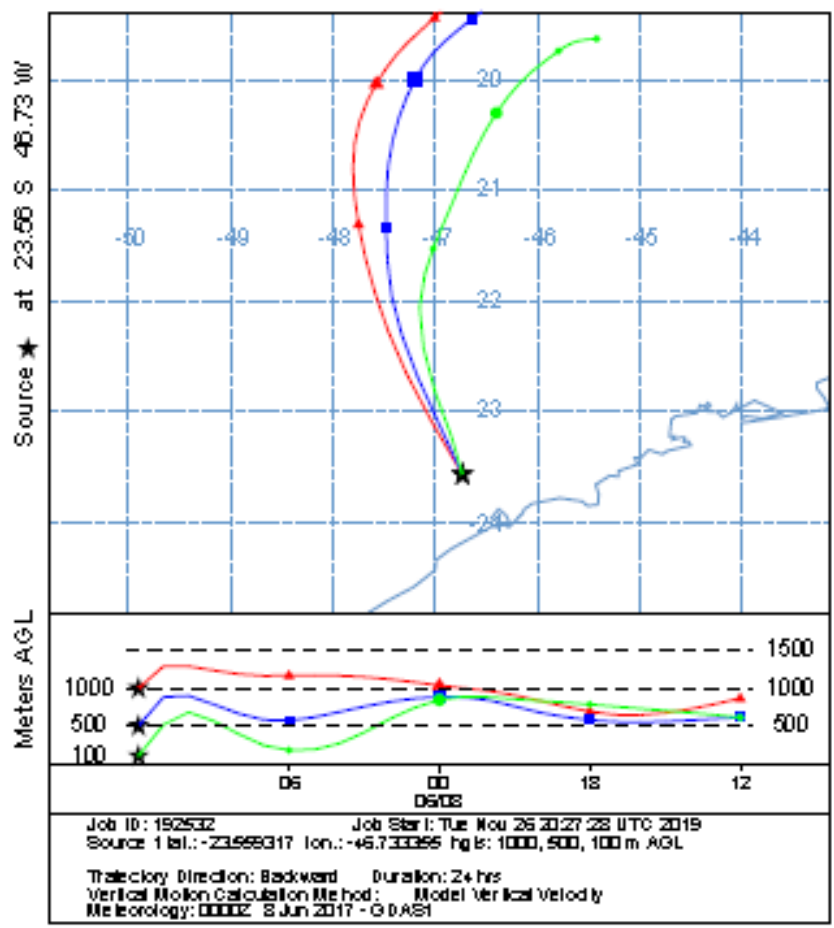


NOAA HYSPLIT MODEL

Backward trajedories ending at 1200 UTC 11 Jun 17

GDAS Meteorological Data

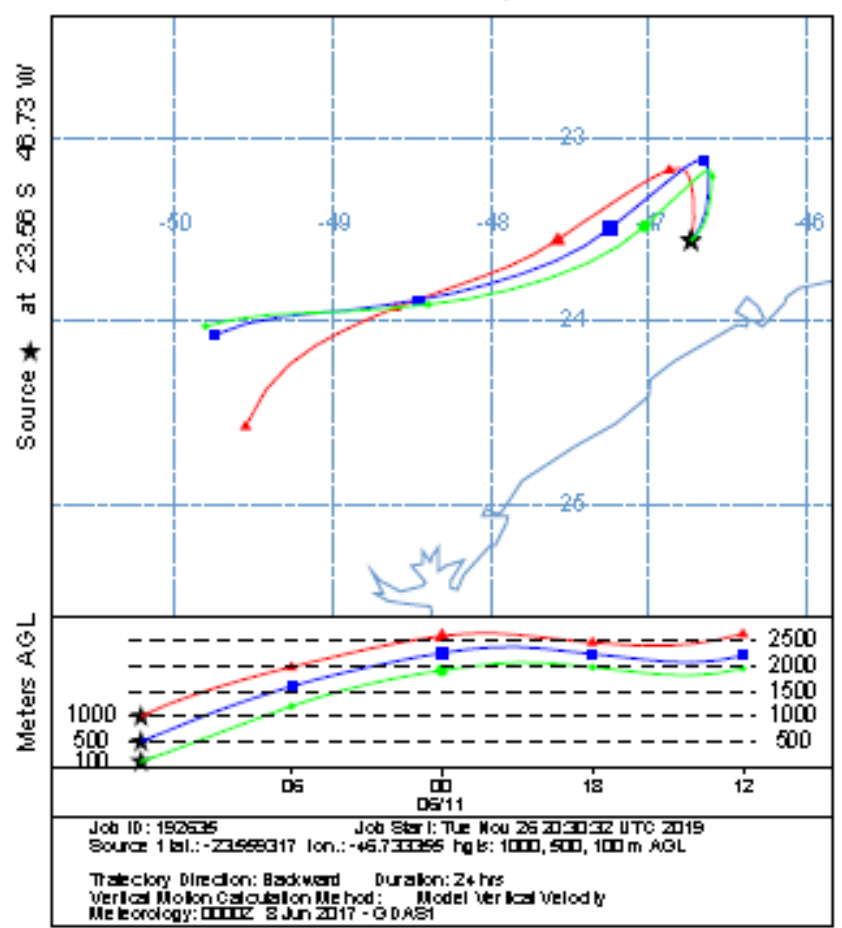

NOAA HYSPLIT MODEL

Backward trajedoriesending at 1200 UTC 12 Jun 17

GDAS Meteorological Data

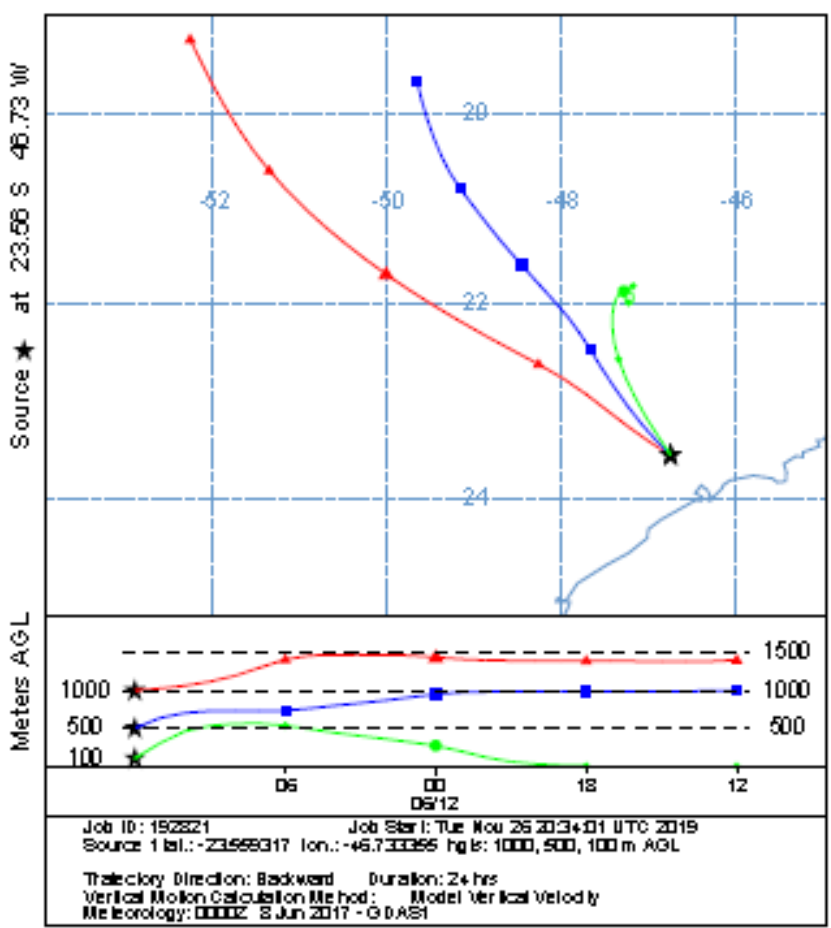


NOAA HYSPLIT MODEL

Backward trajedoriesending at 1200 UTC 13 Jun 17 GDAS Meteorological Data

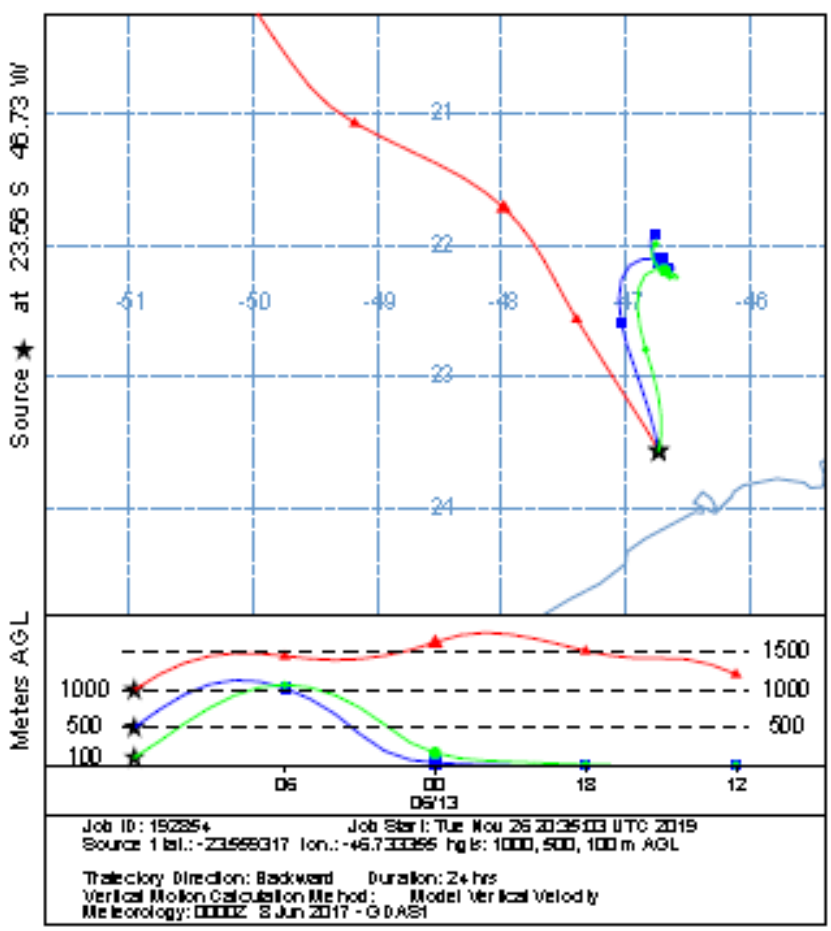

NOAA. HYSPLIT MODEL

Backward trajedories ending at 1200 UTC 14 Jun 17

GDAS Meteorological Data

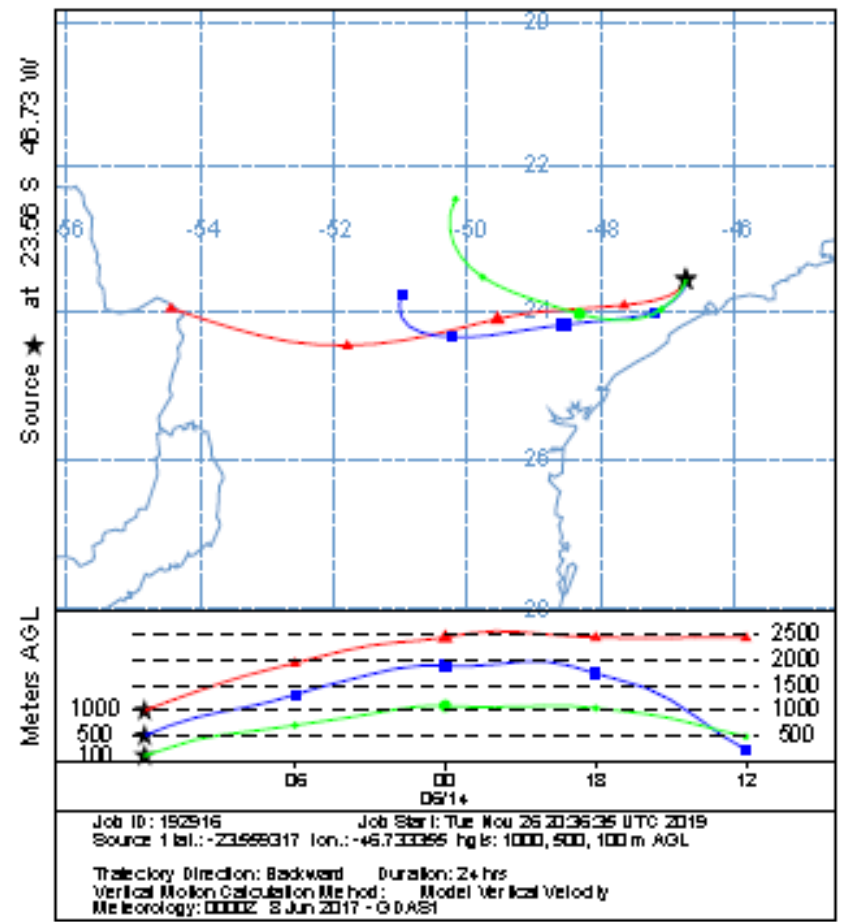


NOAA HYSPLIT MODEL

Backward trajedories ending at 1200 UTC 15 Jun 17

GDAS Meteorological Data

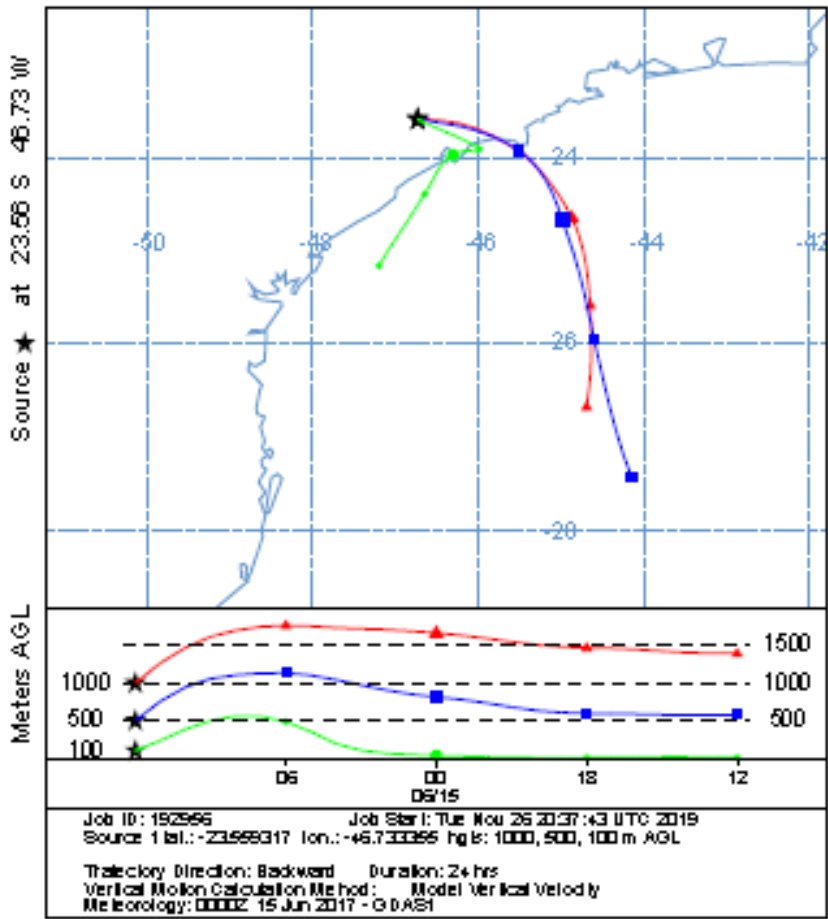

Figura C VI. Tragetória backward do Hysplit dos dias coletados em junho, utilizando o vertical motion model vertical velocity, 24 horas de rodada, 3 alturas da camada $(100,500,1000)$ e meteorologia GDAS (1 degree, global, 2006-present). O dia analisado corresponde ao dia anterior ao dia do final da trajetória.

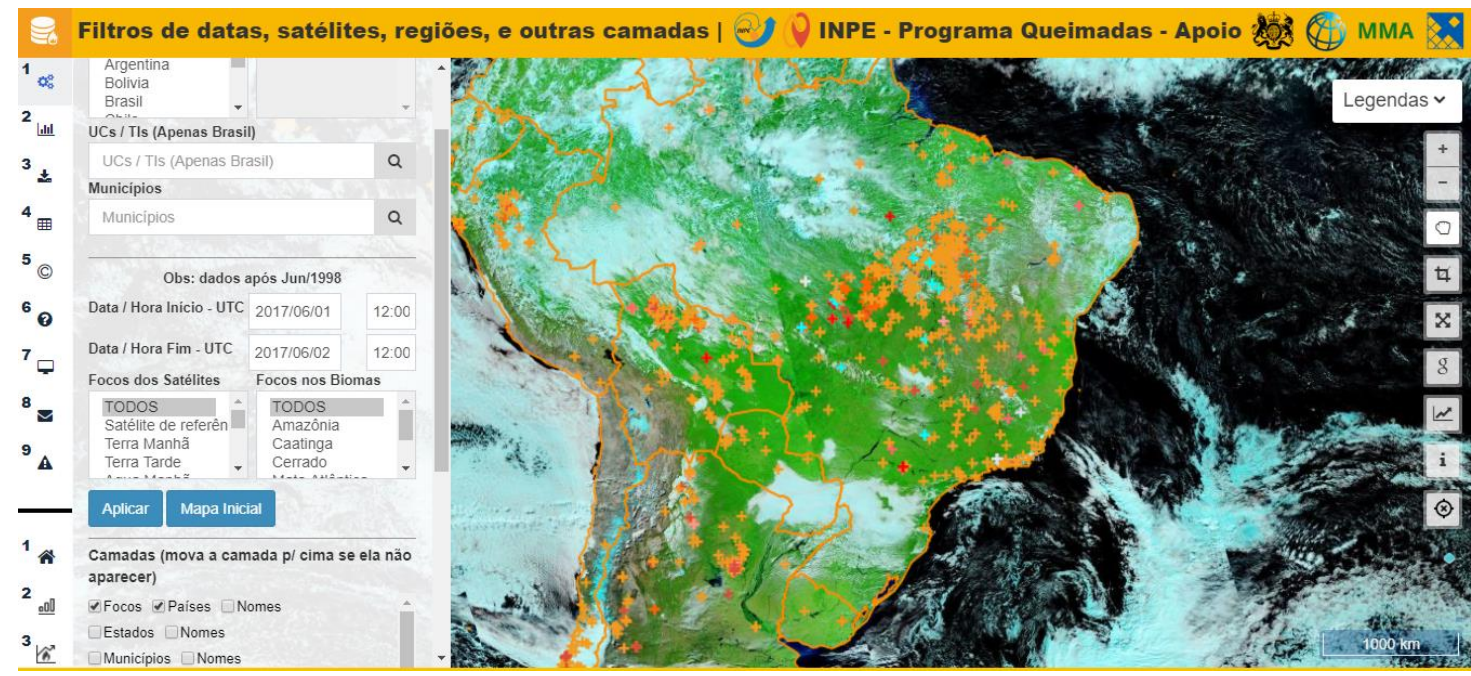




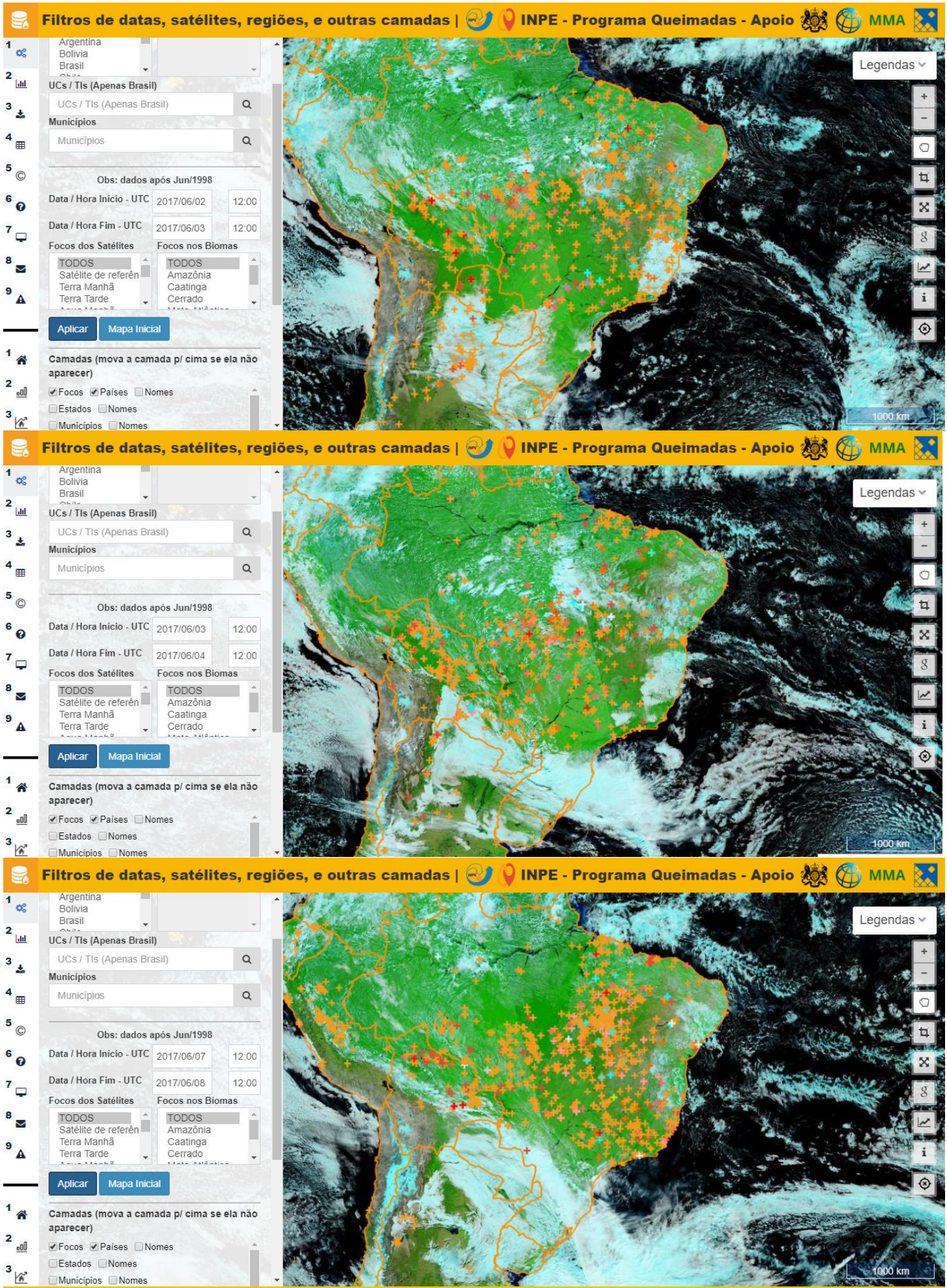




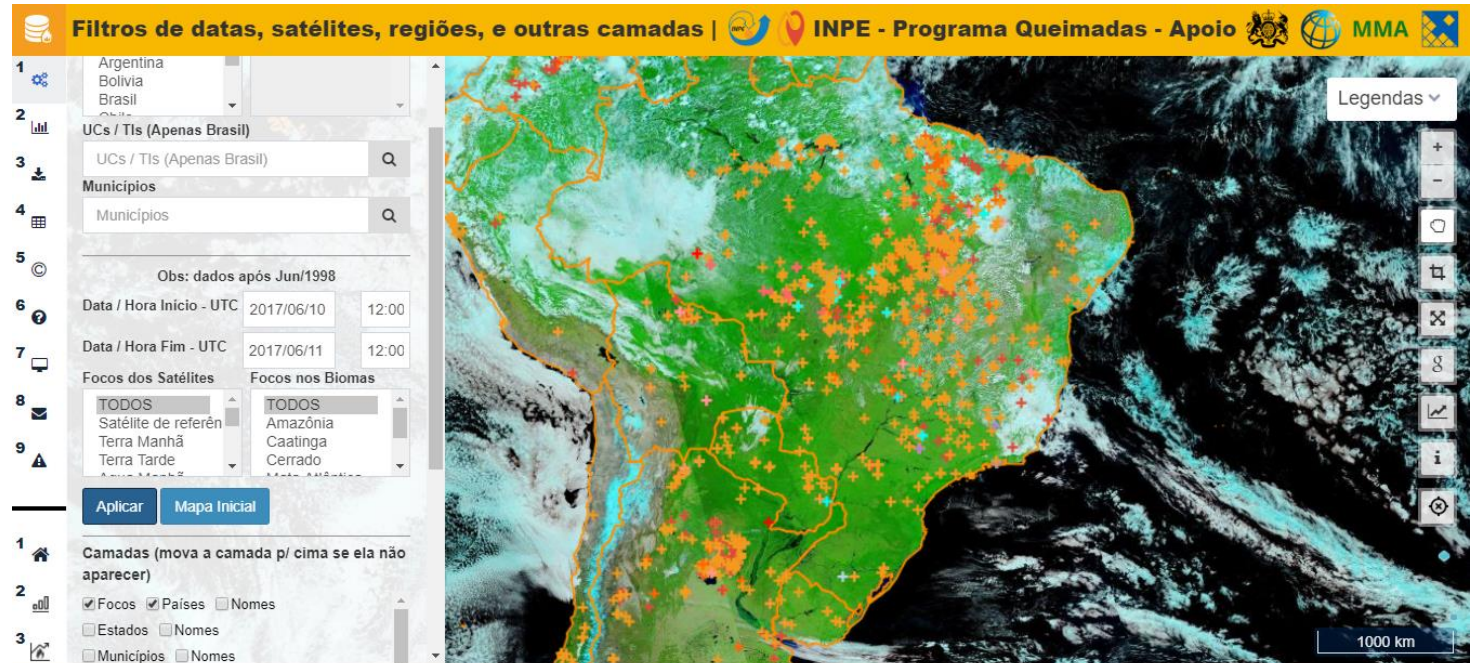

e. Filtros de datas, satélites, regiöes, e outras camadas I P INPE - Programa Queimadas - Apoio 4 MMA

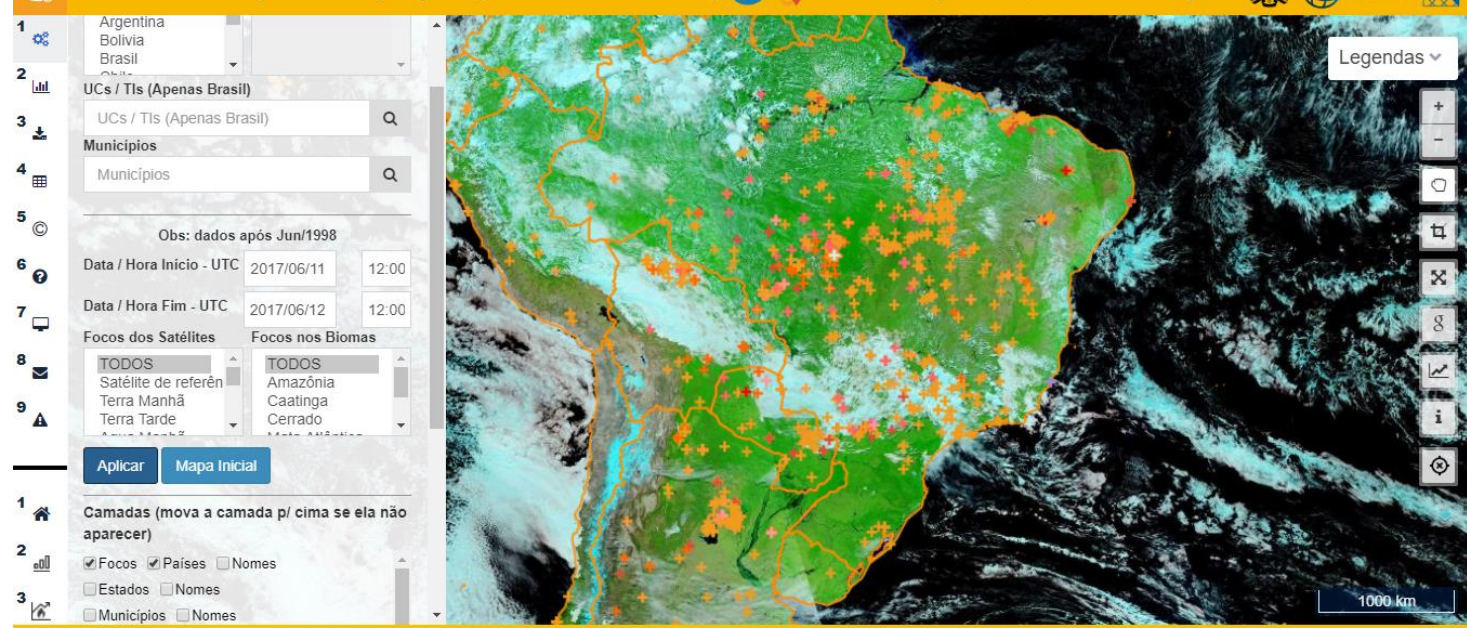

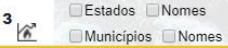

7. Filtros de datas, satélites, regiões, e outras camadas $1 @$ INPE - Programa Queimadas - Apoio 20 $1 \% \quad \begin{gathered}\text { Argentin } \\ \text { Bolivia }\end{gathered}$

$2 \underset{\text { Lill }}{\text { Brasil }}$ UCs / Tls (Apenas Brasil)

3 UCS/TIs (Apenas Brasil)

\pm Municipios a

4 Municipios Q

5 Obs: dados após Jun/1998

6 Data/Hora Inicio-UTC 2017/06/12 12:00

7 Data/Hora Fim - UTC 2017/06/13 12:00

Focos dos Satelites Focos nos Biomas

8 = TODOS

$\begin{array}{lll} & \text { Satelite de referén } & \text { Amazónia } \\ \text { Ceatinga } \\ \text { Cerra Manhã }\end{array}$

Aplicar Mapa Inicial

1 ศ Camadas (mova a camada $p /$ cima se ela não

aparecer)

2 oll $\checkmark$ Focos $\square$ Paises $\square$ Nomes

3 Estados $\square$ Nomes

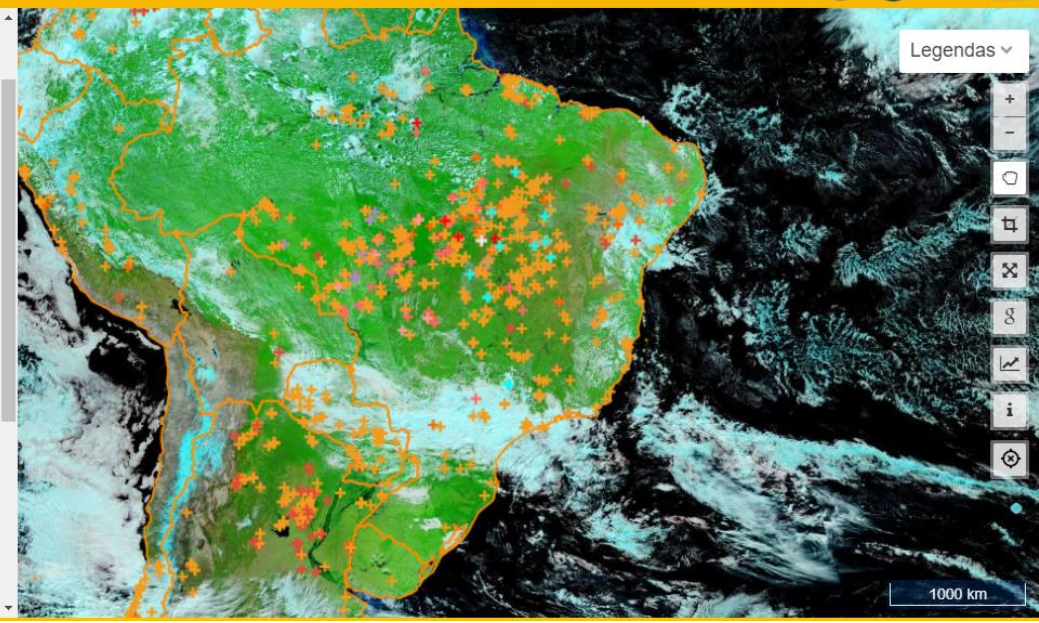




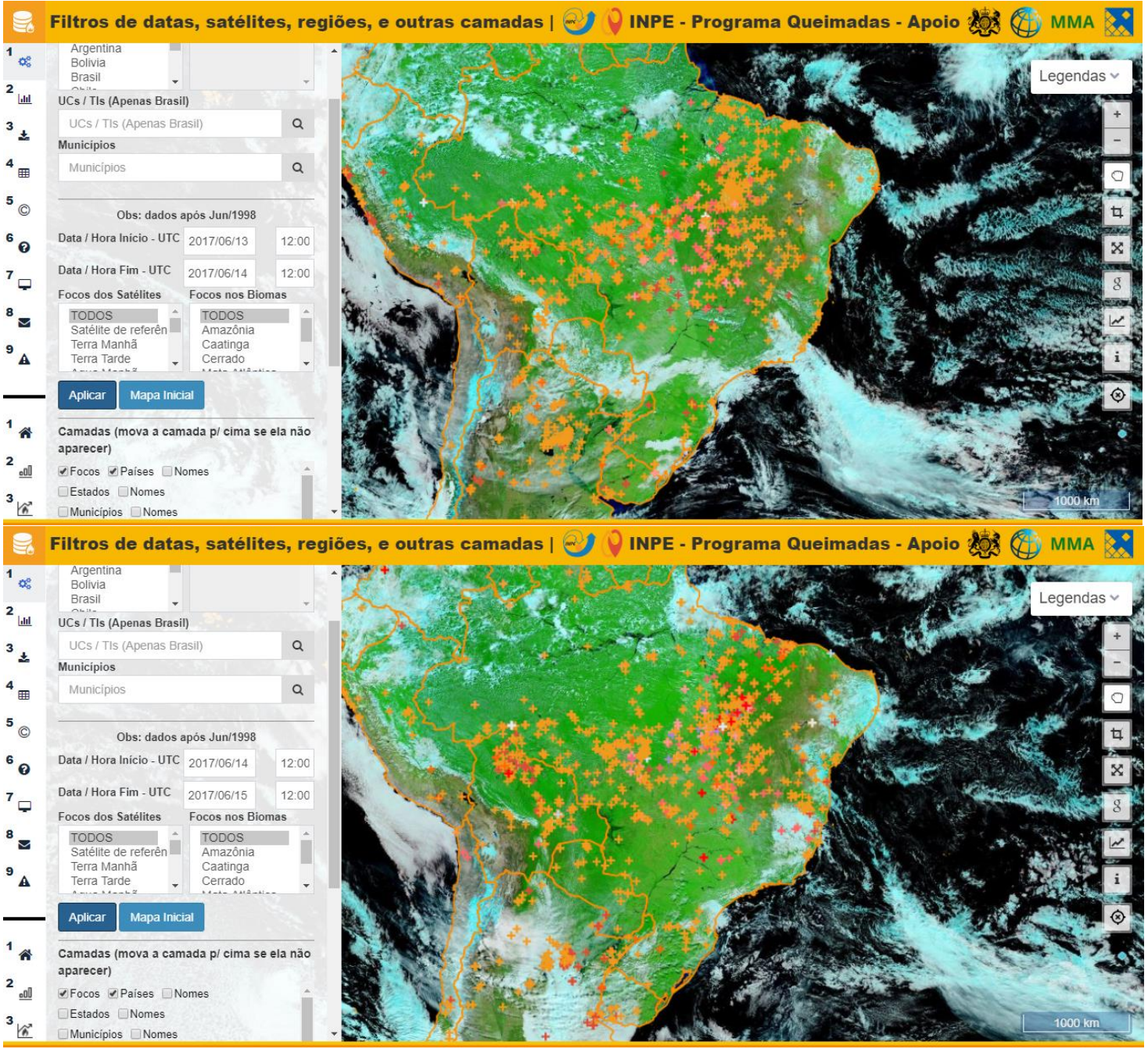

Figura C VII. Focos de queimadas para os dias coletados em junho (INPE, 2019) 


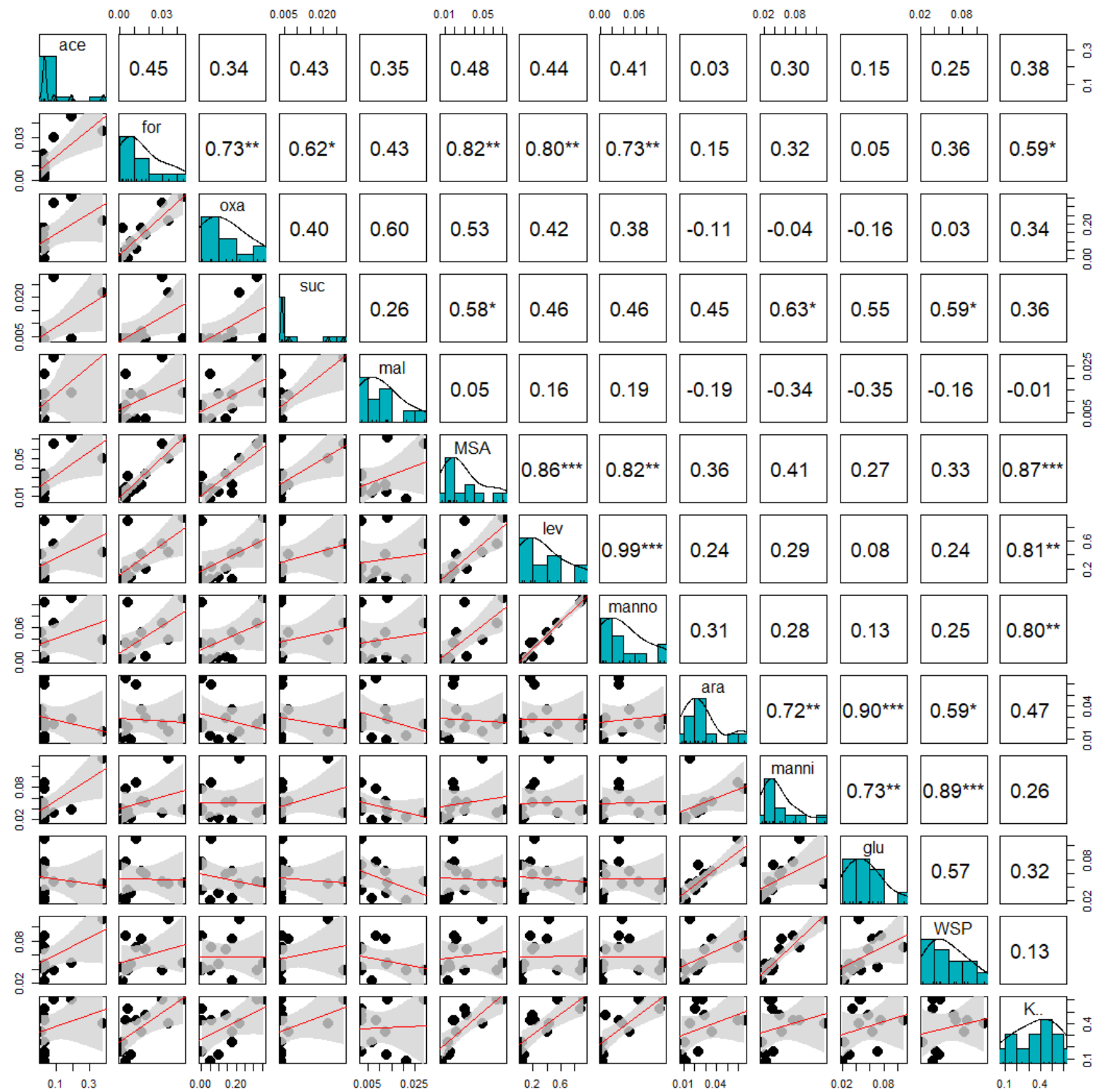

Figura C VIII. Correlação de Spearman entre os ácidos orgânicos, carboidratos e WSP para o outono de 2017. Legenda: Acetato (Ace), Formiato (For), Oxalato (Oxa), Succinato (Suc), Maleato (Mal), Metanosulfonato (MSA), Levoglucosano (Lev), Manosano (Manno), Arabitol (Ara), Manitol (Manni), Glicose (Glu), Proteínas solúveis em água (WSP) e $\mathrm{K}^{+} . *$ indica $\mathrm{p}<0,05, * *$ indica $\mathrm{p}<0,01 \mathrm{e} * * *$ indica $\mathrm{p}<0,001$. 


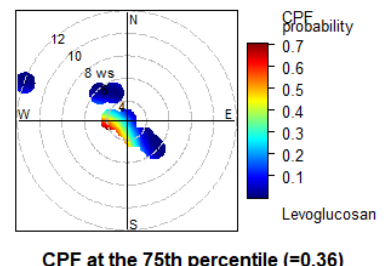

CPF at the 75 th percentile $(=0.36)$

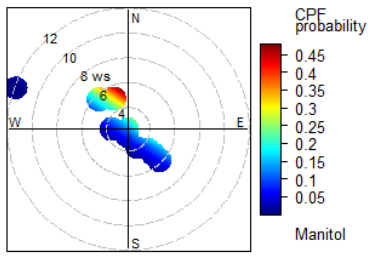

CPF at the 75 th percentile $(=0.071)$

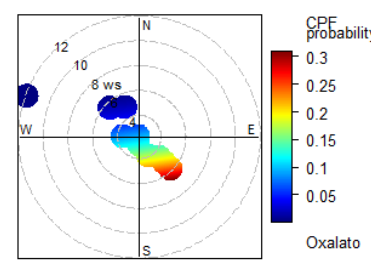

CPF at the 75 th percentile $(=0.18)$

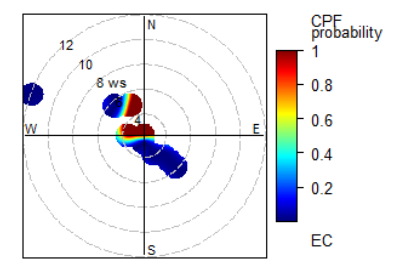

CPF at the 75 th percentile $(=4.9)$

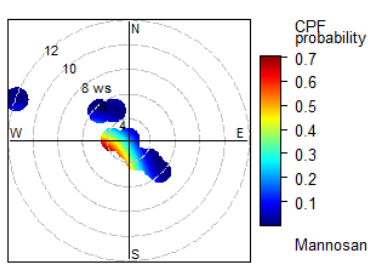

CPF at the 75 th percentile $(=0.037)$

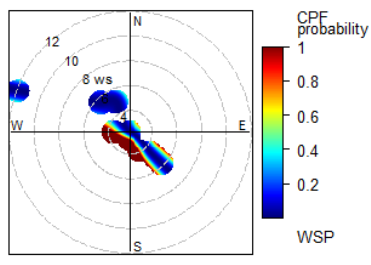

CPF at the 75 th percentile $(=0.08)$

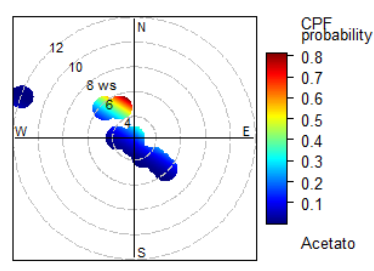

CPF at the 75 th percentile $(=0.036)$

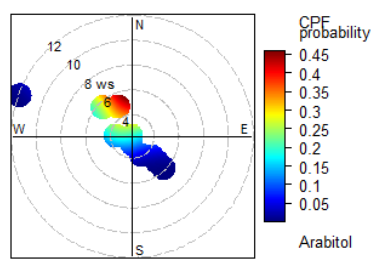

CPF at the 75 th percentile $(=0.034)$

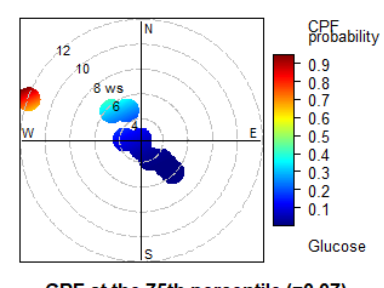

CPF at the 75th percentile $(=0.07)$

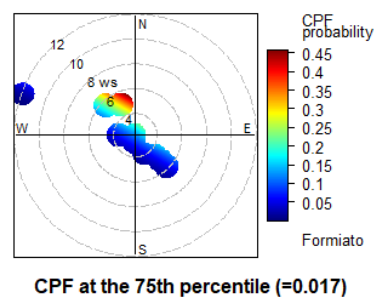

CPF at the 75 th percentile $(=0.017)$
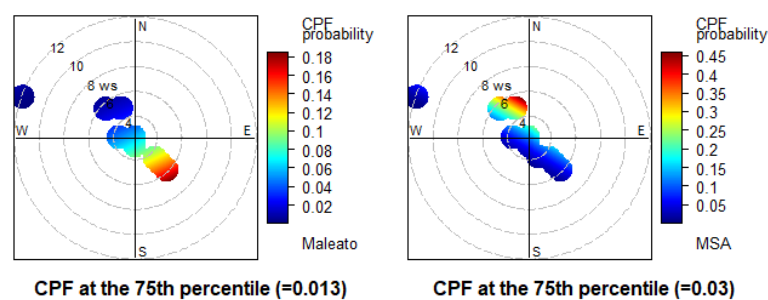

Figura C IX. Gráficos polares bivariados condicional (CBPF) das concentrações de levoglucosano, manosano, arabitol, glicose, manitol, WSP, acetato, formiato, oxalato, succinato, maleato, MSA, EC e OC no outono de 2017. 


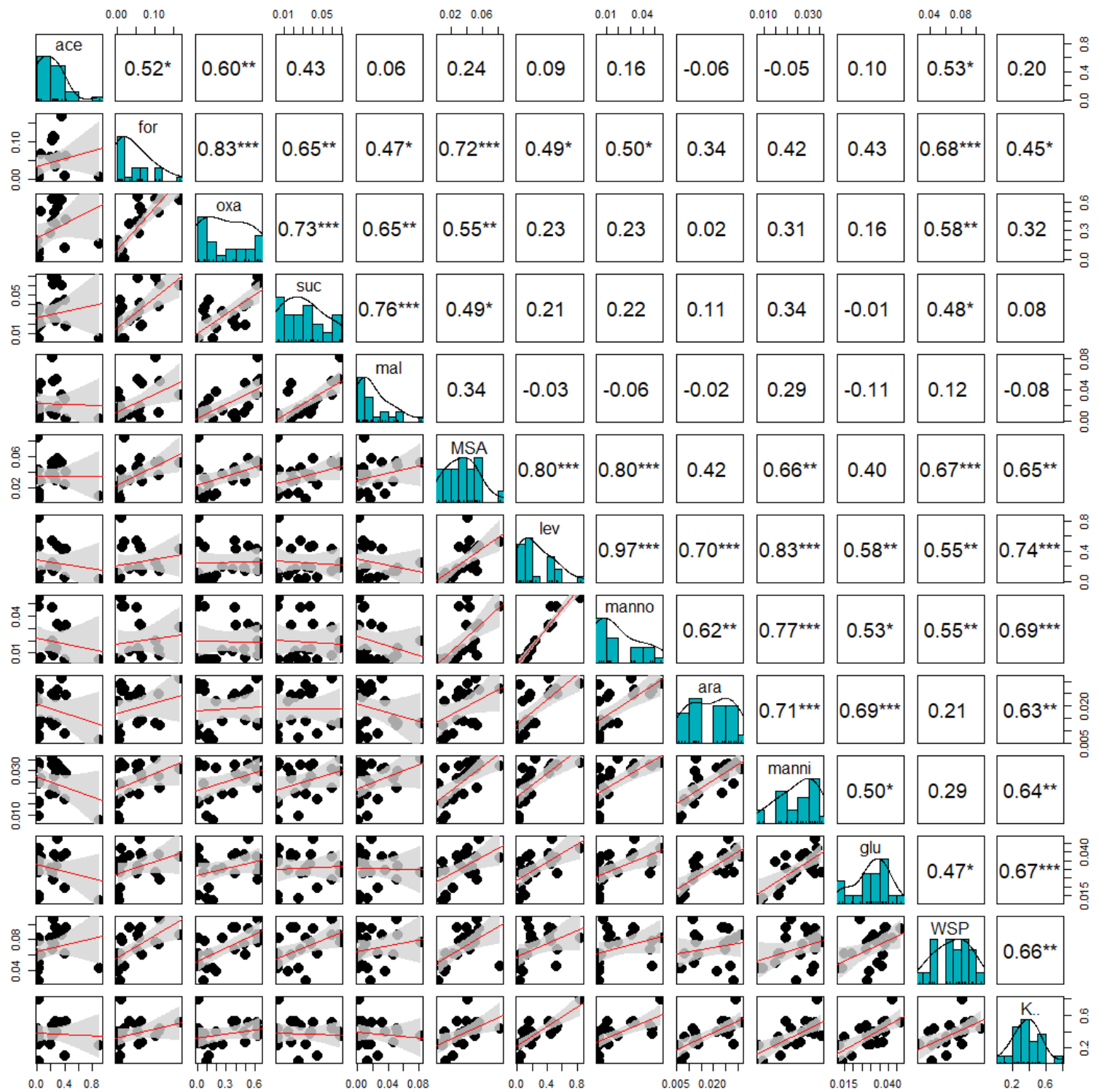

Figura C X. Correlação de Spearman entre os ácidos orgânicos, carboidratos e WSP para o inverno de 2017. Legenda: Acetato (Ace), Formiato (For), Oxalato (Oxa), Succinato (Suc), Maleato (Mal), Metanosulfonato (MSA), Levoglucosano (Lev), Manosano (Manno), Arabitol (Ara), Manitol (Manni), Glicose (Glu), Proteínas solúveis em água (WSP) e $\mathrm{K}^{+}$. * indica $\mathrm{p}<0,05, * *$ indica $\mathrm{p}<0,01 \mathrm{e} * * *$ indica $\mathrm{p}<0,001$. 


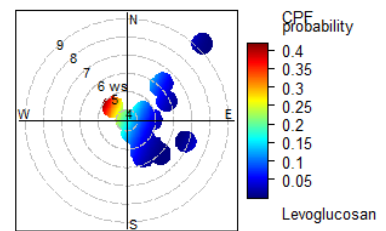

CPF at the 75th percentile $(=0.43)$

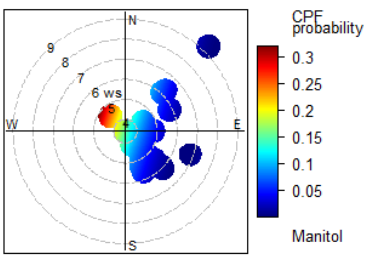

CPF at the 75 th percentile $(=0.032)$

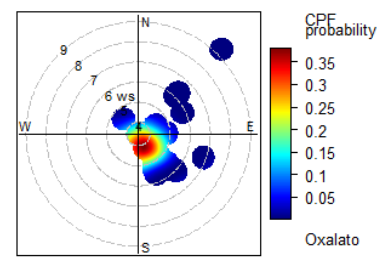

CPF at the 75 th percentile $(=0.5)$

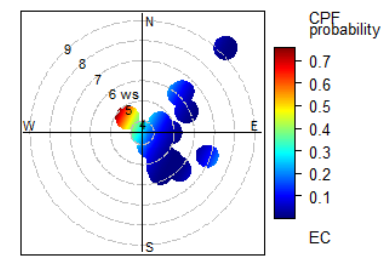

CPF at the 75 th percentile $(=3.4)$

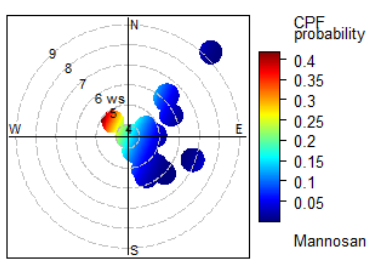

CPF at the 75 th percentile $(=0.033)$

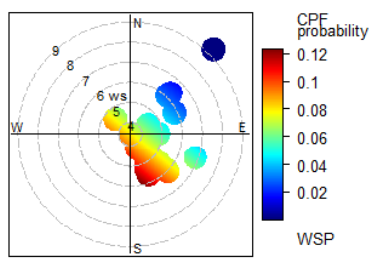

CPF at the 75 th percentile $(=0.085)$

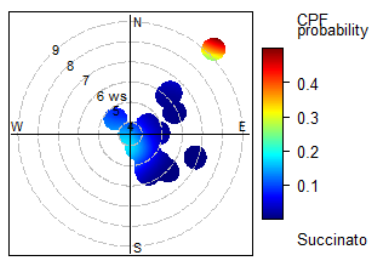

CPF at the 75 th percentile $(=0.041)$

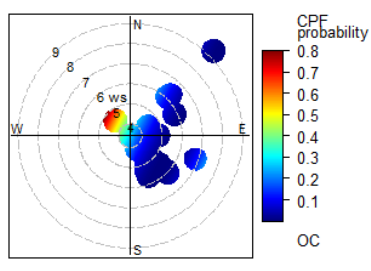

CPF at the 75th percentile $(=9.4)$

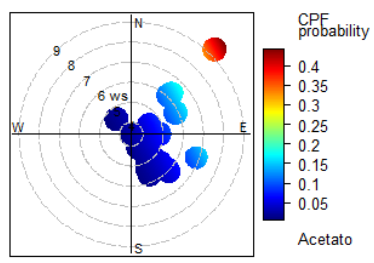

CPF at the 75 th percentile $(=0.28)$

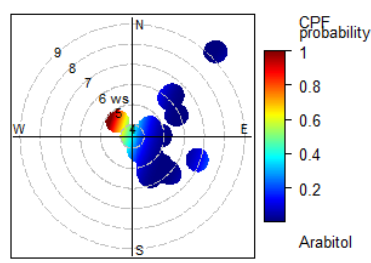

CPF at the 75 th percentile $(=0.026)$

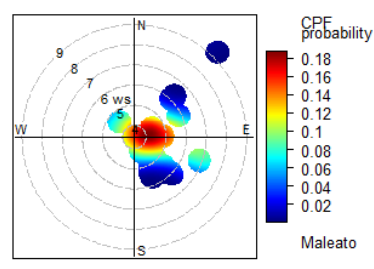

CPF at the 75 th percentile $(=0.033)$

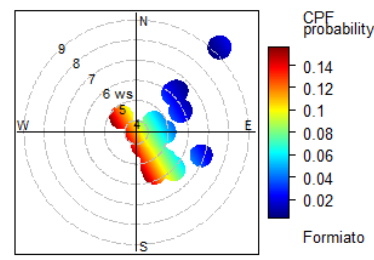

CPF at the 75 th percentile $(=0.063)$

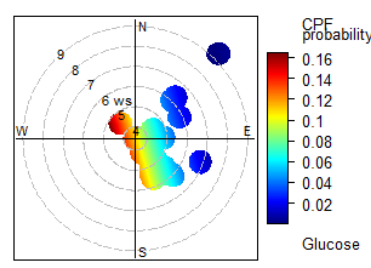

CPF at the 75 th percentile $(=0.037)$

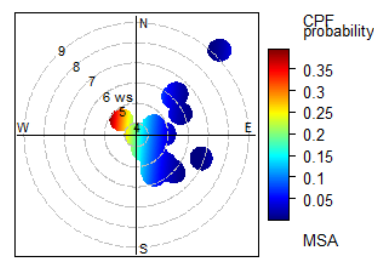

CPF at the 75 th percentile $(=0.048)$

Figura C XI. Gráficos polares bivariados condicional (CBPF) das concentrações de levoglucosano, manosano, arabitol, glicose, manitol, WSP, acetato, formiato, oxalato, succinato, maleato, MSA, EC e OC no inverno de 2017. 


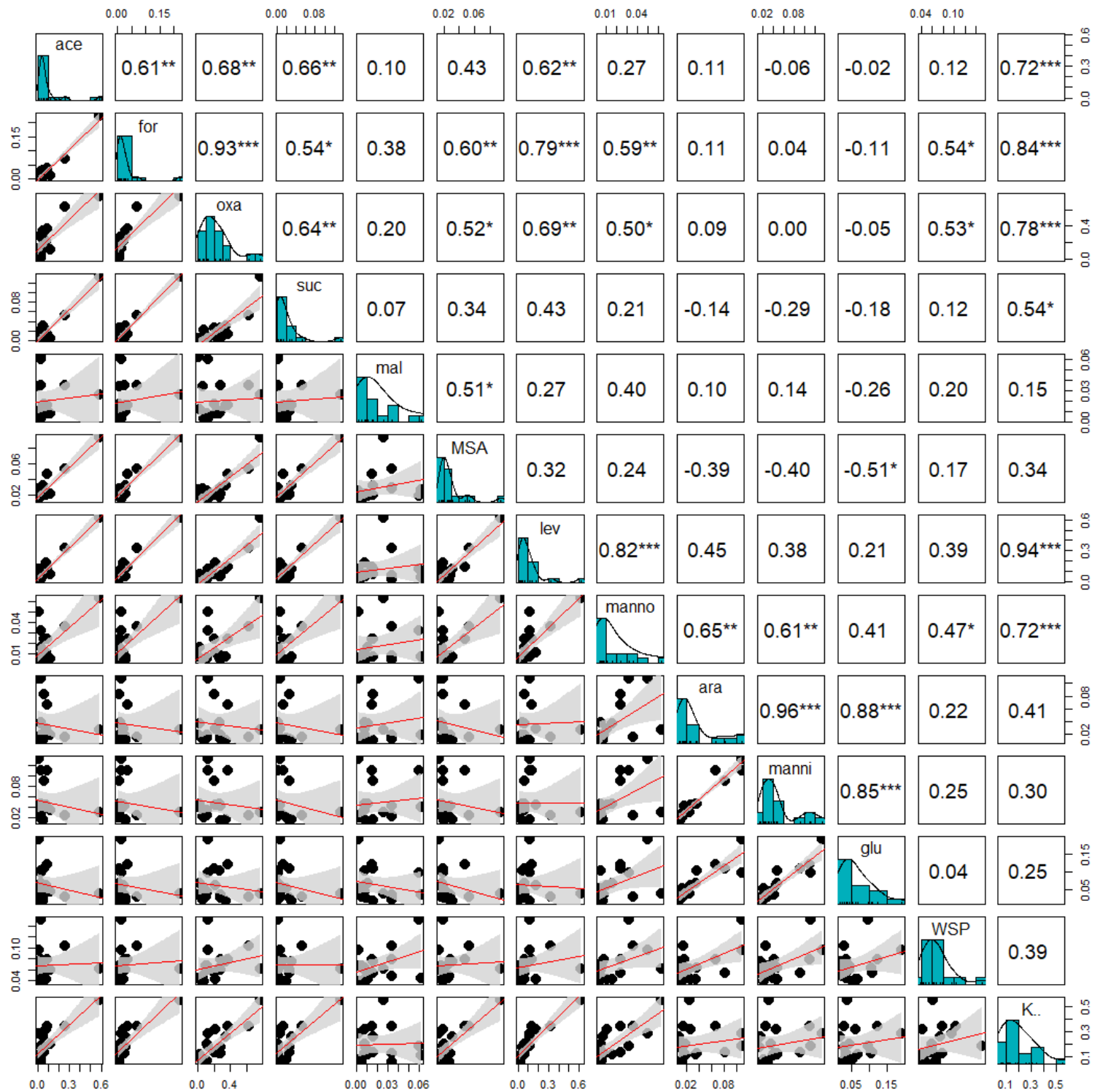

Figura C XII. Correlação de Spearman entre os ácidos orgânicos, carboidratos e WSP para a primavera de 2017. Legenda: Acetato (Ace), Formiato (For), Oxalato (Oxa), Succinato (Suc), Maleato (Mal), Metanosulfonato (MSA), Levoglucosano (Lev), Manosano (Manno), Arabitol (Ara), Manitol (Manni), Glicose (Glu), Proteínas solúveis em água (WSP) e $\mathrm{K}^{+} . *$ indica $\mathrm{p}<0,05, * *$ indica $\mathrm{p}<0,01 \mathrm{e} * * *$ indica $\mathrm{p}<0,001$. 


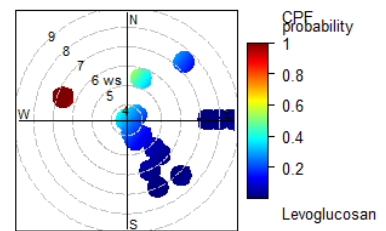

CPF at the 75th percentile $(=0.12)$

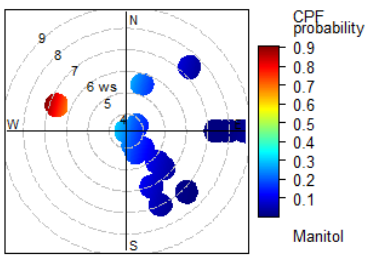

CPF at the 75 th percentile $(=0.047)$

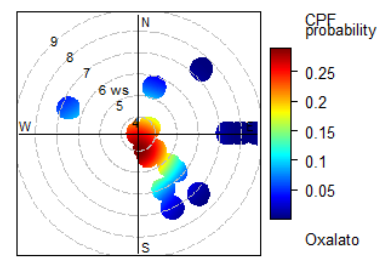

CPF at the 75th percentile $(=0.28)$

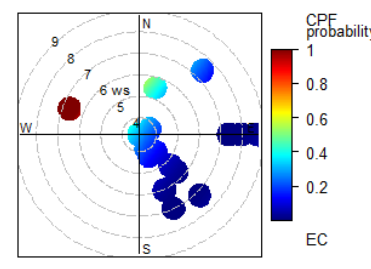

CPF at the 75 th percentile $(=3.3)$

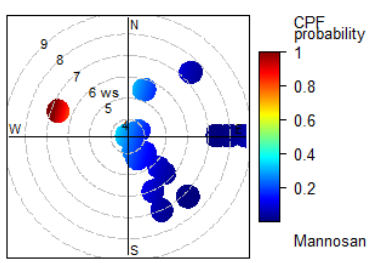

CPF at the 75 th percentile $(=0.024)$

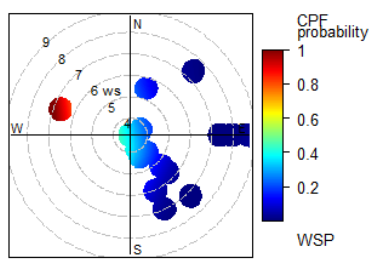

CPF at the 75 th percentile $(=0.077)$

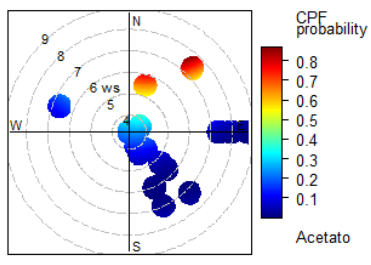

CPF at the 75 th percentile $(=0.08)$

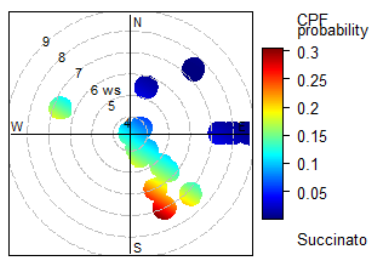

CPF at the 75th percentile $(=0.025)$

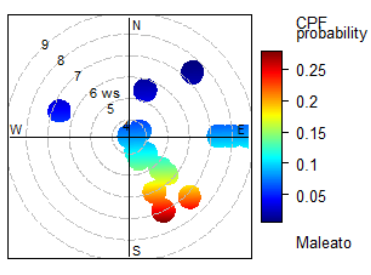

CPF at the 75 th percentile $(=0.032)$

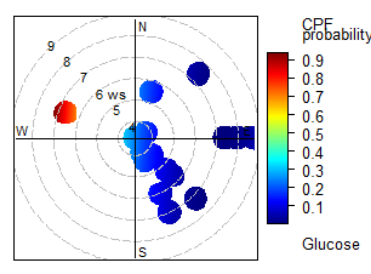

CPF at the 75th percentile $(=0.09)$

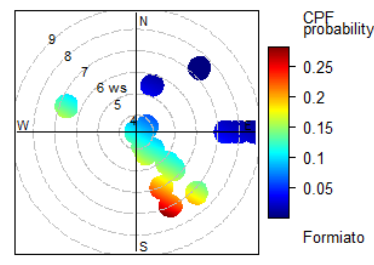

CPF at the 75 th percentile $(=0.028)$

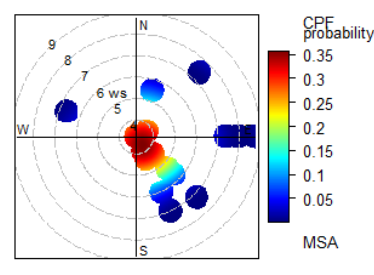

CPF at the 75 th percentile $(=0.029)$

Figura C XIII. Gráficos polares bivariados condicional (CBPF) das concentrações de levoglucosano, manosano, arabitol, glicose, manitol, WSP, acetato, formiato, oxalato, succinato, maleato, MSA, EC e OC na primavera de 2017. 


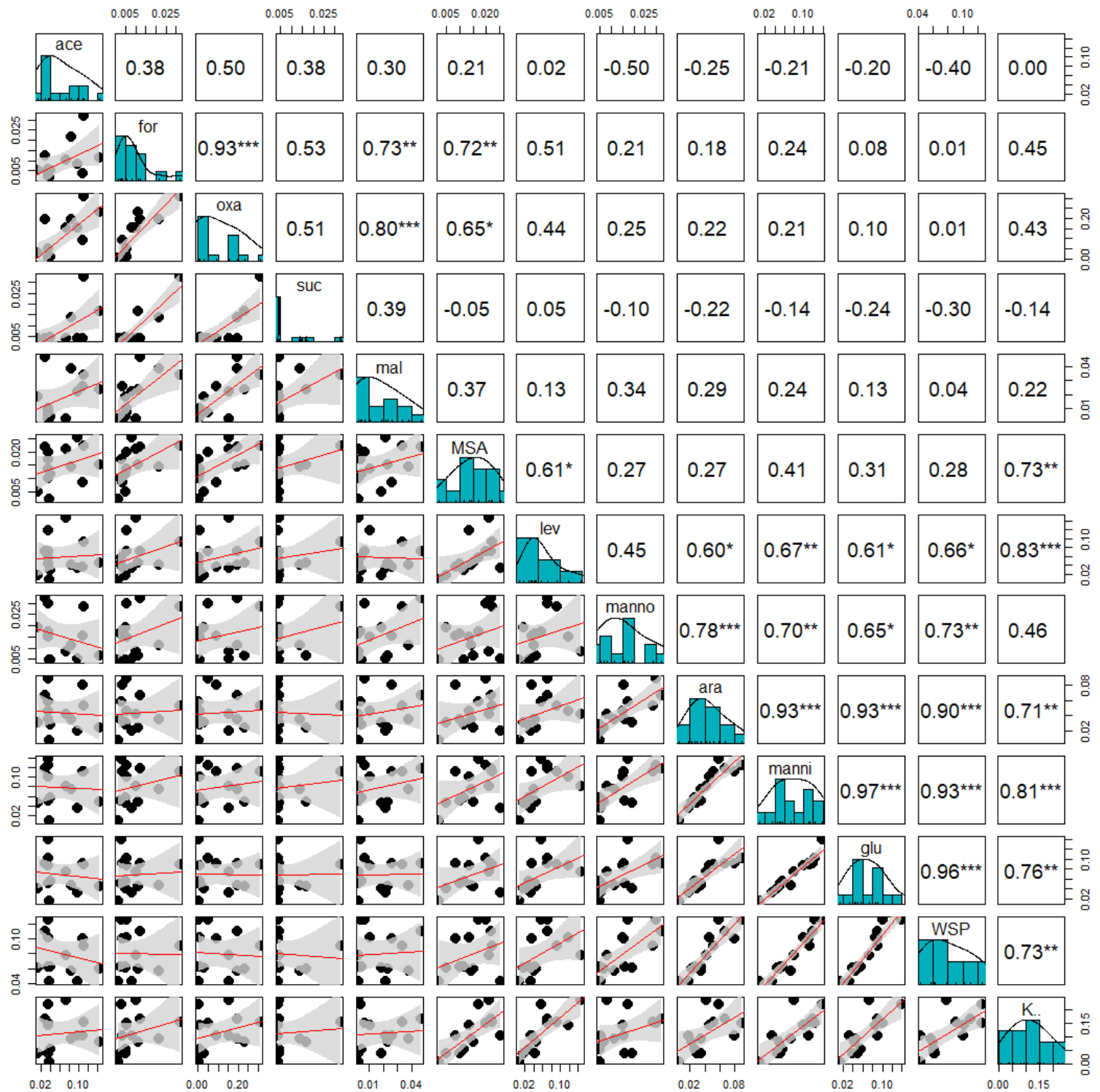

Figura C XIV. Correlação de Spearman entre os ácidos orgânicos, carboidratos e WSP para o outono de 2018. Legenda: Acetato (Ace), Formiato (For), Oxalato (Oxa), Succinato (Suc), Maleato (Mal), Metanosulfonato (MSA), Levoglucosano (Lev), Manosano (Manno), Arabitol (Ara), Manitol (Manni), Glicose (Glu), Proteínas solúveis em água (WSP) e $\mathrm{K}^{+} . *$ indica $\mathrm{p}<0,05, * *$ indica $\mathrm{p}<0,01 \mathrm{e} * * *$ indica $\mathrm{p}<0,001$. 


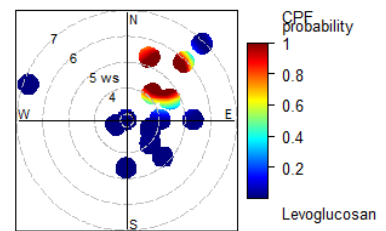

CPF at the 75 th percentile $(=0.072)$

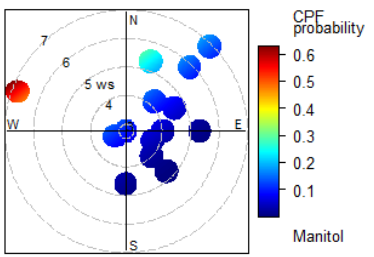

CPF at the 75th percentile $(=0.11)$

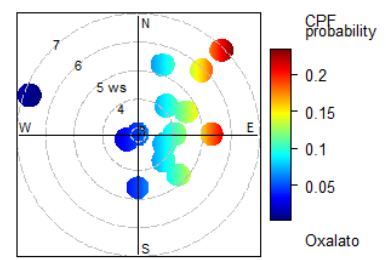

CPF at the 75 th percentile $(=0.18)$

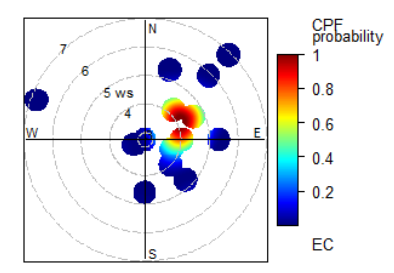

CPF at the 75 th percentile $(=2.1)$

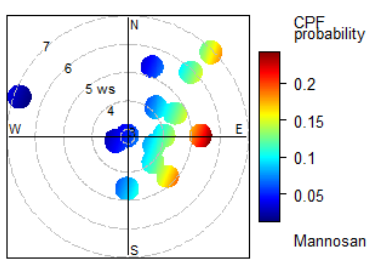

CPF at the 75 th percentile $(=0.019)$

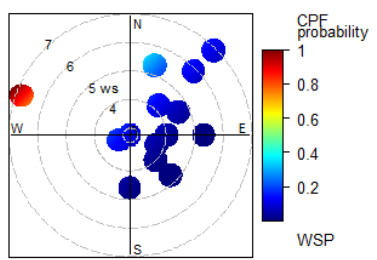

CPF at the 75 th percentile $(=0.1)$

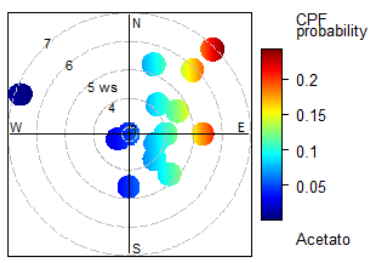

CPF at the 75 th percentile $(=0.094)$

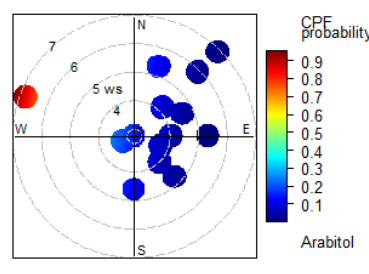

CPF at the 75 th percentile $(=0.057)$

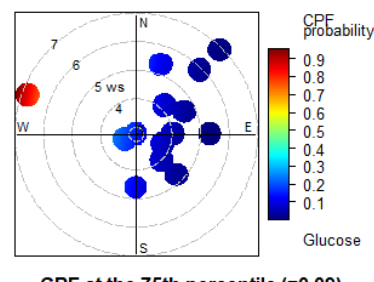

CPF at the 75th percentile $(=0.09)$
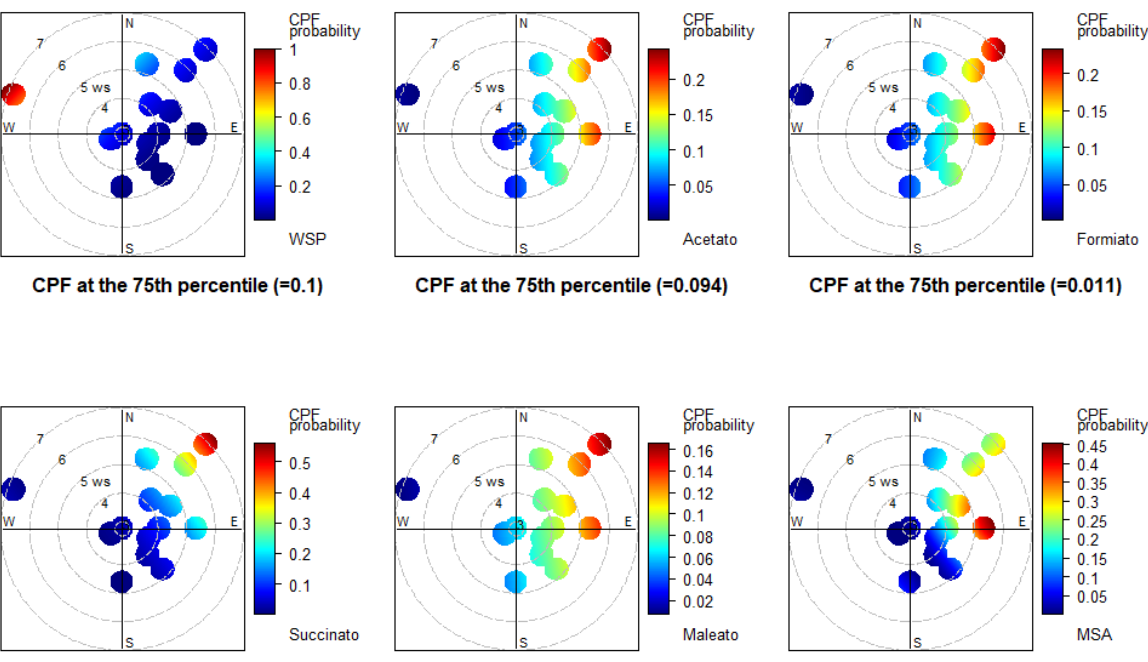

CPF at the 75 th percentile $(=0.0044)$

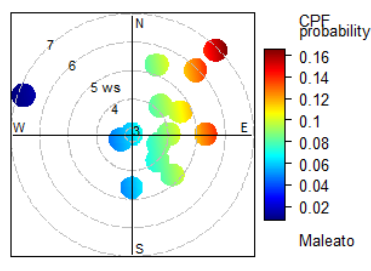

CPF at the 75 th percentile $(=0.025)$

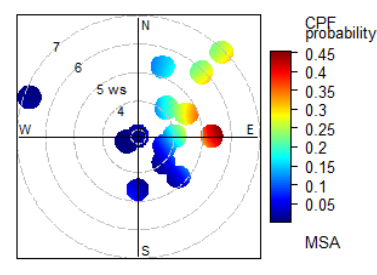

CPF at the 75 th percentile $(=0.021)$

Figura C XV. Gráficos polares bivariados condicional (CBPF) das concentrações de levoglucosano, manosano, arabitol, glicose, manitol, WSP, acetato, formiato, oxalato, succinato, maleato, MSA, EC e OC no outono de 2018. 

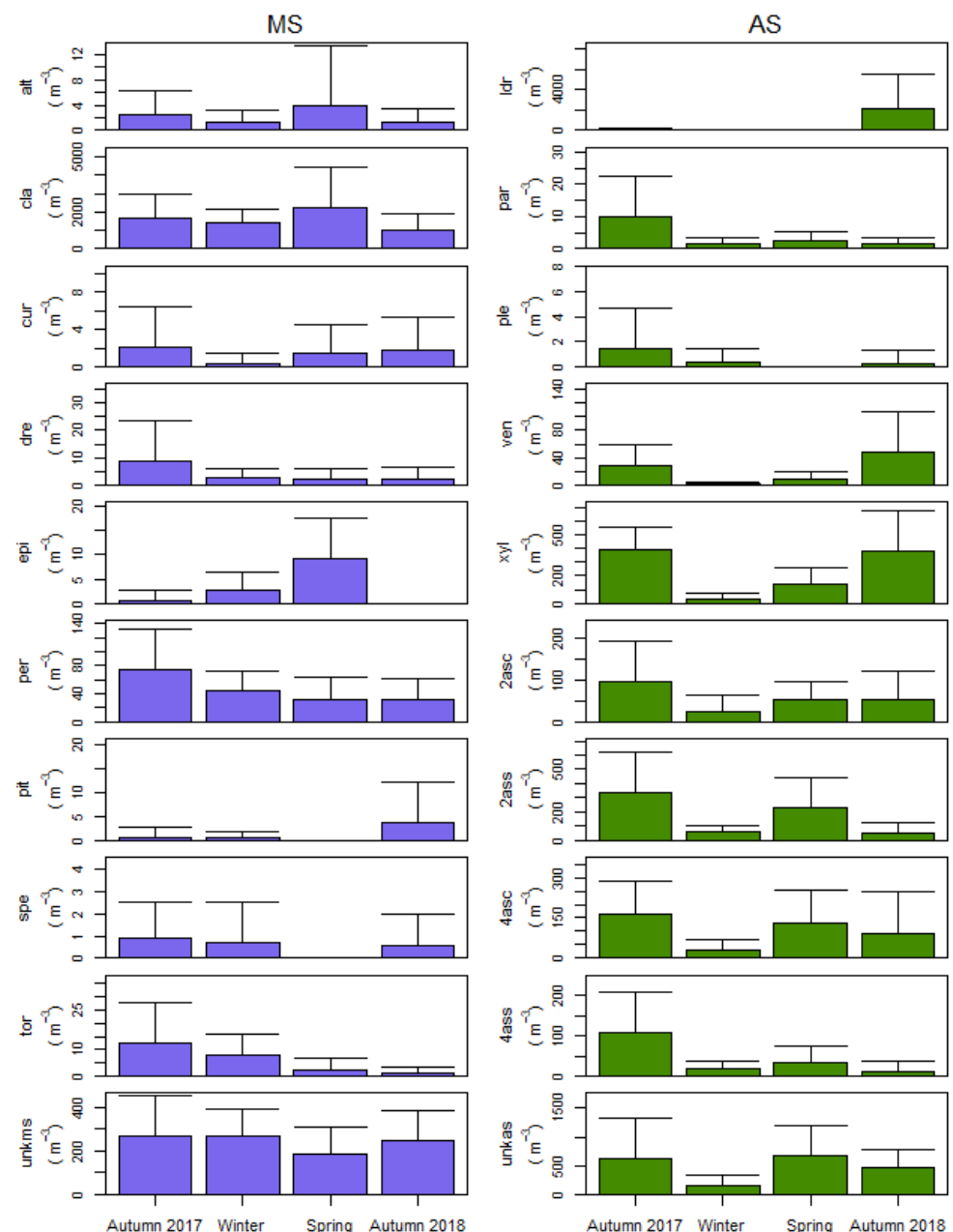
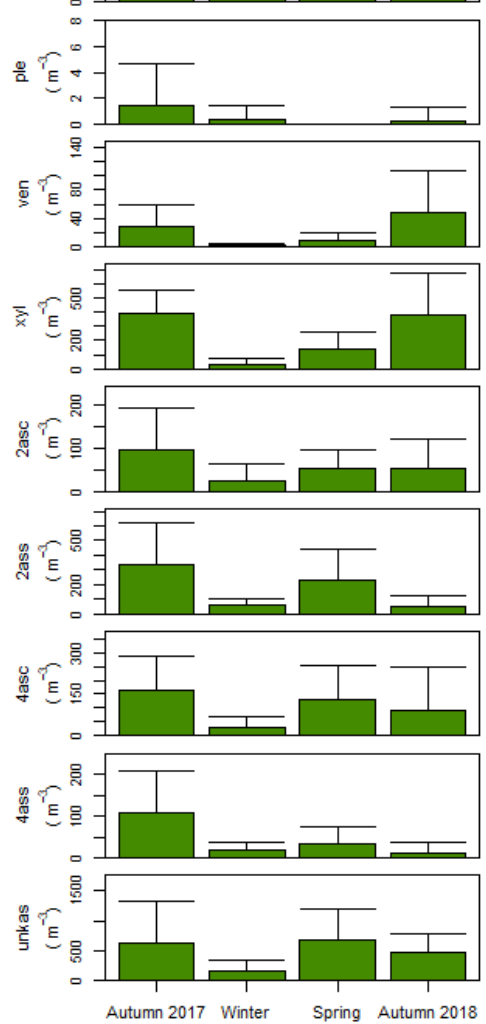
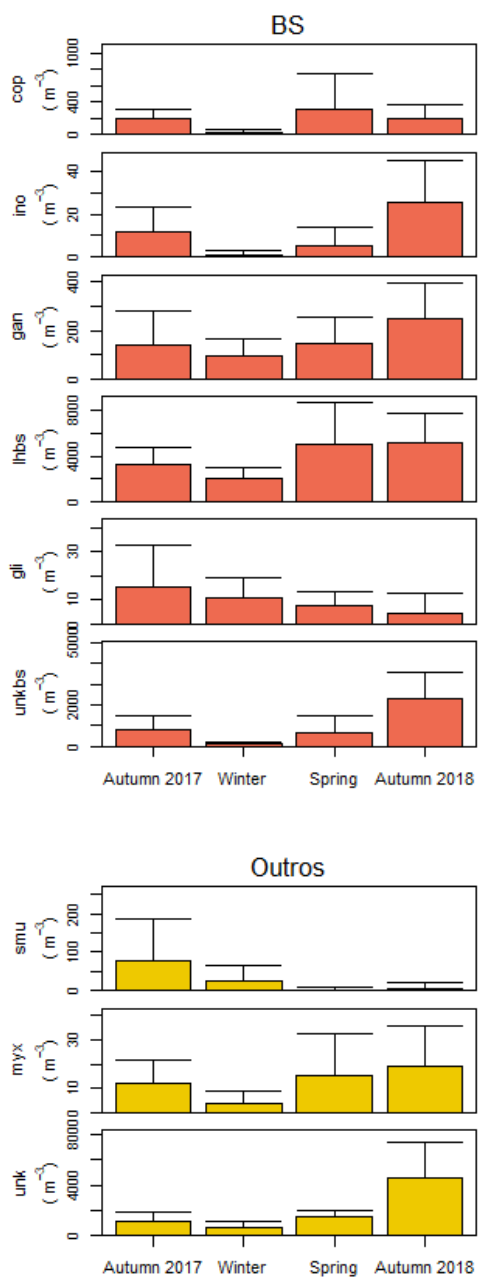

Figura C XVI. Concentração média sazonal dos principais tipos fúngicos.

Legenda: Alternaria-like (alt), Cladosporium (cla), Curvularia-like (cur), Drechslera-like (dre), Epicoccum-like (epi), Periconia-like (per), Pithomyces-like (pit), Spegazzinia-like (spe), Stemphylium-like (ste), Tetraploa-like (tet), Torula-like (tor), MS desconhecido (unkms), média de todos os esporos classificados como fungo anamorfo (mitósporo, MS), Diatrypaceae-like grande (ldr), Paraphaeosphaeria-like (par), Pleospora-like (ple), Venturia-like (ven), Xylariaceae (xyl), 2 celulas com cor AS (2asc), 2 celulas sem cor AS (2ass), 4 celulas com cor AS (4asc), 4 celulas sem cor AS (4ass), AS desconhecido (unkas), média de todos os esporos classificados como Ascomycota (AS). Coprinus-like (cop), Inocybe-like (ino), Ganoderma-like (gan), Basidiósporo hialino grande (lhbs), BS desconhecido (unkbs), média de todos os esporos classificados como Basidiomycota (BS), Gliomastix-like (gli). Smuts-like (smu), Myxomycetes-like (myx), desconhecido (unk). 


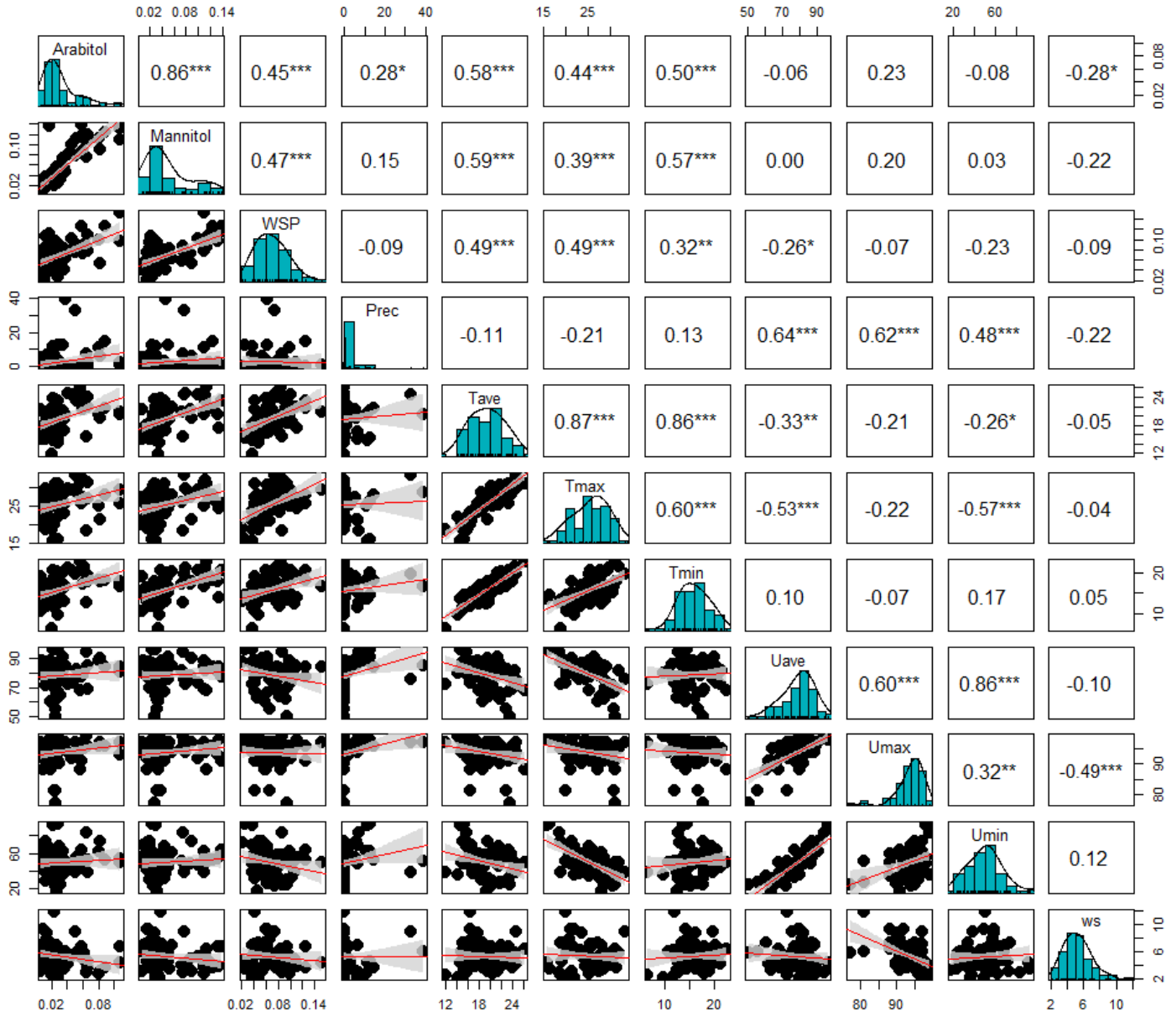

Figura C XVII. Correlação de Spearman entre arabitol, manitol e WSP com variáveis meteorológicas. Legenda: Prec - Precipitação acumulada; Tave - Temperatura média; Tmax - Temperatura máxima; Tmin Temperatura mínima; Uave - Umidade relativa média; Umax - Umidade relativa máxima; Umin - Umidade relativa mínima; WS - velocidade do vento. 


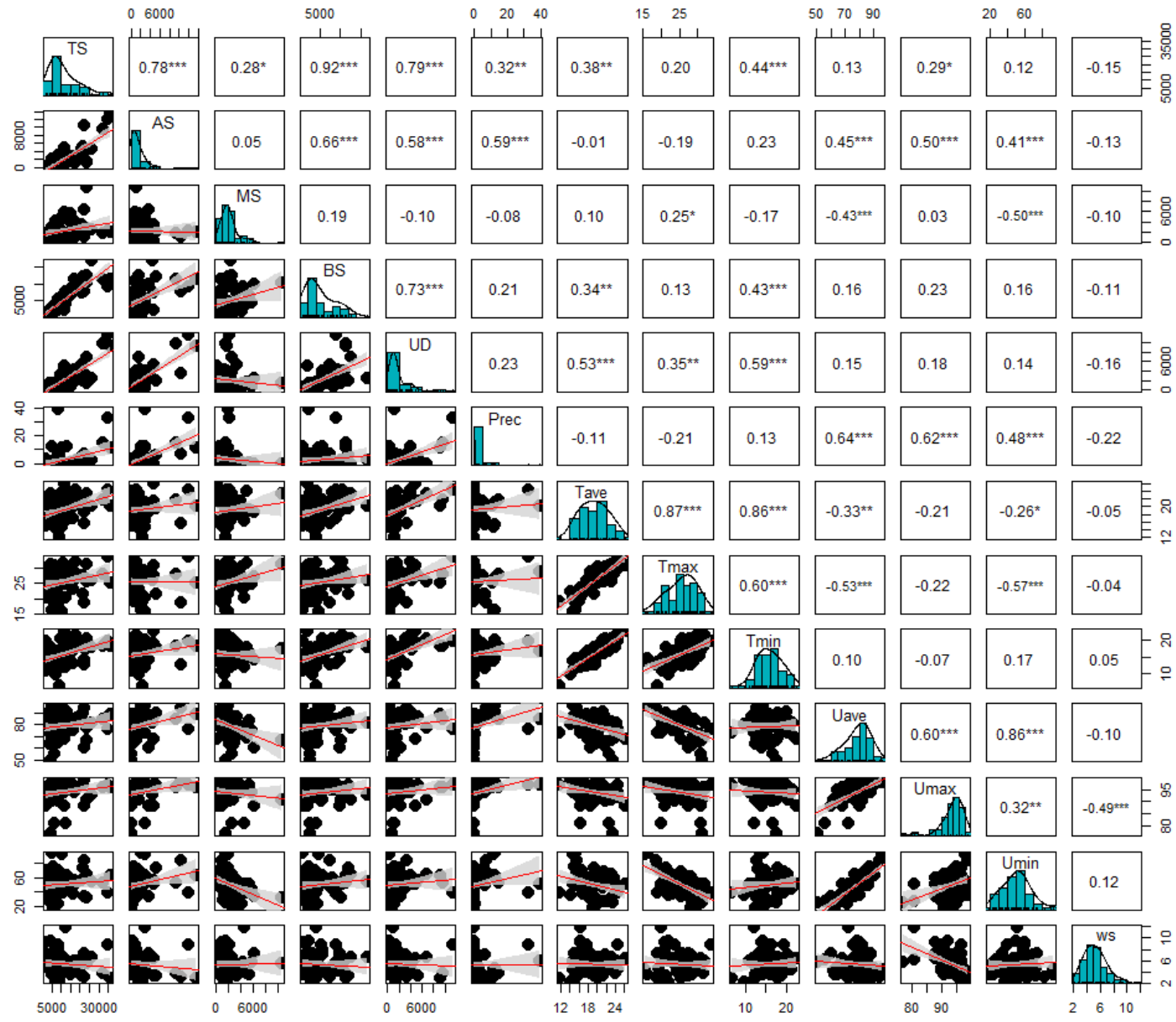

Figura C XVIII. Correlação de Spearman entre TS, AS, MS, BS e UD com variáveis meteorológicas. Legenda: Prec - Precipitação acumulada; Tave - Temperatura média; Tmax - Temperatura máxima; Tmin Temperatura mínima; Uave - Umidade relativa média; Umax - Umidade relativa máxima; Umin - Umidade relativa mínima; WS - velocidade do vento. 


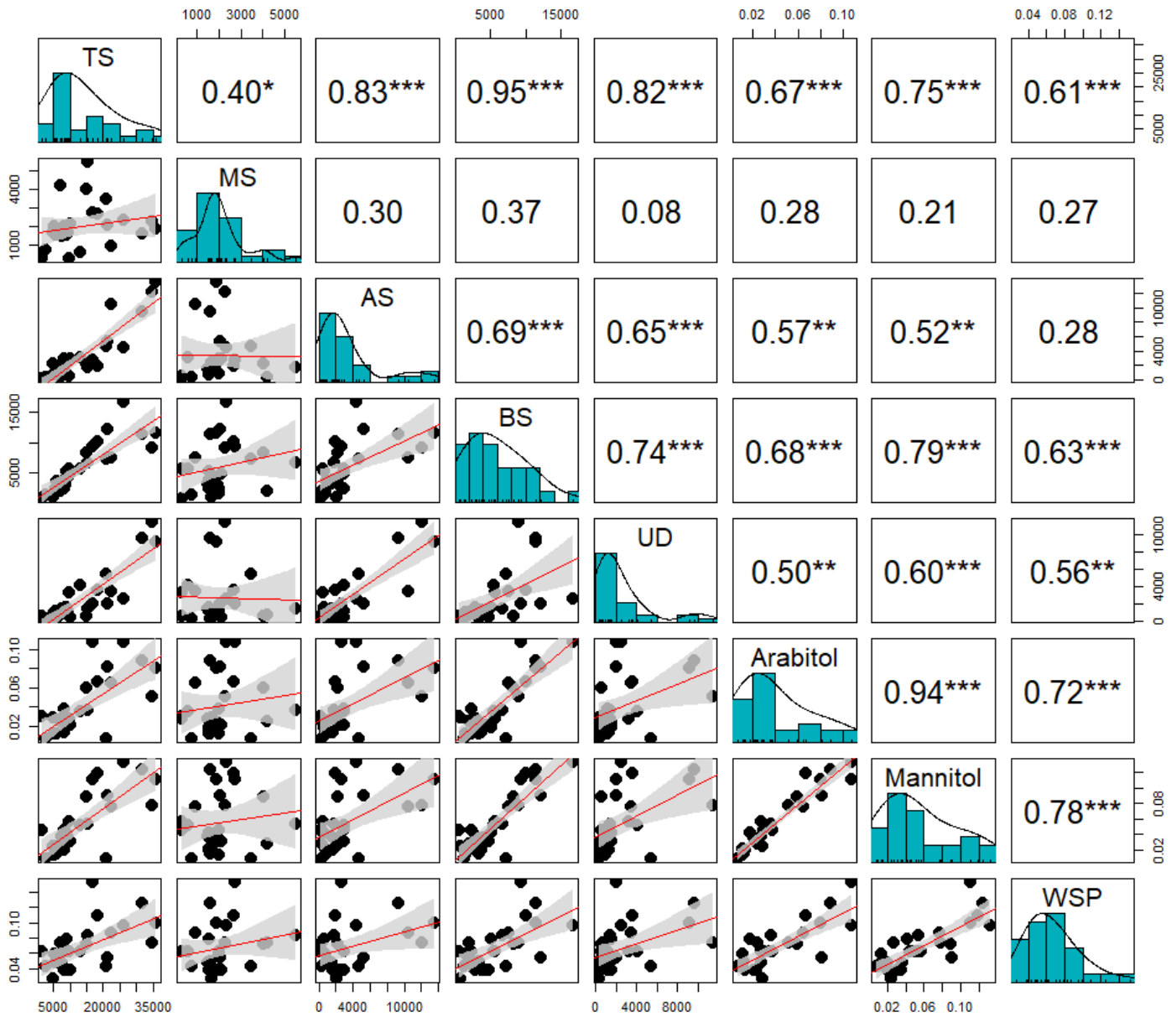

Figura C XIX. Correlação de Spearman entre TS (esporos totais), MS (Mitósporos), AS (ascósporos), BS (basidiósporos), UD (desconhecido), arabitol, manitol e WSP no período úmido (dias com chuva). 


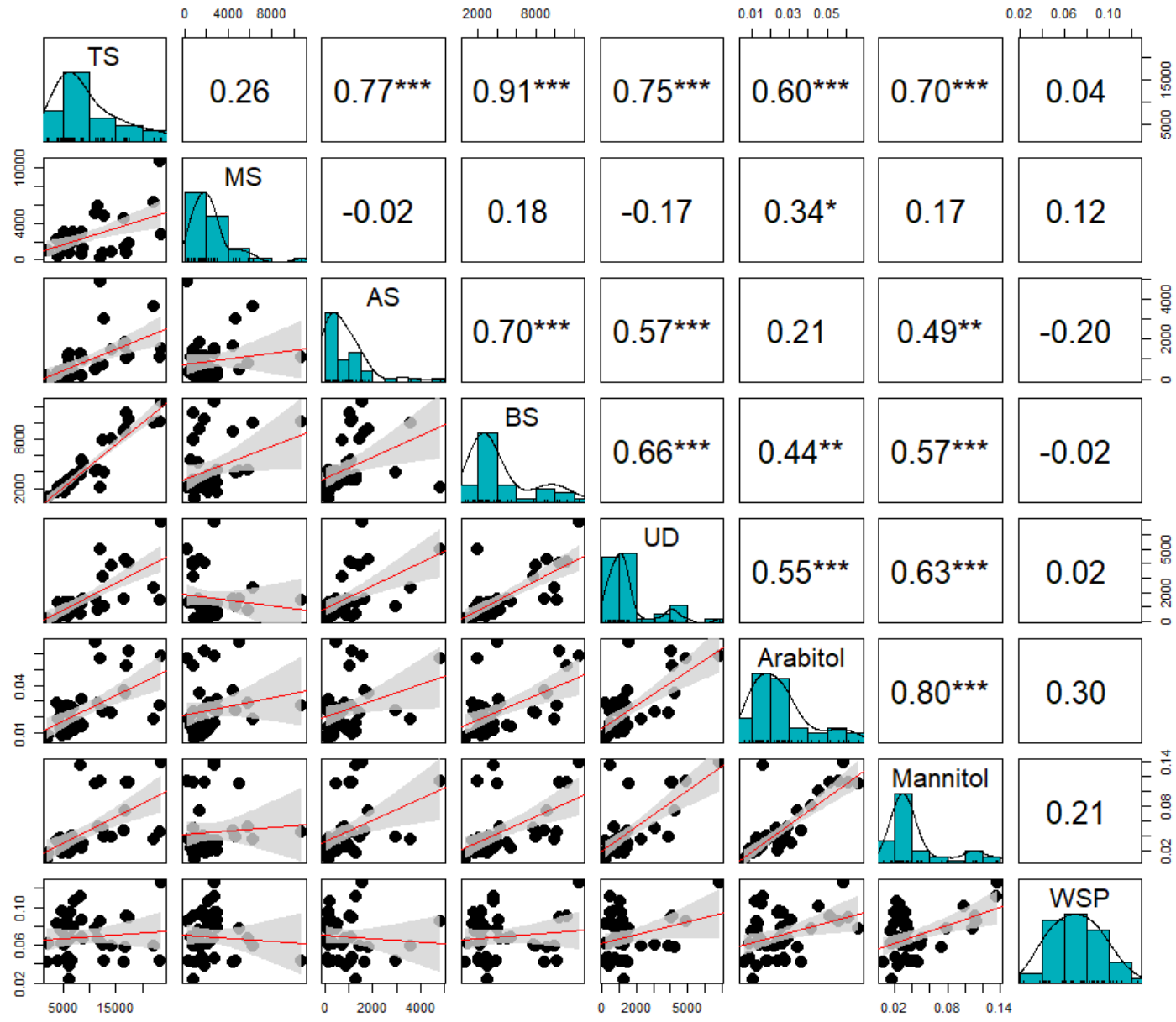

Figura C XX. Correlação de Spearman entre TS (esporos totais), MS (Mitósporos), AS (ascósporos), BS (basidiósporos), UD (desconhecido), arabitol, manitol e WSP no período seco (dias sem chuva). 


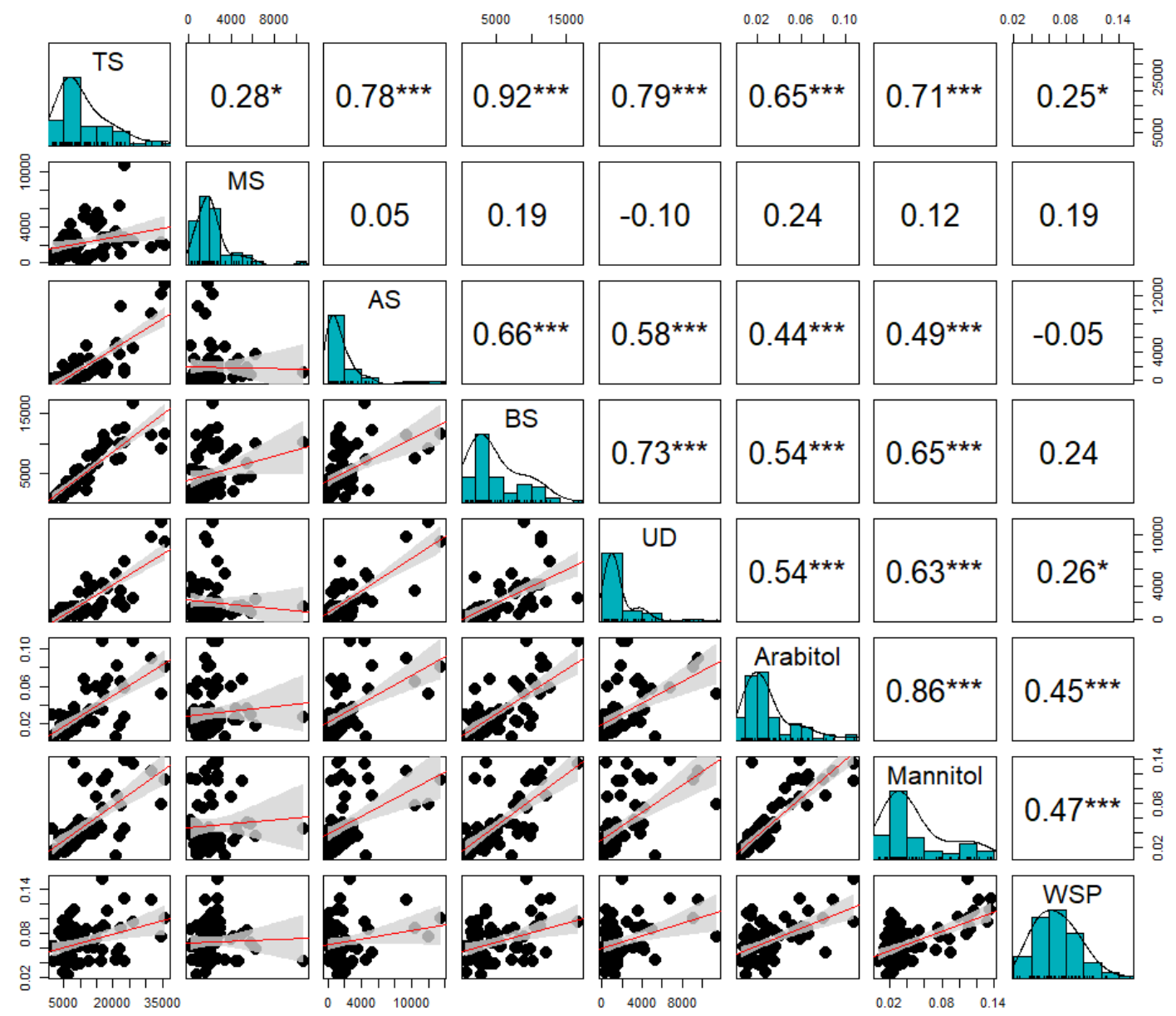

Figura C XXI. Correlação de Spearman entre TS (esporos totais), MS (Mitósporos), AS (ascósporos), BS (basidiósporos), UD (desconhecido), arabitol, manitol e WSP considerando todo o período amostrado. 


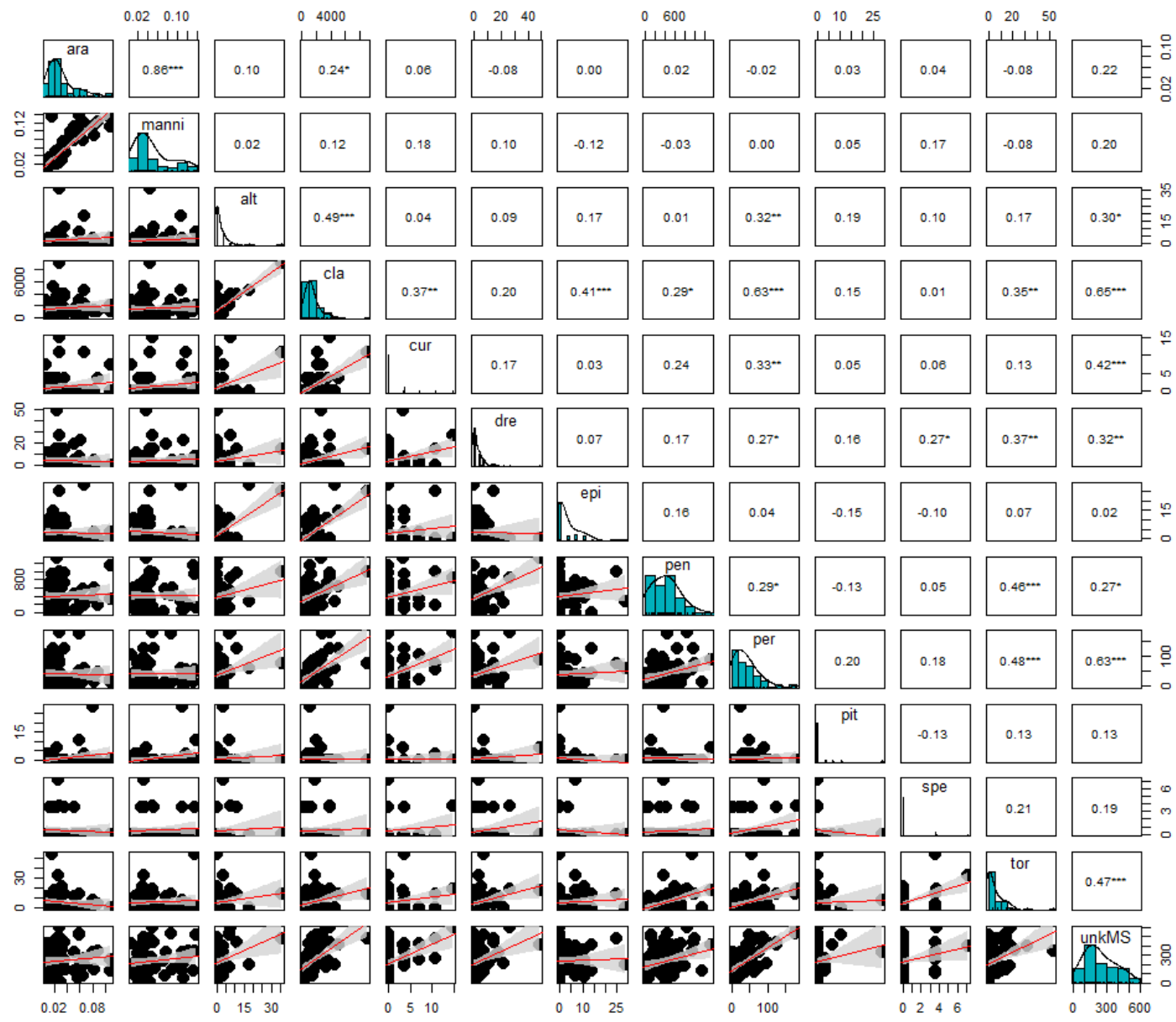

Figura C XXII. Correlação de Spearman entre arabitol e manitol com alguns tipos fúngicos pertencentes ao grupo MS.

Legenda: Arabitol (ara), Manitol (manni), Alternaria-like (alt), Cladosporium (cla), Curvularia-like (cur), Drechslera-like (dre), Epicoccum-like (epi), Penicillium/ Aspergillus (pen), Periconia-like (per), Pithomyces-like (pit), Spegazzinia-like (spe), Stemphylium-like (ste), Torula-like (tor), MS desconhecido (unkMS). 


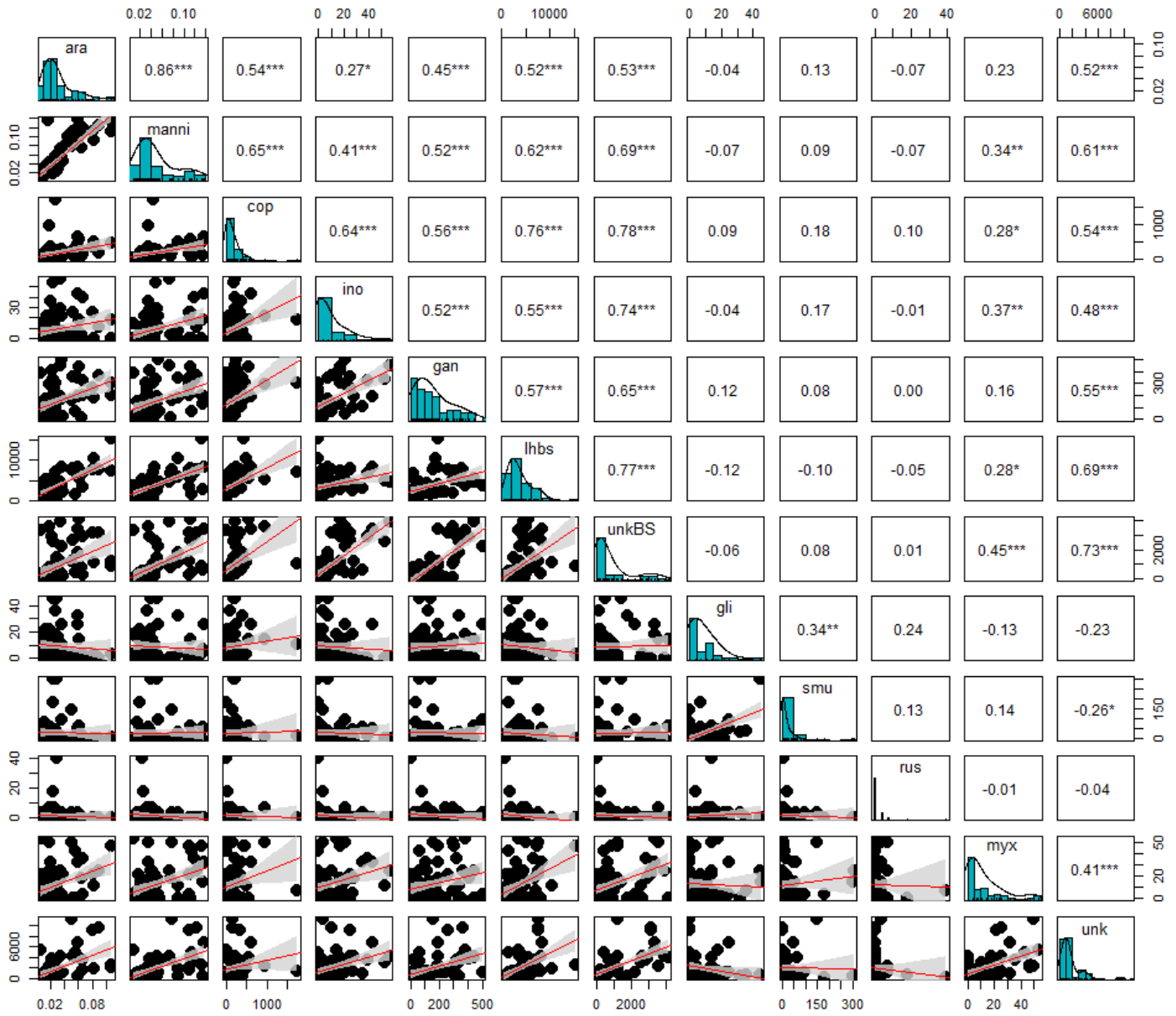

Figura C XXIII. Correlação de Spearman entre arabitol e manitol com alguns tipos fúngicos pertencentes ao grupo BS e desconhecido.

Legenda: Arabitol (ara), Manitol (manni), Coprinus-like (cop), Inocybe-like (ino), Ganoderma-like (gan),Basidiósporo hialino grande (lhbs), BS desconhecido (unkbs). Gliomastix-like (gli), Smuts (smu), Rust (rus), Myxomicetes (myx) and desconhecido (unk). 


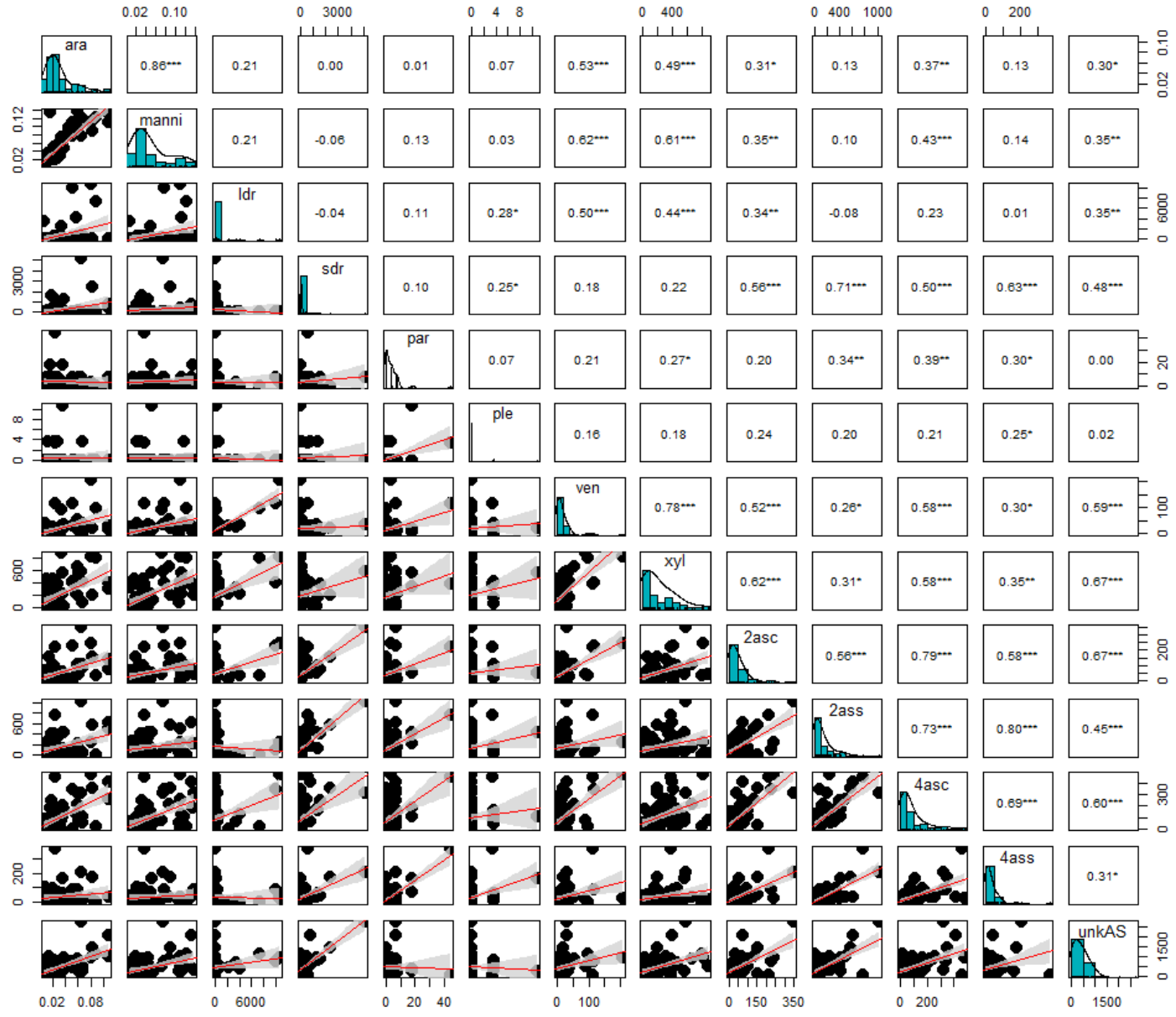

Figura C XXIV. Correlação de Spearman entre arabitol e manitol com alguns tipos fúngicos pertencentes ao grupo AS.

Legend: Diatrypaceae-like grande (ldr), Diatrypaceae-like pequeno (sdr), Paraphaeosphaeria-like (par), Pleosporalike (ple), Venturia-like (ven), Xylariaceae (xyl), 2 celulas com cor AS (2asc), 2 celulas sem cor AS (2ass), 4 celulas com cor AS (4asc), 4 celulas sem cor AS (4ass), AS desconhecido (unkas). 

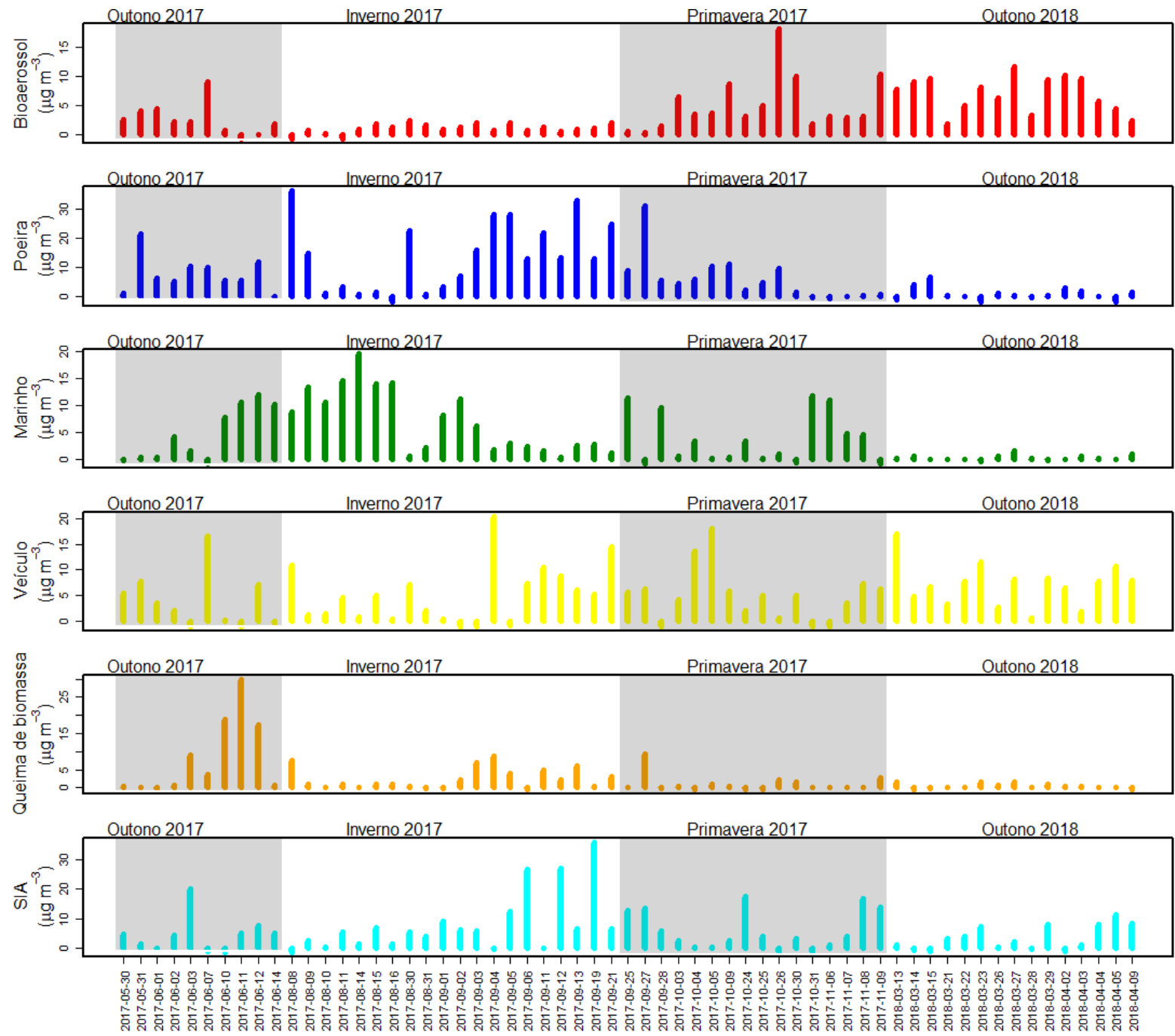

Figura C XXV. Série temporal da contribuição dos fatores obtidos com a Fatoração de Matriz Positiva (PMF) durante o período amostrado.

Legenda: Fator 1: Bioaerossol; Fator 2: Poeira (ressuspensão do solo/ poeira de rua); Fator 3: Marinho (aerossol marinho); Fator 4: Veículo (emissão veículos); Fator 5: queima de biomassa (BB); Fator 6: Aerossol inorgânico secundário (SIA). 

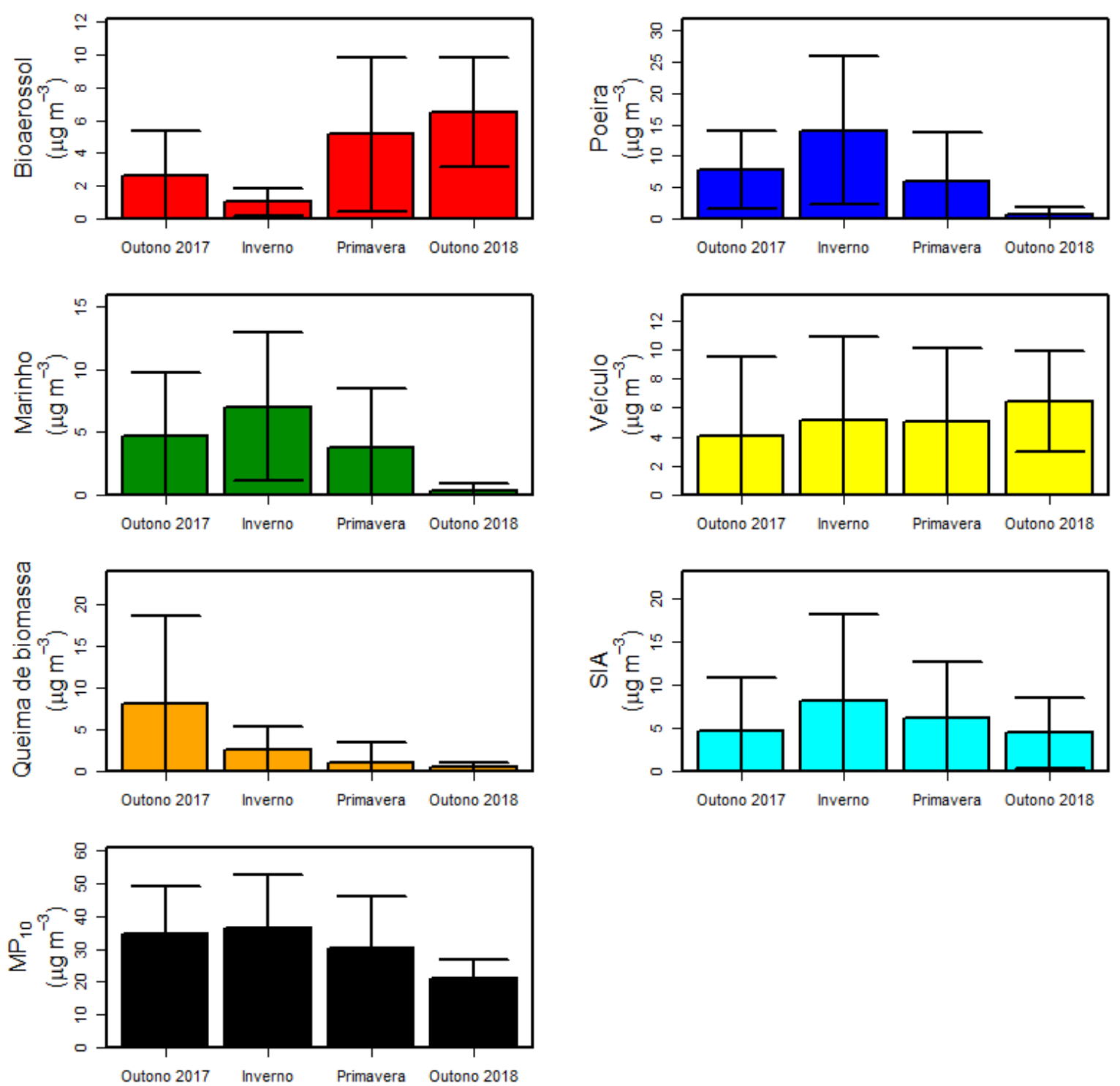

Figura C XXVI. Variação sazonal dos fatores obtidos com a Fatoração de Matriz Positiva (PMF).

Legenda: Fator 1: Bioaerossol; Fator 2: Poeira (ressuspensão do solo/ poeira de rua); Fator 3: Marinho (aerossol marinho); Fator 4: Veículos (emissão veículos); Fator 5: queima de biomassa (BB); Fator 6: Aerossol inorgânico secundário (SIA). 


\section{Levoglucosano}

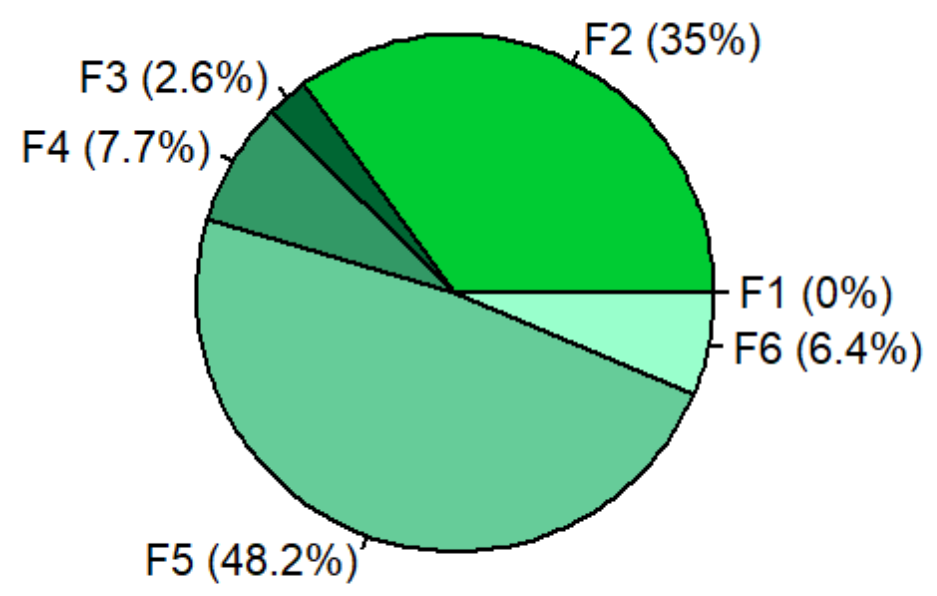

$\square$ F1: Bioaerosol $=0(29.8 \%)$

$\square \quad$ F2: Poeira $=0.061158(13.2 \%)$

$\square$ F3: Marinho $=0.0045758(0 \%)$

$\square$ F4: Veículo $=0.013494(0.5 \%)$

$\square \quad$ F5: Queima de biomassa $=0.084197(52.7 \%)$

$\square \quad$ F6: SIA $=0.011146(3.9 \%)$

Figura C XXVII. Porcentagem da contribuição dos seis fatores para a massa do Levoglucosano na análise de Fatoração de Matriz Positiva (PMF).

Legenda: Fator 1: Bioaerossol; Fator 2: Poeira (ressuspensão do solo/ poeira de rua); Fator 3: Marinho (aerossol marinho); Fator 4: Veículos (emissão veículos); Fator 5: queima de biomassa (BB); Fator 6: Aerossol inorgânico secundário (SIA). 